Portland State University

PDXScholar

Winter 1-9-2014

\title{
Managing for Resistance and Resilience of Northern Great Lakes Forests to the Effects of Climate Change
}

Matthew Joshua Duveneck

Portland State University

Follow this and additional works at: https://pdxscholar.library.pdx.edu/open_access_etds

Part of the Environmental Sciences Commons, and the Forest Management Commons Let us know how access to this document benefits you.

\section{Recommended Citation}

Duveneck, Matthew Joshua, "Managing for Resistance and Resilience of Northern Great Lakes Forests to the Effects of Climate Change" (2014). Dissertations and Theses. Paper 1551.

https://doi.org/10.15760/etd.1550

This Dissertation is brought to you for free and open access. It has been accepted for inclusion in Dissertations and Theses by an authorized administrator of PDXScholar. Please contact us if we can make this document more accessible: pdxscholar@pdx.edu. 
Managing for Resistance and Resilience of Northern Great Lakes Forests to the Effects of Climate Change

\author{
by \\ Matthew Joshua Duveneck \\ A dissertation submitted in partial fulfillment of the \\ requirements for the degree of \\ Doctor of Philosophy \\ in \\ Environmental Sciences and Resources
}

Dissertation Committee:

Robert M. Scheller, Chair

Klaus Puettmann

Alan Yeakley

Todd Rosenstiel

Heejun Chang

Portland State University

2014 
(C) 2013 Matthew Joshua Duveneck 


\section{Abstract:}

Climate change is expected to drastically change the environmental conditions which forests depend. Lags in tree species movements will likely be outpaced by a more rapidly changing climate. This may result in species extirpation, a change in forest structure, and a decline in resistance and resilience (i.e., the ability to persist and recover from external perturbations, respectively). In the northern Great Lakes region of North America, an ecotone exists along the boreal-temperate transition zone where large changes in species composition exist across a climate gradient. Increasing temperatures are observed in the more southern landscapes. As climate change is expected to substantially affect mid-continental landscapes, this region is especially vulnerable to climate change. My research assessed the effects of climate change under business as usual (BAU) management as well as alternative management strategies. To do so, I simulated forest change in two landscapes (northeastern Minnesota and northern lower Michigan) under three climate change scenarios (current climate, low emissions, and high emissions), and four management scenarios (BAU, modified silviculture, expanded reserves, and climate suitable planting) with a spatially-explicit forest simulation model from year 2000 to year 2150. Specifically, I explored how climate change would affect relationships between tree species diversity and productivity (Chapter 2); how expanded reserves and modified silviculture may affect aboveground biomass (AGB) and species diversity (Chapter 3); how climate suitable planting may affect functional diversity, and AGB (Chapter 4); and how alternative management may affect the resistance and 
resilience of forests to multiple disturbances interacting with climate change (Chapter 5).

Under the BAU management scenario, I found that current and low emissions climate scenarios did not affect the relationship between species diversity and productivity; however, under a high emissions climate scenario, a decline in simulated productivity was coupled with a stronger positive relationship between diversity and productivity. Under the high emissions climate scenario, overall productivity declined in both landscapes with specific species declines projected for boreal species such as balsam fir (Abies balsamea) and black spruce (Picea mariana). Under alternative management scenarios, I simulated a limited ability to increase tree species and functional diversity, AGB, and net primary productivity under climate change. The limits of management were especially apparent under the high emissions climate scenario. In a novel approach to measuring resilience, I plotted the recovery of both initial species composition and AGB to stochastic fire events for each simulation. This approach assessed both a general response (i.e. AGB) with a more specific response (i.e. species composition). My results suggest that climate change will reduce the resilience of northern Great Lake forest AGB and species composition and that management effects will be largely outweighed by the declines expected due to climate change. My results highlight the necessity to consider even more innovative and creative solutions under climate change (e.g., planting species from even further south than I simulated). 


\section{Dedication:}

This dissertation is dedicated to the 19 firefighters from the Granite Mountain Hotshot Crew who lost their lives fighting the Yarnell Hill Fire south of Prescott, Arizona in June of 2013. Dedicated to natural resource protection, hotshots are the hardest working people I have ever known. This dissertation addresses long term effects of climate change. In the short term, firefighters will be the first to respond to direct climate change effects such as increased fire frequency and intensity. 


\section{Acknowledgements:}

First, I want to thank my advisor, Robert Scheller. Rob provided tireless advice, critique, and edits to every step of my $\mathrm{PhD}$ program. His wisdom was critical to my research and I am especially appreciative. My committee members: Klaus Puettmann, Alan Yeakley, Todd Rosenstiel, and Heejun Chang all provided invaluable guidance and stimulating questions. Among many extremely helpful colleagues in Scheller's Dynamic Ecosystems \& Landscapes Lab, Alec Kretchun deserves a special mention. Throughout my $\mathrm{PhD}$ experience, Alec provided me generous guidance, design, and ideas to complicated problems.

I am grateful for the funding I received from the Upper Midwest and Great Lakes Landscape Conservation Cooperative. My PhD was made possible through this grant along with generous funding from Portland State University. Early on in my studies, I started collaborating with Mark White from The Nature Conservancy, and Stephen Handler and Chris Swanston from the US Forest Service whom provided me excellent opportunities to explore my research. They helped by sending me data, relevant journal articles, and opportunities to present my work. I am indebted to my longest friend Ethan Plunkett. Ethan taught me how to use R as a statistical and data management tool through sometimes daily phone calls from across the country. I owe a great deal of my dissertation to Ethan.

Finally, I want to acknowledge my wife Anna Gilbert Duveneck who has tirelessly supported my interest in higher education. Anna has been my biggest supporter and strongest ally. I could not have done this without her. 


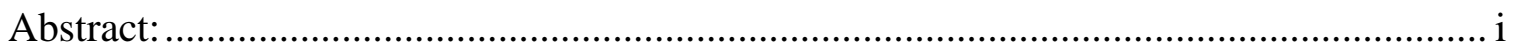

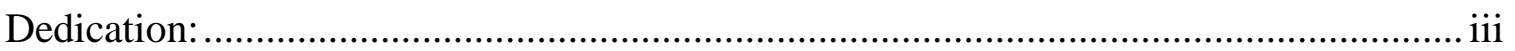

Acknowledgements: ............................................................................................. iv

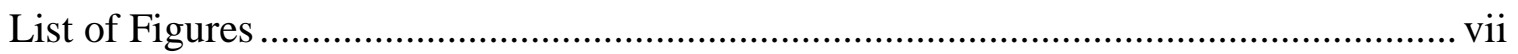

Chapter 1: Introduction ...................................................................................... 1

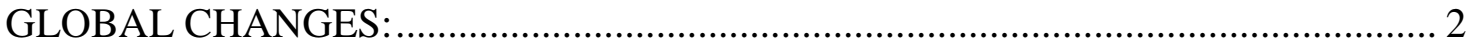

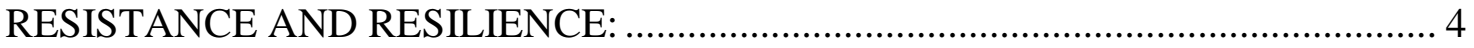

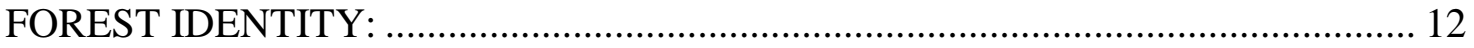

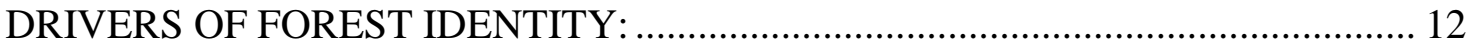

CLIMATE CHANGE THREAT TO IDENTITY:................................................. 15

MANAGING FOR RESISTANCE AND RESILIENCE: ........................................... 17

PROJECTING FOREST CHANGE: .................................................................... 21

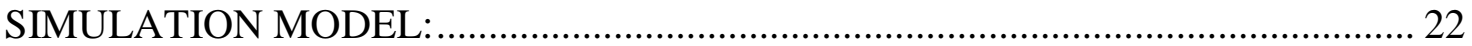

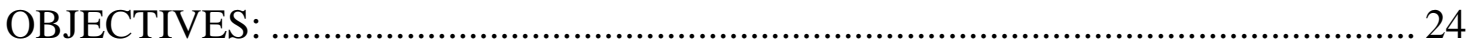

Chapter 2: Climate Change Effects on Northern Great Lake (USA) Forests: A Case for

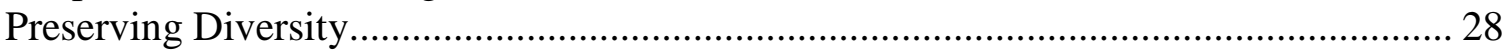

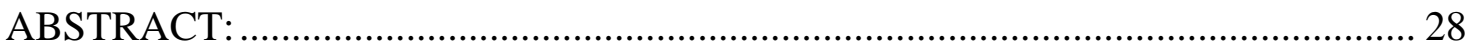

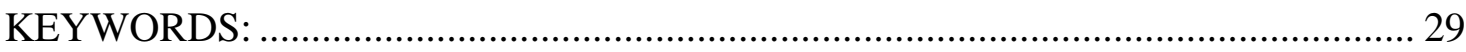

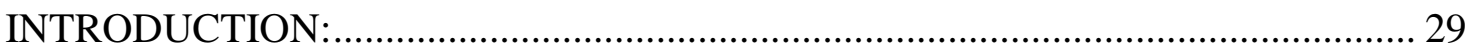

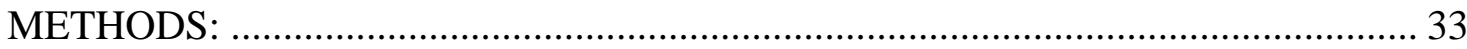

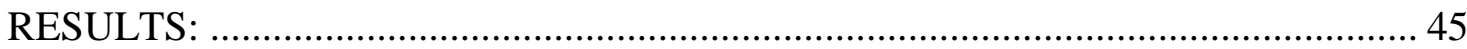

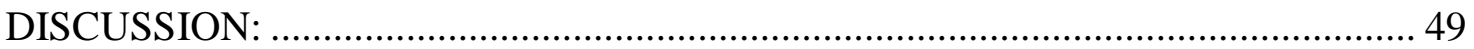

Chapter 3: Effects of Alternative Forest Management in the Face of Climate Change in

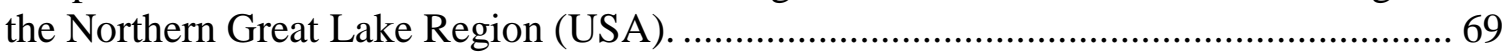

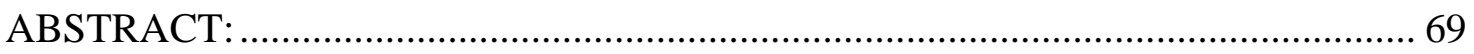

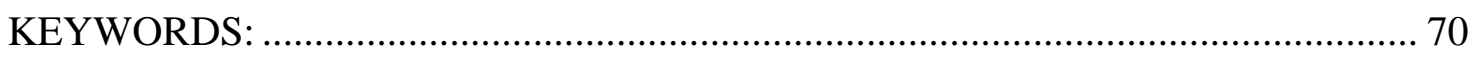

INTRODUCTION:

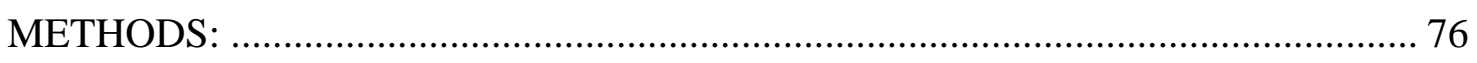

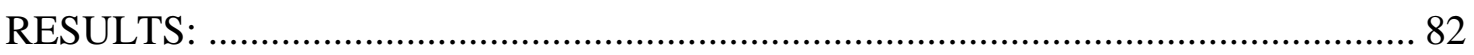

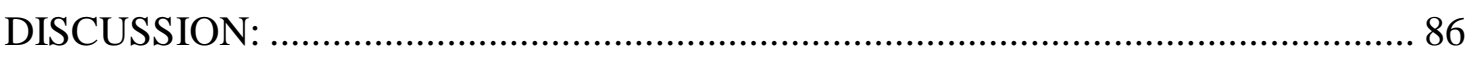


CONCLUSIONS:

Chapter 4: Climate Change Effects to Productivity and Functional Diversity in Northern Great Lake Forests with Climate Suitable Planting................................................. 100

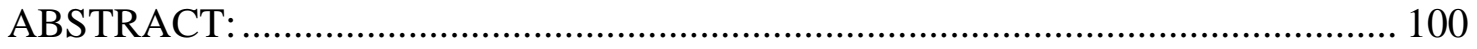

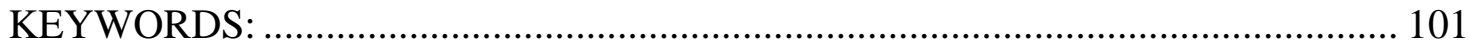

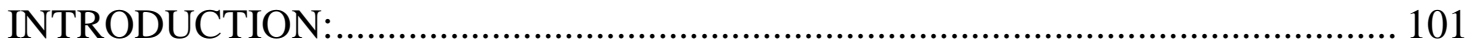

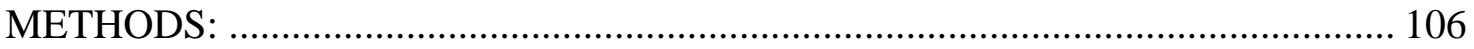

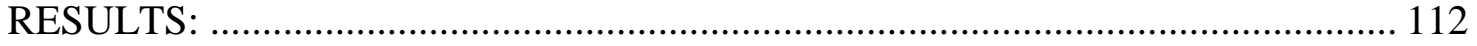

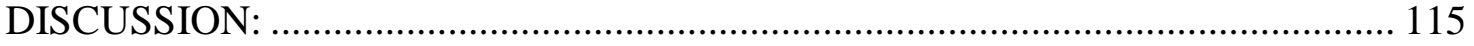

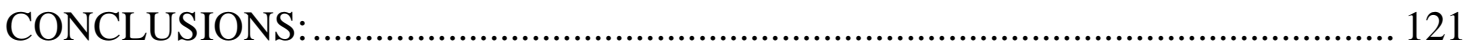

Chapter 5: Alternative Management for Resistance and Resilience of Northern Great Lake forests (USA) to the Effects of Climate Change .............................................. 129

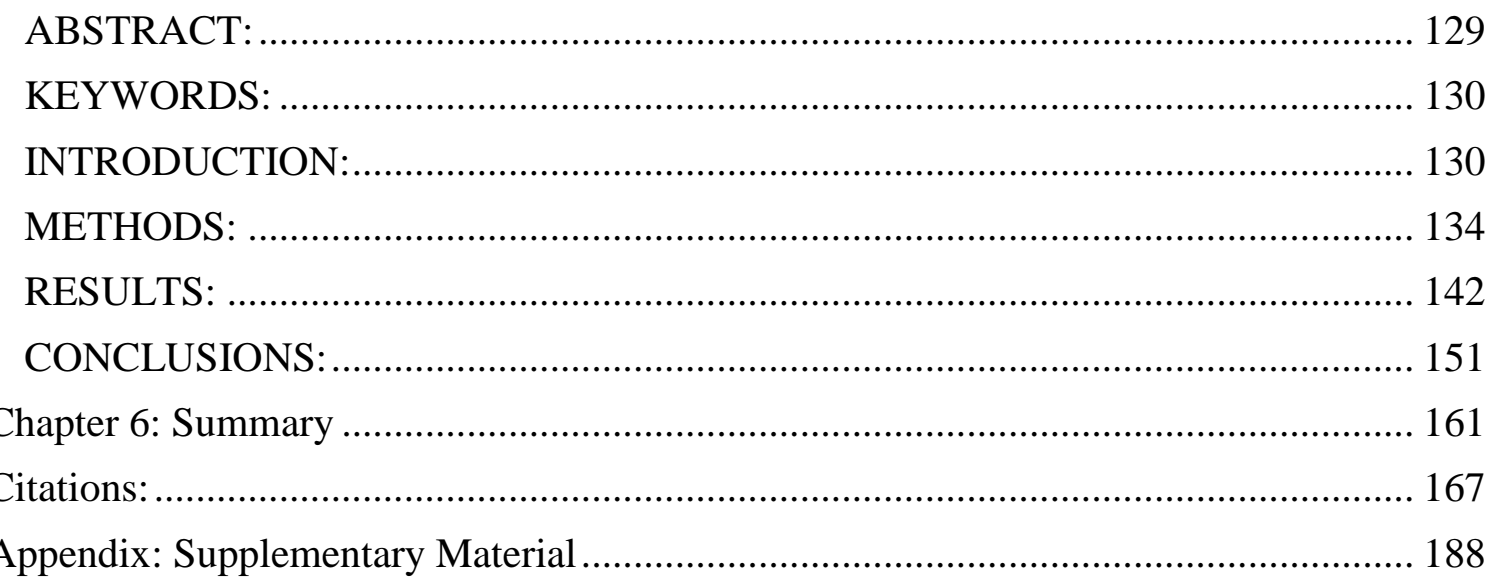




\section{List of Figures}

Figure 1.1: Study areas: Northeastern Minnesota and northern lower Michigan.... 26

Figure 1.2. Conceptual diagram of modeling framework 27

Figure 2.1: Inserted map of study landscapes within continental United States. 58

Figure 2.2: Nested climate and soil regions used to create ecoregions in northeastern Minnesota (left) and northern lower Michigan (right).

Figure 2.3: High (A1FI) and low (B1) emission projections of temperature $\left({ }^{\circ} \mathrm{C}\right)$ in northeastern Minnesota and northern lower Michigan.

Figure 2.4: High (A1FI) and low (B1) emission projections of precipitation $(\mathrm{cm})$ in northeastern Minnesota and northern lower Michigan.

Figure 2.5: Aggregated climate regions based on mean July temperature in each landscape.

Figure 2.6: Relationship between diversity and aboveground ANPP (g m-2 yr -1) at year 2150 in northeastern Minnesota (top) and northern lower Michigan (bottom) for three climate scenarios. 63

Figure 2.7: Diversity ( $\mathrm{eH}^{\prime}$ ) across the last 100 years of simulation (i.e. 2050 to 2150) in northeastern Minnesota and northern lower Michigan.

Figure 2.8: Total aboveground biomass $\left(\mathrm{AGB}_{\text {total }}\right)$ within the northeastern Minnesota and northern lower Michigan landscapes under three climate scenarios assuming BAU management.

Figure 2.9: Aboveground biomass (AGB) $\left(\mathrm{g} \mathrm{m}^{-2}\right)$ by species for 150 simulation years across the northeastern Minnesota (MN) and northern lower Michigan (MI) landscapes for three climate scenarios (Current, B1, and A1FI) assuming BAU forest management.

Figure 2.10: Northeastern Minnesota map of classified forests type at simulation year 2000 (upper left), proportion of forest types changing through time for each climate future (middle), and associated forest type maps at simulation year 2150 (right) 
Figure 2.11: Northern lower Michigan map of classified forest type at simulation year 2000 (upper left), proportion of forest types changing through time for each climate future (middle), and associated forest type maps at simulation year 2150 (right).

Figure 3.1: Northeastern Minnesota and northern lower Michigan study landscapes in northeastern United States.

Figure 3.2: Forest ownership groups in northeastern Minnesota (A) and northern lower Michigan (B) under BAU management.

Figure 3.3: AGB $_{\text {TOTAL }}$ and AGB removed by timber harvest (Teragrams) on each landscape, for three management scenarios, and three climate scenarios over time.

Figure 3.4: Average species AGB $\left(\mathrm{g} \mathrm{m}^{-2}\right)$ for select species over time across, climate, and management scenarios. Line type and colors match Figure 3.3 legend.

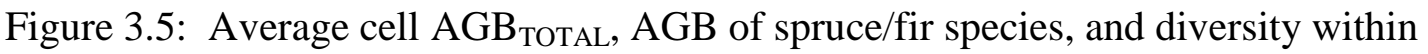
reserve areas and within actively managed forests in the Minnesota and Michigan landscapes across all climate scenarios

Figure 3.6: Average cell diversity across each landscape, climate, and management scenario from year 2050-2150.

Figure 3.7: Northeastern Minnesota forest type maps at year 2150 for each climate and management scenario.

Figure 4.2: Simulated (A) $\mathrm{AGB}_{\text {total }}$ and (B) harvested AGB over time for each landscape, climate, and management scenario.

Figure 4.3: AGB of CSP species simulated in each landscape and climate scenario. American chestnut and bitternut hickory were simulated in both landscapes.

Figure 4.4: Simulated aboveground ANPP measured over time of each landscape, climate and management scenario.

Figure 4.5: Within the CSP scenario, (A) Proportion of landscapes occupied by at least one CSP species; (B) average aboveground ANPP $\left(\mathrm{g} \mathrm{m}^{-2-\mathrm{yr}}\right)$ across actively managed sites where at least one CSP species was present compared to cells where CSP species were absent.

Figure 4.6: Species diversity $\left(\mathrm{e}^{\mathrm{H}^{\prime}}\right)$ and functional diversity (FDis) for each landscape, climate, and management scenario over time. 128 
Figure 5.1: Conceptual representation of diversity and dissimilarity supporting the hypothesis that as initial diversity increases, dissimilarity decreases (solid black line). 152

Figure 5.2: Northeastern Minnesota and northern lower Michigan study regions. 153

Figure 5.3: Conceptual diagram of resilience following a fire measured along two axes.

Figure 5.4: The interacting effects of management, climate, and duration (simulation years 2050,2100 , and 2150) on dissimilarity and initial diversity across climate regions in the Minnesota landscape.

Figure 5.5: The interacting effects of management, climate, and duration (simulation years 2050, 2100, and 2150) on dissimilarity and initial diversity across climate regions in the Michigan landscape.

Figure 5.6: Three spatial resolutions of species and functional diversity effect on dissimilarity in the Minnesota landscape under BAU management and high emissions climate.

Figure 5.7: Three spatial resolutions of species and functional diversity effect on dissimilarity in the Michigan landscape under BAU management and high emissions climate.

Figure 5.8: Resilience of forest AGB and species dissimilarity to the effect of simulated fires and climate change at year 2005 under alternative management scenarios

Figure 5.9: Resilience of forest AGB and species dissimilarity to the effect of simulated fires and climate change at year 2100 under alternative management scenarios. 160 


\section{Chapter 1: Introduction}

The forests of the Great Lake states are unique ecosystems along the temperate boreal forest transition zone. To the north, boreal tree species such as black spruce (Picea mariana), white spruce (Picea glauca), and balsam fir (Abies balsamea) are prominent components of communities. Temperate northern hardwoods such as northern red oak (Quercus rubra), sugar maple (Acer saccharum), and American basswood (Tilia americana) are prominent components of communities to the south. Within the northern Great Lake ecotone (ecological transition zone), a large mix of boreal and temperate species and ecological services and functions exist (Curtis 1959, Heinselman 1996). As many of these species are at the limits to their range, communities within this ecotone are vulnerable to substantial forest shifts as environmental conditions change (Fisichelli et al. 2013).

Human communities are sustained in part through the ecosystem services that these functioning forests provide (e.g., wood products, clean water, and recreation). Since the turn of the century, intensive harvesting practices have logged nearly all northern Great Lake landscapes (Karamanski 1989, White and Mladenoff 1994). Although timber harvesting continues to dominate northern Great Lake disturbance regimes, the value of a diverse suite of ecosystem services is recognized. Recreation and tourism bring \$18.5 billion annually to northern MI, WI, and MN (Kling et al. 2003). Jobs related to the wood products industry remain critically important for many communities bringing \$9.7 billion annually to MN alone (Deckard and Skurla 2011). 
Within the Upper Midwest, the Boreal Hardwood Transition ecological region in the US covers almost 55 million acres (USFWS 2010). Approximately 45.9 percent of this area is under some form of protected status to limit development, but the distribution and size of these reserves varies throughout the region (USFWS 2010). The arrowhead region of northeastern Minnesota and the northern lower peninsula of Michigan provide two examples of northern Great Lake forested landscapes that represent a range of unique forest types and conditions to support them (Figure 1.1). Northeastern Minnesota is largely contiguous forest, with a high proportion of Federal and state lands including the Boundary Waters Canoe Area Wilderness Area and several protected State Parks along Lake Superior. In contrast, the distribution of protected forests in the northern lower peninsula of Michigan is much more fragmented with development with less forest land off-limits to resource extraction (Gustafson and Loehle 2006).

\section{GLOBAL CHANGES:}

Over the next century, the pace of climate induced change is projected to exceed the ability of forests to naturally adapt (Soja et al. 2007, Iverson et al. 2008). This lag may result in species extirpation, a change in forest structure, a loss in productivity, a loss in species diversity, and ultimately a decline of ecosystem resilience (Soja et al. 2007, Iverson et al. 2008), which is particularly concerning in areas such as the Great Lake states whose economies rely in part on multiple ecosystem services provided by these forest ecosystems. Incorporating climate changes and interactive disturbance effects have already presented serious threats to ecosystem services in North America (e.g., Bentz et al. 2010). The Upper Midwest and Great Lakes landscapes are experiencing an anthropogenic global warming trend affecting northern forests beyond our ability to 
manage them with traditional methods (Kling et al. 2003, IPCC 2007). Given the magnitude and uncertainty of expected global change, ecologists and natural resource managers are struggling to determine the stability of future ecosystems.

Throughout the last century, ecologists have debated the measures of a healthy functioning ecosystem (Costanza 2012). Ecosystems were described early on by Tansley (1935) as being "a biotic community or assemblage and its associated physical environment in a specific place.” Pickett and Cadenasso (2002) support Tansley’s definition, however caution that the definition alone covers an inconceivably large selection of examples. Costanza and Mageau (1999) describe a sustainable ecosystem in which there is an interaction of strong vigor, organization, and resilience. Vigor is described as being analogous to productivity with measurements such as gross primary production (GPP). Organization is related to the structure and diversity that a system supports. Finally, resilience is the ability to maintain the vigor and organization in the face of external stress such as disturbance.

To understand ecological resilience we must recognize the relationship of succession and disturbance. Much of our early understanding of succession is attributed to Frederick Clements (Clements 1916) who argued that vegetation could be grouped into discrete communities which followed a predictable pathway to a climax community (Tansley 1935). Gleason rejected this concept arguing that species acted individually rather than in groups, and that species persistence on a landscape did not follow clear "successional" pathways but rather acted independently (Gleason 1926). The modern view of succession both engages and disputes concepts from both Clements and Gleason incorporating the view that natural disturbance regimes cause ecosystems to be constantly 
in a state of flux. For this reason, there is not just one "climax" condition, nor is any single condition a concluding measure of a healthy ecosystem. Indeed, rather than focusing on a single condition in space and time, ecologists are increasingly interested in the disturbance processes that continue to affect patterns in ecosystems (Foster et al. 1998).

By accepting natural disturbance regimes as driving factors in ecological processes (e.g., floods, hurricanes, fires), an stable equilibrium paradigm, inherent in Clementsian succession, becomes harder to accept (Holling 1973). We observe, for example, species disappearing and reappearing as natural systems are continually in transient states. These dynamics result in ecological questions that require assessments of larger spatial and temporal scales (Hanski 1994, Reiners and Driese 2001). Climate change is a disturbance factor expected to stretch environmental conditions of forests beyond the recent historical range of variability. We need a better understanding of the interactions of future climate as a disturbance agent provided by questions in this thesis.

\section{RESISTANCE AND RESILIENCE:}

By including disturbance regimes in our understanding of ecosystems, the term stability has been used to describe ecosystem health (Pimm 1984). Grimm et al. (1992) give warning to the term "stability" used in ecology as it is often used without a clear definition, context, or scale and can have confusing meanings. Stability properties, however, can be useful descriptive parameters to understanding systems. These properties can be described as being 1) unchanged, 2) returning to a reference state following a disturbance, or 3) persisting through time. The use of the term stability must then reference clear definitions of its meaning within an appropriate context (Grimm et 
al. 1992).

The resistance and resilience of a system both describe elements of stability. Resilience is a measure of the ability of a described system to recover from disturbance (Gunderson 2000). Pulse disturbances can be described as disturbances that are repetitive but short in duration (e.g., fire, wind, harvesting); press disturbances can be described as ongoing persistent perturbation (e.g., climate change) (Glasby and Underwood 1996). Resilience is a good measure of pulse disturbance effects and the interaction of climate change with other disturbances (e.g., recovery of a forest following a fire under climate change). Resistance of a system can be defined as the ability of a system to persist through time with little change (Landres et al. 1999, Minckley et al. 2012). Resistance is an informative measure of direct climate change effects such as the ongoing effects of increased temperature on a species (press disturbances).

Holling (1973) first introduced the word resilience to describe aspects of ecological change as that which "determines the persistence of relationships within a system and is a measure of the ability of these systems to absorb changes of state variables, driving variables, and parameters, and still persist." Holling and Meffe (1996) define ecosystem resilience as the "magnitude of disturbance that can be absorbed or accommodated before the system changes its structure by changing the variables and processes that control system behavior." With this definition, there exist multiple alternative states rather than a single stable equilibrium, and that change can happen in unexpected and discontinuous ways such as an sudden insect outbreak (Edburg et al. 2012) or population collapse (O'Dowd et al. 2003). Commonly, resilience refers to prevention of "state-changing" or "threshold" crossing conditions (Gunderson et al. 
2010). Many systems may not result in a sharp transition. Rather, a decline in resilience may be apparent after a slow decline in an ecosystem services or a lack of ability to recover from a disturbance.

A complex system's identity is composed of the system's components, the relationship between the components, and the spatial and temporal scale of interest (Cumming and Collier 2005). Within a temporal scale of interest (e.g., 50 years), the persistence of a system's identity is one measure of resistance (Millar et al. 2007). The persistence of a system through a historical range of variability can be a useful benchmark to understand the stressors and disturbances that have allowed a system to persist (Landres et al. 1999, Keane et al. 2009). Zhang and Hebda (2005) point out the resistance of British Columbia's old growth coastal forests which have maintained themselves for several millennia given a large range in historical climate. There is concern, however, that by changing the stand structure from old growth to second growth, for example, the systems may become less resistant (more vulnerable) to the effects of global change. For example, within British Columbia's coastal old growth stands, arthropod diversity is high, which is critical since they are natural predators to invasive insects reducing herbivory in mature stands (Winchester 1998).

In some cases, a seemingly uniform system may provide conditions for a disturbance that make the system vulnerable for a state change. In the northeastern pine barrens of New Jersey, for example, fire has been largely excluded from the fire dependent ecosystems where uniform monocultures of pitch pine (Pinus rigida) are increasing in fuel load (Clark et al. 2009). In the Rocky Mountain monocultures of aging lodgepole pine (Pinus contorta), the potential for mountain pine beetle outbreaks are 
especially high in stands above 80 years old, but the risk of outbreaks is lower than older stands which have lost the thick phloem layer preferred by the host (Geiszler et al. 1980, Taylor and Carroll 2004). The resistance and resilience for both examples may be enhanced by frequent low intensity disturbances that keep the fire and insect fuel loads lower and create a mosaic of diverse forests within a landscape scale.

\section{Measuring resistance and resilience:}

To measure resistance and resilience, one must define "of what clearly defined system" and "to what disturbance" is being measured (Carpenter et al. 2001). For example, the resistance and resilience of a jack pine (Pinus banksiana) forest may be defined in several ways. The forest may be defined as being resistant and resilient by simply maintaining forest cover with at least $70 \%$ jack pine overstory; or it may include a diversity of jack pine age cohorts with at least $25 \%$ jack pine less than 30 years old, $25 \%$ of the jack pine between 31 and 60 years old, and 50\% of the jack pine greater than 61 years old. Along with identity, it is vital that resistance and resilience specific definitions include a description of which disturbance or other external factors are being considered (Carpenter et al. 2001). The jack pine forest may be resistant and resilient to herbivory, harvesting practices, and stand-replacing wildfire, but not resistant to long term climate change. Finally, to define a system's resistance or resilience, one must include a definition of relevant temporal and spatial scales (Levin 1992, Cumming et al. 2006). An analysis of a small forested stand that is protected from the disturbance regime of the surrounding forest will show a resistance and resilience threshold vastly different from an analysis that includes the surrounding forest. Temporal scale will also clearly affect a system's resistance and resilience. Cumming et al. (2006) point out the challenge for 
forest managers to manage both at short time scales (e.g., the response to an aggressive invasive species) and long time scales (e.g., management of long lived and slowly reproducing species like shade tolerant trees).

Cumming and Collier (2005) suggest that the identity of an ecological (or social) system be defined by: 1) the system components, 2) the relationships between the components, 3) the location and spatial scale at which the system is applicable, and 4) the temporal scale at which the definition is applicable. The spatial scale must capture an adequate resolution and extent to adequately observe, for example, species extirpating and later occupying certain patches in a metapopulation (Wiens 1989). When analyzing a population at a small extent, the population of a keystone species within a patch may be observed to be increasing. However across the larger metapopulation, the species may be in decline. Also, resources used by a population do not always stay within the home range or spatial extent of that population. Bobcats (Felis rufus) in Maine have been found to increase their home-range as the density of their major prey, snowshoe hare (Lepus americanus) declined (Litvaitis et al. 1986). If one was to study the bobcat population, they would have to include a large enough spatial extent as to capture the increase in home range.

Direct measurement of resistance and resilience relies on actually crossing the boundaries which define the system. Outside of experimental manipulation and models, land managers are rightly wary of pushing systems beyond their limit to measure them (Groffman et al. 2006). Rather than measure resistance and resilience itself, empirical work is often limited to measuring surrogates for the functions that define those systems 
(Bennett et al. 2005). Simulation models offer a safe and explorative methodology to experimentally assess the resistance and resilience of a system.

\section{Relationship between diversity and resistance:}

Many natural resource systems provide an ecosystem service such as carbon storage which is provided by a relatively few dominant species. Understanding how these services are affected by diversity has been identified as a research priority (Kremen 2005). Walker et al. (1999) successfully tested a hypothesis that points out the importance of other, minor species in those communities when only a few dominant species provide the bulk of an ecosystem function. The minor species that may seemingly be redundant act in two ways to protect ecosystem function. First, minor species that are analogous in environmental tolerances to the dominants can act as "insurance." When a species-specific disturbance reduces dominants, the similar minor species are able to compete successfully, preserving the original function (Naeem and $\mathrm{Li}$ 1997). Second, minor species can be functionally comparable to the dominant species but have different ranges of environmental tolerances (Walker et al. 1999). As environmental conditions change, the less abundant species provide response capability. The different tolerances of minor species allow the system to adapt and change at different scales (Peterson et al. 1998) and conditions (Walker et al. 1999), providing identical or comparable functional services that the dominants do, creating the building blocks for resistance and resilience.

There are exceptions to the redundancy role of low-abundance species including species that are either: a) habitat specialists that may be on the edge of their range, b) unique keystone species that play a large role even in low abundance, or c) minor species 
that maintain themselves but do not have an observable interlinking role in the ecosystem (Walker 1992). Functional diversity therefore can be split into diversity to maintain current function and diversity to maintain future function. Future functional diversity is met in part by the redundancy of species. Folke et al. (2004b) describes the two diversity groups as being functional diversity and response diversity. Functional diversity includes the species groups that provide specific services or functions to a system. Response diversity includes the species that respond to new conditions. If a system has both species that perform the exact same function as the more dominant ones, and do not demonstrate response diversity traits, they are theoretically redundant and may not add to the insurance value. Nevertheless, our understanding of the functional properties of individual species is limited to our current evolving knowledge. Although species number alone does not adequately capture the role of redundancy and diversity, species functional groups have different functions (e.g., biomass vs. nitrogen fixation) which supports the benefit of having more species overall (Namkoong 2008). My knowledge about complete species function and interacting species function is limited. Holling (1978) points out regarding uncertainty that "however intensively and extensively data are collected, however much we know of how the system functions, the domain of our knowledge of specific ecological and social systems is small when compared to that of our ignorance." Given our ignorance of functional and response diversity, there remains an inherent value in protecting species diversity (Wilson 2010).

Many studies have demonstrated that diversity is a surrogate for stability or that vulnerable systems are a product of low diversity. Taylor and Carroll (2004) modeled forest disturbance dynamics in British Columbia and showed that a low diversity in 
species and age-class following a fire suppression disturbance regime can lead to the susceptibility of large-scale mountain pine beetle (Dendroctonus ponderosae) outbreaks beyond the historical range of variability. Carpenter and Kitchell (1993) show that by experimentally increasing lake fish diversity and ultimately changing the food web, the lake becomes more resilient to algal blooms. Danell et al. (2003) show that large ungulate browse disturbance is often limited to a single plant species. The reduction of one preferred species at browse height can lead to the replacement of another plant species that may have a different functional characteristic than the original.

David Tilman in 1982 began a long-term research study to experimental test the diversity-stability hypothesis in a prairie system in Minnesota (Tilman and Downing 1994, Tilman et al. 2006). In his work, he showed that more diverse communities would preserve more ecosystem function. In addition, their work showed that more diversity resulted in higher overall biomass and productivity (Tilman et al. 2006). There has been some critique of Tilman's work regarding whether his studies show that diversity is directly responsible for stability, pointing out that "hidden treatments" (e.g. indirect effects of selecting drought tolerant species) can falsely indicate diversity as a driver for stability (Huston 1997, McCann 2000). Indeed, some studies have shown that stability declines with increased diversity (Sankaran and McNaughton 1999). It is clear that the diversity-stability debate will only be understood by clearly and thoroughly defining the "of what" system identity and "to what" disturbances (Carpenter et al. 2001). Research priorities remain that explore under what conditions diversity-productivity relationships may flip from positive to negative. 


\section{FOREST IDENTITY:}

Given the value of ecosystem function for ecologists and managers, functional diversity may be a more appropriate surrogate for stability than simply species richness. The challenge is to identify ecosystem functions or services that make up the goals or priorities for management. Often ecologists are focused on the species richness as an indicator of stability (Loreau et al. 2001). Along with the species themselves, it is vital to consider the functions these species provide along with the interactions between species (Bøhn and Amundsen 2004). Although novel forest types are likely to emerge in the face of climate change (Williams et al. 2007), the current suite of forest types provide valuable ecosystem services that are vulnerable to the effects of climate change.

\section{DRIVERS OF FOREST IDENTITY:}

Like many forested systems, northern Great Lake forests are resistant and resilient to the disturbance regimes that define them. The combination of harvesting, wind, and fire play a distinct role in defining the identity of the described forest types. Other drivers of forest change (e.g., climate change) are discussed as threats to identity.

\section{Timber Harvesting:}

Before the turn of the $20^{\text {th }}$ century, wind and fire were the dominant disturbances in the Great Lakes region. With westward expansion, timber harvesting quickly dominated disturbance regimes as the need for pine lumber and later aspen pulp drove intensive forest management across the region (Karamanski 1989, Heinselman 1996). Nearly all forests in the Great Lakes region were harvested for timber and agriculture at one time (Pyne 1997). Today, these forests are characterized by younger more dense forests than their historic counterparts and are more homogeneous as the pine and spruce 
forests gave way to an aspen-birch matrix (Hanberry et al. 2012). Forest management continues to be the dominant disturbance to northern Great Lake Forests; however the timber harvesting trends are changing. In Minnesota, for example, clearcutting continues to be the dominant type of silviculture system, however repeat surveys of silviculture practices $(1991,1996,2008)$ indicates a decline in clearcut prescriptions made up by an increase in the use of patchcutting, clearcutting, seed tree, shelterwood, single-tree, and group selection systems (D' Amato et al. 2009). Additional trends include the increased use of residuals within clearcuts, and using more artificial regeneration (i.e. planting) for species establishment.

Timber harvest in the Great Lakes region is managed by a diverse set of landowners with a diverse set of objectives. In northern Minnesota, owners include State, County and United States Forest Service (USFS), Private Industrial Forests (PIF), and Private Non-Industrial Forests (PNIF). In northern lower Michigan, landowners include state DNR, USFS, PNIF, and a small component of PIF.

\section{Wind:}

Generally, wind blowdown events in the Great Lakes Region are low in frequency and small in size (Lorimer and White 2003, Schulte and Mladenoff 2005, White and Host 2008). These disturbance events, in the absence of management, create heterogeneous forest structures with multiple cohorts and various gap sizes (Hanson and Lorimer 2007). The exceptions are derecho events, a family of down bursts causing straight-line thunderstorm winds that can affect hundreds of kilometers in a narrow band. Several of these events have knocked down thousands of hectares of forest in recent decades (Frelich 2002). Windstorm events generally affect the oldest, most vulnerable cohorts 
(i.e. tall trees most exposed to the wind coupled with those experiencing age related decay). Frelich (2002) approximated rotation periods throughout the Great Lakes Region for intense wind storms. In Northeastern Minnesota, Frelich's estimates include a rotation period >2000 years and in northern lower Michigan rotation periods between 1000 and 2000 years. White and Host (2008) estimate that blowdown events occur on between 0.02 to 0.29 percent of the landscape every year in northeastern Minnesota.

\section{Fire:}

In the northern Great Lake forests, fire events occur with large variability in severity and frequency. Fires in northern hardwoods forests are generally rare with more frequent fires occurring in the pine near-boreal forest types with fire rotations between 50-200 years (Frelich 2002). However, several infamous fires have made history in the region including the Peshtigo Fire burning 50,000 hectares in October of 1871, and the Hinckley Fire burning 100,000 hectares in September 1894 (Heinselman 1973). Large Great Lake Fires are not limited to the distant past, however. Today, human factors along with environmental factors are largely shaping the contemporary fire regime of the Great Lakes region (Cardille and Ventura 2001, Cardille et al. 2001). Human access is a large driver to fire activity in the Great Lakes region with a large proportion of fires started by human causes. Increased access to forests generally increases fire activity with the exception of large fires where access to forests (e.g. road density) can decrease fire activity (Cardille et al. 2001).

Large fires such as the Pagami Creek Fire in August 2011 was started by lightning, and burned 37,000 hectares in northern Minnesota threatening homes and businesses (Sherry 2012). Due to the largely diverse cover types and fuels, large 
infrequent fires in the Great Lakes Region, along with many more smaller fires, result in a mixed severity fire regime (Frelich 2002). White and Host (2008) estimate percent area burned annually in North Eastern Minnesota to be between 0.1 and 0.6 percent of the pat landscape. In northern lower Michigan, Cleland et al.(2004) estimate the percent area burned annually to be between 0.09 and 0.13 percent.

\section{CLIMATE CHANGE THREAT TO IDENTITY:}

By late in the $21^{\text {st }}$ century, mean winter temperatures in the Great Lakes region are projected to increase by $3-7^{\circ} \mathrm{C}$, and mean summer temperatures are projected to increase by $3-11^{\circ} \mathrm{C}$ (Kling et al. 2003, IPCC 2007). As this central continental region is not buffered by oceans, future climate fluxes are expected to be higher than much of the continent (IPCC 2007). In northeastern Minnesota and northern lower Michigan, longer growing seasons and greater variability in precipitation are also expected (Iverson et al. 2008, Frelich and Reich 2010). While, future precipitation projections do not depart drastically from current climate, monthly temperature trends in both Minnesota and Michigan indicate substantial increases in temperature over time (Stoner et al. 2012). In addition, observed increases in temperature over the last century corroborate future projections (Andresen et al. 2012).

Changes to incoming solar radiation also have the potential to change forest dynamics (Gough et al. 2008, Xu et al. 2009); however future solar radiation projections are uncertain. Prior to the early 1990's, many reported a decline in solar radiation; however during the 1990's many sites across the globe report an increase in solar radiation (Wild et al. 2005). The interacting changes of temperature, precipitation, and solar radiation are all expected to alter forest species composition, productivity and 
disturbance regimes (Scheller and Mladenoff 2005, Scheller and Mladenoff 2008). Some research indicates that $\mathrm{CO}_{2}$ fertilization effects on photosynthesis will initiate an increase in Net Primary Productivity (NPP) (Mickler et al. 2002). If increasing NPP is observed at a landscape scale due to the fertilizing effects of $\mathrm{CO}_{2}$, this may be considered increased resistance to NPP. Additional research has shown that soil nitrogen is a constraint on carbon dioxide fertilization of plant biomass (Reich and Hobbie 2012). Furthermore, no increase in NPP has been observed globally by satellite measurements for the last 30 years of increased atmospheric carbon dioxide (Running 2012). In addition, ozone concentrations in the midwest are expected to decrease net primary production (Ainsworth et al. 2012)

With the additional threat of climate change interacting with pulse disturbances (Glasby and Underwood 1996) forests may be more vulnerable to and slower to recover. For example, in the last twenty years, billions of trees across millions of hectares in North America have been killed by bark beetles. These recent outbreaks have included the largest beetle outbreaks in recorded history (Bentz et al. 2010). Much research has been done on bark beetles response to climate as insects life cycles are very much tied to temperature. A decrease in life stage transitional time results in faster population growth (Bentz et al. 1991). Increases insect-induced mortality has the potential to substantially alter forest carbon balance, slowing NPP and increasing respiration (Seidl et al. 2008).

Low species and age diversity forests are often vulnerable to the interacting effects of climate change and invasive species. Compared to the single tree species forests of the Rocky Mountains, the northern Great Lake forests are inherently more diverse. Their resistance and resilience to climate change may depend on the ability to 
maintain, if not improve, structural complexity to buffer the effects of global change.

In addition to direct climate change effects measured by the ability of forest to resist change; timber harvesting, fire, and wind are pulse disturbances resetting successional trajectories that interact with climate change and can be measured by resilience ability. This research addresses both resistance and resilience to change.

\section{MANAGING FOR RESISTANCE AND RESILIENCE:}

Land managers recognize that landscapes are changing around them. Although there is considerable disagreement about management objectives and associated actions, many land managers are seeking information that will guide current decisions for future conditions. Millar et al. (2007), Spies et al. (2010), Puettmann (2011), and Swanston and Janowiak (2012) each provide excellent frameworks for resistance, resilience, adaptation, and mitigation options to global change.

For some managers, tactics that prevent climate effects may seem most desirable. Short-term gains may be achievable by improving defenses to rapid environmental change. These strategies are aimed at improving defenses against direct effects of changing climate. Specific tactics might include placing fuel breaks in the wildland urban interface to lower the risk of catastrophic fire, eradicating an invasive species from a highly sensitive area, or blocking an invading epidemic from a local high-value area. These are recognized as valuable in the short term in high value sites; however, the tactics may not provide long-term refuge to the long-term effects of global change (Hansen and Hoffman 2011).

To allow forests to respond to change and still persist, several potential adaptation tactics have been identified (Millar et al. 2007, Spies et al. 2010, Puettmann 2011, 
Swanston and Janowiak 2012). These practices are specifically aimed at promoting resilience through mimicked natural processes rather than resistance to change. These tactics come with the recognition that forests will not stay within a historical range of variability.

\section{Climate Suitable Planting:}

To augment natural seedling establishment, intensive planting of a desired species following a disturbance may increase forest resilience when an undesirable state changing potential is otherwise possible (Spittlehouse and Stewart 2003). Even with augmented planting however, successful establishment of a desirable native species may become increasingly difficult as climate changes (Ledig and Kitzmiller 1992). There is growing interest in exploring climate suitable planting (CSP) where southern species are planted beyond their current range (O’Neill et al. 2008). This prescription is designed to help facilitate migration and increase diversity while attempting to mitigate the effects of climate change (Millar et al. 2007, O’Neill et al. 2008). For the protection of rare and endangered species, assisted migration has been proposed by some. This management is fraught with controversy since opponents focus on the negative effects of invasive species. For example, Davidson and Simkanin (2008) suggest that assisted migration should only be considered if the recipient ecosystem has less value than the individual transported species. Others, however, have described potential benefits to non-native species (Schlaepfer et al. 2011). With management concerns over invasive species, much effort is spent on preventing and removing non-natives species. Accepting that some of these species provide function in novel locations and assemblages may allow more migration of climate suitable species without planting assistance (Williams et al. 2007). 


\section{Manage for complexity:}

Managing for complexity may allow heterogeneous forests to develop and thereby be resilient to uncertainty (Puettmann et al. 2009). Risks associated with a single species or a single age cohort can be minimized by creating diverse stands thereby spreading rather than concentrating risk (Naeem and Li 1997, Walker et al. 1999). By supporting redundant functional response type species with different environmental tolerances, functional insurance is enhanced (Walker 1992).

Gunderson and Holling describe the panarchy conceptual model (Gunderson and Holling 2002), a system's adaptive cycle, where there exists a period during reorganization when the system can flip into an alternative state. Historical forest structures indicate synchronized periods of drought across broad landscapes (Pyne 1997). At potentially large spatial scales, these synchronized periods may represent the vulnerable points of low resilience in the panarchy model. For example, landscape scale droughts in the western United States have resulted in landscape scale tree mortality (Breshears et al. 2005). Management for asynchrony, and therefore higher resilience, can be achieved by creating diverse age classes, species mixes, and genetic diversity (Millar et al. 2007). The panarchy model assumes that low resilience may result in an alternative state. In many systems however, low resilience may result in a gradual decline or slow recovery from disturbance. Complexity may decrease vulnerability of both state changing systems and systems prone to more gradual declines.

\section{Promote Connected Landscapes:}

The use of protected areas, reserves, and buffers to improve adaptive capacity is well supported (e.g., Hewitt and Kellman 2002, Murphy and Lovett-Doust 2004). 
Preserving contiguous forests is generally recognized as being critical, both as a means to maintain ecological connectivity and to allow for range shifts of vegetation and wildlife. Increased connectivity facilitates species migration in response to global change (Iverson et al. 2004) and climate refuges have the potential to harbor both species and genetic diversity (McLachlan et al. 2005).

Riparian corridors create a connected (often linear) protected area that directly spans an altitudinal, and therefore temperature, gradient. These gradients provide both aquatic species and terrestrial species an "avenue to track appropriate climate conditions" (Hansen and Hoffman 2011). Riparian corridors are often protected at a limited distance from the high water mark from extractive activities. Expanding these existing reserves in width will create larger areas of connected corridors with greater within reserve heterogeneity.

\section{Climate Mitigation-Sequestered Carbon and Reduction of Emissions:}

Forests have potential for increased carbon sequestration at local and regional scales. Globally, however a boundary limit to terrestrial NPP may have been reached (Running 2012). Nevertheless, current forests continue to play a pivotal role in current carbon sequestration and management. There is increasing interest to manage forests for carbon sequestration, including afforestation, reforestation, increasing NPP within existing forests, and long-term storage of sequestered carbon in wood products (Skog and Nicholson 1998, Jandl et al. 2007, D' Amato et al. 2011). One of the challenges of carbon sequestration is the tradeoff between fast growth associated with mitigation of green-house gas emissions and managing for adaptation for resilient forests (D' Amato et al. 2011). These tradeoffs must consider the risk associated with fast-growing, uniform 
stands that are vulnerable to insects, disease, and fire. Emissions from wildfire, insects and disease represent a large source of unintentional release of forest carbon into the atmosphere. By reducing the vulnerability to the sources of forest emissions, forests can provide more carbon mitigating function.

\section{PROJECTING FOREST CHANGE:}

Without broad, empirically based experiments on forest resistance and resilience, many studies suggest using forest simulation models to assess forest resilience and adaptation scenarios (Rehfeldt et al. 2006, Campbell et al. 2009, Moritz and Agudo 2013). Simulation models provide ecologists non-invasive opportunities to experimentally push systems beyond their thresholds and assess the efficacy of adaptation options (Seidl et al. 2011). Landscape simulation models provide unique opportunities to push large-scale systems (i.e. larger than empirically possible) beyond the thresholds that define their identity. In addition, resilience of systems under future conditions can be simulated as experiments (e.g., using future climate change projections) (Cumming et al. 2005). For models to be useful however, the relationship among the ecological system, empirical observations, resilience surrogates, and model components should be explicit and transparent (Carpenter et al. 2005).

With projections of declining forest resistance and resilience due to climate change come tremendous amounts of uncertainty. Along with the largely stochastic nature of forests, it is important to acknowledge the large uncertainty in the economy, emissions scenarios, and Global Circulation Models (GCM)s. Each of these sources of uncertainty contributes to the climate change projections across the globe. 


\section{SIMULATION MODEL:}

I used a combination of data assimilation and modeling to address effects of climate change to forest landscape change. These tools provide valuable means to quantify landscape change and uncertainty associated with future conditions (Moritz and Agudo 2013). I used LANDIS-II, a spatially explicit landscape model that is processdriven, flexible, and well-tested to measure the abundance of tree species and forest types over time (Scheller et al. 2007a). LANDIS-II simulates disturbance, management and succession in a framework that emphasizes spatial interactions across the landscape and among processes (e.g., climate change, harvesting, succession, fire, wind, and seed dispersal) over many decades (Figure 1.2) (Details of LANDIS-II are described in chapter 2). I focused on the biomass of tree species within species functional groups as trees play a foundational role in a forest ecosystem (Ellison et al. 2005).

I used the PnET-II ecosystem model (Aber et al. 1995) coupled with the PnET-II for LANDIS-II tool (Xu et al. 2009) to calculate for every five-year time step speciesspecific parameters including maximum aboveground net primary productivity per year $\left(\mathrm{ANPP}_{\max }\right)$ and probability of establishment $\left(\mathrm{P}_{\mathrm{est}}\right)$. These parameters are the primary mechanisms whereby climate change was incorporated into the simulations. ANPP $\mathrm{Aax}_{\text {is }}$ calculated largely driven by nitrogen availability and is further adjusted by incoming photosynthetic active radiation (PAR), the deviance of temperature from species-specific optimal temperature parameters, and water availability (Aber et al. 1995). Water availability is calculated from precipitation as an input to the soil after subtracting drainage (based on the Soil Water Holding Capacity (SWHC)) and transpiration (based on photosynthesis and water use efficiency) (Aber and Federer 1992). SWHC is largely a 
function of soil texture. $P_{\text {est }}$ is calculated by the product of photosynthesis adjusting factors of light, and water availability. $\mathrm{P}_{\mathrm{est}}$ is further adjusted by the deviance between growing degree days and species-specific optimal growing degree days (Xu et al. 2009). Other inputs to calculate the PnET-II parameters included percent foliar nitrogen content, and maximum foliar mass area (See Appendix: Table A1).

A number of studies have assessed the sensitivity and uncertainty of PnET-II parameters. Pan et al. (2004) described the relative importance of foliar nitrogen concentration to predict forest productivity using PnET-II. Conifer growth was found to be less sensitive to variation in foliar nitrogen. Larger variation in deciduous foliar nitrogen concentration however, resulted in large variation in growth (Pan et al. 2004). Using a Bayesian approach to reduce uncertainty, Radtke and Robinson (2006) identified input parameters: light intensity, growing season, optimal temperature for photosynthesis, and foliar nitrogen concentration as being sensitive to ANPP predictions. Using the coupled PnET-II for LANDIS-II tool to predict forest type composition in Minnesota, Xu et al. (2009) found that temperature, $\mathrm{PAR}, \mathrm{CO}_{2}$, and precipitation all contributed to the greatest uncertainty in predicted forest type composition. Using a version of PnET, Peters et al. (2013) assessed climate input parameters to predict ANPP under current and climate change scenarios in northern Great Lakes landscapes. ANPP max $_{\text {predictions of }}$ deciduous forests was most highly correlated with summer temperature, summer precipitation, and soil water holding capacity. Alternatively, spruce-fir current $\mathrm{ANPP}_{\max }$ was more correlated with annual temperature and precipitation (Peters et al. 2013). These analyses highlight basic input parameters of most significance for simulations of 
forest change. Climate, model, and management uncertainty is described in subsequent chapters.

\section{OBJECTIVES:}

My objectives were to assess the resistance, resilience, and the changing attributes of forests in the northern Great Lakes region to the effects of climate change. My work encompasses a broad range of variation given the large uncertainty in both management and climate change. I compared business-as-usual management to alternative management strategies that may increase resilience. In addition, I compared current climate to a low and high emission climate scenario.

Specifically, I addressed the following questions and hypotheses in subsequent chapters: How might climate change under business-as-usual management affect northern forests and the relationship between tree diversity and productivity? Hypothesis: The relationship between diversity and productivity will become more positive as productivity declines (Chapter 2). How might additional forest reserves and modified silviculture affect biomass and species diversity? Hypothesis: Forest reserves and modified silviculture will increase AGB and species diversity (chapter 3). How might climate-suitable planting treatments affect forest landscape change and species and functional diversity? Hypothesis: Climate-suitable planting treatments will increase AGB, species, and functional diversity (chapter 4)? How might climate change and alternative management affect the resistance and resilience of forests? Hypothesis: Climate change will decrease and alternative management will increase resistance and resilience of forests (Chapter 5).

I examined these questions in the northern Great Lake region since this region is 
expected to experience fast rates of climate change compared to continental edges where climate change is expected to be more buffered by oceans (IPCC 2007). Additionally, the upper Midwest represents an ecotone on the boreal-temperate forest transition zone where many species are at the southern edge of their ranges. The paired landscapes of northeastern Minnesota and northern lower Michigan (Figure 1.1) enabled me to compare forest change across a broad gradient of both environmental conditions. Warmer temperatures and less intensive harvesting are expected in the more southern Michigan landscape whereas the more northern Minnesota landscape is expected to experience more intensive harvesting and cooler temperatures.

My research both advances science and informs managers about the potential of Great Lakes' forests, and our management of them, to adapt to changing climate. Important decisions must be made promptly to address forest management in the face of climate change. My approach to studying the effects of alternative management strategies will provide insight and caution to the ability to manage future forests. 
Figure 1.1: Study areas: Northeastern Minnesota and northern lower Michigan.

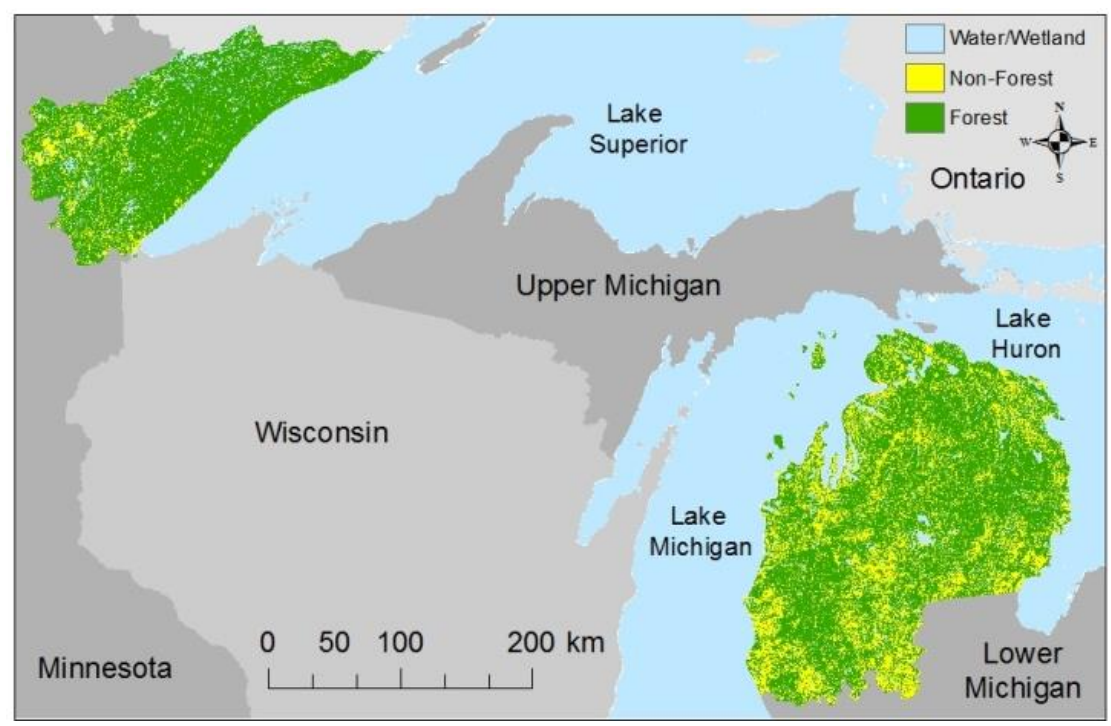


Figure 1.2. Conceptual diagram of modeling framework. A) Climate and soils data are input into PnET-II and a climate envelope model to project tree species maximum growth and probability of establishment. These parameters are inputs to the LANDIS-II forest simulation model. B) Across interacting cells, LANDIS-II simulates spatial processes such as seed dispersal, harvesting prescriptions, and fires. At the cell level the biomass of species-age cohorts is tracked through successional processes of establishment, growth, and mortality.

A

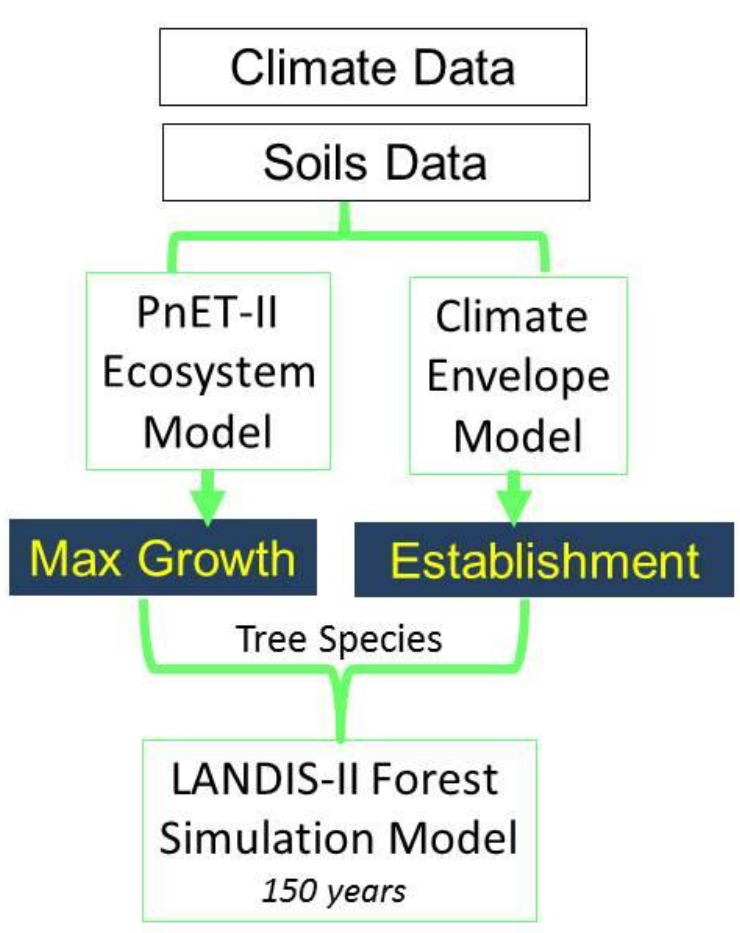

B

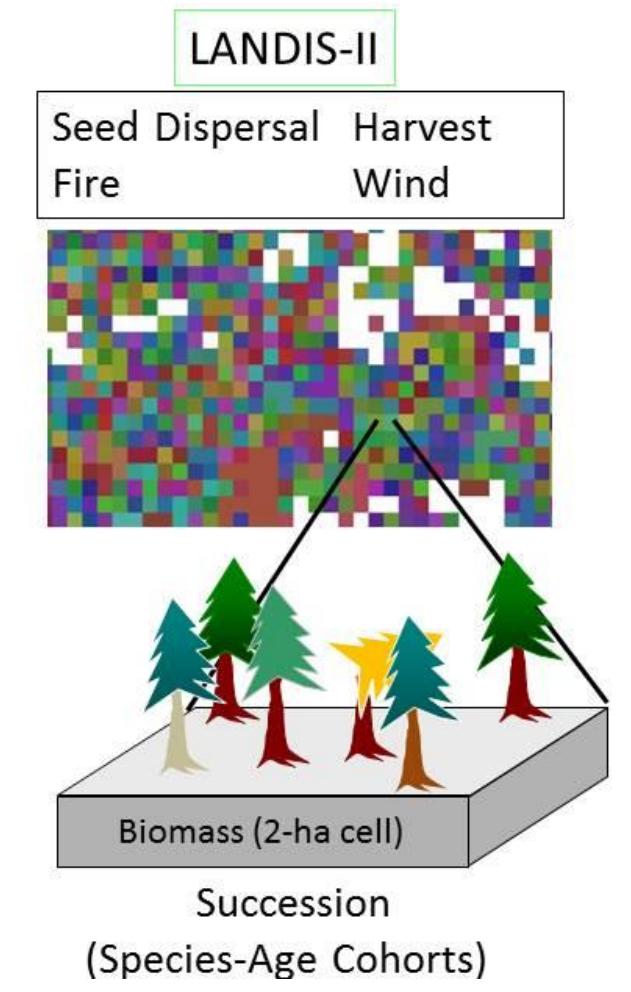




\title{
Chapter 2: Climate Change Effects on Northern Great Lake (USA) Forests: A Case for Preserving Diversity
}

\author{
ABSTRACT: \\ Under business as usual (BAU) management, stresses posed by climate change \\ may exceed the ability of Great Lake forests to adapt. Temperature and precipitation \\ projections in the Great Lakes region are expected to change forest tree species \\ composition and productivity. It is unknown how a change in productivity and/or tree \\ species diversity due to climate change will affect the relationship between diversity and \\ productivity. I assessed how forests in two landscapes (i.e. northern lower Michigan and \\ northeastern Minnesota, USA) would respond to climate change and explored the \\ diversity-productivity relationship under climate change. In addition, I explored how tree \\ species diversity varied across landscapes by soil type, climate, and management. I used \\ a spatially dynamic forest ecosystem model, LANDIS-II, to simulate BAU forest \\ management under three climate scenarios (current climate, low emissions, and high \\ emissions) in each landscape. I found a positive relationship between diversity and \\ productivity only under a high emissions future as productivity declined. Within \\ landscapes, climate change simulations resulted in the highest diversity in the coolest \\ climate regions and lowest diversity in the warmest climate region in Minnesota and \\ Michigan, respectively. Simulated productivity declined in both landscapes under the \\ high emissions climate scenario as species such as balsam fir (Abies balsamea) declined \\ in abundance. In the Great Lakes region, a high emissions future may decrease forest \\ productivity creating a more positive relationship between diversity and productivity.
}


Maintaining a diversity of tree species may become increasingly important to maintain the adaptive capacity of forests.

KEYWORDS: Biodiversity; Climate change; Forest management; Forest simulation model; LANDIS-II; Michigan (USA); Minnesota (USA).

\section{INTRODUCTION:}

Over the next century, the pace of climate change is projected to exceed the ability of forests to naturally adapt (Soja et al. 2007, Iverson et al. 2008, Loarie et al. 2009, Kuparinen et al. 2010, Svenning and Sandel 2013). For example, continental declines in quaking aspen (Populus tremuloides) throughout North America are linked to climate change (Worrall et al. 2013). Generally, substantial shifts in the ranges of tree species are expected under climate change (Zhu et al. 2012). However, a lag in species response may result in tree species extirpation, loss of forest structure and productivity, a decline in species diversity, and ultimately a decline of ecosystem resilience (Soja et al. 2007, Scheller et al. 2008, Frelich and Reich 2010, Fisichelli et al. 2012). The changes will likely exceed land-owners' ability to successfully manage forests with traditional forestry strategies. Within the northern Great Lakes region, vulnerability to climate change will likely depend on both latitude and proximity to the boreal-temperate transition zone (Fisichelli et al. 2013). More specifically, adaptation to climate change may depend on the potential mix of species capable of providing ecosystem services under changing environmental conditions. "Insurance" species are those that may 
currently occur in low abundance however have a response capability (i.e. the ability to provide ecosystem services) beyond the range of environmental tolerances provided by the more dominant species (Naeem and Li 1997, Walker et al. 1999).

The northern Great Lakes region experienced (Andresen et al. 2012) and is expected to experience fast rates of climate change compared to continental edges where climate change is expected to be more buffered by oceans (IPCC 2007). Additionally, the upper Midwest represents an ecotone in the boreal-temperate forest transition zone where many species are at the southern edge of their ranges (Curtis 1959). By late in the $21^{\text {st }}$ century, mean winter temperatures in the Great Lakes region are projected to increase by $3-7^{\circ} \mathrm{C}$, and mean summer temperatures are projected to increase by $3-11^{\circ} \mathrm{C}$ (Kling et al. 2003). In addition, longer growing seasons and greater variability in precipitation are also expected (IPCC 2007). Current greenhouse gas emission observations have been measured at or above the highest projected emissions scenario (A1FI) provided by the Intergovernmental Panel on Climate Change (IPCC 2007, Peters et al. 2012). These results give interest and urgency to understanding future forest dynamics in the Great Lakes region. The Global Circulation Model (GCM) developed by NOAA's Geophysical Fluid Dynamics Laboratory (GFDL) using the A1FI ('high') emissions scenario and future downscaled climate projections throughout the Great Lakes region indicate that temperature will increase in all seasons throughout the year (IPCC 2007, Stoner et al. 2012). In addition to future projected temperature increases, observed increases in temperature over the last century corroborate projections (Andresen et al. 2012).

Having diverse species with a broad range of environmental tolerance may build forest resistance (the ability to persist through disturbance with little change) and 
resilience (the ability to rebound following disturbance) to the effects of changing environmental conditions (Folke et al. 1996, Chapin et al. 1998). Some studies suggest that the relationship between diversity and productivity is more positively correlated in less productive sites compared to highly productive sites (Loreau et al. 2001, Whittaker et al. 2001, Paquette and Messier 2011). In productive temperate forests with deep, rich soils, competitive exclusion allows single species to dominate and increase overall productivity (Paquette and Messier 2011). In less productive boreal forests, positive diversity-productivity relationships have been found indicating less competitive exclusion (Lei et al. 2009, Paquette and Messier 2011). Nevertheless, even in highly productive forests, homogeneous forests may be vulnerable to the effects of a single host pathogen (e.g. bark beetle damage (Bentz et al. 2010)). If a loss of biodiversity is experienced, large impacts to productivity may result (Tilman et al. 2012).

The resilience of northern Great Lakes forests is, in part, generated by their natural disturbance regimes (Frelich 2002). The combination of harvesting, wind, and fire play a distinct role in facilitating the function of the extant major forest types. Within the northern Great Lakes forests, the most frequent and severe disturbances come from timber harvest by diverse land owners (Figure 2.1) (Karamanski 1989, Heinselman 1996). Through a long history of harvesting in the region, these forests are now characterized by denser stands than their historic counterparts and are more homogeneous (Hanberry et al. 2012). In recent decades, an overall decline in harvest intensity and rate has been observed (Woodall et al. 2011), along with an increase in partial harvest systems (D' Amato et al. 2009). 
Generally, wind and fire events in the Great Lakes region are low in frequency and small in size (Lorimer and White 2003, Schulte and Mladenoff 2005, White and Host 2008). Frelich's estimated annual percent area damaged by wind was less than $0.05 \%$ in Northeastern Minnesota, and in northern lower Michigan between $0.05 \%$ and $0.1 \%$. White and Host (2008) estimated that blowdown events historically occurred on between $0.02 \%$ and $0.29 \%$ of the landscape annually in northeastern Minnesota. White and Host (2008) estimate percent area burned annually in Northeastern Minnesota to be between $0.1 \%$ and $0.6 \%$ of the landscape. In northern lower Michigan, Cleland et al.(2004) estimate the percent area burned annually to be between $0.09 \%$ and $0.13 \%$. Associations of tree species ('forest types' or 'species assemblages'), within the Great Lakes region include a mix of boreal and temperate forest types with specific threats, adaptation to disturbances, and vulnerability to climate change (Handler et al. in press-a, Handler et al. in press-b). Given the value of ecosystem services specific to species assemblages (e.g., habitat for the federally listed Kirtland warbler (Dendroica kirtlandii) in jack pine (Pinus banksiana) barrens (Walkinshaw 1983)), or differences in carbon storage and productivity between different forest types (Gheorghe et al. 2010)), the persistence of unique forest types provides insurance for the production of future ecosystem services. Under changing conditions, a diverse suite of forest types may help to maintain or increase productivity (Hooper and Vitousek 1997).

My objectives were to assess how climate change projections under business as usual (BAU) forest management may affect northern forests. Specifically, I addressed the following questions: 1) With the risk of declining productivity, how might climate change affect the relationship between species diversity and forest productivity? 2) 
Given the value of biodiversity, how might regional differences in climate change, soil productivity, and forest management affect tree species diversity in the Great Lakes region? 3) Because many ecosystems services - including productivity - are dependent upon tree species and assemblages, I also asked how might specific tree species and forest types respond to climate change?

\section{METHODS:}

\section{Study Areas:}

Northeastern Minnesota and the northern lower peninsula of Michigan provide two examples of northern Great Lakes forested landscapes that represent a range of forest types and conditions. The Minnesota landscape is largely un-fragmented within the boreal-temperate ecotone (Curtis 1959). With the exception of the Boundary Waters Canoe Area (BWCA) and several protected state parks along Lake Superior, northeastern Minnesota is largely actively managed for timber (D' Amato et al. 2009). In contrast, northern lower Michigan is situated within the northern temperate forest. Northern lower Michigan forests include less actively managed forests but also fewer large tracts of protected contiguous forest land (Gustafson and Loehle 2006, The Conservation Biology Institute 2010). Both landscapes include a large proportion of private non-industrial land whose goals and management regimes vary (Potter-Witter 2005). I chose the landscape extents based on ecological boundaries comprised of 1.6 and 2.6 million hectares of forest land in Minnesota (White and Host 2000) and Michigan (Albert 1995), respectively (Figure 2.1). 


\section{Experimental Design:}

My experimental design includes BAU management in my two landscapes under three climate scenarios (current climate, low emissions future, and high emissions future; see below). I used as consistent an approach as possible to parameterize the model across both the Minnesota and Michigan landscapes. For all simulations, I used a two-hectare resolution and a 150-year simulation horizon starting at year 2000.

I modeled forest change using the LANDIS-II (v6.0) forest landscape model (Scheller et al. 2007a). LANDIS-II is a widely used forest simulation model that simulates successional processes, including disturbance, seed dispersal, growth, and mortality. These processes are spatially dynamic and interact across the landscape. The landscape is made up of interconnected cells within zones or 'ecoregions' of homogeneous climate and soil. Within each cell, regeneration, growth, and mortality occurs and trees are represented as species age-cohort combinations. The LANDIS-II framework is comprised of user-selected extensions that vary in process and complexity. I utilized the Biomass Succession extension (v3.1) (Scheller and Mladenoff 2004), Biomass Harvest (v2.1) (Gustafson et al. 2000), Base Fire (v3.0) (He and Mladenoff 1999), and Base Wind (v2.0) (Scheller and Mladenoff 2004). I ran these extensions at a 5-year time step.

Seed dispersal is an important process within LANDIS-II. A cell can act as a seed source if species-cohorts have grown to reproductive maturity. Seed dispersal probability declines exponentially from the edge of the source cell allowing 5\% probability assigned to long distance seed dispersal and $95 \%$ probability assigned to short distance dispersal 
(Scheller et al. 2007a). Short and long dispersal distances are species dependent (Burns and Honkala 1990).

I used the PnET-II as an input to the LANDIS-II model (Xu et al. 2009) to calculate species-specific parameters including maximum aboveground net primary productivity per year $\left(\mathrm{ANPP}_{\max }\right)$, and probability of establishment $\left(\mathrm{P}_{\mathrm{est}}\right)$ at every time step. These parameters are the primary mechanisms whereby climate change was incorporated into the simulations. I calculated $\mathrm{P}_{\mathrm{est}}$ using monthly maximum and minimum temperature, precipitation, and photosynthetic active radiation (PAR) within unique soil regions in each landscape. I calculated the Maximum Aboveground Biomass $\left(\mathrm{AGB}_{\max }\right)$ based on the species-specific relationships observed between $\mathrm{AGB}_{\max }$ and $\mathrm{ANPP}_{\max }$ (Thompson et al. 2011). Other inputs to calculate the PnET-II parameters included percent foliar nitrogen content, maximum foliar mass area, and soil water holding capacity (See Appendix: Table A1).

$\mathrm{ANPP}_{\max }, \mathrm{AGB}_{\max }$, and $\mathrm{P}_{\mathrm{est}}$ are input parameters to the Biomass Succession extension which grows, matures, and causes age-related mortality of species cohorts (Scheller and Mladenoff 2004). ANPP ${ }_{\max }$ determines the growth potential of above ground biomass moderated by age and competition (Scheller and Mladenoff 2004). $\mathrm{P}_{\text {est }}$ determines the establishment of a new cohort, given a seed source (or seedling source in the case of planting) and adequate light, based on a climate envelope approach (Xu et al. 2009). At the beginning of each simulation, Biomass Succession "spins-up" initial biomass based on the simulated past growth of each species-age cohort, dependent on their age at the beginning of the simulation. Growth is limited by a species specific growth curve parameter which determines how fast actual ANPP achieves ANPP $\max$. 
Maximum biomass of a species-cohort is further limited by competition within a cell as represented by potential growing space, minus space occupied by other species-cohorts. Age-related mortality is represented by an increasing decline in AGB close to the age of maximum lifespan by species. Following age-related mortality, a cohort's biomass is added to a detritus pool where a species-specific decay rate decomposes the biomass and where each species detritus becomes available to be altered by disturbance.

\section{Ecoregion Delineation:}

Within the landscape extents, I identified relatively homogeneous soil regions within climate regions to create unique ecoregions. In Minnesota, I used seven previously defined climate region boundaries (White and Host 2000, Ravenscroft et al. 2010). In Michigan, I used a cluster analysis to delineate nine relatively homogeneous climate regions from the PRISM observed climate database (Daly and Gibson 2002). The inputs for the cluster analysis included 30-year average monthly minimum temperatures for April, May, June, September, October, November, and average annual precipitation. I choose the fall and spring months to delineate temperature as they show large climate variability around thresholds for photosynthesis (i.e. photoperiod, freeze, and thaw temperatures). To delineate soil regions, I calculated soil water holding capacity (SWHC) values ( $\mathrm{cm}$ of water within one meter of soil depth) in northern lower Michigan (SSURGO Soil Survey Staff 2011) and northeastern Minnesota (STATSGO 1994). The SSURGO database provided a preferable finer resolution however was unavailable within most of the northeastern Minnesota landscape. Within each landscape, I binned SWHC into 10 soil regions in ArcGIS (ESRI 2011). Finally, within 
each landscape, I nested my soil regions within climate regions to create unique “ecoregions" (Figure 2.2).

\section{Initial Communities:}

Inputs to LANDIS-II include an initial conditions map with species-age cohorts assigned to every forested cell. For the Minnesota landscape, I utilized previously developed initial community data (Ravenscroft et al. 2010). For the Michigan initial community data, I imputed FIA plot data spatially to a combination of two forest cover maps: I leveraged the Forest Biomass Information System (FBIS) (Falkowski IN PREP) imputation map of stand age and Forest Inventory and Analysis (FIA) forest type (Falkowski et al. 2010). Likewise, I utilized an additional Michigan Department of Natural Resources forest classified map from the Integrated Forest Monitoring, Assessment, and Prescription Stage 1 map (IFMAP) (MDNRS 2001). Both maps were provided at 30-meter resolution. To resample to two-hectare resolution and preserve the proportion of forested land within the landscape, I used a combination of the "majority" rule for contiguous regions (forested cells) and "nearest neighbor" rule for fragmented regions (non-forested cells) to resample the landscape within ArcGIS (ESRI 2011).

As the IFMAP forest types were less aggregated than the FIA/FBIS forest types, I identified the one-to-many (IFMAP forest type to FBIS forest types) relationship with a look-up table. Assuming that the FIA forested plots from the northern lower peninsula of Michigan represent the distribution of forest types present, I adjusted the look-up table to best match percent of cells assigned to a given forest type with percent of the FIA plots with that forest type. Based on the final look-up table, I assigned an IFMAP forest type to every FIA forest type. Although the FBIS map provided more precise forest type 
detail, the accuracy of the data was less robust than the IFMAP forest type. For every cell with a matching FBIS and IFMAP forest type, I randomly imputed a FIA plot with the matching FBIS Forest type and FBIS stand age. For cells whose forest type values did not match between FBIS and IFMAP, I randomly imputed a FIA plot with the

matching combination of: IFMAP forest type, FBIS stand age, and county from where the plot came.

To populate the initial communities map, I selected all the forested FIA plots from within the northern Lower Peninsula of Michigan and converted individual trees to species age cohorts. I used site index curves to estimate the age of each tree in my FIA plots (equation 4.7.2.2 in Dixon and Keyser (2008) based on Carmean et al. (1989)). When multiple site index curves were provided for a species, I choose the curve coefficients with the closest geographic match to the northern Great Lake region. This method resulted in a better fit of FIA estimated biomass to LANDIS-Year 0 biomass compared to multiple regression equations using height, diameter, and crown class to predict tree age based on the assumption that stand age is equal to the average age of trees in the plot. Finally, I aggregated the calculated tree ages to five-year age cohorts.

\section{Climate Data:}

I simulated three climate futures. I utilized greenhouse gas emission scenarios as representative of plausible futures. Emission scenarios are based on specific future changes in population, technology, and environmental priorities. I simulated current climate based on randomly selecting simulation years from 30 years of past observed climate (1969-1999) (Daly and Gibson 2002). I simulated a low emissions climate future based on the Parallel Climate Model (PCM) GCM (Washington et al. 2000) and 
the B1 emission scenario (IPCC 2007). The B1 emission scenario represents the lowest future increase in fossil fuel use. I simulated a high emission climate future based on the GFDL GCM (Delworth et al. 2006) and the A1FI emission scenario (IPCC 2007). The A1FI emission scenario represents the most fossil fuel intensive future described by IPCC and represents the closest emission scenario to current observed global emissions (Raupach et al. 2007). I chose these emission projections to bracket a range of uncertain climate futures. PCM climate projections are considered to have low sensitivity to emissions while GFDL projections are considered to be more moderately sensitive to emissions. I choose the combination of the B1 emission scenario coupled with the PCM global climate model and the A1FI emission scenario coupled with the GFDL global climate model to bracket a large range of plausible futures. These emission and GCM combination scenarios are also being used in other coordinated research efforts covering the region and will ensure consistency among model projections (Peters et al. 2013). Climate change projections for the GCMs and emission scenarios I utilized are summarized in Handler et al. (in press-a) and Handler et al. (in press-b) for Minnesota and Michigan, respectively. For each unique climate region, I accessed downscaled temperature and precipitation data through the USGS data portal http://cida.usgs.gov/climate/gdp/ (Stoner et al. 2012). To estimate projected PAR, I accessed point source projected radiation data from meteorological stations throughout the landscape. After observing the low variability in PAR across observation sites, I used mean monthly PAR within each climate region.

The IPCC climate projections include climate futures to year 2100 (IPCC 2007). To simulate forest change to 2150, I interpolated climate variables (maximum and 
minimum temperature, precipitation, and PAR) for the remaining 50 years based on trends and variability in each climate variable within the original 100 years of data using the Amelia library in R (R Development Core Team 2011). Climate projections under both emission scenarios indicate increased temperature in all seasons over the next 100 years (Figure 2.3). As expected, the lower latitude (more southern) Michigan landscape and the higher emission climate scenario (more greenhouse gases) indicate higher temperatures than the Minnesota landscape and the low emission scenario, respectively. Precipitation is more variable; nevertheless a decrease in precipitation is projected under the high emission climate scenario in summer months after 2050 (Stoner et al. 2012) (Figure 2.4).

In order to aggregate climate regions for analysis, I calculated average July temperatures for each climate region in each landscape from 30 years of historic observations (1969-1999) (Daly and Gibson 2002). I then grouped each of the 9 climate regions in the Michigan landscape and the 7 climate regions in the Minnesota landscape into 5 aggregated and ordered climate regions in each landscape based on the mean July temperature. For analysis of climate change, the aggregation and ordering assumes that the regions would stay ordered relative to each other (e.g. the warmest regions within a landscape will be the future warmest regions within a landscape). The warmest aggregated climate region in the Minnesota landscape was cooler than the coolest aggregated climate region in the Michigan landscape (Figure 2.5).

\section{Disturbance Regimes:}

To estimate the wind and fire patch size and disturbance rotation period, I used historical assessments of disturbance in Minnesota (White and Host 2008) and Michigan 
(Whitney 1986, Zhang et al. 1999, Cleland et al. 2004). I assumed constant fire and wind disturbance regimes for each climate scenarios. Compared to timber harvesting in the region, wind and fire disturbances represent minor disturbance regimes. I adjusted the mortality parameters of American beech (Fagus grandifolia) and ash (Fraxinus spp.) due to the current and expected pathogens beech bark disease and emerald ash borer, respectively. As these vectors primarily affect the older age cohorts for ash (Kashian and Witter 2011) and beech (Busby and Canham 2011), I adjusted the mortality shape parameter to allow the species to live to their maximum longevity but reduced their maximum biomass at an earlier age. I calibrated these values with the LANDIS-II-Site v2.3 tool (Brian Miranda, personal communication) which is designed to simulate succession on a single site using parameters from Biomass Succession extension to

\section{LANDIS-II.}

I simulated harvesting and management with the Biomass Harvest extension (Gustafson et al. 2000, Syphard et al. 2011). The Biomass Harvest extension selects and removes biomass based on specific timber harvest prescriptions. Stands are selected for harvest based on a user defined ranking (e.g. when cohorts reach economically merchantable age). Within a selected stand, user defined prescription criteria are applied, including patch size, percent biomass removed, whether harvests are repeated, species specific removal, planting, etc. Rotation periods define the amount of the landscape harvested within each prescription and management area for each time step (Gustafson et al. 2000).

To simulate BAU management, I simulated current harvesting regimes practiced in northeastern Minnesota and northern lower Michigan. I delineated stands within 
management areas based on ownership groups (Figure 2.1). In the Minnesota landscape, I utilized landowner group specific BAU harvesting regimes previously described (Ravenscroft et al. 2010). I adjusted these prescriptions based on expert opinion (Anthony W. D'Amato, personal communication) (See Appendix: Table A2). In the Michigan landscape, I included specific prescriptions used by Michigan DNR and the Huron-Manistee National Forest and made adjustments for Private Non-Industrial Forest Land (Potter-Witter 2005) and Private Industrial Land (Christopher Webster, personal communication) (See Appendix: Table A3). My BAU harvesting regimes represent my best guess at currently practiced management. They do not portray precisely what is nor will be practiced in the future.

I defined management areas (i.e. ownership groups) using both the Conservation Biology Institute (CBI) Protected Areas Map (The Conservation Biology Institute 2010), and the FIA program forest ownership map (Nelson et al. 2010). I used a combination of the two maps as the CBI map did not delineate private industrial land from private nonindustrial land but otherwise had better land owner precision. My management area delineation assumes that ownerships will stay static within aggregated groups. Within management areas, I implemented the individual prescription rotation periods based on the proportion of each prescription cover type present at year zero. I delineated individual stands within management areas based on the IFMAP forest types in Michigan and used previously delineated stands from northeastern Minnesota (Ravenscroft et al. 2010).

Along with individual species and species richness, I considered species assemblages as representative of forest types (Eyre and Society of American Foresters 
1980, Bøhn and Amundsen 2004) (See Appendix: Table A4). An analysis of forest type provides summary information about species groups. To quantify spatially explicit species Aboveground Biomass (AGB) $\left(\mathrm{g} \mathrm{m}^{-2}\right.$ ) and to classify forest type, I utilized the biomass output extension (v2.0) and the Biomass Reclassification extension (v2.0) respectively. Although novel forest types are likely to emerge in the face of climate change (Williams et al. 2007), I focused on the current suite of forest types in my assessment of the effects of climate change. I identified forest types using indicator species common on the landscape but relatively unique to each forest type. I adjusted forest reclassification species assignment based on matching the proportion of individual forest types found in regional FIA plots to the proportion of individual forest types found in LANDIS-II cells at year zero (See Appendix: Table A5). To process outputs and visualize results, I used the raster library in R (R Development Core Team 2011).

\section{Data Analysis:}

I initially used five replicates to explore the stochastic variation within scenarios caused by the stochastic nature of disturbance events. Maximum variance of AGB at year 2150 was $<2 \%$ of the mean for each landscape. Given the low among-scenario variance caused by the low stochastic variation in disturbance events compared to the size of the landscapes, I randomly selected one replicate from each climate scenario and landscape for further analysis. For each tree species, I calculated AGB as the mean biomass density $\left(\mathrm{g} \mathrm{m}^{-2}\right)$ across the landscape for each scenario and time step. I calculated $\mathrm{AGB}_{\text {total }}$ on each landscape as the total above ground biomass (Tg) on each landscape for each scenario and time step. I considered $\mathrm{AGB}_{\text {total }}$ in order to assess each landscapes biomass contribution to the region. 
To assess species diversity, I calculated Shannon index of diversity (H') using AGB abundance of tree species. In order to reduce the magnitude of inaccuracies comparing diversity across scenarios, I transformed Shannon indices to the effective numbers of species $\left(\mathrm{e}^{\mathrm{H}^{\prime}}\right)(\mathrm{Jost} 2006) \cdot \mathrm{e}^{\mathrm{H}^{\prime}}$ represents the number of species present if all species were equal in abundance. I calculated diversity within individual cells across each landscape for each climate change scenario at 10-year time steps starting after year 2050. As a measure of productivity within each ecoregion, I used aboveground Annual Net Primary Productivity (ANPP) as calculated within the Biomass Succession extension. As my simulations did not account for migration of new species from outside the landscapes, I assessed diversity within a $10 \mathrm{~km}$ buffer from the southern edge of each landscape. Scheller and Mladenoff (2008) found movement of common southern Great Lake species less than $10 \mathrm{~km}$ within 200 years. This rate is comparable to other studies of species migration under climate change (McLachlan et al. 2005). The Minnesota landscape is largely surrounded by boreal lowland forest and Lake Superior. The Michigan landscape is largely surrounded by Lake Michigan, and Lake Huron (Figure 2.1). Additional limits to species migration into my landscapes include fragmentation of forests due to agriculture, and competitive lags to establishment.

For each simulation, I assessed the relationship between diversity and productivity at ecoregion levels using linear regression models. To assess landscape variability of diversity, I calculated average cell diversity within ranked climate and soil regions. Using management area maps (Figure 2.1), I also calculated mean diversity within ownership groups. All raster data analysis was completed using Base R and Raster Library software (R Development Core Team 2011). 
Full model validation is not possible against future empirical data. Nonetheless, to evaluate my ability to simulate AGB for initial conditions, I analyzed AGB estimates as measured in the 2140 FIA field plots compared to the imputed LANDIS-II year zero biomass using the Pearson's correlation coefficient and the root mean squared error (RMSE). While this method does not truly validate future successional trajectories, a strong relationship between empirical estimates and modeled biomass after the spin-up phase suggests that the spin-up is comparable to current successional trajectories of biomass (Thompson et al. 2011). In addition, most of the species-specific parameters, PnET-II, LANDIS-II, and the Biomass Succession extension have been evaluated in similar landscapes in the Great Lakes Region (Scheller and Mladenoff 2004, Radeloff et al. 2006, Xu et al. 2007, Ravenscroft et al. 2010).

\section{RESULTS:}

For each FIA plot imputed onto the northern lower Michigan landscape, my evaluation of AGB resulted in a Pearson's correlation between initial (year 2000) LANDIS-II AGB and observed FIA estimated AGB of 0.64. The RMSE, representing the spread of the fit, was $44.3 \mathrm{Mg} \mathrm{ha}^{-1}$. I accepted this model evaluation as an adequate representation of empirically measured conditions.

\section{Productivity and Diversity:}

Across both Minnesota and Michigan landscapes, I found weak to no diversityproductivity relationships under current and low emission climate scenarios (Figure 2.6). Under these scenarios, effects of Soil Water Holding Capacity (SWHC) stratify ecoregions along a productivity gradient. Low SWHC was associated with lower 
productivity. Average simulated productivity across ecoregions at year 2150 was similar for current climate (206 and $236\left(\mathrm{~g} \mathrm{~m}^{-2} \mathrm{yr}^{-1}\right)$, and the low emissions scenario 216 and 227 $\left(\mathrm{g} \mathrm{m}^{-2} \mathrm{yr}^{-1}\right)$ for the Minnesota and Michigan landscapes, respectively. Under the high emissions climate scenario, however, I found positive relationships between diversity and productivity in both landscapes. Linear regression slopes were 20.2 and 21.9; adjusted $\mathrm{r}^{2}$ were 0.142 and 0.416 for the Minnesota and Michigan landscapes, respectively. Within this climate scenario, average simulated productivity at year 2150 was 87 and $82\left(\mathrm{~g} \mathrm{~m}^{-2}\right.$ $\mathrm{yr}^{-1}$ ) representing 58\% and 65\% lower ANPP compared to current climate in the Minnesota and Michigan landscapes, respectively.

\section{Landscape Variation in Diversity:}

Simulations in the Michigan landscape resulted in higher tree species diversity compared to the Minnesota landscape (Figure 2.7). Under all climate scenarios, high SWHC did not result in the highest simulated diversity within each landscape, however the lowest SWHC regions resulted in the lowest diversity under the climate change scenarios. Within the Minnesota landscape, the warmest climate region resulted in the highest diversity under the current climate scenario. Under the high emissions climate scenario, the coolest climate region had the highest diversity. In the Michigan landscape, the warmest climate region resulted in the lowest diversity under both climate change scenarios. In the Minnesota landscape, the forest reserve management areas had the highest diversity for all three climate scenarios and all time steps. In the Michigan landscape, Private Industrial Forests (PIF) had seemingly high diversity under the current and low emission climate scenario. These lands represent a very small proportion of the landscape and with a small number of cells could easily have resulted in low diversity 
given the management history and relative size of the landscape (Figure 2.1). In the Minnesota landscape, diversity across climate scenarios resulted in the highest diversity in the low emissions climate scenario. In the Michigan landscape, diversity across climate scenarios resulted in higher diversity in the current climate, and progressively lower diversity in the low and high emissions climate scenario.

\section{Aboveground Biomass:}

The initial simulated $\mathrm{AGB}_{\text {total }}$ in the Michigan landscape was substantially larger than the Minnesota landscape (Figure 2.7) due in large part to the larger Michigan landscape (Figure 2.1). Simulated forest growth resulted in an initial increase for all climate scenarios in both landscapes. For both landscapes, the $\mathrm{AGB}_{\text {total }}$ in the low emissions climate scenario resulted in a trajectory almost identical to that of current climate. $\mathrm{AGB}_{\text {total }}$ in the high emissions climate scenario resulted in a departure after approximately two decades and decreased to approximately initial levels by year 2150 .

I found substantial differences in AGB for individual species among landscapes and their response to climate change. Most species had higher AGB in the Michigan compared to the Minnesota landscape (Figure 2.9) except for black spruce (Picea mariana), quaking aspen, balsam fir, and paper birch. Under current climate, the simulated species response suggests that both landscapes would favor more late successional species such as balsam fir and white spruce (Picea glauca) in the future. The response to climate change suggests that boreal species at the southern edge of their range will decline in both Minnesota and Michigan landscapes. Compared to current climate, both climate change scenarios generally resulted in less black spruce, white spruce and paper birch (Betula papyrifera) AGB in both landscapes. In contrast, many 
northern hardwoods, including red maple, sugar maple (Acer saccharum) and American basswood (Tilia americana), increased rapidly in response to climate change for the first 80 years of my simulations.

\section{Forest Type Shifts:}

In the Minnesota landscape, the current climate scenario under BAU management resulted in an increase in the late successional spruce-fir forest type between 2000 and 2150 (Figure 2.10). The aspen-birch and red/jack pine forest types slightly declined. The northern hardwoods, white pine, and oak forest types all persisted through the simulation as small components of the landscape. The climate change scenarios resulted in a departure from current conditions as northern hardwoods and white pine forest types became more dominant on the landscape and the spruce-fir type declined. The climate change scenarios resulted in a larger magnitude of change under the high emission compared to the low emission scenario. Under both climate change scenarios, the Boundary Waters Canoe Area Wilderness provided a refuge for the spruce-fir forest type (Figure 2.10; northern component of the Minnesota landscape).

In the Michigan landscape, the current climate scenario under BAU management resulted in substantial increases in the white pine forest type and minor shifts for other forest types (Figure 2.11). Both climate change scenarios resulted in an increase in northern hardwoods and oak association forest types and a decrease in spruce-fir. By simulation year 2150 , the low emission scenario resulted in a greater increase in white pine and a smaller increase in oak forest types compared to the high emissions scenario.

My results suggest that climate change may alter the relationship between diversity and productivity under conditions of declining productivity. Furthermore, 
diversity may be affected by regional climate differences, soils, and forest management. In addition, my results suggest less total biomass under a high emissions climate scenario compared to current climate.

\section{DISCUSSION:}

With the threat of climate change, there is strong support to preserve and manage for biodiversity in the ecological literature (e.g. (Chapin et al. 1998, Hampe and Petit 2005, Wilson 2010) as well as the forest management literature (e.g. (D' Amato et al. 2011, Puettmann 2011). A future decline in biodiversity has the potential to decrease productivity (Tilman et al. 2012). The positive diversity-productivity relationship under the high emission climate scenario, and the lack of relationship under current and low emissions climate scenarios (Figure 2.6) supports the diversity-productivity hypothesis that diversity will follow a transposed bell shaped curve with productivity (Loreau et al. 2001, Whittaker et al. 2001). Under this hypothesis, a positive diversity-productivity relationship exists under relatively low productivity, and a negative diversity-productivity relationship exists under relatively high productivity. As simulated productivity decreased with climate change, competitive exclusion (the ability of one species to dominate over another) decreased as complementarity (the ability of a diverse community to use resources more completely) increased. Regardless of the cause and effect relationship, the association between diversity and productivity may become stronger under less favorable conditions due to climate change. Whittaker et al. (2001) describe at what spatial and temporal scale productivity and diversity may be more regulated by topdown explanatory variables compared to bottom-up local influences. My results imply a 
bottom-up regulated system under current and low emissions climate where productivity and diversity is largely regulated by local variables (e.g., SWHC). Under a high emissions climate future, however my results indicate more of a top-down regulated system. Climate change may impinge on productivity-diversity relationships at a finer spatial resolution than under current climate.

\section{Contrasting Landscapes:}

My results indicate that the Michigan landscape has higher diversity of tree species (Figure 2.7) and forest types (Figure 2.11) compared to the Minnesota landscape. These results reflect biotic, abiotic, and management differences. The pattern of diversity within forest reserves highlights the difference in overall management in the Minnesota and Michigan landscapes (Figure 2.7). The reserves in the Minnesota landscape result in a larger contrast to the actively managed forests compared to the Michigan landscape. Within the actively managed forests, the Minnesota landscape includes more frequent low diversity aspen silviculture systems (D' Amato et al. 2009) compared to the Michigan landscape (See Appendix: Table A2 and A3). In the Minnesota landscape, $50 \%$ of the landscape was initially classified as aspen-birch (Figure 2.10) and reflects the large component of aspen silviculture in the managed landscape. In the Michigan landscape, forest types were more equally represented. Aspen-birch accounted for only $22 \%$ of the landscape (Figure 2.11).

These results suggest that the Michigan landscape with higher diversity of forest types and species, and less management intensity may be better poised to adapt to climate change compared to the Minnesota landscape. ANPP declines more in the Michigan landscape under high emissions climate than the Minnesota landscape, however. 
Although more diverse than Minnesota, the suite of species simulated under BAU management in Michigan and the high emissions climate is not capable of maintaining the equivalent high productivity simulated under current climate. My simulations, however, did not allow the migration of novel species from outside the landscape. Future forest resilience may depend on the ability of novel species to migrate at the pace of changing climate (Buma and Wessman 2013).

In addition to higher diversity in less intensively managed forests, my results indicate a general pattern of higher diversity within cooler climate regions and more productive soils (Figure 2.7). Regional variation in climate may have profound effects on species composition in the Great Lakes region (Davis et al. 2000) and beyond (Davidson and Janssens 2006, Svenning and Sandel 2013). For example, Davis et al. (2000) found, in 10,000 years of pollen records, that species composition changed less in sites within close proximity to Great Lakes where temperature and precipitation were moderated. In the Minnesota landscape, diversity declined along a gradient of progressively warmer climate regions under the high emissions climate scenario. However, the Michigan landscape resulted in a less variation in diversity due to climate region. This may be due to the inherent higher diversity within all climate regions in the Michigan landscape. Notwithstanding climate, available soil water and soil type in general, may affect future species diversity (Knapp et al. 2002, Anderson and Ferree 2010). In the Michigan landscape, there was a positive relationship between SWHC and diversity in all climate scenarios. In the Minnesota landscape, the effect of SWHC on diversity was less distinct. Although I did not explore this hypothesis, regions of high SWHC may be currently managed for intensive even-aged aspen silviculture which would result in lower diversity. 


\section{Aboveground Biomass:}

There is increasing interest in forests contribution to carbon sequestration and storage (Lal 2005, Fahey et al. 2010, Böttcher et al. 2012, Clemmensen et al. 2013). Under all climate futures, my results indicate an initial large increase in $\mathrm{AGB}_{\text {total. }}$. The capacity for increased AGB in both landscapes is likely due to forest recovery following a history of intense timber harvesting (Pyne 1982, Flader 1983, Böttcher et al. 2012). As forests mature, the sustained increase in $\mathrm{AGB}_{\text {total }}$ expected under current climate can be further explained by the projected increase in canopy structural complexity (Hardiman et al. 2011). In addition, the simplification of the initial communities within the modeling framework results in a simulated increase in cohort heterogeneity. Under the high emissions climate scenario my simulations indicate a decline in AGB (Figure 2.8). Empirically, Fisichelli et al. (2012) studied saplings across a boreal-temperate transition gradient in Minnesota and found that with increasing temperature, height and radial growth rates of boreal species declined and those of temperate species increased. Successful insurance species are capable of responding positively to changing conditions (Naeem and Li 1997, Walker et al. 1999). My results suggest that the species expected to be insurance species (i.e. northern hardwoods) especially in the warmer southern landscape, may not be tolerant of a future warmer climate projected under the high emissions scenario. Poorly suited species under a high emissions climate future has been documented in other regions (Buma and Wessman 2013). My simulations result in declining AGB of black spruce, white spruce, balsam fir, jack pine, and paper birch under climate change. Common trends of increasing species abundance under climate change include white pine (Pinus strobus), black cherry (Prunus serotina), American basswood 
(Tilia americana), and American elm (Ulmus americana). All four of these species from the northern lower Michigan landscape, however, indicate a decline before the end of the simulation (Figure 2.9). The species that share a simulated increase or decrease across landscapes are consistent with empirical observations (Fisichelli et al. 2012, Fisichelli et al. 2013) and other modeling throughout the Great Lakes region (Iverson et al. 2008, Xu et al. 2009, Ravenscroft et al. 2010).

A climate change increase in $\mathrm{AGB}_{\text {total }}$ composed of responding hardwood and oak species was found by other modeling research in the region (Scheller and Mladenoff 2005). In contrast, both of my landscapes had declining $\mathrm{AGB}_{\text {total }}$ under the high emissions scenario after year 2050 compared to the current climate scenario (Figure 2.8). Compared to current climate, the high emissions climate scenario resulted in an initial increase in the hardwood and oak species (e.g. red maple, American basswood, black cherry, northern red oak (Quercus rubra)). This increase, however, did not make up the difference in lost AGB by boreal species. The high emissions climate future that I used (i.e., GFDL A1FI) includes higher $\mathrm{CO}_{2}$ and temperature projections than the $\mathrm{A} 2$ climate futures used by Ravenscroft et al. (2010) or the IS92A climate future used by Scheller and Mladenoff (2005) (IPCC 2007). In addition, my work simulated an increasing trend of climate warming beyond year 2100 while previous work held climate constant after year 2100.

\section{Forest Type:}

Ecotones around the globe are valuable and vulnerable to the effects of climate change (Smith et al. 1997, Goldblum and Rigg 2010). The Minnesota landscape is centered closer to the boreal-temperate ecotone while the Michigan landscape is located 
further into the temperate forest matrix (Albert 1995). My results suggest that the Minnesota landscape will experience rapid forest type conversion under the high emissions climate scenario (Figure 2.10) as expected within an ecotone (Allen and Breshears 1998). These results corroborate previous forest simulation research indicating forest type conversions expected under climate change in the region (Iverson and Prasad 2001). The Michigan landscape also indicates rapid forest type conversion, however the large forest type shifts occur under all three climate scenarios (Figure 2.11), not only within the low and high emissions climate futures. This suggests that forests in the Michigan landscape (more than the Minnesota landscape) have strong successional trajectory changes expected, notwithstanding climate changes. My simulated transition of early to more mid-successional species in both landscapes under current climate is corroborated by observed shifts in northern lower Michigan (Gough et al. 2010) and Minnesota (Hanberry et al. 2012).

The future of early successional forests will depend on highly variable disturbance regimes, which are difficult to predict. The homogenizations of aspen forests are closely linked to harvesting; my results reflect future harvest regimes based on my best approximation of BAU management. Harvesting regimes are largely a product of market demand for different wood products. The recent recession has resulted in a decline in aspen harvests for pulpwood (Woodall et al. 2011). If this trend continues, I expect to see a shift to more shade tolerant species. A change in future markets however could change harvesting regimes and resulting forests, considerably. Further uncertainties may also include changing regulations, technology, and landowner priorities. 
Forest type changes in the Minnesota landscape indicate more of a climate effect compared to the Michigan landscape. Hooper and Vitousek (1997) experimentally found that both species composition and the number of functional groups positively affected grassland productivity. The higher diversity of species biomass (Figure 2.7) and of forest types in the Michigan compared to Minnesota landscapes may contribute to the greater adaptive capacity of future forest types.

\section{Climate and Management Uncertainty:}

My projections assumed that climate warming will continue beyond year 2100 based on trends and variability projected by GCM's (IPCC 2007) and downscaled climate (Stoner et al. 2012). In addition to the large uncertainty in both the GCM and emission scenarios, my results should be interpreted with a gradient of increasing uncertainty beyond the range of GCM projections. Although observed carbon emissions suggests that our current carbon emission trajectory is at or above that of the high emissions scenario (Raupach et al. 2007, Jennings 2012, Peters et al. 2012), the low emissions scenario coupled in my simulations to a less sensitive GCM indicates substantial differences in ANPP, AGB, and diversity from the high emissions scenario. Nevertheless, even with current climate futures, successional trajectories indicate the potential for future novel ecosystems rather than a stable state.

Although my analysis of diversity excluded a $10 \mathrm{~km}$ buffer at the southern edge of each landscape to account for potential species migrating north, species migration rates vary and could exceed my $10 \mathrm{~km}$ spatial restriction (Scheller and Mladenoff 2008). Nevertheless, forest distribution shifts are expected to be slow and will be limited by 
fragmentation, competition, and the island-like design of my landscapes (McLachlan et al. 2005, Vanderwel and Purves 2013).

My results should not be interpreted as predictions. Rather, scenario projections illuminate interactions between processes and regional trends. And like all simulation models, my results represent a simplification of reality with associated inherent uncertainty in model and parameters used (Xu et al. 2009). LANDIS II does not simulate individual stems nor does it track shrub and herbaceous vegetation. Within climate and soil regions, LANDIS-II assumes homogeneous conditions. Finer resolution microclimate and soil conditions are not incorporated although recognized as being important to fine scale plant-climate interactions (Liancourt et al. 2012). In addition the PnET-II ecosystem calculates potential ANPP based on a simplification of water availability not incorporating the effects of long term drought. There are processes that I did not include in the modeling framework but that likely will be important. These include, but are not limited to the effects of migrating invasive earth worms which may change the soil substrate required for regeneration (Holdsworth et al. 2007, Hale et al. 2008, Larson et al. 2010) and the effects of browse damage by large ungulates (Anderson et al. 2002, Danell et al. 2003, Frelich and Reich 2010, Fisichelli et al. 2012). If deer browsing continues to affect forest communities at present rates, the affects will be severe and extensive.

The effects of $\mathrm{CO}_{2}$ fertilization, without considering additional limits to growth, will increase the photosynthetic rate of future forests (Mickler et al. 2002, Norby et al. 2005). Growth enhancement by $\mathrm{CO}_{2}$ fertilization will be limited by Nitrogen (Körner 2006, Hyvönen et al. 2007, Reich and Hobbie 2012), which I did not include as a 
dynamic process. Additional research suggests that compared to the forest response to prior land use history, $\mathrm{CO}_{2}$ fertilization has little affect (Caspersen et al. 2000).

Furthermore, I did not include the influence of ozone which will likely diminish the effects of $\mathrm{CO}_{2}$ fertilization (Wittig et al. 2008, Ainsworth et al. 2012) and may decrease overall growth especially in northern lower Michigan where ozone pollution is more prevalent (Koo et al. 2012). Globally, no increase in NPP has been observed by satellite measurements for the last 30 years of increased atmospheric carbon dioxide (Running 2012).

In addition to emission and climate uncertainty, there exists tremendous uncertainty about how future forests will be managed. My simulations assume BAU timber harvest which includes the continuation of intensive resource extraction. Current timber management relies heavily on the continued production of fiber for the pulp industry (Hanberry et al. 2012). Additional modeling research should address the growing trend (D' Amato et al. 2009) and interest (Millar et al. 2007) to manage forests for complexity (Puettmann 2011) and adaptability (Kuparinen et al. 2010). In addition, there is support to preserve the trailing edge of a migrating ecotone which may contain high genetic diversity (Hampe and Petit 2005, Willis et al. 2010). Future research will address management's ability to affect the resistance and resilience of future forests to the effects of climate change. 
Figure 2.1: Inserted map of study landscapes within continental United States.

Ownership groups within study landscapes in northeastern Minnesota and northern lower Michigan.

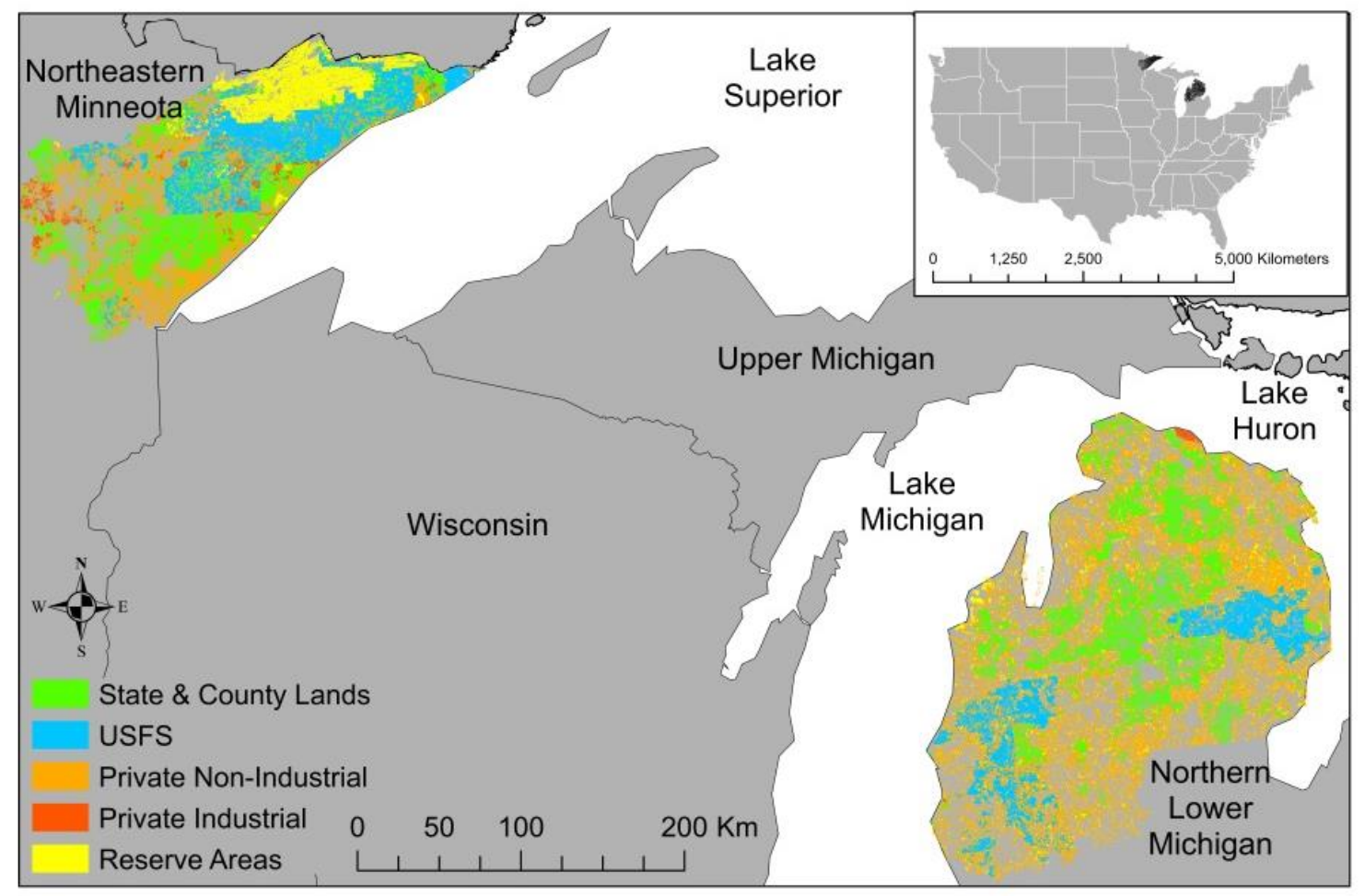


Figure 2.2: Nested climate and soil regions used to create ecoregions in northeastern Minnesota (left) and northern lower Michigan (right). Climate regions are designated by numbered polygons in each landscape. Nested soil regions represent binned SWHC (cm / $\mathrm{m}$ depth) values and are designated by colored pixels within climate regions. Note that finer resolution of SWHC data were available in northern lower Michigan and not northeastern Minnesota.

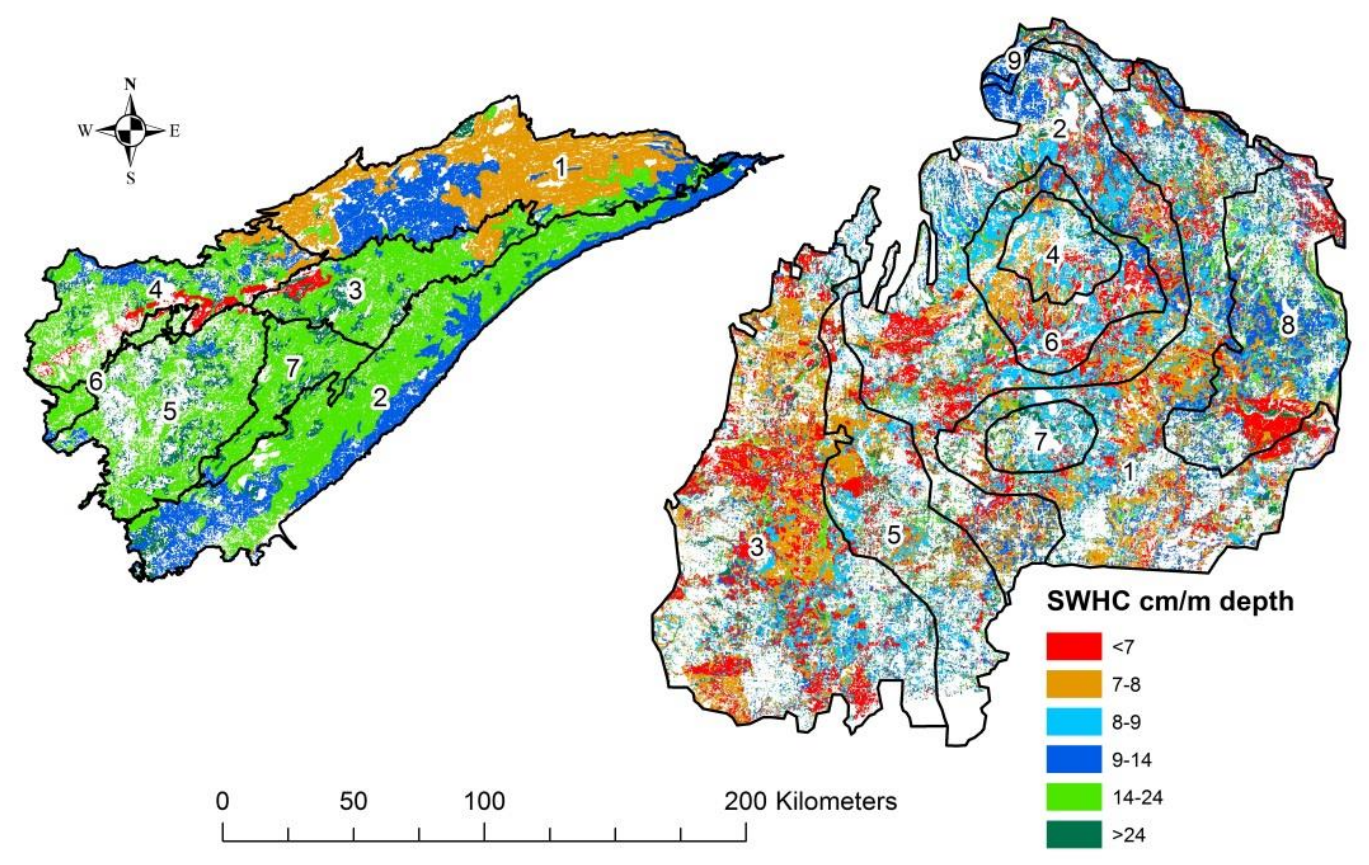


Figure 2.3: High (A1FI) and low (B1) emission projections of temperature $\left({ }^{\circ} \mathrm{C}\right)$ in northeastern Minnesota and northern lower Michigan. Downscaled projections were from climate region 1 in each landscape from Figure 2.2 (Stoner et al. 2012). Monthly temperature projections were aggregated by season (spring = March, April, May; summer = June, July, August; fall = September, October, November; winter = December, January, February).
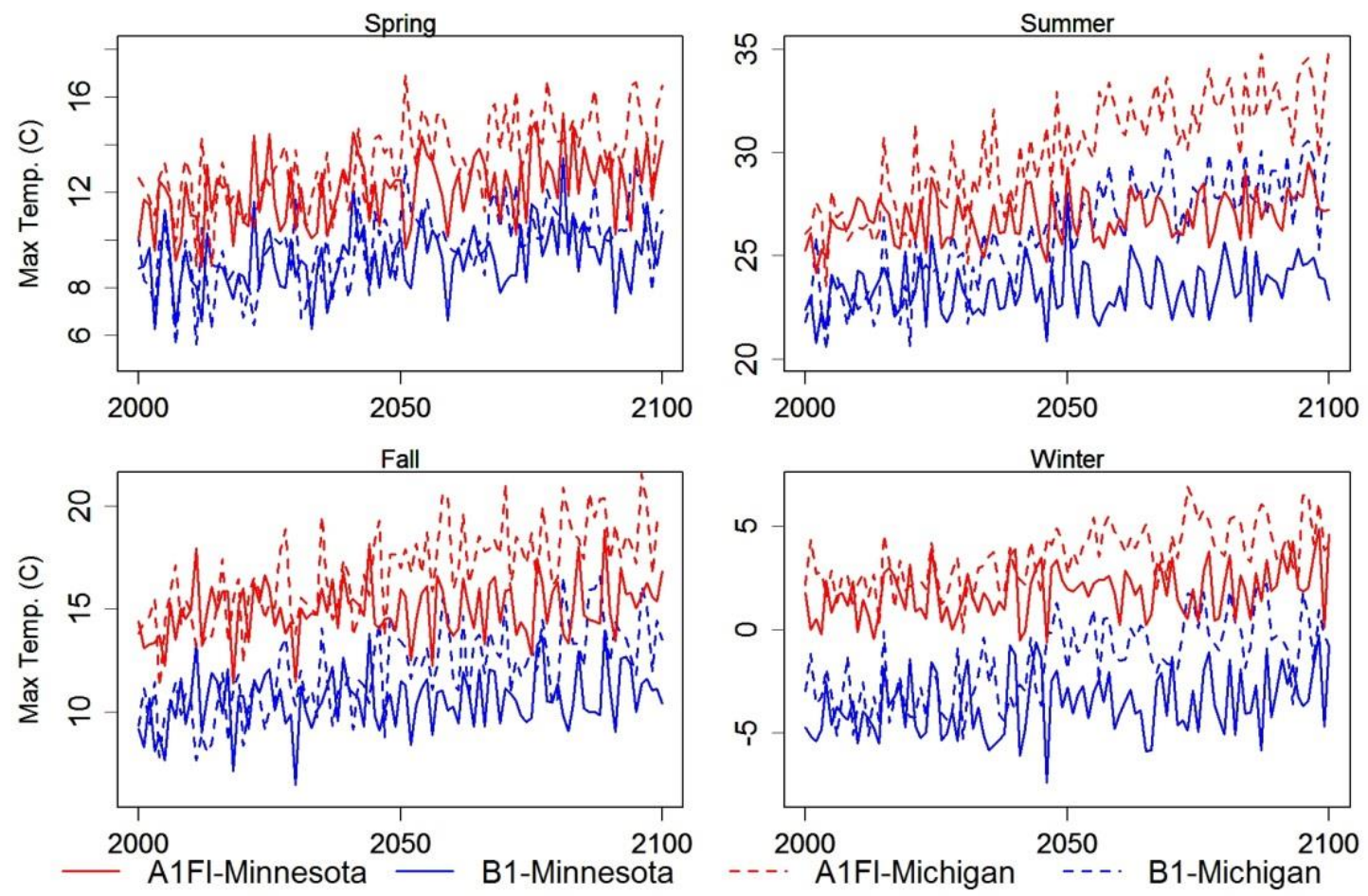
Figure 2.4: High (A1FI) and low (B1) emission projections of precipitation $(\mathrm{cm})$ in northeastern Minnesota and northern lower Michigan. Downscaled projections were from climate region 1 in each landscape from Figure 2.2 (Stoner et al. 2012). Monthly precipitation projections were aggregated by season (spring = March, April, May; summer $=$ June, July, August; fall $=$ September, October, November; winter $=$ December, January, February).
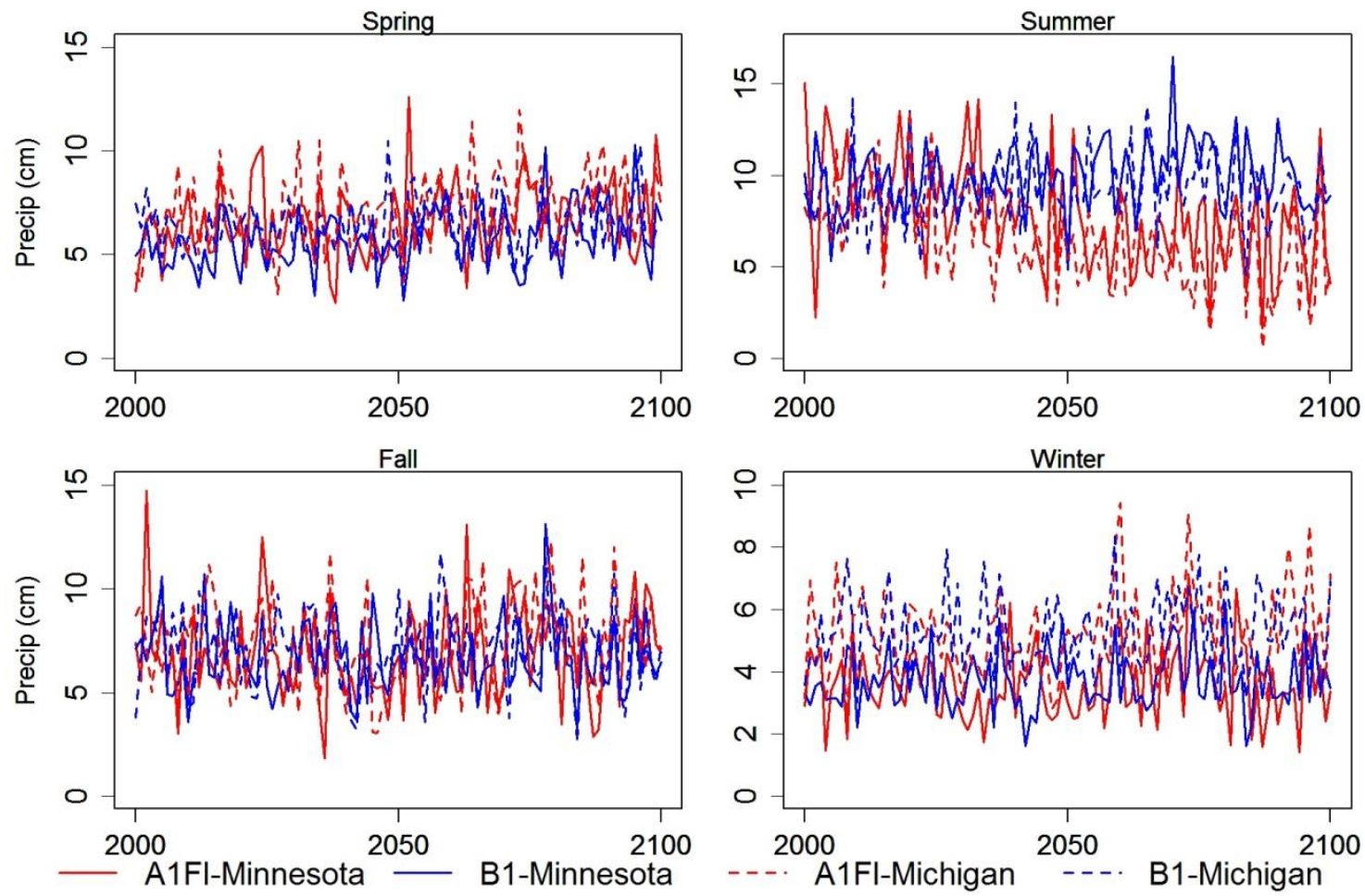
Figure 2.5: Aggregated climate regions based on mean July temperature in each landscape. Labels indicate average current July temperature (C) from 30 years of PRISM observations. Note that warmest climate region in Minnesota landscape is cooler than coolest climate region in Michigan landscape.

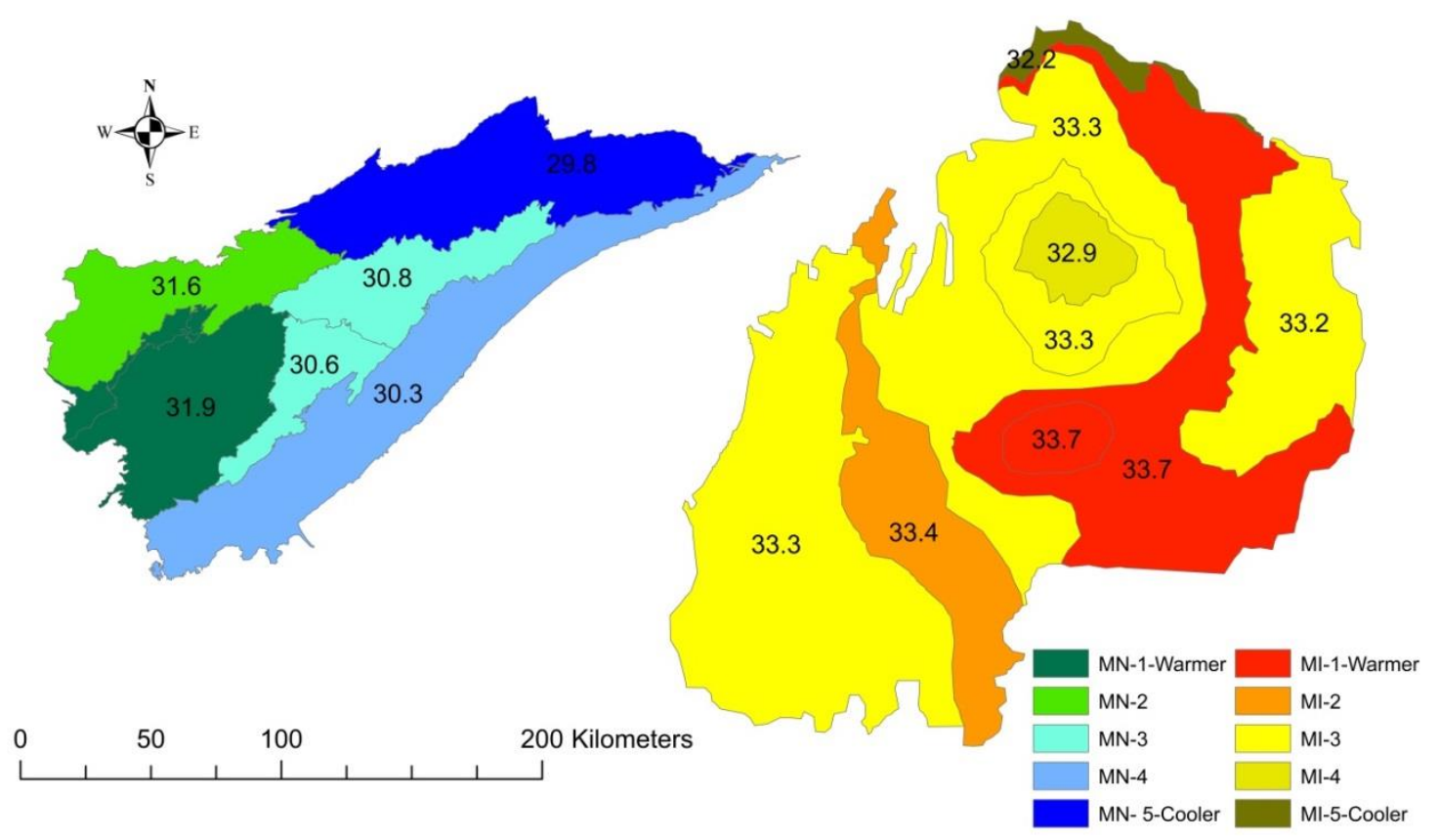


Figure 2.6: Relationship between diversity and aboveground ANPP ( $\mathrm{g} \mathrm{m}-2 \mathrm{yr}-1$ ) at year 2150 in northeastern Minnesota (top) and northern lower Michigan (bottom) for three climate scenarios. Unique point symbols represent soil regions across a gradient of SWHC values $(\mathrm{cm} / \mathrm{m})$. Diversity is represented by effective number of species $\left(\mathrm{e}^{\mathrm{H}}\right)$ and is calculated from Shannon Index.
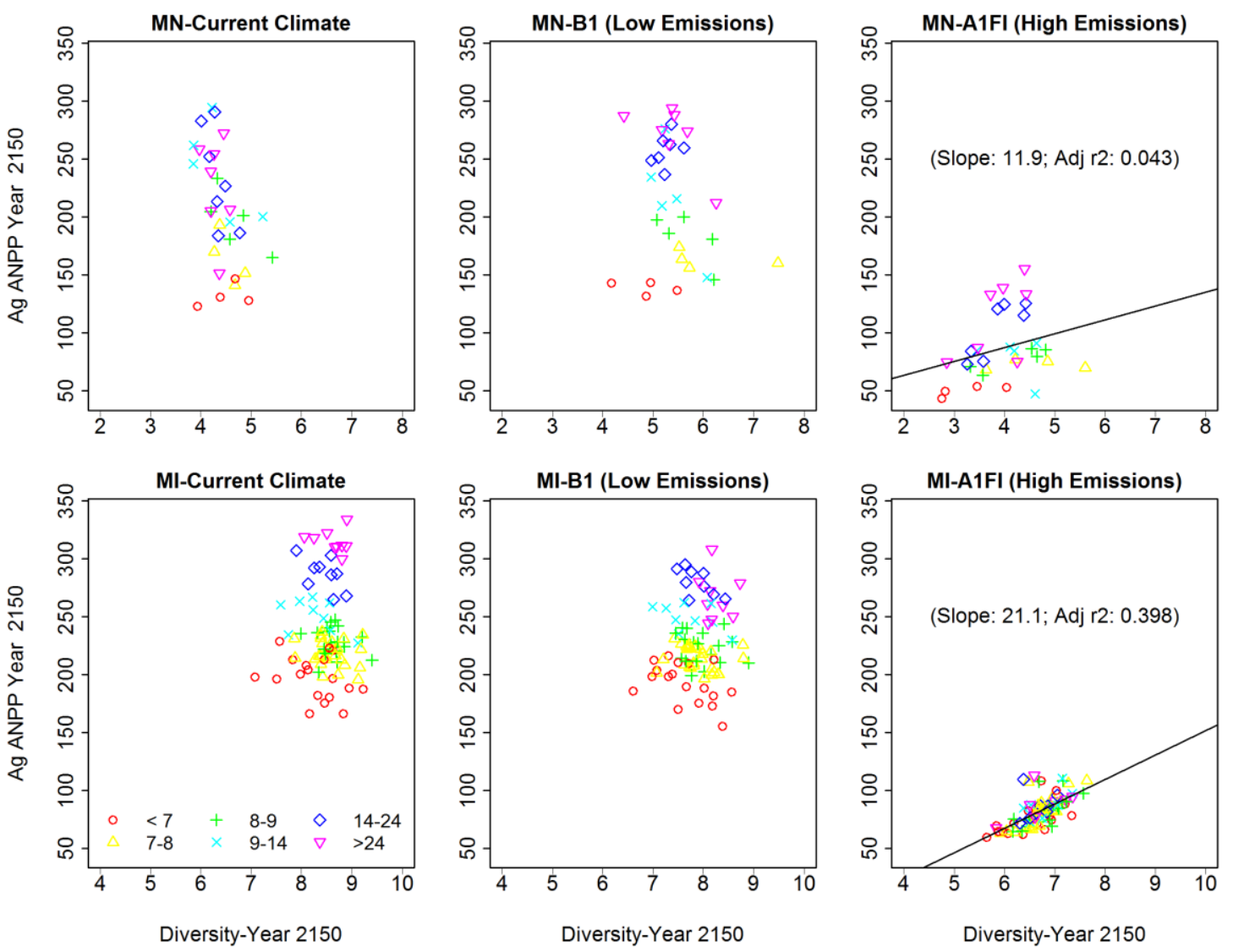
Figure 2.7: Diversity (eH') across the last 100 years of simulation (i.e. 2050 to 2150) in northeastern Minnesota and northern lower Michigan. Each group of clustered data points represents a single time series plot for a given climate scenario. Soil Water Holding Capacity (SWHC) plots represent diversity within SWHC regions. The variation in SWHC is represented by the different colored and shaped points. Climate region plots represent diversity within aggregated climate regions. The variation in climate region is represented by the different colored and shaped points (Climate region $1=$ warmest climate region, climate region $5=$ coolest climate region). Management area plots represent diversity within forest management groups. The variation in management area is represented by the different colored and shaped points. DNR represents both DNR and county lands in Minnesota and only DNR lands in Michigan.
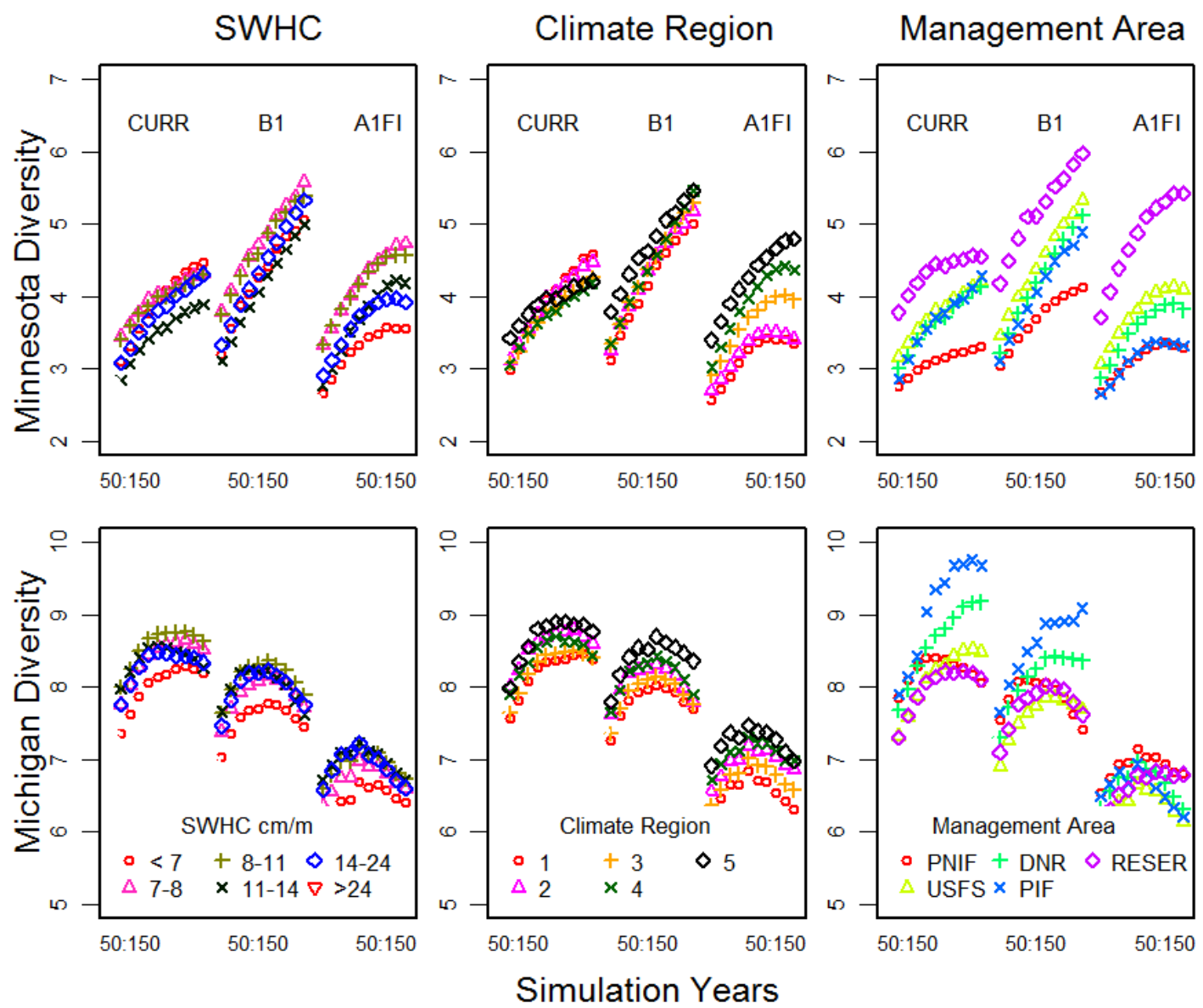
Figure 2.8: Total aboveground biomass $\left(\mathrm{AGB}_{\text {total }}\right)$ within the northeastern Minnesota and northern lower Michigan landscapes under three climate scenarios assuming BAU management.
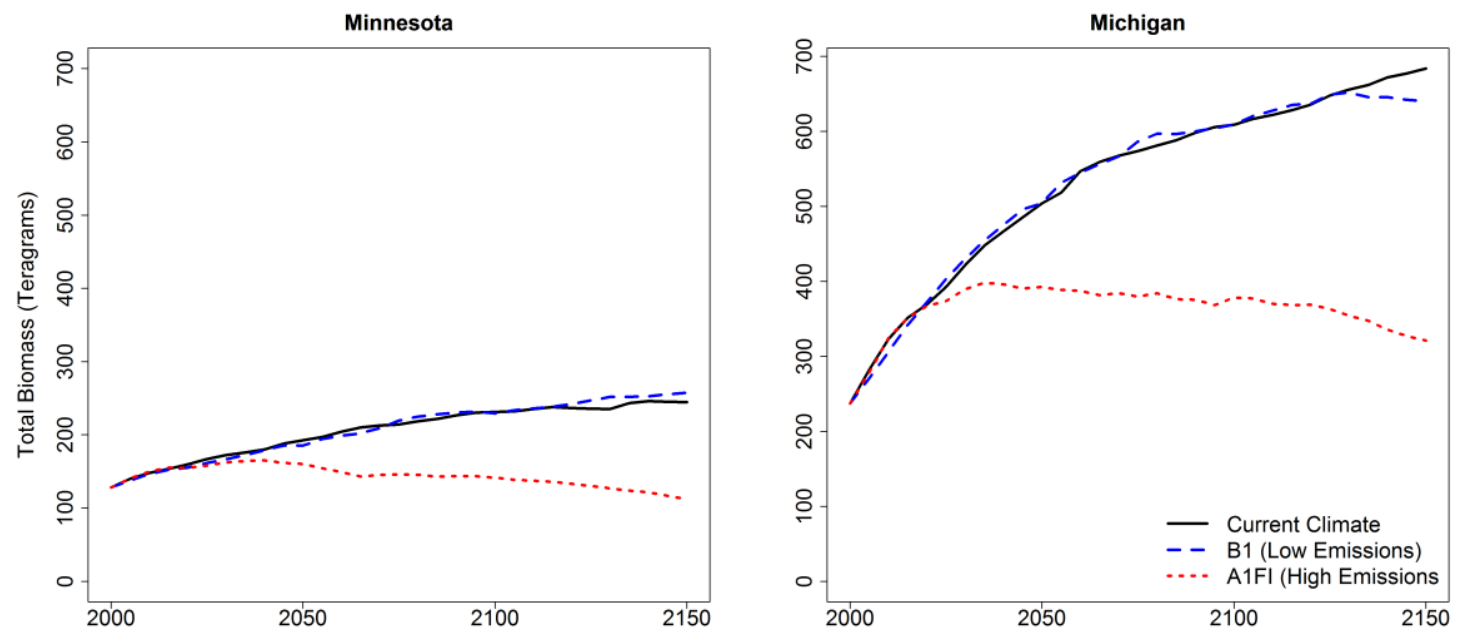
Figure 2.10: Northeastern Minnesota map of classified forests type at simulation year 2000 (upper left), proportion of forest types changing through time for each climate future (middle), and associated forest type maps at simulation year 2150 (right). Figure colors consistent throughout.
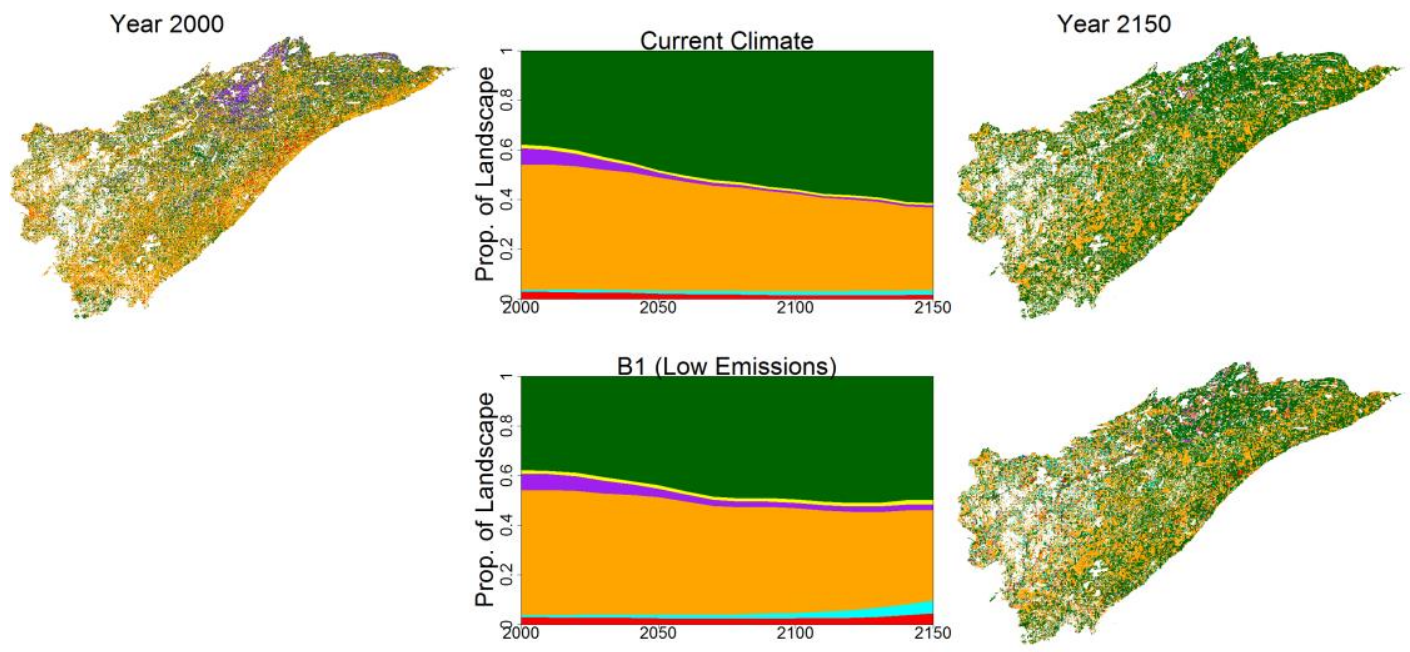

- spruce-fir
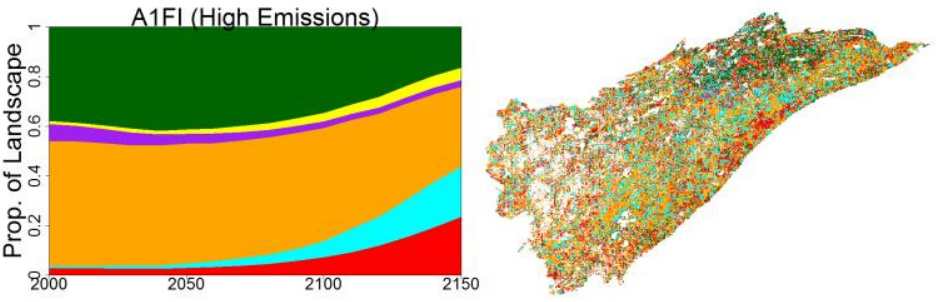
Figure 2.11: Northern lower Michigan map of classified forest type at simulation year 2000 (upper left), proportion of forest types changing through time for each climate future (middle), and associated forest type maps at simulation year 2150 (right). Figure colors consistent throughout.
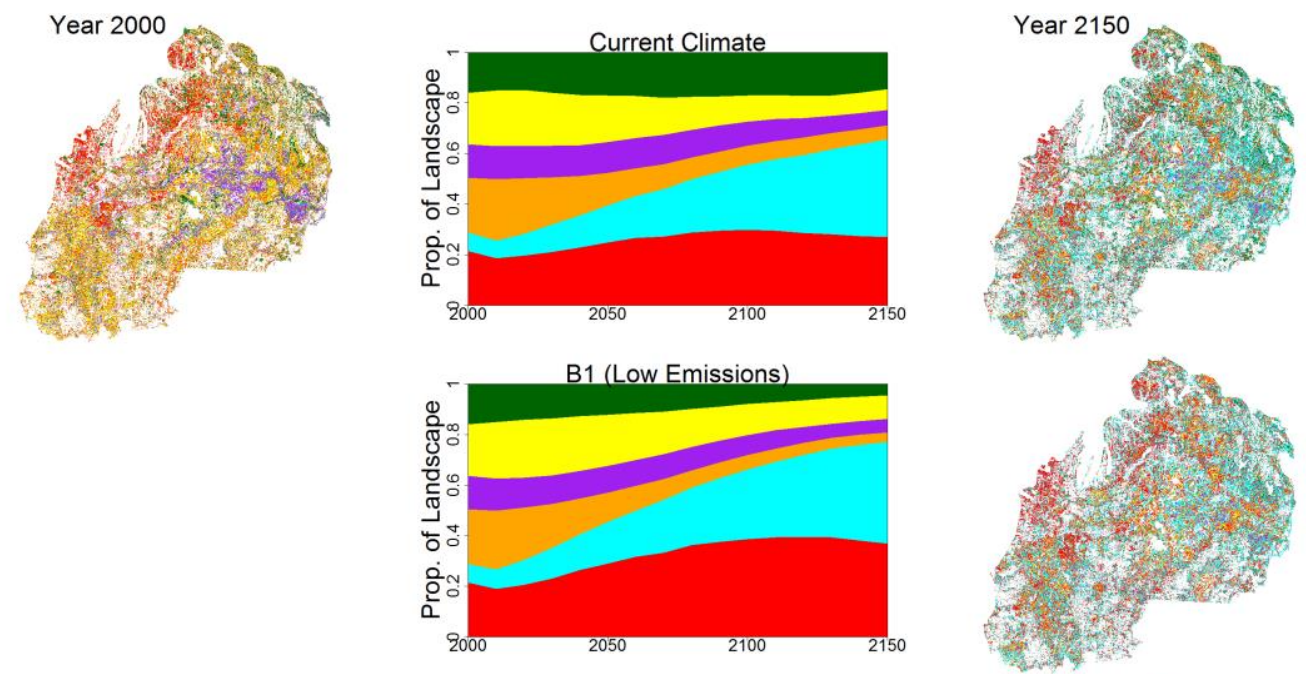

- spruce-fir oak association

- red/jack pine

aspen-birch

white pine

- northern hardwoods
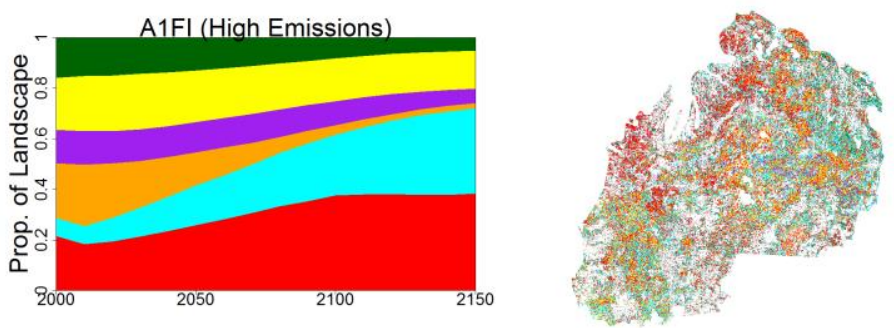


\title{
Chapter 3: Effects of Alternative Forest Management in the Face of Climate Change in the Northern Great Lake Region (USA).
}

\author{
ABSTRACT: \\ Northern Great Lake forests represent a unique ecotone in the boreal-temperate \\ transition zone, and are expected to change dramatically with climate change. Managers \\ are increasingly seeking adaptation strategies to manage these forests. I explored the \\ efficacy of two alternative management scenarios compared to Business-As-Usual \\ (BAU) management: expanding forest reserves (areas off limits to harvesting) meant to \\ preserve forest composition and modified silviculture (reduction in harvesting frequency \\ and patch size) meant to preserve forest function. My study landscapes encompassed \\ northeastern Minnesota and northern lower Michigan, which are predicted to experience \\ significant changes in a future climate and represent a gradient of latitude, forest type, \\ and management. I used the LANDIS-II forest simulation model to simulate forest \\ change under a current climate, a low emissions climate, and a high emissions climate \\ future. My results suggest that under a low emissions climate scenario, expanded \\ reserves and modified silviculture strategies can be effective at preserving forest \\ composition including legacy species (e.g., balsam fir (Abies balsamea)) and preserving \\ function by maintaining or increasing aboveground biomass compared to BAU \\ management. Under a high emissions climate scenario, the expanded reserve strategy \\ was not effective at preserving legacy species; however, the modified silviculture strategy \\ was effective at increasing aboveground biomass compared to BAU management. To
}


maintain ecosystem services that we depend, these results highlight alternative management options and limitations in the face of climate change.

KEYWORDS: Alternative silviculture; Climate change; Expanded reserves; Forest management; Forest simulation model; LANDIS-II; Michigan (USA); Minnesota (USA), Resilience; Resistance.

\section{INTRODUCTION:}

There is interest to preserve temperate-boreal forest ecosystems, such as found in the northern Great Lakes. In addition to being a "haven for biodiversity"(Bradshaw et al. 2009), these forests provide a large carbon sink, wood products for the timber industry (D' Amato et al. 2009), suitable wildlife habitat for numerous charismatic or endangered species (Heinselman 1996), and numerous recreational opportunities. Given the limits of forest ability to naturally adapt to climate change (Soja et al. 2007, Iverson et al. 2008), natural resource managers are increasingly interested in novel techniques to enhance the adaptive capacity of forests to provide the ecosystem services for which I depend (Millar et al. 2007, Spies et al. 2010, Seidl et al. 2011). In addition, there is a growing acceptance that effective management must occur at a landscape scale (Menz et al. 2013).

Given certain management objectives, resistance to climate effects may seem most desirable. Short term gains in ecosystem services may be achievable by improving defenses to rapid environmental change. These strategies are aimed at improving defenses against direct effects of changing climate in the short term. Specific resistance tactics might include restoration to a historical range of variability (e.g., Ravenscroft et 
al. 2010), protecting at risk species within climate refuges (e.g., Maschinski et al. 2012), eradicating climate driven invasive species from highly sensitive areas (e.g., Chapuis et al. 2004), or blocking an invading epidemic from a local high-value area (e.g., Rizzo and Garbelotto 2003). Resistance strategies are recognized as valuable in the short term in high value sites, however the tactics may not provide long-term protection against the long-term effects of global change (Ravenscroft et al. 2010).

As an alternative to resistance, managing for resilience has the potential to allow forests to change while maintaining ecosystem services. Utilizing resilience management comes with the recognition that future forests may not stay within the historical range of variability (Buma and Wessman 2013). Potential adaptation tactics have been identified for managing for resilience (Millar et al. 2007, Puettmann 2011, Seidl et al. 2011). Rather than creating resistance to change, these practices allow change through mimicked natural processes which continue to provide ecosystem services.

\section{Expanded Reserves:}

Maintaining ecological connectivity has been identified as a primary strategy available to natural resource managers to avoid severe climate disruption (Moritz and Agudo 2013). Limiting forest fragmentation is critical as a means to maintain ecological connectivity and to allow for species' range shifts (Chapin et al. 2007). While increasing habitat connectivity may be considered a resilience strategy (e.g., to increase wildlife migration ability (Collingham and Huntley 2000)), creating forest reserves along connected corridors may also be considered a resistance strategy to allow vulnerable species a less-disturbed place of refuge (Millar et al. 2007). Current forest reserves such as the Boundary Waters Canoe Area Wilderness (BWCA) in northeastern Minnesota 
provide landscapes with limited human development and high connectivity (Heinselman 1996). Increased connectivity facilitates tree species migration in response to climate change (Iverson et al. 2004), and refugia have the potential to harbor genetic and species diversity (McLachlan et al. 2005). Compared to managed forests, unmanaged old growth forests may provide: more carbon storage, greater structural complexity, higher volumes of coarse woody debris, and higher snag basal area (Silver et al. 2013). In addition, increased canopy closure can moderate microclimate conditions for seedlings (De Frenne et al. 2013). To date, little research has addressed the role that forest reserves (i.e. forested areas without extractive harvest) may play in increasing connectivity and providing refugia in the face of climate change.

Some of the most valued ecological reserves will occur where high diversity is expected, and where large climate shifts are projected (Rudnick et al. 2012). Anderson and Ferree (2010) found that the diversity of both plants and animals within thirteen US states and three Canadian provinces was explained by four geophysical factors (number of geologic classes, latitude, elevation range, and the amount of calcareous bedrock) and suggest that selecting areas for conservation based on geophysical settings will help "conserve the stage" for future biodiversity. These regions have high diversity potential as the factors effecting diversity are fixed on the landscape. A particular suite of species may change, however the conditions will continue to support a high number of species (Anderson and Ferree 2010). Riparian corridors create a connected area that directly spans an altitudinal, therefore adiabatic temperature gradient. These gradients provide both aquatic and terrestrial species the ability to migrate easily to suitable climate conditions (Rudnick et al. 2012). Under current best management practices, riparian 
corridors are generally protected from extractive activities at a limited distance from the high water mark. Expanding the width of these existing reserves will create larger areas of connected corridors with the potential for greater within-reserve heterogeneity.

\section{Modified Silviculture:}

Altering existing silviculture practices to manage for climate change can be considered a resilience strategy. Specific tactics can potentially increase structural (e.g. age) or compositional (e.g. species) diversity. Risk of a damaging forest pathogen associated with a single species or a single age cohort can be minimized by creating diverse stands, thereby spreading the risk (Walker et al. 1999). By supporting redundant functional species with different environmental tolerances, functional insurance is enhanced (Walker 1992). With so much uncertainty in climate change projections (IPCC 2007) and impacts on forests (Scheller and Mladenoff 2005, Xu et al. 2009, Duveneck et al. accepted), managing forests for complexity will strategically allow heterogeneous forests to adapt to future conditions (Puettmann 2011). Specific silviculture systems to manage for complexity include extended rotation prescriptions (Silver et al. 2013), managing for asynchrony with patch harvesting, and planting future climate-suitable species (Millar et al. 2007).

Some systems can change into an alternative state during reorganization of a successional trajectory. This vulnerable period may be triggered by potentially large scale disturbances such as a synchronized repeated periods of drought. For example, landscape scale droughts in the western United States have resulted in broad regional tree mortality (Breshears et al. 2005). Management for asynchrony, and therefore higher resilience, can be achieved by creating diverse age classes, species mixes, and genetic 
diversity (Millar et al. 2007). This may be achieved by utilizing more partial cutting silviculture systems (e.g. selection cutting) rather than even-aged management (e.g. clear cutting). For asynchrony to be achieved however, these systems require appropriate recovery periods. With favorable environmental conditions, productive forests are often managed in low diversity stands, favoring competitive exclusion over complementarity. Under stressed conditions, however, complementarity may be favored over competitive exclusion creating a positive correlation between diversity and productivity (Paquette and Messier 2011). In the Great Lakes region, Duveneck et.al. (accepted) found an increasingly positive relationship between simulated forest productivity and diversity under increasingly higher emission scenarios and declining productivity. These results add support for managing for diversity under anticipated climate change.

In Minnesota, and presumably throughout the Great Lakes region, there is a trend toward decreased use of clear-cuts, increased patch cutting, and increased rotation ages (D' Amato et al. 2009). Intermediate treatments (i.e. low intensity harvesting) have much different impacts on carbon cycling than large scale even-aged management. With longer rotation ages, or less frequent harvests, more carbon from older stands is transferred to a more permanent pool of soil carbon (Aber et al. 1982). More frequent harvests result in more carbon being exported off site. Powers et al. (2012) found that thinning treatments in Minnesota red pine (Pinus resinosa) stands resulted in a minor reduction to carbon stocks as compared to unthinned stands. This suggests that low intensity harvesting designed to achieve a forest products objective may not conflict with a carbon storage objective. Nonetheless, recent interest and speculation exist regarding forests ability to provide biofuels through large scale short rotation whole tree harvesting treatments. 
These silviculture systems could result in large reductions to carbon storage (Berger et al. 2013) and would be a contrast to the growing trend towards less intensive and extensive silviculture systems (D' Amato et al. 2009).

\section{Tradeoffs Between Adaptation and Mitigation:}

Forests have potential for increased carbon sequestration at local and regional scales, however globally, a boundary limit to terrestrial NPP may have been reached (Running 2012). Nevertheless, current forests continue to play a pivotal role in current carbon sequestration and management (Jandl et al. 2007). Managers are increasingly interested in the tradeoffs between the ability of forests to adapt to climate change and forests contribution to climate change mitigation (D' Amato et al. 2011, Steenberg et al. 2011). Within mitigation strategies, there are also tradeoffs between carbon sequestration and carbon storage. Both reserve expansion and altering current silviculture treatments have the potential to increase carbon storage while increasing the adaptive capacity by increasing structural and compositional diversity.

Intensively managed young forests (i.e. short rotation silviculture systems), will result in lower stand ages which can sequester more carbon annually (Bradford and Kastendick 2010). These silviculture systems must consider the risk associated with fastgrowing, uniform stands that are vulnerable to insects, disease, and fire (e.g., Kurz et al. 2008). By reducing the vulnerability to the sources of forest emissions, forests can provide more carbon mitigating function.

While longer rotations and increased use of partial harvest systems may results in less harvested AGB, these management approaches can produce greater volumes of higher value wood products such as saw timber that can compensate for the decrease in 
harvested biomass (White 2011). The increase in timber value however, comes at the cost of time. Durable wood products also contribute to long-term carbon storage due to their slow decay rates (Harmon et al. 1990).

My objectives were to assess the ability of alternative scenarios to increase or maintain representative forest ecosystem services under climate change. My assessment compared BAU management to two alternative management strategies in northeastern Minnesota and northern lower Michigan. I assessed the tradeoffs between resisting and adapting to climate change. Specifically, I addressed the following question: In the face of climate change, how will alternative management strategies affect future aboveground biomass, harvested timber, tree species diversity, and forest type?

\section{METHODS:}

\section{Study Areas:}

I selected the northern Great Lakes region to study these questions as scientists predict large changes in the climate in the midcontinent (IPCC 2007) and the borealtemperate forest transition zone within the region is especially vulnerable to environmental changes (Fisichelli et al. 2013). Within the region, I choose two landscapes (i.e. northeastern Minnesota and northern lower Michigan) representing a gradient of latitude, forest type, and management (Figure 3.1). Minnesota is cooler, centered in the boreal-temperate ecotone, and is more intensively managed. Michigan is in the temperate-hardwood region and has a more diverse suite of tree species and forest types. Disturbance regimes, timber management, forest types, species composition, and 
climate change effects under BAU management are described previously for each landscape (Ravenscroft et al. 2010, Duveneck et al. accepted).

\section{Simulation Model and Experimental Design:}

My experimental design included three forest management scenarios: 1) BAU timber management, 2) Modified silviculture, and 3) Expanded Reserves. For each management scenario I assessed three climate scenarios: 1) Current Climate, 2) Low Emissions Future, and 3) High Emissions Future. In order to compare my results between landscapes and prior research (Duveneck et al. accepted), I used as consistent an approach as possible to parameterize the scenarios. For all simulations, I used a twohectare cell resolution and a 150-year time horizon starting at year 2000.

I assessed forest dynamics using the LANDIS-II v6.0 forest landscape model (Scheller et al. 2007a) (See supplemental material for model input data). LANDIS-II is a modeling tool for simulating forest change within a landscape. LANDIS-II is flexible in scale, process-driven, and has been evaluated on many landscapes (e.g., Gustafson et al. 2010, Ravenscroft et al. 2010). LANDIS-II operates across interconnected cells within climate and soil regions ('ecoregions') on a landscape. LANDIS-II simulates succession, disturbance, and management and emphasizes spatial interactions across the landscape and among processes (e.g., climate change, harvesting, succession, fire, wind, and seed dispersal).

LANDIS-II incorporates multiple user-chosen extensions that interact with each other. Each extension ran at a five-year time step. To calculate species-specific parameters (i.e. Maximum Aboveground Net Primary Productivity per year (ANPP ${ }_{\max }$ ), and Probability of Establishment $\left.\left(\mathrm{P}_{\text {est }}\right)\right)$ I used the PnET-II for LANDIS-II model (PnET) 
(Xu et al. 2009). PnET incorporates climate data (temperature, precipitation, and photosynthetic active radiation (PAR)) along with Soil Water Holding Capacity (SWHC), and species-specific physiological parameters (e.g. foliar nitrogen content, and maximum foliar mass area) for each climate-soil region on the landscape (Duveneck et al. accepted). ANPP ${ }_{\max }$ and $\mathrm{P}_{\text {est }}$ are incorporated into the LANDIS-II Biomass Succession extension (v3.1), which regulates the succession mechanisms of growth, and age-related mortality for species-cohorts (Scheller and Mladenoff 2004). ANPP ${ }_{\max }$ determines the maximum growth possible of above ground biomass for a species-cohort (Scheller and Mladenoff 2004). Growth is further limited by competition and a growth curve parameter that determines how fast simulated ANPP reaches ANPP ${ }_{\max }$. Age-related biomass decline is defined by a mortality curve that represents an increasing decline in biomass as the species reaches its maximum longevity. $\mathrm{P}_{\text {est }}$ determines the probability of a new cohort establishing given a local seed source and adequate light and is based on a climate envelope approach (Xu et al. 2009). To start a simulation, biomass succession goes through a "spin-up" phase where the past growth of current species-cohorts on the landscape is simulated up to the starting year.

I used the Biomass Harvest extension (v2.1) to simulate harvest scenarios (Gustafson et al. 2000). Specific prescriptions were applied to management areas based on ownership groups (Figure 3.2). Stands are delineated within management areas. At each 5-year time step, the extension selects stands for treatment based on a user-defined stand ranking. Simulated biomass is removed from cells within stands based on prescription specific criteria. For each management area, specific rotation periods define the amount of the management area treated at each time step. (Gustafson et al. 2000). 
I used the Base Fire (v3.0) (He and Mladenoff 1999), and Base Wind (v2.0) (Scheller and Mladenoff 2004) extensions to simulate fire and wind disturbance. To quantify spatially-explicit species Aboveground Biomass (AGB) $\left(\mathrm{g} \mathrm{m}^{-2}\right)$ and to classify forest type, I utilized the Biomass Output extension (v2.0) and the Biomass Reclass extension (v2.0) respectively. To process outputs and visualize results, I used the raster library in R (R Development Core Team 2011). Within each landscape I leveraged previously developed initial communities, fire and wind regimes, BAU timber harvest regimes, delineated ecoregions, and tree species by ecoregion ecosystem response (Duveneck et al. accepted).

\section{Climate Data:}

I simulated the current climate scenario based on randomly assigning 30 years of observed PRISM climate (1969-1999) to future simulation years (Daly and Gibson 2002). I simulated a low and high emission scenario to bracket a range of uncertain futures. For the low emission climate I used the IPCC B1 emission scenario (IPCC 2007) and the Parallel Climate Model (PCM) Global Circulation Model (GCM) (Washington et al. 2000) . For the high emission climate I used the IPCC A1FI emission scenario (IPCC 2007) and the Geophysical Fluid Dynamics Laboratory (GFDL) GCM (Delworth et al. 2006). For each unique climate region, I downscaled and accessed temperature and precipitation data through the USGS data portal http://cida.usgs.gov/climate/gdp/ . To estimate projected PAR, I accessed projected radiation data from meteorological stations throughout the landscape. After observing the low variability in PAR across observation sites, I used mean PAR within each climate region.

In order to simulate forest change to year 2150 , I interpolated monthly climate 
variables (maximum and minimum temperature, precipitation, and PAR) for the 50 years beyond the range of IPCC climate projections (IPCC 2007). The initial 100 years of climate projections encompassed an increase in temperature in all seasons in both emission scenarios however the precipitation projections were more variable (Stoner et al. 2012, Duveneck et al. accepted). I interpolated the final 50 years of climate data using the Amelia library in R (R Development Core Team 2011) based on the variability in each of the climate variables within the original 100 years of data. For the temperature projections, I included a linear regressed increase in interpolated temperature.

\section{Alternative Management Scenarios:}

I represented forest reserves as sites void of any timber harvest. I used the Protected Areas Database (The Conservation Biology Institute 2010) to delineate areas across the landscapes that had existing formal protection status. These reserves include the large BWCA in Minnesota, state parks, and state natural areas. In northern lower Michigan, fewer large reserve areas exist, however I included 38\% of Private NonIndustrial Forests (PNIF) in reserve status under the assumption that $62 \%$ of PNIF lands are actively managed for timber (Butler 2008). In my expanded reserve scenario, I created a forest reserve buffering 1500 meters on either side of major river corridors. The rivers included the Cloquet and St. Louis Rivers in notheastern Minnesota and the Manistee, Au Sable, and Muskegon Rivers in northern lower Michigan. In addition to the river reserves, I created a 1000 meter buffer along the Great Lake shore boundaries in both landscapes (Figure 3.2). Under BAU management, 13\% and 11\% of the forested landscape was in reserves in the Minnesota and Michigan landscapes, respectively. Under my expanded reserve scenario, $18 \%$ of forested lands were in reserves in each 
landscape. Although the increase in reserve area in the Michigan landscape was larger, the percent area under active management was comparable to the Minnesota landscape in both the BAU and expanded reserve scenarios.

To simulate modified silviculture I altered BAU prescriptions (Duveneck et al. accepted) based on increasing uneven aged silviculture systems and increasing regeneration of northern hardwoods and oak species (e.g. American basswood (Tilia americana), black cherry (Prunus serotina), American elm (Ulmus americana), white oak (Quercus alba), northern pin oak (Quercus ellipsoidalis), northern red oak (Quercus rubra) (See Appendix Table A6 and A7). Rather than prescribe identical harvest prescriptions to each landscape, I adjusted the BAU prescriptions in each landscape to decrease harvested AGB by approximately $60 \%$ from BAU management. Generally, these adjustments resulted in a reduction in clearcuts, an increase in northern hardwood patch cuts, and planting of native northern hardwoods and oaks currently present on the landscapes, albeit in low abundance.

\section{Data Analysis:}

Stochastic variation in model outputs is largely influenced by natural disturbance events (i.e. fire and wind). I examined the stochastic variation within scenarios by replicating each simulation five times. Maximum AGB variance at year 2150 was $<2 \%$ of the mean AGB within each simulation. Due to the low stochastic variation of natural disturbance events relative to the size of the landscapes, I randomly selected one replicate from each simulation for further analysis. While strict validation of simulation results is not possible, I evaluated AGB estimates as measured in USFS Forest Inventory \& Analysis field plots to LANDIS-II biomass at year 2000 (Pearson's correlation of 0.64) . 
Details of my biomass evaluation are described in Duveneck et al. (accepted).

For each scenario and time step, I calculated Shannon Index of diversity (H') within each cell based on the simulated AGB abundance of tree species. I transformed Shannon Index to the effective number of species measure of diversity $\left(\mathrm{e}^{\mathrm{H}^{\prime}}\right)$ as the number of species present if all species were equal in abundance in order to reduce bias when comparing between scenarios (Jost 2006). I used the vegan-community ecology, and raster libraries in R ( $\mathrm{R}$ Development Core Team 2011) for all calculations and analysis.

To examine effects of reserve expansion, I compared the AGB of the BAU scenario to the AGB of the expanded reserve scenario (by species and total biomass). To understand dynamics within reserves, I compared average simulated AGB within reserves to that outside reserves. I examined spruce-fir species (balsam fir (Abies balsamea), white spruce (Picea glauca), and black spruce (Picea mariana) as the group of species most vulnerable to climate change related decline (Duveneck et al. accepted). In addition to spruce-fir $\mathrm{AGB}$, I assessed $\mathrm{AGB}_{\text {total }}$ and species diversity within and outside reserves. I compared within and outside reserve AGB and diversity by spatially separating outputs that occur within and outside reserve areas (Figure 3.2) using the raster library in R (R Development Core Team 2011).

\section{RESULTS:}

\section{Aboveground biomass:}

Compared to BAU management, both alternative management simulations (i.e. expanded reserves and modified silviculture), resulted in an increase in total AGB for all 
climate scenarios in both landscapes (Figure 3.3). The expanded reserve scenarios closely track the BAU scenarios with a small increase in AGB compared to BAU over time. Compared to the expanded reserve scenario, the modified silviculture prescription resulted in a larger increase in AGB in both landscapes and all three climate scenarios. Under each management scenario, the relationship of total AGB between climate scenarios stay relatively constant (i.e. current climate >> low emission climate >> high emission climate) with the exception of more biomass in the low emission climate scenario than the current climate scenario after 100 years in the Minnesota landscape.

Although the Michigan landscape is larger than the Minnesota landscape (More $\mathrm{AGB}_{\text {total }}$ in Michigan (Figure 3.3), approximately the same magnitude of biomass was simulated to be harvested off each landscape in each management scenario. In each landscape and climate scenario, the modified silviculture scenario removed less biomass than the expanded reserves which removed less biomass than the BAU scenario. Within management scenarios, the current climate and low emission climate scenario resulted in nearly the same amount of harvested biomass. In contrast, the high emission climate scenario resulted in substantially less timber harvested in each management scenario.

The simulated AGB response of select species to modified silviculture further explains differences between scenarios in both landscapes (Figure 3.4). In general, the alternative scenarios were more effective at increasing AGB in the Minnesota than in the Michigan landscapes. For example, in Minnesota, under the high emissions climate scenario, American basswood and sugar maple (Acer saccaharum) both resulted in large increases in simulated AGB under the modified silviculture scenario. In general, the northern hardwoods and oaks experienced larger increases in simulated AGB under the 
modified silviculture scenario compared to expanded reserves. In both landscapes, the low emissions climate scenario and the modified silviculture management scenario resulted in the largest increases in northern red oak and white pine (Pinus strobus). Simulated quaking aspen (Populus tremuloides) AGB declined under the alternative management scenarios in both landscapes with the largest decline under the high emissions climate scenario. In the Minnesota landscape, both alternative management scenarios resulted in increases in simulated black spruce AGB however the Michigan landscape resulted in very little management effect. In the Minnesota landscape, balsam fir resulted in larger and white spruce resulted in smaller simulated AGB under alternative, compared to BAU management scenarios. Under the high emission climate, the effect of alternative management was diminished for both balsam fir and white spruce.

Under the expanded reserve management scenario, cells in the reserve areas had a larger $\mathrm{AGB}_{\text {total }}$ compared to cells outside the reserve with actively managed forests (Figure 3.5-top). For the spruce-fir species, reserve areas resulted in large increases in simulated AGB under current and low emissions climate scenarios in both landscapes (Figure 3.5-middle). Under the high emissions climate however, reserve areas resulted in less of an increase in spruce-fir.

\section{Diversity:}

Average tree species diversity in each cell was lower in the Minnesota than the Michigan landscape (Figure 3.6). In both landscapes, the high emission climate scenarios resulted in the lowest simulated diversity. Compared to BAU management, the expanded reserve scenario resulted in a limited increase in diversity. The modified silviculture 
scenario resulted in larger increases in diversity compared to BAU and expanded reserve management in all three climate scenarios in the Minnesota landscape. Compared to BAU management, the modified silviculture scenario in the Michigan landscape resulted in a small decrease in diversity under the current and low emissions climate scenario and a small increase in diversity under the high emission climate scenario.

Under the expanded reserve management scenario, forest reserves resulted in generally higher diversity compared to managed forests outside reserves (Figure 3.5). This effect was most pronounced in the high emission climate scenario in the Minnesota landscape. In the Michigan landscape, the effect of reserves on diversity was limited.

\section{Forest Type:}

The spatial distribution of changing forest types due to management was best represented by the Minnesota landscape (Figure 3.7). Under the current and low emission climate simulations, the spruce-fir forest type persisted within the reserves of the expanded reserves scenario at year 2150 (Figure 3.7). The reserves within the high emission climate scenario, however, were occupied with more northern hardwood forest type after year 2150 resembling the spatial distribution of BAU management.

The effect of the modified silviculture management scenario in all climate scenarios resulted in a more diverse distribution of forest type abundance compared to BAU management (Figure 3.7). The higher diversity of forest types under modified silviculture was represented by a decrease in aspen/birch forest type and an increase in white pine, and northern hardwoods forest types. Under modified silviculture, the current and low emission climate scenarios resulted in an increase in the spruce/fir forest type 
however not in the high emissions climate scenario.

\section{DISCUSSION:}

Forest managers and policy makers are increasingly seeking best management strategies to manage forests in the context of climate change (Millar et al. 2007, Seidl et al. 2011). Both resistance and resilience strategies are being considered, however successful management to adapt to climate change in the Great Lakes region may be limited.

\section{Forest Reserves:}

For populations with long generation times (i.e. tree species), limiting external stressors has been identified as a climate management priority (Moritz and Agudo 2013). My expanded reserve scenario may be considered a resistance strategy in the context of providing refuge with limited disturbance along environmental gradients (Rudnick et al. 2012). There is support to conserve the trailing edge of a species migration, such as balsam fir in the boreal temperate ecotone. Genetically, a species within the trailing edge of its range will be adapted to more extreme conditions having had more generations (Hampe and Petit 2005). In my low emissions climate scenario, the expanded reserves did function as a resistance strategy. Spruce-fir forest types in the Minnesota landscape (Figure 3.7), and spruce-fir species AGB in both landscapes (Figure 3.5) persisted more in the reserve areas than in actively managed forests. These species are shade tolerant and common within minimally disturbed late successional forests. Under my high emissions climate scenario, however, the forest reserves provided limited refuge to the spruce-fir species (Figure 3.5), and spruce-fir forest types (Figure 3.7). These results are 
consistent with other research that found adaptive forest management for climate change less successful under increasingly higher emission climate scenarios (Buma and Wessman 2013).

As expected, forest reserves provided more simulated on-site AGB than actively managed forests (Figure 3.5) which is consistent with previous research comparing managed vs. unmanaged stands (Powers et al. 2012). An increase in AGB implies higher on-site carbon storage. While managing for carbon storage in the Great Lake region does not currently provide a direct financial incentive, there is a growing interest to manage forests specifically for climate mitigation (Malmsheimer et al. 2008). As my results indicate, a decrease in AGB is expected under the high emissions compared to current climate scenario. For this reason, there may be an increased interest in maintaining, if not increasing, AGB on the landscapes.

The higher simulated alpha diversity within reserves (Figure 3.5) suggests that the forest reserves under low frequency natural disturbance regimes may result in an increase in diversity over the long term. Conversely, the diversity of actively managed forests with mixed frequency of disturbance may increase less. At the landscape scale, the expanded reserves scenario resulted in very little change in simulated diversity compared to the BAU scenario (Figure 3.6). These results suggest that at the 2-hectare grain size, forest reserves may have the potential to increase forest diversity. This is consistent with empirically measured increasing heterogeneity in less disturbed forests at a sub-hectare grain size (Bradford and Kastendick 2010). My results do not include old growth gap dynamics within a grain size less than 2-hectares and I do not suggest that my results would necessarily scale down to a smaller grain size (Urban 2005). 
While attempting to increase resistance, forest reserves may increase resilience by increasing alpha diversity. This may be considered counter to carefully managed disturbances as opportunities for desirable change (Puettmann 2011, Buma and Wessman 2013). While I did not measure genetic adaptability, the evolutionary adaptability of forests to the effects of climate change can be improved with shorter generation times (Kuparinen et al. 2010). Forest reserves in landscapes with low natural disturbance frequency will have long generation times. Shorter generation times can be managed for by adjusting harvest rotation periods within actively managed forests (Puettmann 2011).

Regardless of the success of the resistance goal of providing refuge to spruce-fir and increased carbon storage, additional ecosystem services can be enhanced through expanded forest reserves. Specifically, forest reserves along riparian corridors have the potential to increase wildlife habitat and connectivity (Collingham and Huntley 2000, Rudnick et al. 2012). In addition, forest reserves in the Great Lakes region enhance scientific inquiry due to the ability to separate processes within regions free from anthropogenic influences or threats. Large forest reserves such as the BWCA allow landscape scale processes to occur (e.g. fire) with limited anthropogenic restrictions (Heinselman 1996). These sites provide natural laboratories to study the interactions and processes between species, climate change, pollution, invasive species, and other processes (Heinselman 1973).

The spruce-fir species increased more in the Minnesota landscape reserves. In the warmer Michigan landscape, the reserve areas had less of an effect to spruce-fir species (Figure 3.5). This is likely due to climate and management differences between the landscapes (Duveneck et al. accepted). The interaction between climate and the 
competitive advantage of spruce-fir species (i.e. shade tolerance) in reserve areas allow larger increases where the conditions are more favorable. In addition, the less intensively managed Michigan landscape resulted in less of a contrast in spruce-fir AGB and diversity between reserves and actively managed forests. Finally, the Minnesota landscape initially contained more spruce-fir AGB within the boreal-temperate ecotone. In order to receive the largest gains in ecosystem services (with limited resources), landscapes with less intensive BAU management may not be appropriate for reserve selection.

\section{Alternative Silviculture:}

Recent research has considered tradeoffs between forest adaptation and mitigation strategies (D’Amato et al. 2011). My results suggest that modified silviculture may increase climate mitigation by increasing carbon storage and may increase adaptation by increasing species diversity. This scenario may be considered a resilience option in the context of managing for complexity with a diverse species mix (Puettmann 2011). A complex forest with high diversity can promote low abundance species capable of responding to changing environmental conditions (Walker et al. 1999). My modified silviculture scenario was designed to increase heterogeneity with less frequent even-aged silviculture systems and more frequent smaller patch cuts. In addition to complexity, the modified silviculture scenario was designed with an adaptation component to favor and plant species expected to respond well to climate change (See Appendix: Table A6 and A7). For planting to be successful, a substantial financial investment in successful artificial regeneration is required.

By managing for heterogeneity and adaptation, the modified silviculture scenario 
generally resulted in both increased on-site AGB (Figure 3.3) and diversity (Figure 3.6) at the expense of a decline in boreal tree species (Figure 3.4) and a decrease in harvested timber (Figure 3.3). In the case of white spruce in the Minnesota landscape, the BAU scenario includes planting white spruce following red pine clear cut prescriptions (See Appendix: Table A6). Under the modified silviculture prescription, I ceased planting white spruce which resulted in a decline in white spruce AGB compared to BAU management. For forest policy makers, a tradeoff exists between harvested and on-site AGB. The modified silviculture scenario represents a change in priority to increase onsite AGB at the expense of a reduction in harvested AGB. The modified silviculture scenario however may result in higher value timber products compared to BAU management products. For example, short rotation even aged silviculture systems will produce lower value products compared to group selection harvested with a patch cut or extended rotation silviculture system (White 2011). This may at least partially offset losses due to the reduction in harvested AGB.

Except for the high emissions scenario, the Michigan landscape did not result in an increase in diversity under the modified silviculture scenario. The Michigan landscape experienced less of a contrast between BAU and modified silviculture where there are less frequent even-aged silviculture prescriptions under BAU management compared to the Minnesota landscape (Duveneck et al. accepted). In addition, the current species composition of the Michigan landscape is more common of a northern temperate forest compared to the boreal-temperate Minnesota landscape (Curtis 1959). The alternative management in Michigan landscape has less influence on composition and productivity. This suggests that opportunities to adapt existing BAU management may 
be easier to implement in the Minnesota landscape; however, BAU management may be better poised to naturally adapt to climate change in the Michigan landscape. Adaptive management in Michigan could focus on species and silviculture characteristics of the central hardwood region. This might be more effective at increasing diversity, especially under the high emission climate scenario.

\section{Uncertainty and Model Limitations:}

A tremendous amount of uncertainty exists in the emission scenarios and GCM's (IPCC 2007). My choice of a low and high future emission scenario was meant to bracket a range of future uncertainty. Recent carbon emission observations, however suggest that our present global carbon emission trajectory is on track or above that of the high emission (A1FI) emissions scenario I used in my projections (Jennings 2012).

My simulations should not be interpreted as predictions. Rather, my results are plausible future scenarios with increasing future uncertainty. My model results are simplifications of reality based on the best available data. I did not include species migrating from outside the landscape, effects of large ungulate browse damage (Fisichelli et al. 2012), $\mathrm{CO}_{2}$ fertilization (Reich and Hobbie 2012), or ozone pollution (Ainsworth et al. 2012). I recognize that a large amount of uncertainty exists in how landowner's priorities will shift regarding management. My alternative management scenarios were based on informed speculation and adjustments to BAU forest management (Duveneck et al. accepted). Future management will depend on dynamic individual management priorities, market fluctuations, and policy restrictions. 


\section{CONCLUSIONS:}

In contrast to other adaptation studies simulating an increase in biomass under climate change (e.g., Steenberg et al. 2011), my results suggest a decline in both harvested and on-site AGB under the high emissions climate scenario. Therefore, my results suggest an even greater need to consider alternative management options to maintain AGB. Under a low emissions scenario, the ability to manage for climate change was much greater than under the high emissions scenario. The expanded reserve scenario was effective at preserving legacy species under the low emission climate scenario. Under the high emission climate scenario, my ability to manage for climate adaptation was limited. Under my modified silviculture scenario, simulations under the high emission scenario resulted in increased AGB and diversity. Ultimately, these scenarios highlight the limitations and challenges of alternative management in the face of climate change. 
Figure 3.1: Northeastern Minnesota and northern lower Michigan study landscapes in northeastern United States.

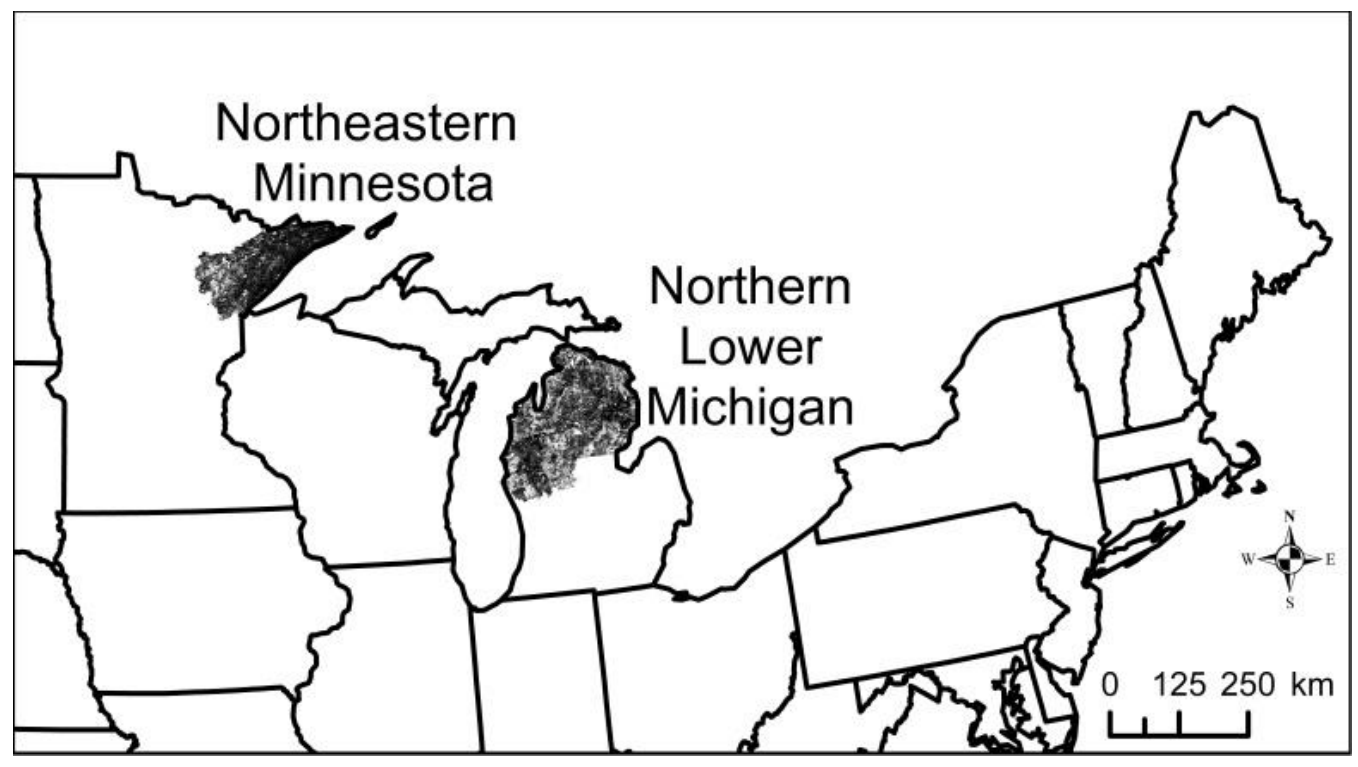


Figure 3.2: Forest ownership groups in northeastern Minnesota (A) and northern lower Michigan (B) under BAU management. Simulated forest reserve expansion in northeastern Minnesota (C) and northern lower Michigan (D) along river corridors and Great Lake shorelines. DNR= Minnesota and Michigan Department of Natural Resources, USFS=United States Forest Service, PNIF=Private Non-Industrial Forests, $\mathrm{PIF}=$ Private Industrial Forests.

A

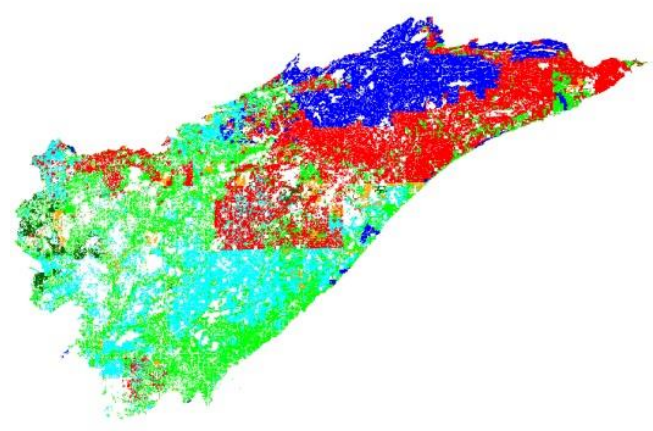

C

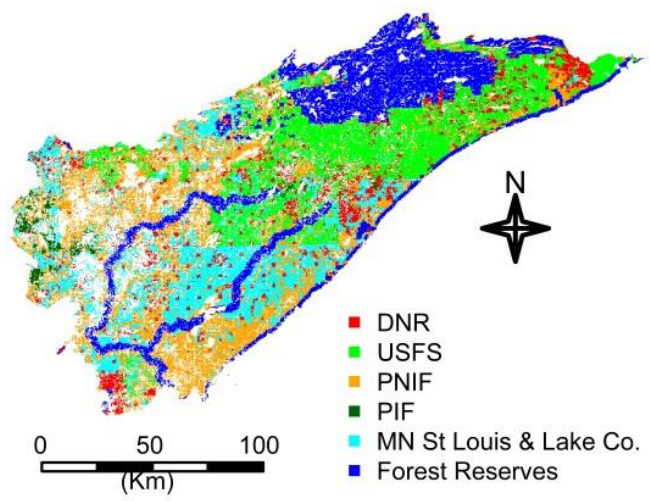

B

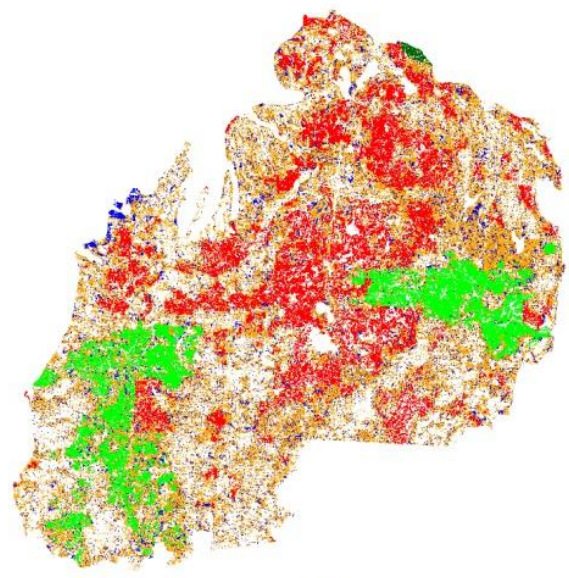

D

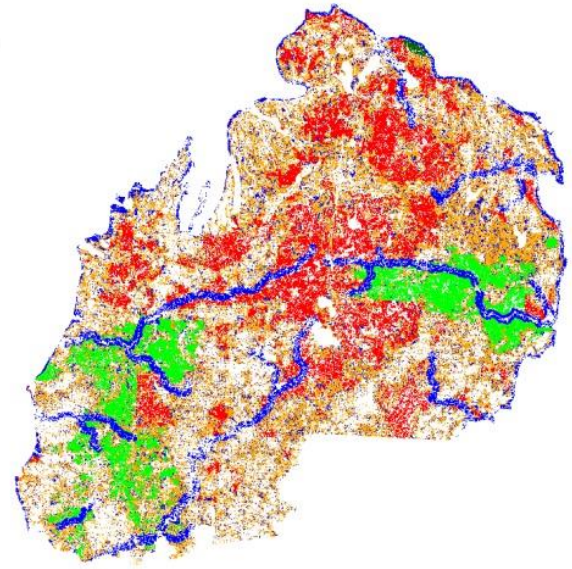


Figure 3.3: AGB $_{\text {TOTAL }}$ and $\mathrm{AGB}$ removed by timber harvest (Teragrams) on each landscape, for three management scenarios, and three climate scenarios over time.

\begin{tabular}{lll}
\multicolumn{1}{c}{ Current Climate } & Low Emissions Climate & High Emissions Climate \\
- BAU & - BAU & - BAU \\
- - Expanded Reserves & -- Expanded Reserves & - - Expanded Reserves \\
-..- Modified Silv. & -..- Modified Silv. & -..- Modified Silv.
\end{tabular}
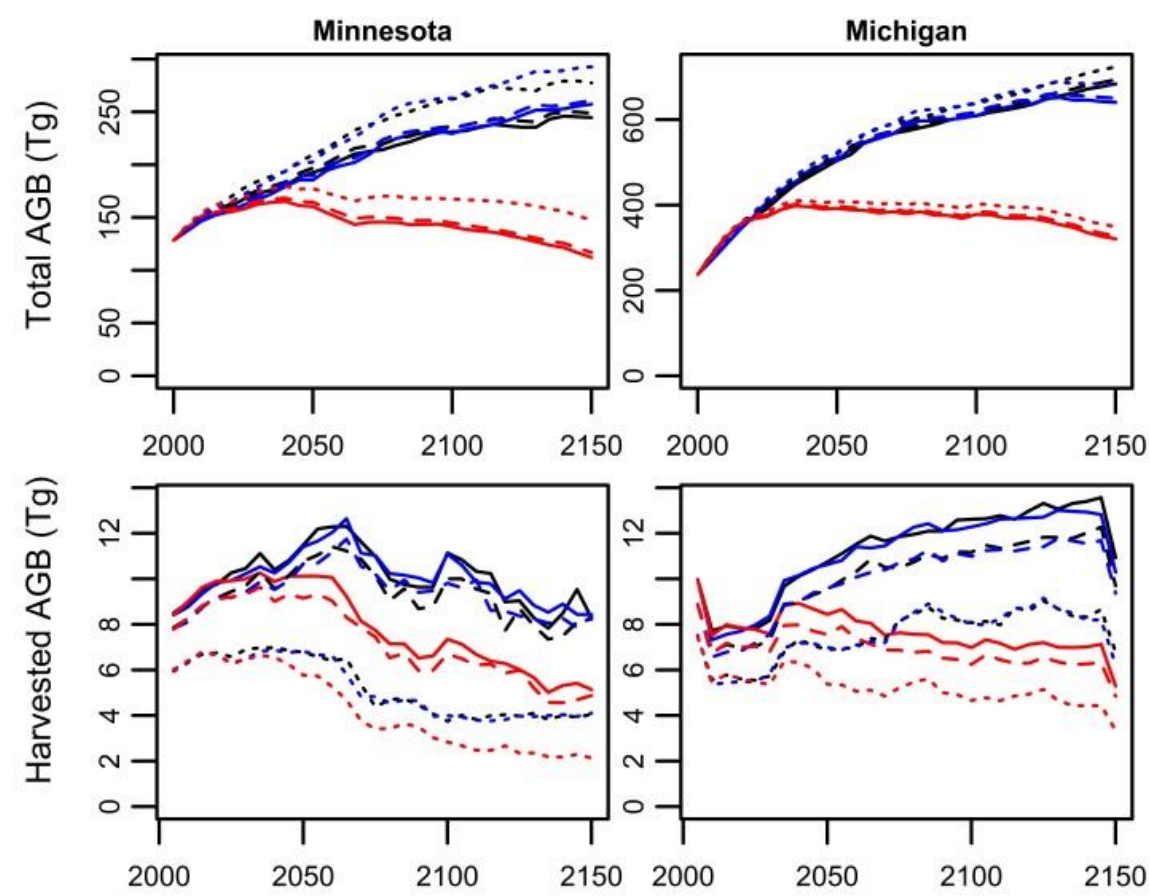
Figure 3.4: Average species AGB $\left(\mathrm{g} \mathrm{m}^{-2}\right)$ for select species over time across, climate, and management scenarios. Line type and colors match Figure 3.3 legend.
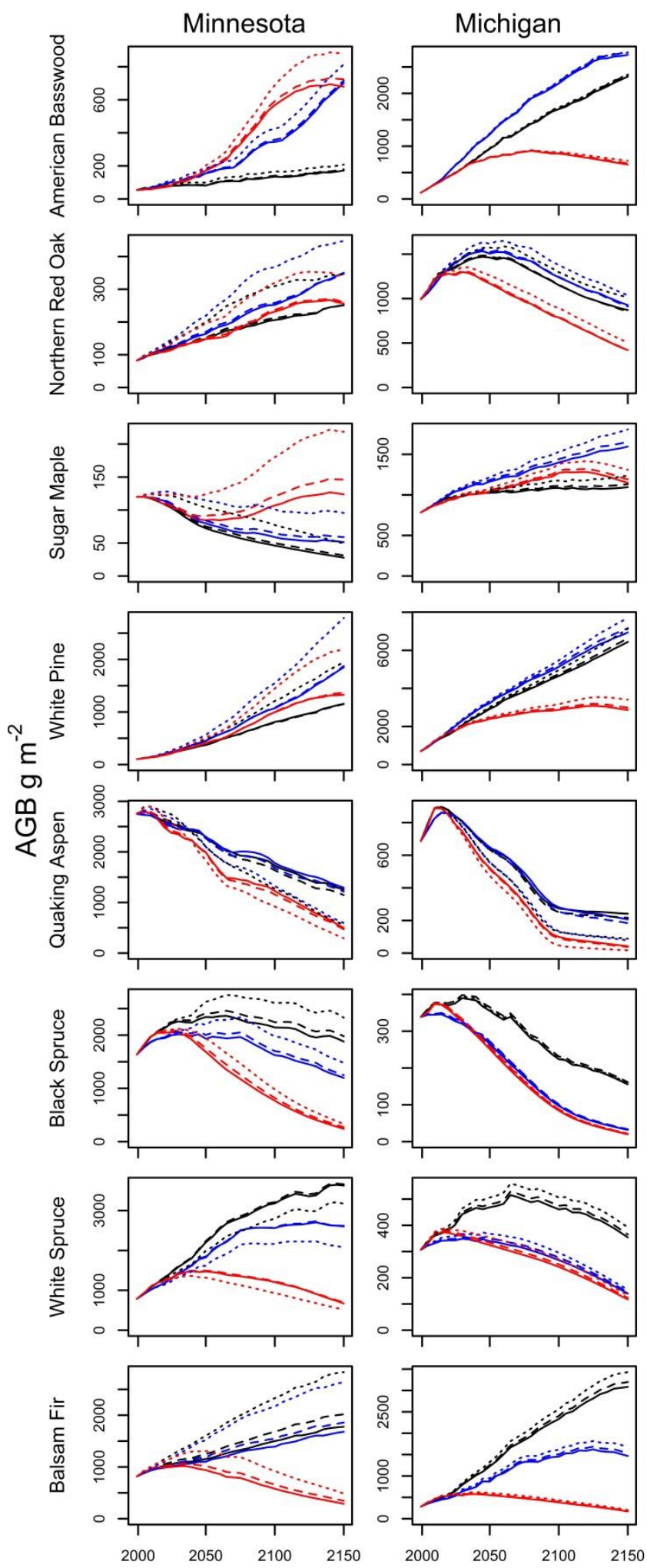
Figure 3.5: Average cell AGB TOTAL, AGB of spruce/fir species, and diversity within reserve areas and within actively managed forests in the Minnesota and Michigan landscapes across all climate scenarios. Diversity is represented as effective number of species $\left(\mathrm{e}^{\mathrm{H}^{\prime}}\right)$ calculated from Shannon index.
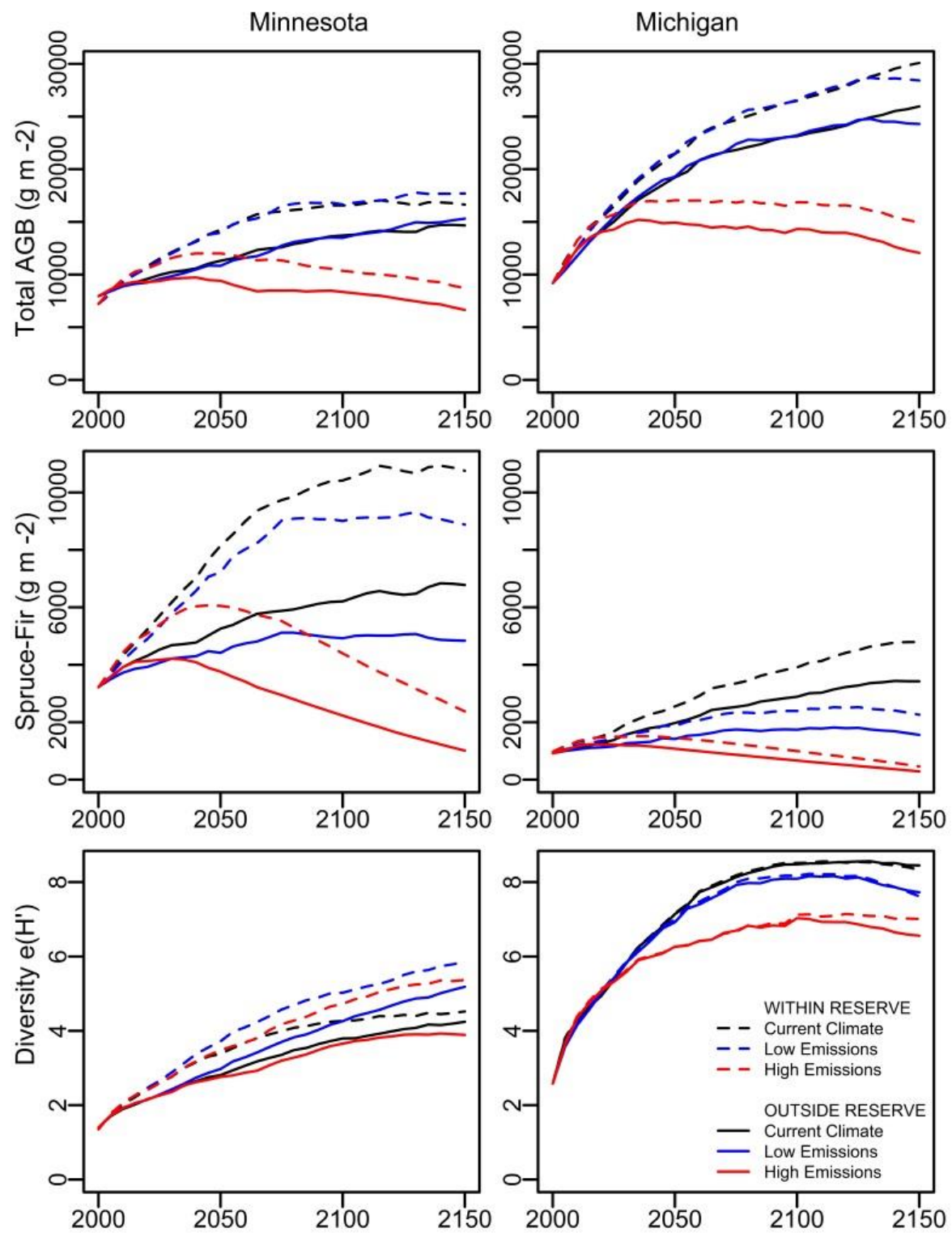
Figure 3.6: Average cell diversity across each landscape, climate, and management scenario from year 2050-2150. Diversity is represented as effective number of species $\left(\mathrm{e}^{\mathrm{H}}\right)$ calculated with the Shannon Index.
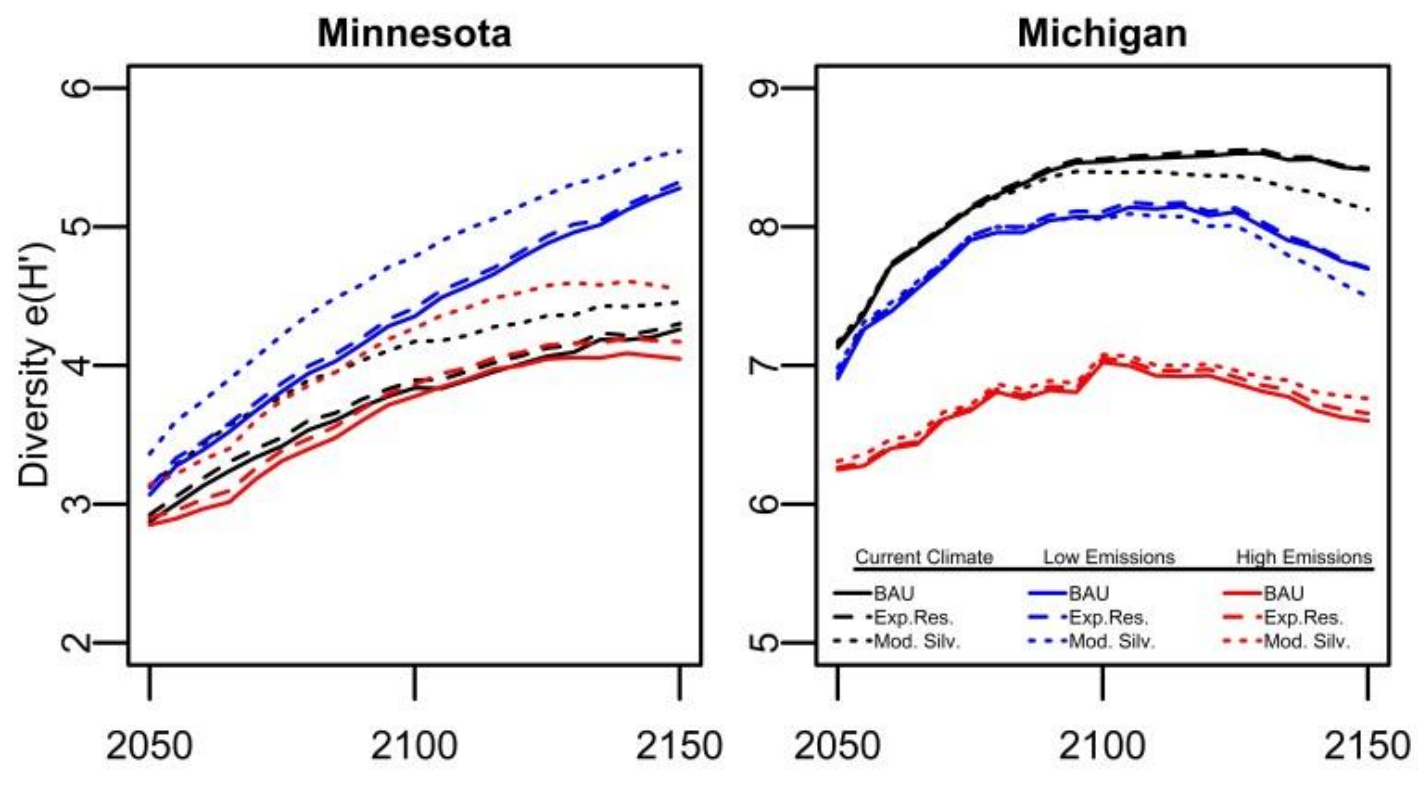
Figure 3.7: Northeastern Minnesota forest type maps at year 2150 for each climate and management scenario. Forest types represent dominant species associated with each forest type within each cell.
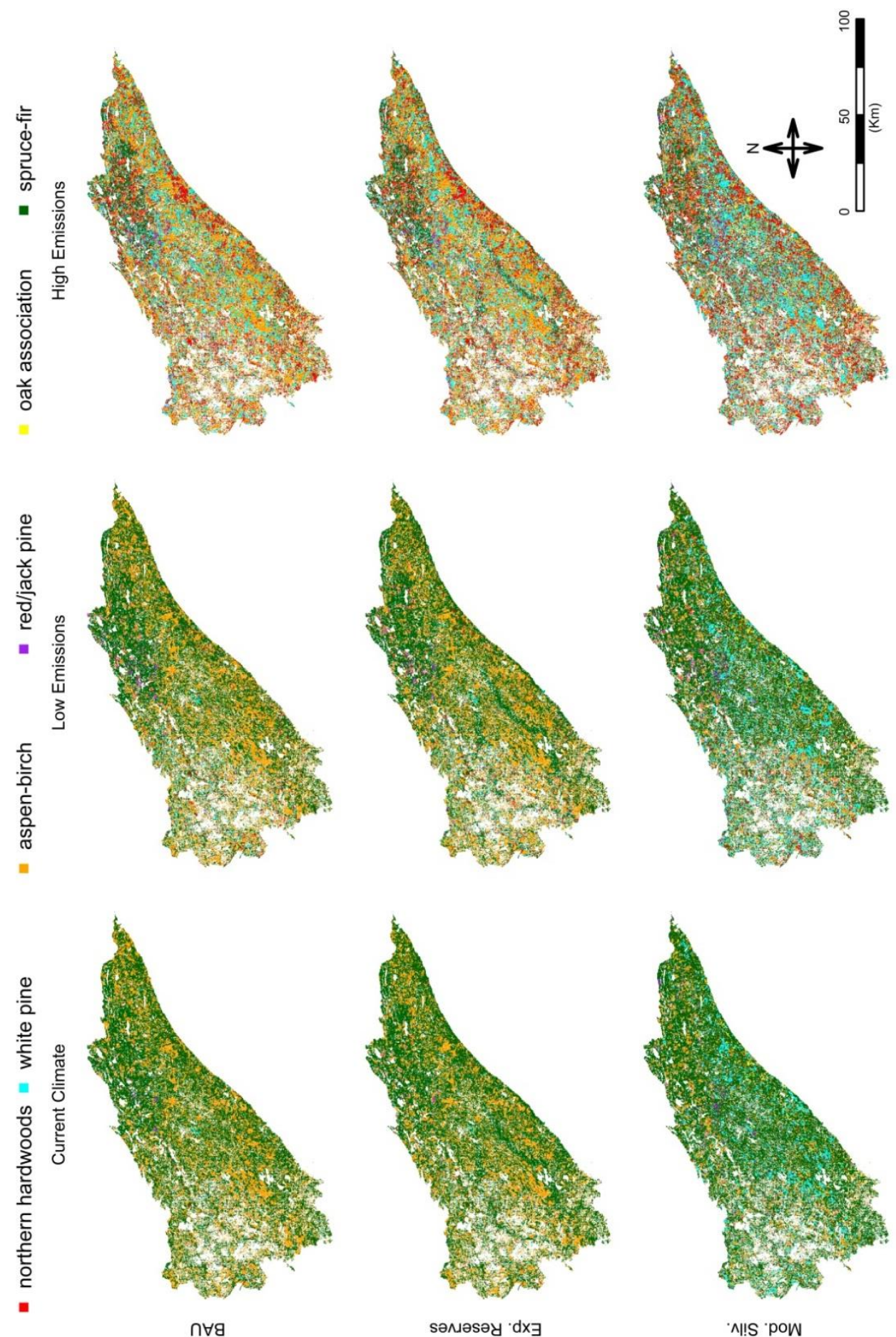


\title{
Chapter 4: Climate Change Effects to Productivity and Functional Diversity in Northern Great Lake Forests with Climate Suitable Planting.
}

\author{
ABSTRACT: \\ Within the timeframe of the longevity of common Great Lake tree species, \\ climate change will change faster than the ability of natural tree migration. Declines in \\ Annual Net Primary Productivity (ANPP) may be expected in forests under current \\ management and a high carbon emission climate future. I evaluated the efficacy of \\ planting climate suitable species (CSP), native to regions just south of my study \\ landscape, in order to maintain or increase aboveground biomass, ANPP, and species and \\ functional diversity. I modeled forest change with the LANDIS-II forest simulation \\ model under low and high emission scenarios in two landscapes in the Great Lake region \\ (northeastern Minnesota and northern lower Michigan). I included American chestnut \\ (Castanea dentata) under the assumption that commercially available seeds from disease \\ resistant strains will become available. I compared business as usual to CSP \\ management. I found that simulated CSP species, including American chestnut, \\ successfully established in both landscapes under all climate scenarios. I found that the \\ presence of CSP species generally increased simulated aboveground biomass, and ANPP. \\ Species diversity increased in both landscapes due to CSP; however the effect on \\ functional diversity was mixed. As the planted species were functionally similar to many \\ native species, CSP did not result in a consistent increase nor decrease in functional \\ diversity. These results provide an assessment of the potential efficacy and limitations of \\ CSP management.
}


KEYWORDS: (Michigan, Minnesota, LANDIS-II, climate suitable planting, functional diversity, Annual Net Primary Productivity)

\section{INTRODUCTION:}

Forest management for future climate conditions must accept and use new paradigms for continued success in delivering ecosystem services (e.g., carbon sequestration, biodiversity, biomass, and wildlife habitat). Restoration of forest species composition to a historical range of variability (HRV) (Landres et al. 1999) may not be a realistic goal (Hobbs et al. 2011). Despite adaptation strategies to manage for resilience (Seidl et al. 2011, Duveneck et al. in review), extant tree species may not be suitable for future establishment given their climate tolerances.

Within the next century, many tree species may not be capable of naturally migrating to more suitable sites at the rate of the changing climate (Scheller and Mladenoff 2008, Loarie et al. 2009, Bradshaw et al. 2010, Zhu et al. 2012, Diffenbaugh and Field 2013, Svenning and Sandel 2013). Even if suitable species are present or arrive in low abundance, a temporal lag is expected between arrival and expansion (Bradshaw and Lindbladh 2005, Wangen and Webster 2006, Birks and Birks 2008). Although this lag may not result in a species extirpation, the site or landscape may experience a decline in ecosystem services. There is growing interest to explore climate suitable planting (CSP) where tree species are planted beyond their current range (Marris 2009, Richardson et al. 2009). This alternative management prescription is designed to help facilitate migration while maintaining forest function (e.g., species diversity and carbon 
sequestration) (Millar et al. 2007, O’Neill et al. 2008). Given the lack of experimental work focused on climate suitable planting, landscape modeling provides a suitable and singular framework to assess the ability of CSP to overcome spatial and temporal barriers in forested ecosystems (Rehfeldt et al. 2006, Campbell et al. 2009).

\section{Climate Suitable Planting:}

Northeastern Minnesota and northern lower Michigan landscapes (Figure 4.1) provide island-like landscapes nearly surrounded by a combination of lakes, lowland conifer forests, and agricultural development along the boreal-temperate forest ecotone (Curtis 1959, Duveneck et al. accepted). If future climate conditions reduce the boreal spruce-fir forest type (Duveneck et al. accepted, Duveneck et al. in review), a decline in species and forest type diversity threatens the adaptive capacity of ecosystems. Fewer species will reduce the response capability of forests to changing environmental conditions (Walker 1992, Walker et al. 1999). In addition, low diversity forests are also more susceptible to single-host insect or disease outbreaks (Naeem and Li 1997, Bentz et al. 2010). Increasing or maintaining diversity in these forests may allow more climate change resilient forests (Chapin et al. 2007). This may be done by intensively planting a climate suitable species following a disturbance when an undesirable condition is otherwise possible (Spittlehouse and Stewart 2003).

Planting a desired extant native species may become increasingly difficult as climate changes (Ledig and Kitzmiller 1992), making species from outside the range of a site more desirable (O’Neill et al. 2008, Gray et al. 2010). Many northern and central hardwood species are abundant directly south of the landscapes in warmer climates (e.g., black oak (Quercus velutina) and bitternut hickory (Carya cordiformis)). These species 
are absent or low in abundance within the study landscapes (Burns and Honkala 1990), however may be considered suitable under climate change in the northern Great Lake region (Iverson et al. 2008). In order to consider CSP management, it is vital to consider the biotic interactions of novel ecosystems, ecosystems comprised of new species compositions (Blois et al. 2013). Assessing how these species might replace or expand niche space will provide a framework to evaluate the efficacy of CSP.

Rather than assisted migration for the refuge of a threatened species, maintaining a high level of function within a site or region may require new terminology and frameworks for success. A CSP prescription is designed to maintain or increase the ecosystem services of a site (e.g., biodiversity, carbon storage, timber products (Millar et al. 2007, O'Neill et al. 2008). These objectives are different from the interest to protect or save an endangered species (Barlow and Martin 2004, Hoegh-Guldberg et al. 2008, Lunt et al. 2013). Assisted migration proposals for the protection of rare and endangered species are fraught with controversy, including a concern caused by the negative effects if a species becomes invasive (Barlow and Martin 2004, McLachlan et al. 2007, Davidson and Simkanin 2008, Ricciardi and Simberloff 2009). Others however, have described potential benefits of non-native species. These benefits include providing functional substitutes for declining or extinct native species (Schlaepfer et al. 2011). For example, within intensively managed or degraded forests, CSP may be one of the only options to maintain ecosystem services (Lunt et al. 2013).

The agriculture community has a growing recognition of species suitability shifts as evidenced by the difference between the 1990 and 2012 plant hardiness maps (Daly et al. 2012). For silviculturists, this concept is familiar. Many commercial tree seedlings 
come from nursery stock grown in different regions of the country from where they are planted. Seedlings are selected based on the suitability matched by site conditions.

Given the longevity of tree species, forest managers are seeking information about future suitability of seedlings. Online tools such as the "Seedlot Selection Tool" have been developed to assist managers find climate suitable species for select sites based on projected future conditions (http://sst.forestry.oregonstate.edu/). As climate change uncertainty is high (IPCC 2007), simulation modeling of CSP is considered a vital component to understanding potential outcomes and choosing management alternatives regarding CSP (Pérez et al. 2012, Breed et al. 2013).

\section{American Chestnut Restoration:}

American chestnut (Castanea dentata) once was widespread throughout the midAtlantic United States (Russell 1987). The introduction of the Chestnut blight (Cryphonectria parasitica), first discovered in New York City in 1904, wiped out mature American chestnut throughout its range (Keever 1953, Lovett et al. 2006, Jacobs et al. 2013). Prior to the blight infection, American chestnut was considered a foundation species that is a species that has a strong role in structuring a community. American chestnut provided the central Appalachians region numerous ecosystem services such as fast growth (Jacobs et al. 2013), strong structural properties (Smith 2000), and important seed crops for wildlife (Youngs 2000).

Given the auspicious properties of American chestnut, there has been considerable interest and investment in restoring the species with a blight resistant hybrid (Smith 2000), likely available in the near future (The American Chestnut Foundation 2013). As a restoration species, recent research suggests that the species has the potential 
to fulfill much of its historical role as a foundation species (Gauthier et al. 2013, Jacobs et al. 2013). As climate has changed and will likely continue to change since American chestnut dominated the canopy of Eastern forests (Andresen et al. 2012), assessing landscape and site conditions for habitat suitability will be vital for reintroduction success. In the northern Great Lake region, disease resistance chestnut seedlings have successfully established within experimental plots (Jacobs and Severeid 2004).

\section{Species and Functional Diversity:}

Species diversity is recognized as having a strong tie to potential ecosystem services (Tilman et al. 2006, Duveneck et al. accepted). As an alternative to species diversity, functional diversity (FD) based on functional traits has proven to be a useful measure of diversity. Rather than individual species, FD is based on the range of ecological functions provided by a community (Cornelissen et al. 2003, Laliberté and Legendre 2010). There is strong evidence that FD is a driver to ecosystem resilience (Folke et al. 2004b) and ecosystem services (Díaz et al. 2007, Mokany et al. 2008). Rather than counting species or groups of species, FD is based on user defined a priori traits (Villéger et al. 2008, Laliberté and Legendre 2010). For example, two separate species with identical user defined traits would contribute the same FD as one species. By definition, individual species are different from one another. Therefore, it is important to consider traits that effect potential ecosystem functions of interest (e.g., nutrient cycling, carbon storage, carbon sequestration, and wildlife habitat) (Cornelissen et al. 2003).

My objectives were to assess the efficacy of CSP to increase aboveground biomass (AGB), aboveground annual net primary productivity (ANPP), and species and 
functional diversity of northern Great Lake forests. Specifically, I addressed the following questions: 1) As an alternative to business as usual (BAU) management, how might CSP under climate change effect AGB and ANPP? 2) Assuming future availability of disease resistant American chestnut, how might American chestnut and other oaks and hickories respond in northern Great Lake landscapes? 3) As a surrogate for future ecosystem services, how might CSP affect functional and species diversity under climate change?

\section{METHODS:}

\section{Study Area:}

I selected two landscapes in the northern Great Lake region within the borealtemperate transition zone (i.e. northeastern Minnesota and northern lower Michigan) (Figure 4.1). I choose this region as the climate (IPCC 2007) and forests (Fisichelli et al. 2013, Duveneck et al. accepted) are expected to change substantially. By the end of the $21^{\text {st }}$ century, temperatures in the region are expected to increase by $3-11^{\circ} \mathrm{C}$ (Kling et al. 2003). In addition, these landscapes are naturally bounded by fragmentation, large bodies of water, and boreal-swamp forests (to the north of northeastern Minnesota) creating island-like conditions. For these reasons, I expect new species moving into these landscapes to be limited. I leveraged previous work in the region to parameterize natural disturbance regimes, initial species composition conditions, and BAU silviculture prescriptions (Duveneck et al. accepted). 


\section{Simulation Model and Experimental Design:}

My experimental design included both BAU and CSP management. For each management scenario I assessed three climate scenarios: 1) current climate, 2) low emissions, and 3) high emissions future. For all simulations I used a 150-year time horizon starting at year 2000 and two-hectare cell resolution. In order to make my results more comparable to prior research in the region, I used consistent methodology whenever possible between this study and prior research (Duveneck et al. accepted, Duveneck et al. in review).

I modeled forest change using the LANDIS-II v6.0 forest landscape model at five-year time steps (Scheller et al. 2007a). LANDIS-II is a spatially explicit landscape change model. Driven by ecological processes, LANDIS-II can be run at multiple temporal and spatial scales, and has been widely used (Gustafson et al. 2010, Ravenscroft et al. 2010, Thompson et al. 2011). Processes included within the LANDIS-II modeling framework include tree species establishment, growth, mortality, and seed dispersal; fire; wind; and timber harvesting. These processes interact spatially and functionally across interconnected cells within climate and soil regions on a landscape.

I used the PnET-II for LANDIS-II tool (PnET) (Xu et al. 2009) to calculate species-specific parameters (i.e. Maximum Aboveground Net Primary Productivity per year $\left(\mathrm{ANPP}_{\max }\right)$, and Probability of Establishment $\left.\left(\mathrm{P}_{\mathrm{est}}\right)\right)$. These parameters are a function of climate (temperature, precipitation, and photosynthetic active radiation (PAR)) along with Soil Water Holding Capacity (SWHC), and species-specific physiological parameters (e.g., foliar nitrogen content, and maximum foliar mass area). I employed the PnET-II tool for each unique climate-soil region (Duveneck et al. 
accepted).

LANDIS-II is built around a core modeling structure that incorporates processes such as seed dispersal. The core interacts with user-chosen extensions of varying complexity. I used the LANDIS-II Biomass Succession extension (v3.1), which regulates the succession mechanisms of growth, reproductive maturity, and age-related mortality for species-cohorts (Scheller and Mladenoff 2004). The PnET output parameters $\mathrm{ANPP}_{\max }$ and $\mathrm{P}_{\mathrm{est}}$ are utilized directly by the Biomass Succession extension. $\mathrm{ANPP}_{\max }$ regulates the maximum growth possible of above ground biomass for a species-cohort (Scheller and Mladenoff 2004). $\mathrm{P}_{\text {est }}$ determines the probability of a new cohort establishing given a local seed source and adequate light (Xu et al. 2009).

I directly simulated harvesting, fire, and wind disturbances. I used the Biomass Harvest extension (v2.1) to simulate harvest and planting prescriptions (Gustafson et al. 2000, Syphard et al. 2011). I applied specific prescriptions to unique management areas, described previously (Duveneck et al. accepted). These management areas are based on ownership groups (i.e. state, county, United States Forest Service, private industrial, private non-industrial, and forest reserve areas). I delineated harvest stands within each management area to represent the range and variability of current stands within specific forest types. For each 5-year time step, multiple unique prescriptions were implemented. First, the biomass harvest extension selects stands for treatment based on a user defined stand ranking. Next, biomass is harvested from cells within stands based on prescription specific criteria. Specific rotation periods, within each management area define the proportion of the management area to be treated at each time step. (Gustafson et al. 2000). I simulated natural fire and wind disturbance utilizing the Base Fire (v3.0) (He 
and Mladenoff 1999), and Base Wind (v2.0) (Scheller and Mladenoff 2004) extensions. To quantify spatially-explicit species Aboveground Biomass (AGB) $\left(\mathrm{g} \mathrm{m}^{-2}\right)$ I used the Biomass Output extension (v2.0). I utilized previously developed initial communities, fire and wind regimes, BAU timber harvest regimes, delineated ecoregions, and PnET-II parameters (Duveneck et al. accepted).

\section{Climate Data:}

I simulated current climate by randomly assigning observed monthly PRISM climate data (from 1969 to 1999) to future simulation years (Daly and Gibson 2002). I simulated a low emission climate future with the IPCC B1 emission scenario (IPCC 2007)and the Parallel Climate Model (PCM) Global Circulation Model (GCM) (Washington et al. 2000) . I simulated a high emission climate future with the IPCC A1FI emission scenario (IPCC 2007) and the Geophysical Fluid Dynamics Laboratory (GFDL) GCM (Delworth et al. 2006). Climate projections from the PCM GCM are considered less sensitive to emissions than the GFDL GCM. I bracketed a large range of plausible futures by coupling the emission scenarios to the GCM's. In addition, these GCM emission scenario combinations are being used in other research in the region providing model projection consistency (Handler et al. in press-a, Handler et al. in pressb).

For each unique climate region (Duveneck et al. accepted), I accessed downscaled monthly climate data through the USGS data portal http://cida.usgs.gov/climate/gdp/ (Stoner et al. 2012). The IPCC projections include climate data to year 2100 (IPCC 2007). In order to simulate forest change to year 2150 , I interpolated the final 50 years of climate data (maximum and minimum temperature, precipitation, and PAR) based on the 
variability within the original 100 years of data. For, temperature projections, I

incorporated a regression component based on the increasing trend in the initial 100 years of climate projections using the Amelia library in R (R Development Core Team 2011).

\section{Climate Suitable Planting:}

With the exception of American chestnut, I selected species with current ranges directly south or rare within the study landscapes (Burns and Honkala 1990). In northeastern Minnesota, I simulated planting American chestnut, bitternut hickory, black oak, and northern pin oak (Quercus ellipsoidalis). In northern lower Michigan, I simulated planting American chestnut, bitternut hickory, shagbark hickory (Carya ovata), and scarlet oak (Quercus coccinea).

The CSP prescriptions were implemented within existing harvesting regimes and management areas (Duveneck et al. accepted). CSP prescriptions were only simulated in actively managed forests, excluding reserve areas such as the Boundary Waters Canoe Area Wilderness in Minnesota. Specifically, I simulated CSP following patchcutting harvest prescriptions in northern hardwood stands. Compared to BAU management, I simulated a fourfold frequency increase in implementing the northern hardwoods patch cutting prescription. The planting intensity resulted in a target planting of 5.28 and 4.97 percent of forested cells per five year time step in the Minnesota and Michigan landscapes, respectively. This equates to planting approximately 17,111 and 22,180 hectares per year in the Minnesota and Michigan landscapes, respectively.

\section{Species and Functional Diversity:}

As a measure of species diversity, I calculated the Shannon Index of diversity (H') (Gotelli and Ellison 2004). I calculated H' within each landscape, utilizing species 
abundance (i.e. simulated AGB of individual tree species). I transformed H' to the effective number of species $\left(\mathrm{e}^{\mathrm{H}^{\prime}}\right)$ as the number of species present if all species were equal in abundance. This transformation reduces inaccuracies when comparing diversity between scenarios (Jost 2006).

I calculated functional diversity within each landscape with the functional dispersion (FDis) index (Laliberté and Legendre 2010). FDis is the spread of species in a trait-dimensional space (Anderson et al. 2006). Specifically, FDis is the weighted (by abundance) mean distance of species traits in multidimensional space to the centroid of all species. FDis is a flexible FD framework allowing both quantitative and qualitative traits, more traits than species, and the ability to weight individual traits. FDis is not strongly influenced by outliers as it takes into account relative abundance (Laliberté and Legendre 2010). To calculate FDis in my landscapes, I represented abundance as simulated tree species AGB. I utilized a species trait matrix used in previous research (Paquette and Messier 2011). I added species to the trait matrix that were unique to my study however; I did not adjust traits obtained from Paquette and Messier (2011). Specific species traits included: maximum height, growth rate, leaf size, longevity, foliar mass per area, foliar nitrogen content, wood density, decay resistance, vegetative reproduction, seed mass, pollination vector, mycorrhizal infection type, shade tolerance, drought tolerance, and water-logging tolerance (See Appendix: Table A8).

\section{Analysis:}

I compared aboveground ANPP and diversity of BAU management to CSP management under each climate scenario. I calculated diversity for every cell in a simulation and created raster files for each diversity index and scenario. I used these 
raster files and LANDIS-II ANPP output raster maps for further spatial analysis. Under the CSP management scenario, I selected cells within actively managed forests. Of the actively managed cells, I separated sites where CSP species were present vs. absent to compare ANPP. I used the vegan-community ecology, FD functional diversity, and raster libraries in $\mathrm{R}$ (R Development Core Team 2011) for all calculations and analysis.

I replicated each simulation five times in order to examine the stochastic variation within scenarios. The model stochastic behavior was largely driven by natural disturbances of fire and wind. The low stochastic variation of natural disturbance events relative to the size of the landscapes resulted in a maximum variance in mean replicate AGB at year 2150 compared to replicate AGB of $<2 \%$ for each scenario. Therefore, I randomly selected one replicate from each simulation for additional analysis. While strict validation of future simulation results is not possible, species-specific parameters used in PnET-II and the Biomass Succession extension to LANDIS-II have been evaluated in other northern Great Lakes landscapes (Scheller and Mladenoff 2004, Xu et al. 2007, Ravenscroft et al. 2010). Furthermore, I evaluated LANDIS-II simulated AGB to USFS Forest Inventory \& Analysis field plot estimates of AGB in northern lower Michigan (Pearson's correlation of 0.64 , and RMSE of $44.3 \mathrm{Mg} \mathrm{ha}^{-1}$ ). Details of my biomass evaluation are described in Duveneck et al. (accepted).

\section{RESULTS:}

\section{Aboveground Biomass and Annual Net Primary Productivity}

The high emissions climate scenario resulted in substantially less simulated total AGB compared to current and low emissions climate scenarios by year 2150. CSP management resulted in a projected increase in total AGB compared to BAU 
management (Figure 4.2A). In the Minnesota landscape, AGB at year 2150 increased under the CSP scenario by $12 \%, 13 \%$ and $38 \%$ in the current, low emissions, and high emissions climate scenario, respectively. In the Michigan landscape, where less total AGB was simulated in general, AGB at year 2150 increased less under the CSP scenario (3\%, $4 \%$ and $12 \%$ in the current, low emissions, and high emissions climate scenario, respectively). In the Minnesota landscape, each climate scenario resulted in a similar increase in total AGB due to CSP. In the Michigan landscape, the increase in AGB due to CSP was most pronounced in under the high emissions climate scenario. Harvested AGB followed a similar pattern to total AGB. As simulated planted species matured to a merchantable age, more simulated biomass was harvested compared to BAU management (Figure 4.2B). The initial increase in harvested biomass in the Michigan landscape due to CSP is due to an increase in implementation frequency of the northern hardwoods patch cutting prescription necessary to implement the CSP treatment.

In each simulated landscape, CSP species established and increased in AGB through time (Figure 4.3). The current and low emission climate scenario generally resulted in larger increases in CSP species AGB compared to the high emissions climate scenario. The Michigan landscape resulted in larger climate scenario effects and larger increases in CSP species AGB compared to the Minnesota landscape. Of the planted species, American chestnut and bitternut hickory resulted in the largest increases in simulated AGB by year 2150 .

Like AGB, aboveground ANPP declined more under the high emission scenario compared to the current and low emission scenario (Figure 4.4). Although both landscapes resulted in similar ANPP at year 2150, the Minnesota landscape started with 
higher ANPP, and resulted in larger declines. In both landscapes the effect of CSP resulted in increases in simulated ANPP in both climate change scenarios after year 2100 compared to BAU management. The increases due to CSP under the high emissions climate scenario however, did not equal simulated ANPP under current climate and BAU management.

Although AGB of CSP species increased less in the high emission scenario, the proportion of cells occupied by CSP species increased more in the high emission scenario followed by the low emission and current climate (Figure 4.5A). Compared to actively managed cells unoccupied by CSP species, actively managed cells occupied by CSP species resulted in an increase in simulated aboveground ANPP under the high emissions climate scenario after year 2100 (Figure 4.5B). The results of the current and low emissions climate scenario were mixed. Simulations in the Minnesota landscape resulted in generally reduced ANPP within CSP occupied sites compared to unoccupied CSP sites within the current and low emissions climate scenario. After year 2100, the Michigan landscape had an increase in simulated ANPP within CSP occupied sites compared to unoccupied CSP sites within the current and low emissions climate scenario. The initial lower simulated aboveground ANPP in CSP species cells is expected due to the delayed growth in young cohorts. As the initial planted species mature, the effect of the growth lag in young cohort cells is reduced.

\section{Species and Functional Diversity:}

The CSP scenario resulted in an increase in simulated species diversity $\left(\mathrm{e}^{\mathrm{H}}\right)$. The increase in species diversity due to CSP was found in both landscapes under all climate scenarios and time steps (Figure 4.6). In the Minnesota landscape, the CSP scenario also 
resulted in an increase in FDis in all climate scenarios. The CSP scenario however, reached an asymptote after 2050 while functional diversity under the BAU scenario continued to increase. In the Michigan landscape, where initial functional and species diversity was higher, CSP resulted in a decrease in functional diversity in all climate scenarios.

In the Minnesota landscape, the high emissions climate scenario generally resulted in the largest increase in both species and functional diversity. Nevertheless, the increase in species diversity under the high emissions climate scenario diminished and slightly decreased after year 2120 . These results are in contrast to the current and low emissions climate scenarios which resulted in a consistent, although slower increase in species diversity through time. The Michigan landscape resulted in higher initial diversity than Minnesota, however resulted in decreased species diversity over time. The Michigan landscape resulted in relatively consistent FDis over time. The high and low emissions climate scenario resulted in less species diversity than current climate. The high emissions climate scenario however, resulted in the highest functional diversity in the Michigan landscape.

\section{DISCUSSION:}

In some sites, CSP management may provide an opportunity to increase ecosystem services such as AGB, ANPP, and diversity under climate change. CSP may be most effective in sites or landscapes when otherwise large declines in productivity are expected. With enough time (e.g., 1000 years), species may maintain equilibrium with climate (Webb 1986). At shorter time scales (e.g., 100 years), however climate is expected to change faster than species ability to maintain equilibrium (Diffenbaugh and 
Field 2013, Svenning and Sandel 2013). Forest management is often focused at rotation period time scales (i.e. < 100 years). The ability to maintain forest ecosystem services at those time scales is expected to be limited within traditional (Duveneck et al. accepted) and even alternative management (without the use of CSP) (Duveneck et al. in review).

\section{Aboveground Biomass and Annual Net Primary Productivity}

As reported earlier (Duveneck et al. accepted), under high emissions climate and BAU management, my scenarios suggest a large decline in simulated total and harvested AGB (Figure 4.2) as well as ANPP (Figure 4.4 and 4.5B). The increase in ABG and ANPP due to CSP suggests that planting climate suitable species may increase the persistence of forests to the effects of climate change. The increases in AGB and ANPP are small in relation to the treatment intensity. Planting intensity was 5.28 and 4.97 percent of each landscape at each five year time step in the Minnesota and Michigan landscapes, respectively. This suggests that the CSP scenario did not grossly expand the current niche space used by extant tree species. Although the species selected for planting are native to regions south of the landscape, the high emissions climate scenario did not result in the most optimized climate selection for those species (Figure 4.3). Had I simulated planting species from even further south, I expect to have simulated more use of niche space resulting in larger increases in AGB and ANPP under the high emissions climate.

The CSP treatment was implemented following patch cutting harvests. The initial decrease in ANPP within CSP cells is due to the expected lag in growth response of young cohorts (Bowler et al. 2012). Compared to older stands, ANPP of recently harvested sites would expect to lag behind for a few years before increasing. Although 
the non CSP occupied cells were also vulnerable to disturbance, the majority of non CSP cells were mature stands. Nevertheless, average ANPP within CSP sites surpassed unoccupied CSP sites after year 2050 despite continual harvesting and new planting throughout the simulation.

The effect of CSP on ANPP was limited in the current and low emission compared to the high emission climate scenario. Both the largest increase in proportion of cells occupied by CSP species (Figure 4.5A) and the largest decline in AGB (Figure 4.2) and ANPP (Figure 4.4) under BAU management were found under the high emissions climate scenario. Under the high emission climate scenario, CSP species would have replaced species declining under climate change (e.g., balsam fir (Abies balsamea) and black spruce (Picea mariana)) that would otherwise be abundant under current climate (Duveneck et al. accepted). This supports the suggestion that CSP may be most appropriate where large declines in productivity are expected (Lunt et al. 2013). Although the CSP scenario increased AGB less under high emissions climate than current and low emissions climate, CSP did increase total and harvested AGB under the high emissions climate scenario where the largest declines were simulated (Figure 4.2). This suggests a net benefit in some ecosystem services under the CSP scenario.

\section{Species and Functional Diversity:}

As expected, planting new species increased species diversity (Figure 4.6). In addition to inherent benefits of maintaining biodiversity (e.g., more species are less vulnerable to single host pathogens) (Wilson 2010), increasing diversity has potential to enhance the range of environmental tolerances of the ecosystems providing ecosystem services (Walker 1992, Naeem and Li 1997). Within lower productivity sites, the 
relationship between diversity and productivity may become more important (Loreau et al. 2001, Paquette and Messier 2011, Duveneck et al. accepted). Furthermore, under a high emissions scenario, my results suggest productivity and AGB declines are expected. CSP was more effective at increasing functional diversity in Minnesota than Michigan. Where initial species diversity was lower and decline in productivity was higher (Minnesota), CSP increased functional diversity compared to BAU management. Over 150 simulation years of high emissions however, FDis under the BAU scenario surpassed FDis under the CSP scenario. This may be due to a simulated decrease in initially dominant species under BAU (e.g., balsam fir and quaking aspen) (Duveneck et al. accepted). As these species declined, the simulated response of less dominant species became more equal increasing FDis but decreased AGB and ANPP.

Where initial species diversity was higher and decline in productivity was less (Michigan), FD under CSP management declined compared to BAU management (Figure 4.6). In the Michigan landscape, the CSP scenario may have replaced functionally dissimilar species while increasing functionally similar species. Therefore, landscapes expected to decline in productivity and diversity may have more opportunity for effective climate management such as climate suitable planting. Landscapes with less productivity and diversity declines expected may be better poised to naturally adapt to climate change without active management. These results may help managers prioritize allocation of scarce resources to areas more critically vulnerable than others.

Given the controversy regarding assisted migration (Lawler and Olden 2011) and the social limits to change (Adger et al. 2009), I choose CSP species based on close proximity to my landscapes. This resulted in species that were functionally similar (i.e. 
functionally redundant (Walker 1992)) to the species expected to persist under climate change (i.e. northern hardwoods and oaks). As such, CSP under the high emissions climate did not maintain an increase in functional diversity. Under BAU management and high emission climate, I expect a decline in spruce-fir species in these landscapes (Fisichelli et al. 2013, Duveneck et al. accepted). Had I simulated planting central Appalachian conifers such as shortleaf pine (Pinus echinata), I would have likely seen a larger and sustained increase in functional diversity under climate change. Future work should consider exploring CSP treatments based on function replacement. Nevertheless, functional diversity generally increased through time and was highest under the high emission climate scenario in both landscapes (Figure 4.6).

\section{Management Challenges to Climate Suitable Planting:}

Much discussion in the literature has centered on the debate for or against assisted migration (McLachlan et al. 2007, Hoegh-Guldberg et al. 2008, Ricciardi and Simberloff 2009, Lawler and Olden 2011). Most of this discussion has centered around movement for rare or endangered species protection (e.g., (Barlow and Martin 2004). Less discussion has explored movement of species in order to maintain or increase ecosystem function of a site or region (Lunt et al. 2013). I recognize the risks of introduced species becoming invasive (Hoegh-Guldberg et al. 2008, Ricciardi and Simberloff 2009); however the potential for novel ecosystems under climate change is unavoidable (Williams et al. 2007, Hobbs et al. 2009). In addition, benefits from ecosystem services from managed non-native species are plausible (Lugo 2004, Schlaepfer et al. 2011). Restoring a specific species or forest type may not be obtainable, however maintaining a more general ecosystem service (e.g., AGB) may be (Buma and Wessman 2013). 
Regardless of management limitations surrounding CSP, my results provide a modeling component of outcomes which is recognized as an important piece to decision support for CSP (Gray et al. 2010, Lawler and Olden 2011, Pérez et al. 2012).

Existing guidelines for genetic forest management minimize the movement of genetic material to avoid contamination of populations with poorly adapted genotypes (Millar et al. 2007, Breed et al. 2013). These guidelines were developed under the assumption that climate and the environment was stationary. Resampling commongarden experiments have demonstrated that native seed stock can be poorly adapted to changing climate (Millar and Brubaker 2006). Expanding guidelines for seed zone sizes based on the non-static and uncertain future should be considered (Breed et al. 2013).

\section{Uncertainty and Model Limitations:}

CSP represents a more radical climate change management strategy than previous work described (i.e. (Ravenscroft et al. 2010, Duveneck et al. in review)). My CSP scenarios were not intended to be a "recipe-book" for CSP, rather an introduction to understanding a management alternative. My results should not be interpreted as predictions but plausible futures with large uncertainty. There exists a large amount of variation across GCM and emission projections (IPCC 2007). Beyond year 2100, my climate scenarios include interpolation of climate which encompass additional uncertainty (Duveneck et al. accepted). My low and high emission scenarios were designed to bracket GCM and emission uncertainty, however, carbon emissions have been observed at or above the high emission scenario I used (Jennings 2012, Peters et al. 2012), suggesting that my low emissions climate scenario is grossly under estimating the climate change trajectory. 
In addition to climate uncertainty, there exist ecological processes that I did not include in my modeling framework. In addition, model parameters were based on the best available input data. Future empirical research will reduce parameter uncertainty. I did not include the fertilization effect of rising $\mathrm{CO}_{2}$ concentration. While I recognize that increasing $\mathrm{CO}_{2}$ will positively affect photosynthesis (Norby et al. 2005), limits to growth such as nitrogen (Luo et al. 2004) or ozone (Ainsworth et al. 2012) may diminish the positive effects. I did not consider browse damage by white-tailed deer (Odocoileus virginianus) which can severely limit regeneration and growth of seedlings (Fisichelli et al. 2012, Nuttle et al. 2013). I also did not directly model effects of insects such as spruce budworm (Choristoneura fumiferana) (MacLean and Ostaff 1989). As many forest damaging insects are single host specific, the interaction of management on diversity combined with insect damage represent important opportunities for future research. Finally, BAU forest management represents my best guess at current silviculture practices (Duveneck et al. accepted). Future management will depend on difficult to predict landowner objectives, market fluctuations, and changing ecosystem service priorities.

\section{CONCLUSIONS:}

For forests and other landscapes that are substantially degraded or disturbed, restoration treatments are often implemented with an objective to restore conditions to pre-disturbance conditions within a historical range of variability (HRV) (Landres et al. 1999). Hobbs et al. (2011) suggest "intervention" ecology as a more direct and meaningful strategy than restoration. Rather than considering restoration to a historical range of variability, intervention ecology can consider expected future ranges of 
variability (Harris et al. 2006). Tradeoffs exist however, between preserving (to what once was) and adapting (to what is possible) (Marris 2009, Buma and Wessman 2013). HRV continues to contain important information as many organisms still depend on habitats represented by the HRV. For example, CSP may increase the adaptive capacity of a forest's ANPP, however outcompete or reduce habitat for a vulnerable native species (Ackerly 2003). Ideally, tradeoffs can be managed through CSP treatment intensity, allowing some areas reserved for historic processes and species (e.g., Duveneck et al. in review).

As pressures for increased agriculture develop (Wheeler and von Braun 2013), further fragmentation of forest land (due to agriculture) may further limit seed dispersal (Scheller and Mladenoff 2005, Iverson et al. 2008). In more fragmented landscapes, interest in CSP may increase. Finally, a future increase in the value of carbon sequestration to mitigate climate change may provide more impetus to manage forests to maximize ANPP. 
Figure 4.1: Management areas (i.e. ownership groups) within landscape study areas in northeastern Minnesota and northern lower Michigan.

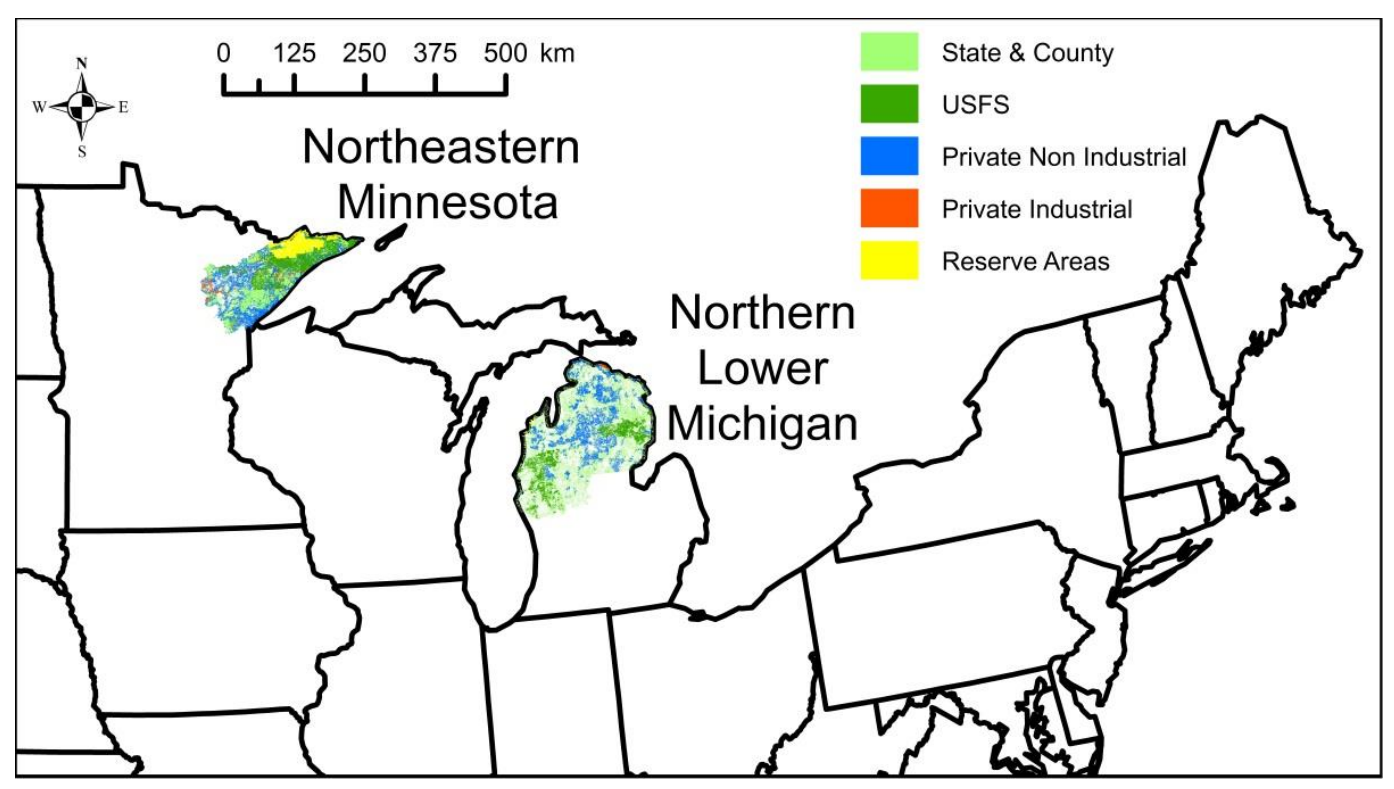


Figure 4.2: Simulated (A) $\mathrm{AGB}_{\text {total }}$ and (B) harvested AGB over time for each landscape, climate, and management scenario.
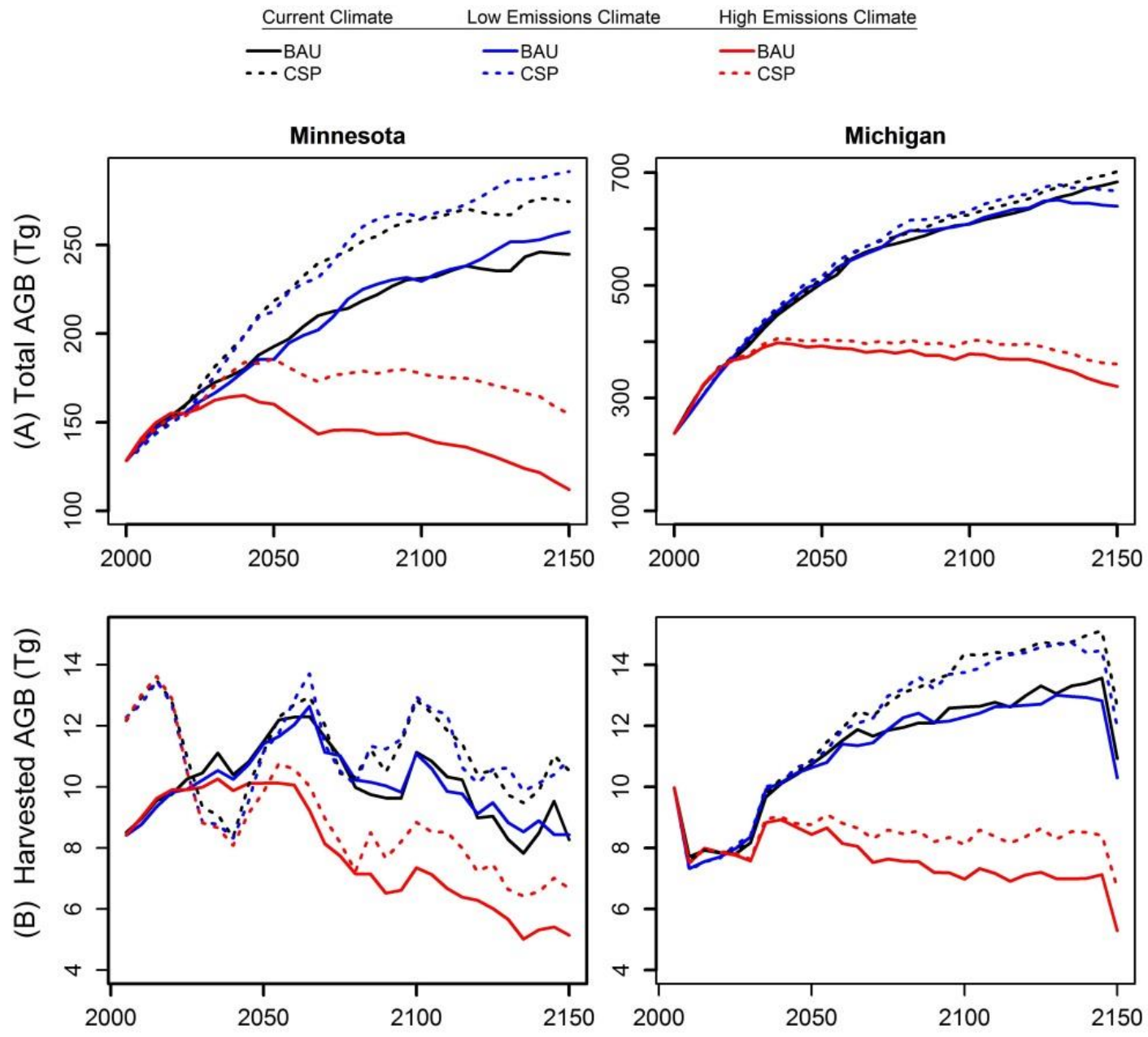
Figure 4.3: AGB of CSP species simulated in each landscape and climate scenario. American chestnut and bitternut hickory were simulated in both landscapes.

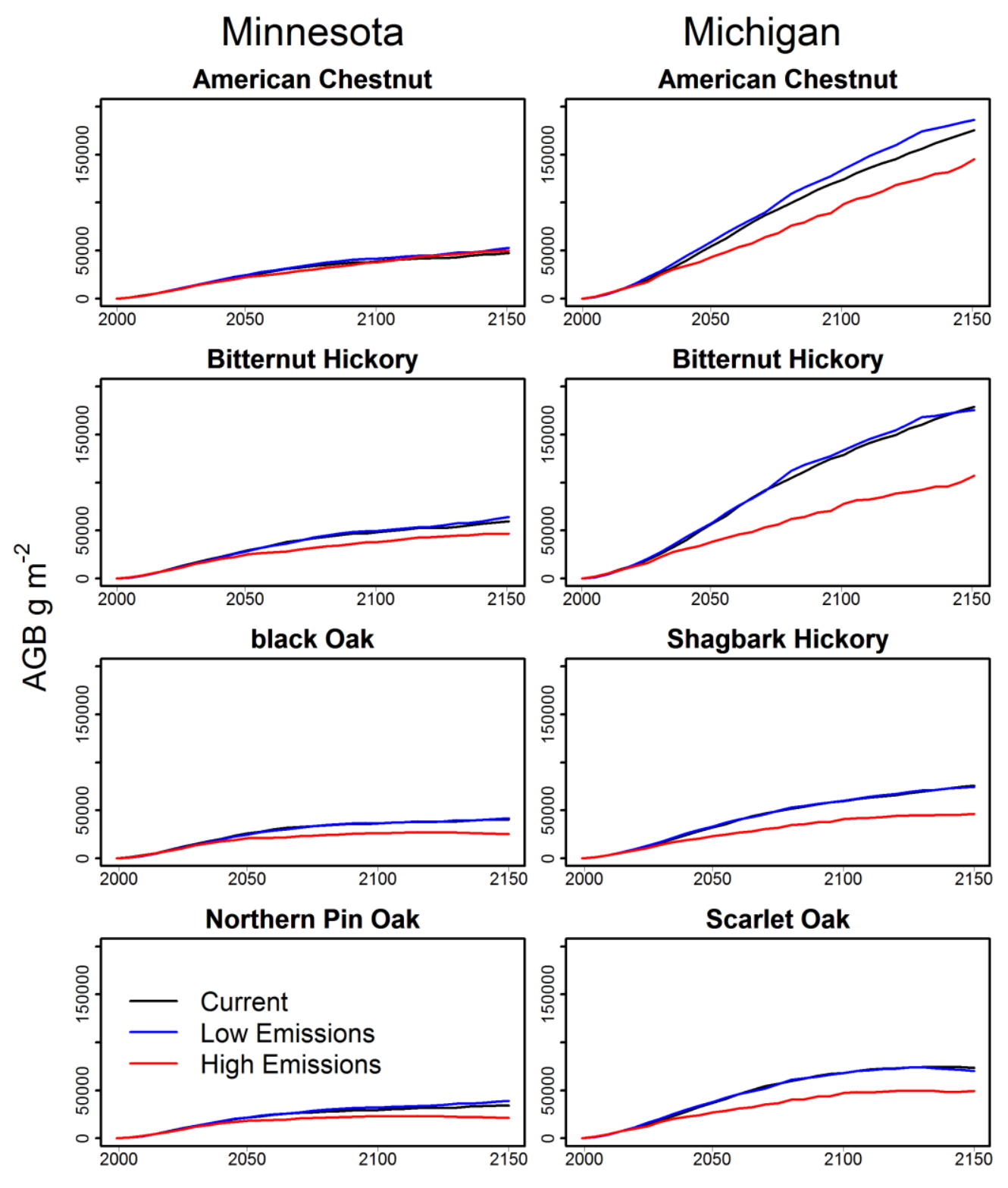


Figure 4.4: Simulated aboveground ANPP measured over time of each landscape, climate and management scenario.
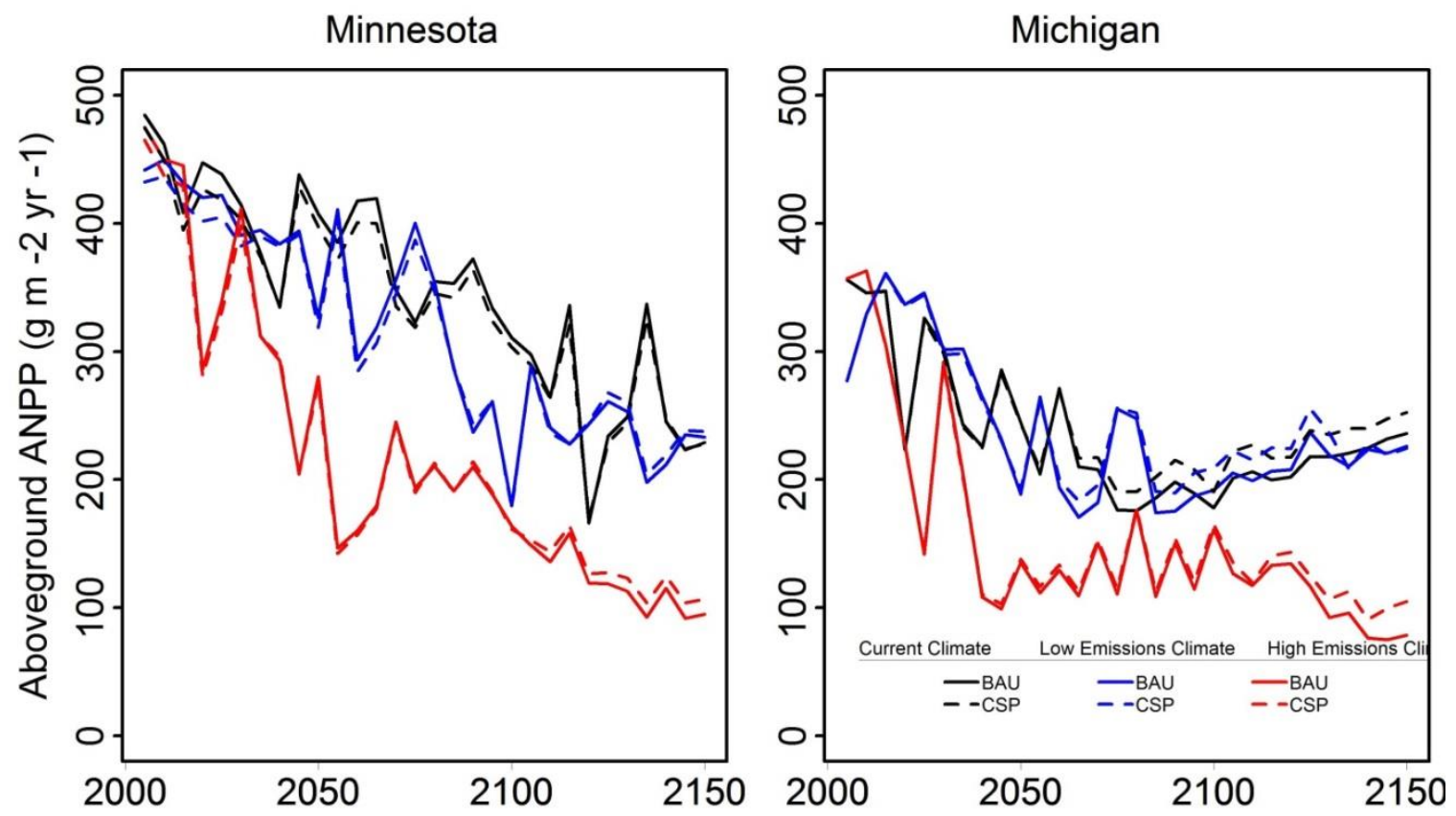
Figure 4.5: Within the CSP scenario, (A) Proportion of landscapes occupied by at least one CSP species; (B) average aboveground ANPP $\left(\mathrm{g} \mathrm{m}^{-2-y r}\right)$ across actively managed sites where at least one CSP species was present compared to cells where CSP species were absent.
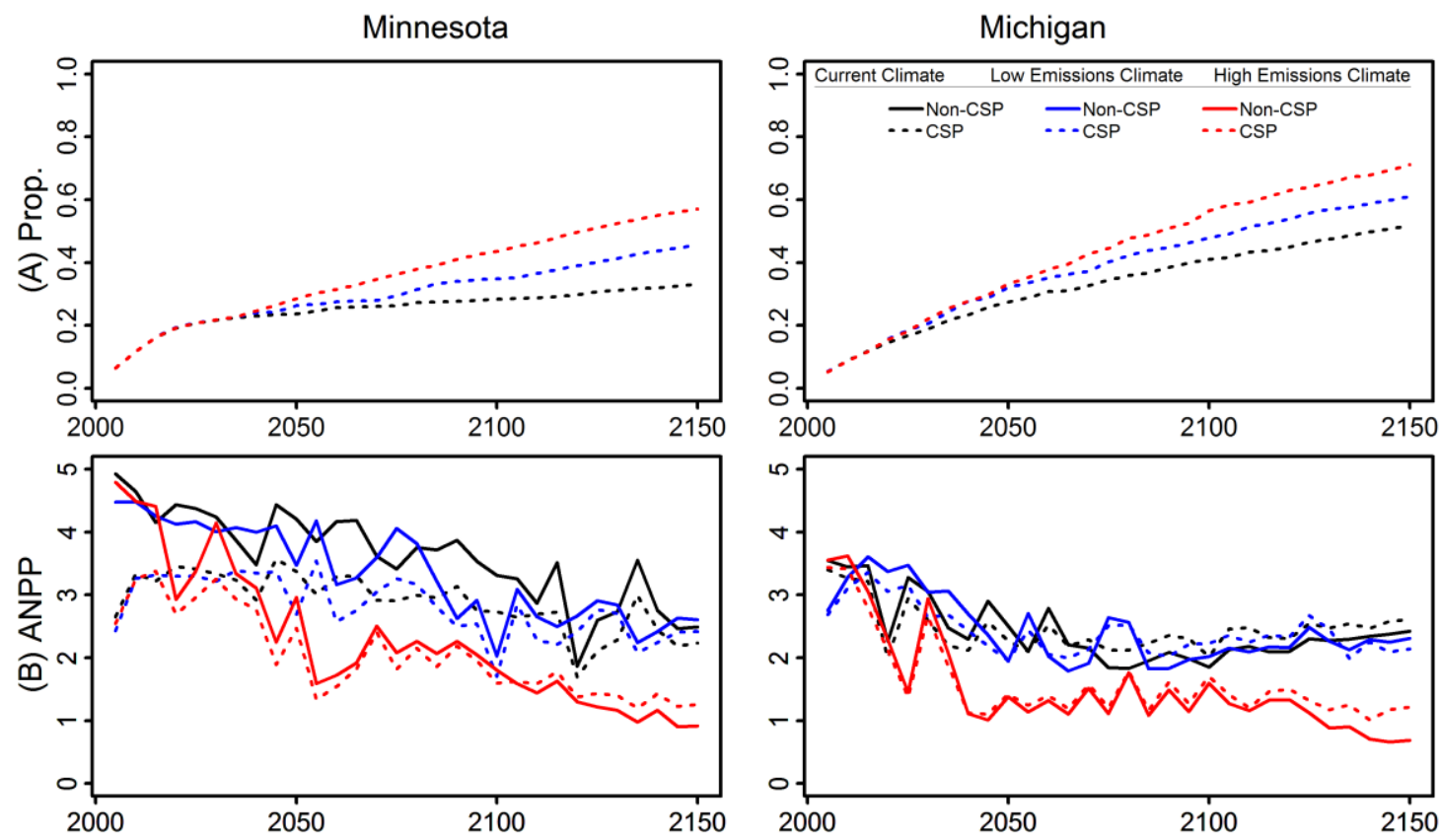
Figure 4.6: Species diversity $\left(\mathrm{e}^{\mathrm{H}}\right)$ and functional diversity (FDis) for each landscape, climate, and management scenario over time. Light dotted lines represent $(+-)$ standard error around each scenario.
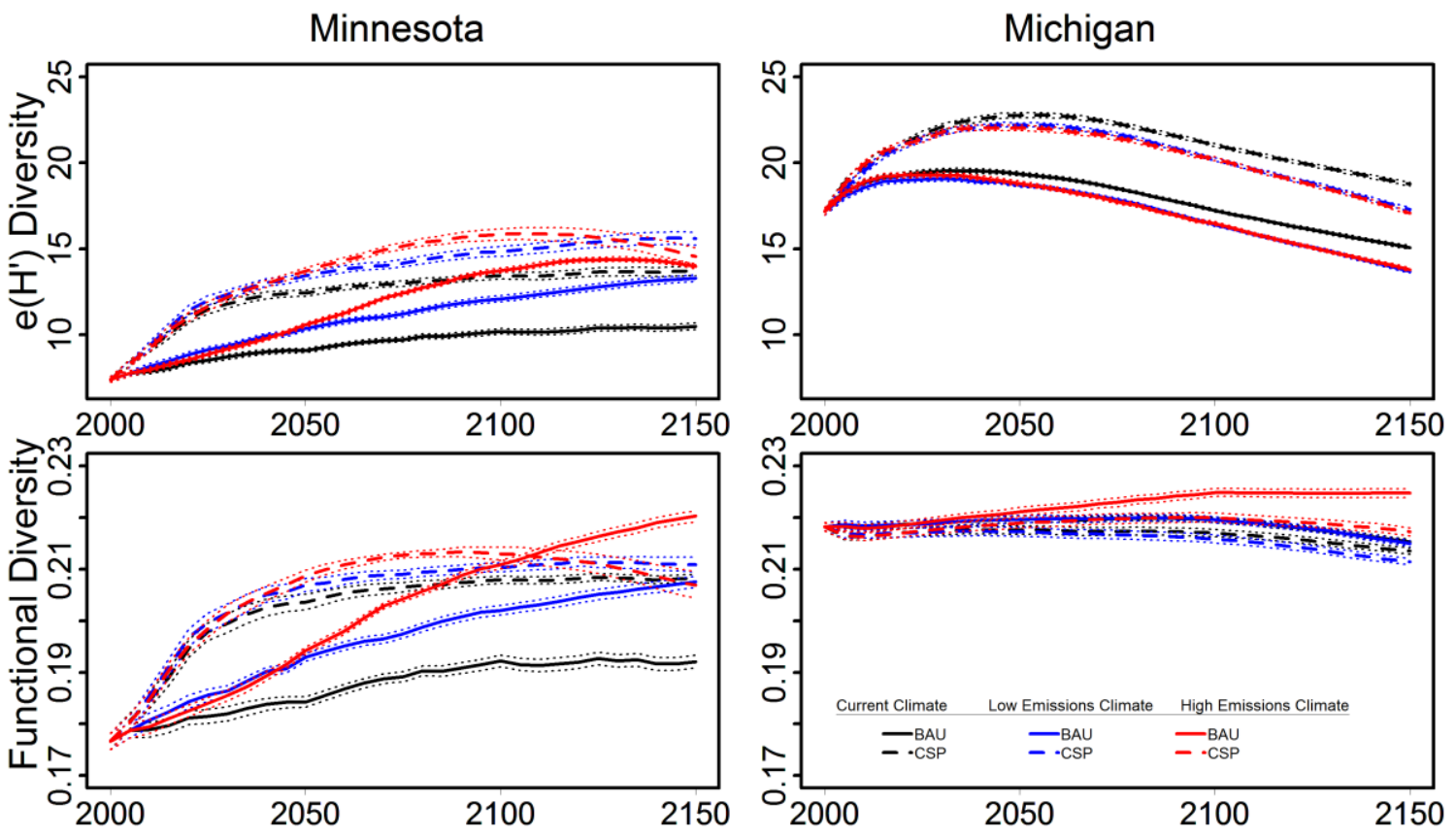


\section{Chapter 5: Alternative Management for Resistance and Resilience of Northern Great Lake forests (USA) to the Effects of Climate Change}

\section{ABSTRACT:}

The most dramatic climate change effects to forests may be a decline in both resistance to chronic change and in resilience to acute disturbances such as fire. I assessed the interactions of climate change, resistance, resilience, diversity, and alternative management of northern Great Lake forests using a simulation modeling approach. I simulated two landscapes (northern Minnesota and northern lower Michigan), three climate scenarios (current climate, low emissions, and high emissions), and four management scenarios (business as usual (BAU), expanded forest reserves, modified silviculture, and climate suitable planting (CSP)). I simulated each scenario with a landscape forest simulation model (LANDIS-II) for 150 future years. I assessed resistance as the change in species composition over time at three different spatial scales. Within simulated fire sites, I assessed resilience as the recovery of aboveground biomass (AGB) and species composition. Results indicate a positive relationship between diversity and resistance to change within sites of low diversity. Simulations of the high emission climate scenario resulted in a decline in both resistance and resilience. The alternative management scenarios generally resulted in more resilience of AGB to fires compared to BAU management but little variation in resilience of initial species composition. Nevertheless, my results suggest that differences in management are largely outweighed by effects of climate. Particularly innovative strategies such as planting species from further south will be required of management to maintain forest 
ecosystem function in the face of climate change.

KEYWORDS: Alternative forest management; climate change; LANDIS-II; Michigan (USA); Minnesota (USA); resistance; resilience.

\section{INTRODUCTION:}

Climate change is expected to dramatically change species composition across landscapes (Svenning and Sandel 2013). With species composition changes, I expect loss in annual net primary productivity, biomass, and other ecosystem functions under a high emissions climate scenario (e.g., (Duveneck et al. accepted)). There is however, large variation in ecosystem functioning across landscapes and this variation may be magnified by climate change (Scheller et al. 2012). Some regions may continue to persist providing similar function while others may change dramatically. Understanding the mechanisms of stability will help managers plan future actions and priorities. Some sites or regions may naturally adapt to change while continuing to provide ecosystem function. Other sites or regions may be well suited for alternative management to maintain or enhance ecosystem function (Duveneck et al. accepted, Duveneck et al. in review).

Forests are affected by both acute and chronic disturbances. Glasby and Underwood (1996) describe the difference between ongoing "press" (or 'chronic') disturbances and short term "pulse" disturbances. I consider climate change a press disturbance that may, for example, directly affect species growth and regeneration potential through long term changes in environmental conditions (Fisichelli et al. 2012, Fisichelli et al. 2013). Climate change can also indirectly result in changes in pulse 
disturbance regimes (Dale et al. 2001), for example insect outbreaks (Bentz et al. 2010).

The resistance of a system is the ability to persist through disturbance with little change (Landres et al. 1999, Minckley et al. 2012). To assess the vulnerability of a system, resistance is an informative measure of direct climate change effects (press disturbances). Resilience can be defined in multiple ways. The resilience of a system can be defined as the ability to recover from a disturbance back to a similar initial state (Gunderson 2000), however any discussion of resilience must include a description of: "what system" and to: "what disturbance" (Carpenter et al. 2001). Resilience, as related to recovery is an informative measure of indirect climate change effects (pulse disturbances).

Compared to low diversity forests, larger species assemblages may be less vulnerable to climate change induced ecosystem service decline such as aboveground biomass (AGB) (Duveneck et al. accepted). As environmental conditions change under climate change (IPCC 2007), less abundant species with different environmental thresholds can theoretically provide response potential to make up for loss of more abundant species (Walker 1992). The relationship between diversity and productivity may follow a bell-shaped curve with positive relationships expected under low productivity and negative relationships expected under high productivity (Paquette and Messier 2011). The relationship between diversity and stability may follow similar patterns with low diversity sites having a stronger relationship than higher diversity sites (Peterson et al. 1998).

Resistance of plant communities will be affected by climate change (Buma and Wessman 2013, Moritz and Agudo 2013). Nevertheless, the relationship between 
diversity and resistance, however, has been largely unexplored. A single extirpated foundational species, a species with a strong role in structuring a community, in a low diversity community would result in a large decline in resistance of that community. The extirpation of a single species from a more diverse community may not affect the resistance of that community (Folke et al. 2004a). Ecologists have long theorized (Elton 1958), tested (Tilman and Downing 1994, Tilman et al. 2006, Moore et al. 2011), and debated (McCann 2000) the diversity-stability hypothesis. Most would agree that a higher diversity of plant communities will increase the stability of those communities to external perturbations. As a stabilizing mechanism, diversity can be due to both complementarity and identity effects (Eisenhauer et al. 2013). In addition to species diversity, functional diversity based on species traits rather than species themselves (Laliberté and Legendre 2010, Duveneck and Scheller in prep) may provide an informative relationship to the persistence of future ecosystem functioning.

In the Great Lake region, previous studies have simulated AGB and ANPP response of northern Great Lake forests to climate change under business as usual (BAU). These studies show a decline in simulated AGB and ANPP of tree species under a high emissions climate scenario (Duveneck et al. accepted). Alternative management scenarios including expanded reserves, modified silviculture, and climate suitable planting indicate a limited ability to maintain ecosystem services (Ravenscroft et al. 2010, Duveneck and Scheller in prep, Duveneck et al. in review). Although these studies describe landscape and ecoregion scale dynamics under climate change they did not explore resistance or resilience at the site or aggregated site scales.

In order to assess the on-going effects of climate change, species compositional 
dissimilarity between time periods of a site can represent resistance as the change from initial to future conditions (Bradt et al. 1999, Rydgren et al. 2004, Thrush et al. 2008). Ecological resilience refers to the recovery of a system's identity. Identity refers to how a system is explicitly defined as related to recovery (Carpenter et al. 2001). Engineered resilience refers to the time required for recovery (Holling 1996). Dissimilarity can be used in a definition of both ecological and engineered resilience as the recovery of a system's identity compared to initial conditions and the time required to return to initial conditions. The Bray-Curtis index of dissimilarity is one measure of the degree of difference between two objects. The index divides the amount of shared abundance in each attribute (e.g., species) by the total abundance from each site (Quinn and Keough 2002). Using dissimilarity assumes that resistance and resilience of a system is defined by the initial species composition and abundance. A different measure of resistance and resilience could be defined simply by the persistence or recovery of AGB irrespective of species composition. Furthermore, resistance and resilience could be defined, for example not by the presence of initial species composition, but by a species composition that is suited for a future climate.

To date few studies (e.g., Buma and Wessman 2013) have measured resistance and resilience in the context of managing forests for climate change. Spatially explicit models that incorporate dispersal, disturbance, and intrinsic limits have been identified as being important research priorities for understanding species response to climate change (Moritz and Agudo 2013). These models are useful to evaluate multiple interacting spatial processes on landscapes. I explored the effect of climate change, scale, and management on resistance and resilience of forests in the Great Lakes region via 
simulation modeling. To assess resistance, I measured dissimilarity of initial species composition and abundance to the effects of climate change interacting with harvesting, fire, and wind. To measure resilience, I assessed the recovery of both AGB and initial species composition to the effect of simulated fires. Specifically, I addressed the following hypotheses (represented by conceptual diagram (Figure 5.1)): 1) Initial diversity will increase resistance to change as measured by dissimilarity. 2) Climate change will decrease resistance of initial tree species composition and abundance over time. 3) Management for climate change (i.e., expanded reserves, modified silviculture, and climate suitable planting) will increase resistance to change. 4) Following acute disturbance, climate change will decrease and management alternatives will increase resilience of forests under climate change.

\section{METHODS:}

My results include landscapes in Northeastern Minnesota and northern lower Michigan that represent a gradient of conditions in Great Lake Forests (Figure 5.2). In each landscape, I delineated unique climate regions that represent relatively homogenous climate (White and Host 2000, Duveneck et al. accepted). Within these climate regions, I assessed the resistance of initial species composition to the effects of climate change.

The Minnesota landscape has more contiguous forest than the Michigan landscape which includes large forest reserves not present in northern lower Michigan. The Michigan landscape is further south with higher projected temperatures than Minnesota (Andresen et al. 2012, Duveneck et al. accepted). The Minnesota landscape is managed intensively, dominated by a matrix of aspen forests (D' Amato et al. 2009), and closer to 
the boreal forest ecotone (Curtis 1959). The Michigan landscape is more diverse with less aspen and further from the boreal forest ecotone (Duveneck et al. in review).

\section{Experimental Design:}

My experimental design encompassed two landscapes (northeastern Minnesota and northern lower Michigan), four management scenarios (BAU, expanded reserves, alternative silviculture, and climate suitable planting), multiple climate regions (Figure 5.2), and three climate scenarios (current climate, low emission future, and high emissions future). I used a two-hectare resolution and a 150 year simulation horizon for all simulations replicated five times starting at year 2000. Within each scenario, I examined the effect of simulated fires at 2050 and 2100.

\section{Simulation Model:}

I used the LANDIS-II (v6.0) forest landscape model to simulate forest change (Scheller et al. 2007b). LANDIS-II is a successional process model that emphasizes disturbance interactions on a landscape of interconnected grid cells. Within cells, species-age cohort combinations are tracked. Tree species-specific processes include seed dispersal, regeneration, growth, and mortality. Species cohorts can act as seed source when they have grown to reproductive maturity. From a source cell, seed dispersal is assigned to probabilities of long (5\%) and short (95\%) species dependent distances (Burns and Honkala 1990, Scheller et al. 2007b). User selected extensions to the LANDIS-II core framework allow additional processes be incorporated. At every 5year time step, I utilized the following extensions: Biomass Succession (v3.1) (Scheller and Mladenoff 2004), Biomass Harvest (v2.1) (Gustafson et al. 2000), Base Fire (v3.0) (He and Mladenoff 1999), and Base Wind (v2.0) (Scheller and Mladenoff 2004). 
Climate change was incorporated into Biomass Succession through variation in annual estimates of maximum aboveground annual net primary productivity $\left(\mathrm{ANPP}_{\max }\right)$, and probability of establishment $\left(\mathrm{P}_{\text {est }}\right)$ for each species. To calculate $\mathrm{ANPP}_{\max }$ and $\mathrm{P}_{\mathrm{est}}, \mathrm{I}$ used the PnET-II for LANDIS-II tool which incorporates monthly climate data (maximum and minimum temperature, precipitation, and photosynthetic active radiation (PAR) (Xu et al. 2009). To incorporate variation in growth and establishment, I ran PnET for unique tree species within unique soil and climate regions in each landscape. Percent foliar nitrogen content, maximum foliar mass area, and soil water holding capacity are required PnET parameters. In addition, I calculated $\mathrm{AGB}_{\max }$ for each species, climate and soil region based on the species specific relationships between $\mathrm{AGB}_{\max }$ and $\mathrm{ANPP}_{\max }$ (Thompson et al. 2011).

Driven by $\mathrm{AGB}_{\max }, \mathrm{ANPP}_{\max }$, and $\mathrm{P}_{\mathrm{est}}$, Biomass Succession establishes, grows, matures, and causes age-related mortality of species cohorts. The establishment of a new cohort is determined by $\mathrm{P}_{\text {est }}$ provided a seed or seedling source and available light based

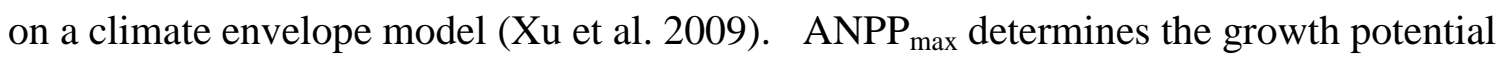
of a species given no competition. ANPP is limited by a species specific growth curve parameter that regulates how fast $\mathrm{ANPP}$ reaches $\mathrm{ANPP}_{\max }$. Competition further reduces growth through utilization of finite growing space (Scheller and Mladenoff 2004). Input parameters and soil and climate region delineations for each landscape are provided in Duveneck et al. (accepted).

I initialized each simulation with an initial community map with species-age cohorts in every forested cell. The initial community maps were based on spatial 
imputations of plot inventory data. I utilized previously developed initial community data for Minnesota (Ravenscroft et al. 2010) and Michigan (Duveneck et al. accepted).

\section{Climate Scenarios:}

My objectives were not to create the most accurate and precise projections of future climate. Rather, my objectives were to broadly bound potential climate futures based on potential emission futures. In doing so, I hoped to learn about the interactions of potential climate. I simulated a current climate scenario by populating future climate years through randomly selecting historic years from a pool of possible historic years (1969-1999). For each randomly selected historic year, I used monthly PRISM climate data to represent current climate (Daly and Gibson 2002). I simulated a low emissions climate future based on the Parallel Climate Model (PCM) Global Climate Model (GCM) (Washington et al. 2000) and the B1 emission scenario (IPCC 2007). I simulated a high emission climate future based on the Geophysical Fluid Dynamics Laboratory (GFDL) GCM (Delworth et al. 2006) and the A1FI emission scenario (IPCC 2007). The B1 and A1FI emission scenario represent the least and most fossil fuel intensive future described by IPCC, respectively and are comparable to the new IPCC scenarios of carbon dioxide concentration projections (IPCC 2013). I accessed monthly downscaled temperature and precipitation projections through the USGS data portal http://cida.usgs.gov/climate/gdp/ (Stoner et al. 2012) averaged within each climate region (Duveneck et al. accepted). The IPCC climate projections provide climate data to year 2100 (IPCC 2007). In order to simulate forest change to year 2150, I interpolated climate data (temperature and precipitation) from 2100 to 2150 based on the variability within the initial 100 years of IPCC projections. For temperature interpolations, I included a linear regression 
component based on the increasing trend in temperature from 2000 to 2100 using the Amelia library in R (R Development Core Team 2011).

\section{Management Scenarios:}

I used the Biomass Harvest extension to simulate forest management scenarios (Gustafson et al. 2000). Stands are selected for harvest based on user defined criteria (e.g., when cohorts reach merchantable age). At each time-step, biomass is removed within stands based on user defined prescriptions regulating patch size, percent biomass by species removed, and planting. Rotation periods are incorporated by defining the proportion of each prescription implemented within each management area (ownership group) and time-step (Gustafson et al. 2000).

I developed four separate management scenarios in each landscape. 1) I implemented a BAU scenario based current management regimes in Minnesota and Michigan (Potter-Witter 2005, D' Amato et al. 2009, Ravenscroft et al. 2010). This scenario represents intensive even-aged management. Details of this scenario are provided in Duveneck et al. (accepted). 2) I implemented an expanded reserve scenario where forest reserve areas were expanded along river corridors. Although individual harvest prescriptions did not change compared to BAU, this scenario represents a decline in harvested biomass as more of each landscape become off limits to harvesting. 3) I implemented a modified silviculture scenario where individual prescriptions were adjusted to include smaller patches and longer rotation periods. In addition, I simulated planting species from within the landscape expected to respond well to climate change rather than plant species expected to decline. Details of the expanded reserve and modified silviculture scenario are available in Duveneck et al. (in review). 4) I 
implemented a climate suitable planting (CSP) scenario where species from outside the landscapes were planted within existing northern hardwood patch cutting prescriptions. With the exception of American chestnut (Castanea dentata), I choose species present directly south of each landscape. This scenario was meant to increase the suite of species that may not be able to naturally migrate under climate change. Details of the CSP scenario are available in (Duveneck and Scheller in prep).

\section{Spatial Analysis:}

I replicated each scenario five times to assess the stochastic variation in AGB within scenarios. Response of individual disturbances varies spatially due to variation in soils, climate, and tree species. Due to the low stochastic variation in natural disturbances in relation to the size of my landscapes, maximum variance of total AGB of each replicate at the end of the simulation was $<2 \%$ of the mean of replicates. Therefore, I randomly selected one replicate for the remaining analysis. For each landscape cell, I calculated initial species and functional diversity. I used the Shannon index (H') as a measure of species diversity (Gotelli and Ellison 2004). I exponentially transformed

Shannon index $\left(\mathrm{e}^{\mathrm{H}}\right)$ to represent the equivalent number of species (Jost 2006). I used the functional dispersion (FDis) measure of functional diversity. FDis is a measure of the range of predefined functional traits that describe the functions of a community of species (Laliberté and Legendre 2010). FDis uses relative abundance thus is not sensitive to outliers. I selected functional traits used in previous work (Paquette and Messier 2011, Duveneck and Scheller in prep). Specific species traits included: maximum height, growth rate, leaf size, longevity, foliar mass per area, foliar nitrogen content, wood density, decay resistance, vegetative reproduction, seed mass, pollination vector, 
mycorrhizal infection type, shade tolerance, drought tolerance, and water-logging tolerance (See Appendix: Table A8).

The Bray-Curtis index has been used to measure dissimilarity between sites in space (e.g., Scheller and Mladenoff 2002, Moore et al. 2011, Thompson et al. 2013) and time (Rydgren et al. 2004, Thrush et al. 2008). I calculated the Bray-Curtis index of dissimilarity $(B)$ where, $B$ is determined largely by species with high abundance. $B$ ignores joint absences and is not overly sensitive to outliers (Quinn and Keough 2002) (Equation 1). Bray-Curtis values range between 0 and 1 with 1 being the most dissimilar. I used simulated species AGB within cells as a measure of abundance between time periods recognizing however, that some species will naturally have a higher AGB than others.

$$
B_{j k}=\left(1-\frac{2 W_{j k}}{T_{j}+T_{k}}\right)
$$

Where,

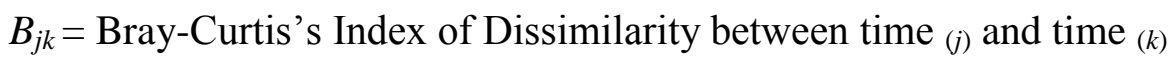
$\mathrm{W}_{j k}=$ Sum of minimum simulated abundance from time ${ }_{(j)}$ and time ${ }_{(k)}$ $\mathrm{T}_{j}=$ Sum of total simulated abundance at time ${ }_{(j)}$ $\mathrm{T}_{k}=$ Sum of total simulated abundance at time ${ }_{(k)}$

I assessed multiple spatial scales and temporal durations. At simulation years 2050, 2100, and 2150, I assessed the relationship between climate, management, species 
diversity, and dissimilarity within homogeneous climate regions (Duveneck et al. accepted) (Figure 5.2). I explored the effect of spatial resolution under the high emissions climate scenario and BAU management. I used raster layers of species biomass for each landscape. I aggregated raster layers from 2 hectares to 50, 100, and 200 hectares, respectively. Within each aggregated cell, I calculated species and functional alpha diversity. Finally, I plotted and assessed the fit of a model describing the relationship between initial diversity and dissimilarity.

To measure resilience, I assessed the simulated response following fire disturbances. I selected cells within simulated fires at years 2005, 2050, and 2100 from each landscape, climate, and management scenario. I calculated both Bray-Curtis dissimilarity and the change in total AGB within burned sites from the time-step prior to the fire year to 50 successive simulation years. In a novel approach, I plotted both change in total AGB and change in species composition as measured by dissimilarity for all time-steps prior to and following simulated fires (Figure 5.3). This allows two measures of resilience plotted together for each landscape, climate, and management scenario. I assessed management scenario differences after 50 years for the high emissions climate scenario with an ANOVA and Tukey-Kramer HSD test for unequal samples $(\mathrm{p}<0.05)$. I completed all calculations and analysis using the DTK, raster, vegan-community ecology, and FD functional diversity libraries in R (R Development Core Team 2011). 


\section{RESULTS:}

\section{Effect of Diversity on Dissimilarity:}

At the climate region scale, dissimilarity increased with time. In each scenario, dissimilarity between simulation years 2000 and 2050 was less than between years 2000 and 2100, and 2000 and 2150 (Figures 5.4 and 5.5). The effect of management on dissimilarity was minimal. In the Minnesota landscape, the CSP scenario at simulation years 2100 and 2150 resulted in the largest dissimilarity compared to the BAU, modified silviculture, and expanded reserves scenario (Figure 5.4). Generally, however, variation in management did not result in differences in dissimilarity.

The effect of simulated diversity on resistance was more pronounced in the lower diversity and more intensively managed Minnesota landscape (Figures 5.4 and 5.6) compared to the Michigan landscape (Figure 5.5 and 5.7). In the Minnesota landscape, lower simulated functional and species diversity resulted in less resistance to change (greater dissimilarity) and more of a positive relationship between diversity and dissimilarity. In contrast, simulations in the Michigan landscape resulted in larger species diversity and to some extent, functional diversity. With the exception of lower

diversity sites in the finest resolution (Figure 5.7), simulations in Michigan did not result in a diversity-dissimilarity effect.

For the high emissions climate scenario, the effect of spatial resolution resulted in the strongest relationship between diversity and dissimilarity at the finest resolution (50 ha) (Figure 5.6). As expected, larger grain size (100 and 200 ha) resulted in larger alpha diversity (local diversity). At finer resolutions, the relationship between diversity and dissimilarity had the strongest effect. In the Michigan landscape, the effect of spatial 
scale was less apparent (Figure 5.7). Although the bulk of sites did not result in a diversity-dissimilarity effect, the 50 and 100 hectare aggregation resulted in a portion of lower species sites increasing in dissimilarity.

\section{Effect of Climate Change on Resilience of Forests Following Fires:}

The simulated response of forests to fire disturbances resulted in progressively less resilient forests under the high emissions climate future compared to the low emissions and current climate scenario. The AGB and dissimilarity response of simulated fires at year 2005 under current climate resulted in the fastest recovery and the greatest AGB after 50 years compared to climate change scenarios (Figure 5.8). While none of the scenarios resulted in recovery to an identical pre-fire species and biomass composition (dissimilarity $=0$ ), the current climate scenario resulted in the fastest recovery to the inflection point before additional successional departure. Furthermore, I would not expect recovery to an identical species and biomass composition.

Compared to simulated fires in 2005 , the climate change effect following fires in year 2100 was more pronounced (Figure 5.9). Successional changes resulted in larger pre-fire AGB in 2100 than 2005. Under current and low emission climate scenarios, simulations resulted in complete or near complete AGB recovery at 2150 . Under the high emissions climate scenario, simulations following fires in 2100 resulted in less initial AGB and less biomass removed compared to current climate. With less initial AGB, this resulted in less change from initial to post-fire AGB compared to current and low emissions climate. Nevertheless, long term recovery from reduced AGB did not recover to pre-fire conditions (Figure 5.9). The high emissions climate scenario also resulted in greater dissimilarity response following simulated fires in 2100. 
Although the Minnesota and Michigan landscapes differed in latitude, management, and diversity, the variation between landscapes in response to fires was minimal compared to the variation due to climate. Compared to Minnesota, the more diverse and larger total AGB Michigan landscape resulted in less dissimilarity by the inflection point after 2005 fires (Figure 5.8) and after 50 years after 2100 fires (Figure 5.9). In addition, response after simulated fires in Michigan resulted in larger increases in AGB than Minnesota.

Management differences resulted in small variation in resilience to simulated fires (Figure 5.8-5.9). After simulated fires in 2100, resilience following fires in the high emission climate scenario resulted in few significant differences (See Appendix: Table A9). In the Michigan landscape, the CSP scenario resulted in small increases in AGB resilience, likely due to more climate suitable species available recovering more biomass than the current species mix. In the Minnesota landscape, no significant differences were found between resilience to AGB however the BAU scenario resulted in the least recovery of AGB compared to alternative management scenarios.

In both landscapes, the CSP management scenario resulted in significantly lower resilience of species composition to simulated fires in 2100 under the high emission climate scenario compared to BAU management (See Appendix: Table A9). The CSP decrease in dissimilarity resilience is due to the additional species further changing the species mix from the original community composition. In the Minnesota landscape, the BAU scenario resulted in the highest resilience of species composition however; the expanded reserves resulted in the highest resilience of species composition in the Michigan landscape. 


\section{DISCUSSION:}

\section{Effect of Diversity on Resistance:}

I hypothesized that diversity would affect future resistance as measured by dissimilarity between two time periods. My results suggest that diversity has a diminishing effect on resistance as diversity increases. Resistance of sites or landscapes above a threshold of high diversity may not be affected by diversity (e.g., the Michigan landscape), however below a threshold of diversity, resistance of sites were negatively affected by diversity (e.g., the Minnesota landscape). This is consistent with conceptual frameworks discussed by Peterson et al. (1998) who describe how functionally overlapping species will result in complementary effects which are eventually overcrowded at high diversity. Thereby, the diversity-stability relationship is positive at low diversity but reaches an asymptote at higher diversity.

There is considerable debate surrounding studies of diversity's effect on stability (McCann 2000). In contrast to complementary effects, identity effects recognize that within higher diversity sites, there will be a higher probability that a highly successful species will be present (Clark 2013). My experimental design is not immune to the same criticisms regarding identity effects. For identity effects to be present, I would expect an initial dominant species to stay dominant over time. This would cause lower dissimilarity and higher resistance to change regardless of diversity. However, projections of individual species biomass in these landscapes suggest large variation in species AGB through time, especially under the high emissions climate scenario (Duveneck et al. accepted). Nevertheless, separating complementarity and identity effects was not the objective of this research. Furthermore, both complementary and identity effects can 
affect resistance.

I hypothesized that climate change would reduce the resistance of initial communities over time. Results in Minnesota suggest that the high emissions climate scenario will reduce the resistance of initial communities to change compared to current and low emissions climate (Figure 5.4). Large shifts in forest type and species composition are expected in the Michigan landscape under current climate (Duveneck et al. accepted). In the Michigan landscape, simulations suggest that the high emissions climate scenario will reduce dissimilarity compared to current and low emissions climate (Figure 5.5). This suggests that climate change may slow the successional trajectory that would otherwise shift the species composition under current climate. The Minnesota landscape is closer to the boreal transition zone (Curtis 1959). Boreal species (e.g., balsam fir (Abies balsamea) and black spruce (Picea mariana)) are expected to decline in both landscapes under climate change and are initially more dominant in the Minnesota landscape than the Michigan landscape (Duveneck et al. accepted).

I hypothesized that management for climate change could increase resistance to change. Duveneck et al. (in review) found increased simulated diversity within expanded reserves under climate change in these landscapes. Under modified silviculture, and CSP (Duveneck and Scheller in prep), they found an increase in AGB with climate change. Nevertheless, my results show limited management ability to increase resistance as measured by dissimilarity under climate change (Figure 5.4 and 5.5).

\section{Effect of Spatial Scale and Temporal Duration:}

It is well established in the literature that species richness increases with grain size and extent (Palmer and White 1994, Whittaker et al. 2001). An increase in grain size 
will increase alpha diversity (i.e. local diversity) as more species fit within a specific area. My results suggest that increasing grain size increases both functional and species diversity (Figures 5-6). Specifically, increasing grain size reduces the number of low diversity sites. As a stronger negative relationship exists between diversity and dissimilarity under low diversity, the finer resolution of analysis (lower alpha diversity) has a stronger dissimilarity-diversity relationship than the coarser resolution (higher alpha diversity) (Figure 5.6 and 5.7). As management decisions are increasingly focused at landscape scales, my results highlight the variation in conclusions drawn from scale dependent results. Managers must assess at what scale management actions will affect which processes under climate change. For example, larger alpha diversity within a larger grain size may be less susceptible to change however, may be limited by the movement ability of species within and across larger grain size sites. Ultimately, ecological processes with complex interactions must be considered at multiple scales.

Like spatial scale, the temporal duration of analysis will influence results and uncertainty of resistance and resilience (Wiens 1989). In the Minnesota landscape, the negative relationship between diversity and dissimilarity becomes stronger with increased duration (Figure 5.4). In the case of resistance, dissimilarity simply increases with duration as species composition shifts over time. In the case of resilience, duration can be part of a definition for resilience (i.e., engineered resilience) (Holling 1996, Rydgren et al. 2004).

\section{Effect of Climate Change on Resilience:}

The resilience of boreal-temperate transition forests to acute disturbance (e.g., fire) may decline with climate change (Dale et al. 2001, Moritz and Agudo 2013). 
Systems with low frequency of disturbances may be the most poorly poised to naturally adapt (Puettmann 2011). Northern Great Lake forests may be more vulnerable to regime shifts than ecosystems with more frequent natural disturbance regimes. In the Rocky Mountains, lodgepole pine (Pinus contorta) forests for millennia have been resilient to frequent natural disturbance regimes, including fire, drought, and insect outbreaks (Minckley et al. 2012). Although Minnesota includes a higher frequency of harvest disturbances (Duveneck et al. accepted), both landscapes in my study recovered similarly to simulated fires (Figure 5.8-5.9). Although a longer time frame may be required to assess the effect of my disturbance regimes, the variation in disturbance frequency between my two landscapes suggests that climate effects on resilience outweigh disturbance effects.

\section{Effects of Management:}

Under the high emission climate scenario, simulated fires in year 2100 resulted in poor resilience of $\mathrm{AGB}$ and species composition. Magnitude of change is affected by disturbance severity (Rydgren et al. 2004) and in this case, related to pre-fire biomass (Whelan 1995). Despite attempts to design alternative management scenarios to make forests more resilient and resistant; my simulations suggest that management will have limited ability to increase resistance and resilience of species composition in the face of climate change. The alternative management scenarios did show some increase in resilience of AGB to fires however the differences were minor and the individual management scenarios were inconsistently effective between landscapes. Although there is strong support to adapt existing management to climate change (e.g., Millar et al. 2007), others emphasize the risk to managing for resilience may inadvertently increase 
the vulnerability of a system (Côté and Darling 2010). Furthermore, alternative management under a high emissions climate future will likely be outweighed by the effects of climate change (Figure 5.8-5.9, See Appendix: Table A9). This is consistent with other modeling research that found a limited effect to resilience with management alternatives (including CSP) under a high emission climate scenario (Buma and Wessman 2013). Forest management under climate change may need to be far more innovative and aggressive than my alternative management scenarios. For example, in my CSP scenario, I selected species adjacent to current landscapes. Although these species are currently present in warmer climates to the south of the landscapes, the high emission climate scenario may not have been optimized for these species (Iverson et al. 2008, Duveneck and Scheller in prep). Planting species found from further south may be more effective at increasing resilience of forests under climate change. Determining appropriate CSP species for desired functional traits is possible through climate envelope modeling (Iverson et al. 2008). The challenge will be to choose which emission scenario and time horizon to match climate suitability given the uncertainty and limits to social change (Adger et al. 2009).

Another management strategy may be to shorten rotation ages to make sites more adaptable to climate change. As trees have long generation times, genetic adaptation to climate is expected to be slow (St Clair and Howe 2007). In sites that are degraded to begin with, shortening generation times by decreasing rotation ages will increase the number of generations within a time period. Increasing the number of generations will increase the likelihood for genetic adaptation. In addition, shortening rotation ages will create more opportunities to adapt management options (Puettmann 2011). Advance 
regeneration (i.e. planting climate adapted species below a canopy prior to harvest) can also result in more frequent turnover (Kuehne and Puettmann 2008) and provide protection for seedlings that are vulnerable to environmental conditions (Puettmann 2011, De Frenne et al. 2013). Experimental treatments should not be limited to degraded landscapes however, may provide the most socially accepted sites to experiment with innovative approaches (Adger et al. 2009).

\section{Uncertainty:}

There exists a large amount of uncertainty with simulations of climate change on forests, and northern forests specifically (Xu et al. 2009). I present a high and low emission climate future to represent a range of uncertainty associated with climate change. My current trajectory in carbon emissions however, has been observed at or above my high emission scenario (Jennings 2012). The uncertainty in future emissions may represent the largest amount of uncertainty in models of future forests. In addition to climate uncertainty, there is a large amount of uncertainty in future management. My BAU management scenarios are best guess estimates of what is currently practiced. I recognize that future forest management will be largely driven by an uncertain market demand for ecosystem services including timber.

The challenge to any simulation modeling research is to balance realistic assumptions against ecological theory (i.e. that might require completely artificial landscapes and millennia time scales). Although I provided reasonable parameters, I did not attempt to include every ecological process effecting northern forest futures. Therefore, my simulations are not predictions, rather plausible futures where I can explore the effects of alternatives. Although I did not assess variation in local 
environmental conditions response to resilience, I recognize that variation in resilience will be effected by local conditions such as high soil moisture (Speed et al. 2010). In addition, I did not include the effect of carbon dioxide fertilization on tree growth. I know that carbon dioxide fertilization will affect growth however I don't know where a fertilization effect will be limited by other factors such as nitrogen (Luo et al. 2004, Reich and Hobbie 2012). Some of the factors that I did not include in my analysis along with additional alternative management strategies (e.g., planting more southern species) represent excellent future opportunities for research.

\section{CONCLUSIONS:}

Given the large range of uncertainty in climate change and other factors, there will clearly not be one forest management strategy effective for all circumstances. Rather, a broad range of tools must be explored (Millar et al. 2007). Innovative strategies must consider both resistance and resilience. Resistance strategies may provide remnant ecosystem services and functions such as preserving spruce-fir species in forest reserves (Duveneck et al. in review). Resilience strategies may increase the ability to recover some ecological identity following disturbances. Disturbances such as timber harvest, fire, wind, and insect outbreaks will continue to cause immediate effects to forests. Not only will climate change likely change the frequency and direct effects of these disturbances, my results suggest that when disturbances occur, climate change may result in more dramatic long term effects. Increasing resilience further may require changing the measurement of resilience to include not species necessarily currently present but species suitable for a changing climate. 
Figure 5.1: Conceptual representation of diversity and dissimilarity supporting the hypothesis that as initial diversity increases, dissimilarity decreases (solid black line). As time period increases, dissimilarity increases (blue double arrow). An exogenous threat (e.g., climate change) may increase the dissimilarity between two time periods (red dotted lines). Adaptive management may decrease (or inadvertently increase) dissimilarity between two time periods (green dashed lines). Climate change and management may affect dissimilarity in non-linear ways in respect to diversity (length of dotted and dashed lines).

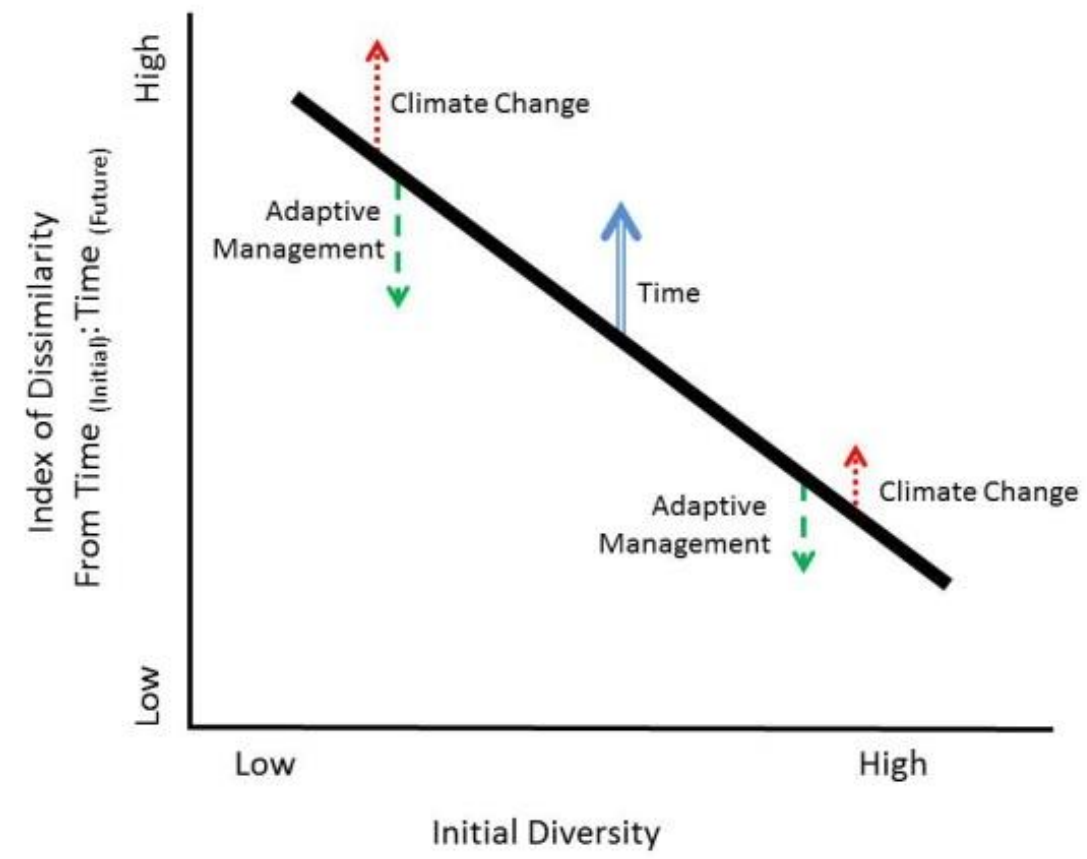


Figure 5.2: Northeastern Minnesota and northern lower Michigan study regions.

Numbers represent unique climate regions within each landscape. Inset, study regions within continental United States.

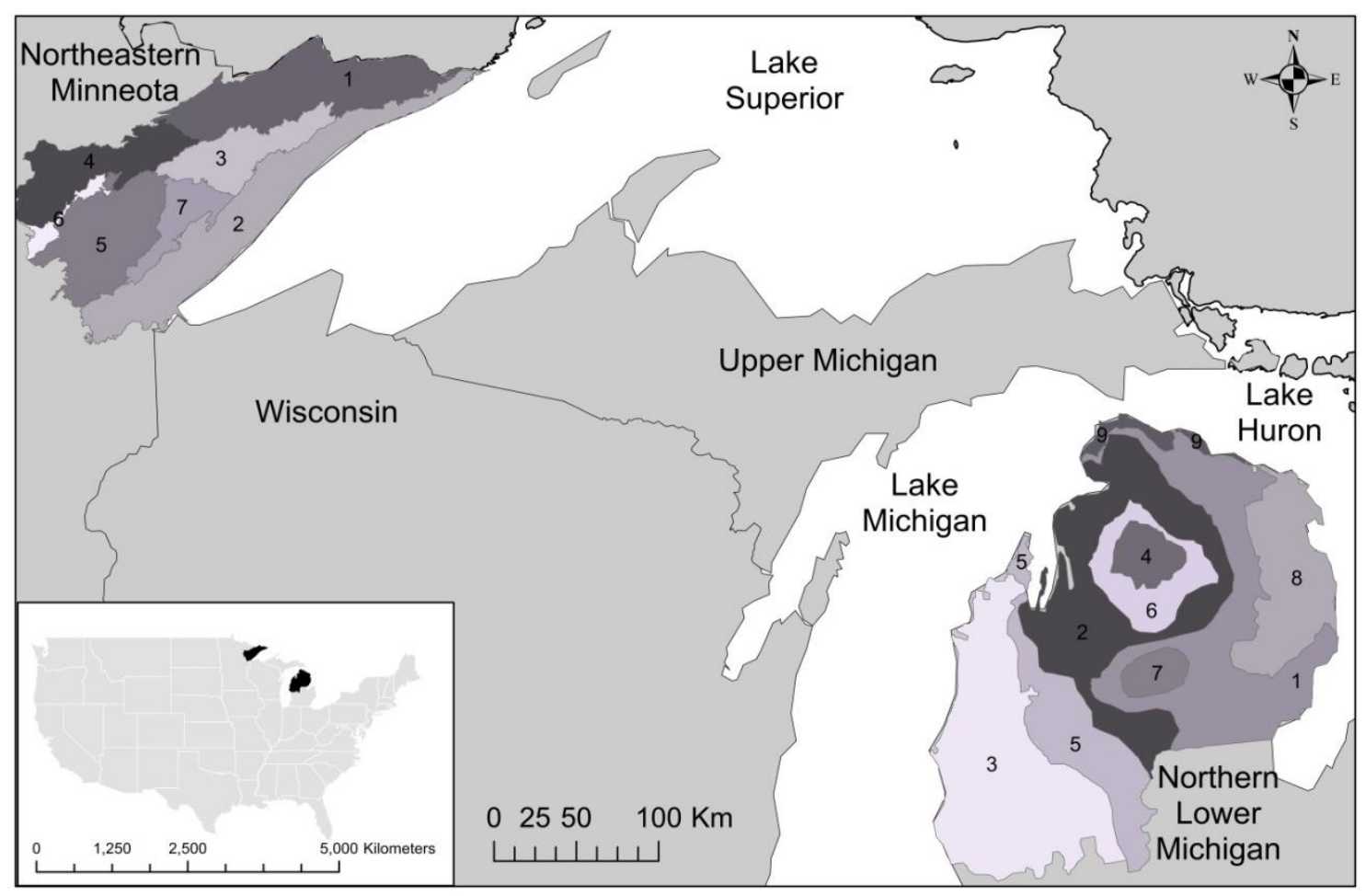


Figure 5.3: Conceptual diagram of resilience following a fire measured along two axes. Pre-fire conditions represent zero change in biomass and zero dissimilarity. Immediately post fire represents a reduction in biomass and an increase in dissimilarity. The years following the fire represent recovery of biomass and dissimilarity towards pre fire conditions. It is possible to fully recover (if not surpass) pre fire biomass. Due to successional trajectories, it is unlikely that a system will recover exactly to pre-fire species composition.

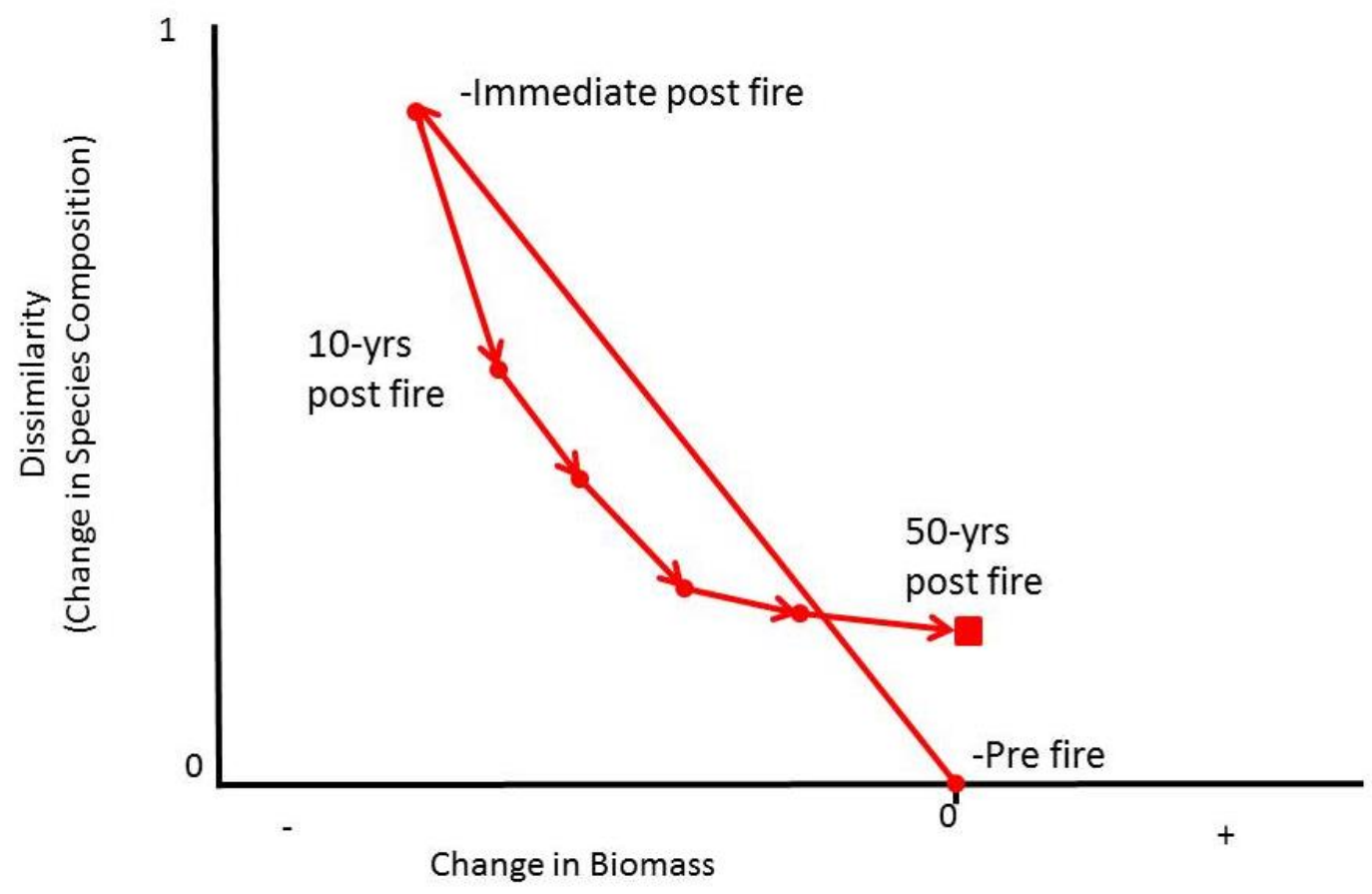


Figure 5.4: The interacting effects of management, climate, and duration (simulation years 2050, 2100, and 2150) on dissimilarity and initial diversity across climate regions in the Minnesota landscape.
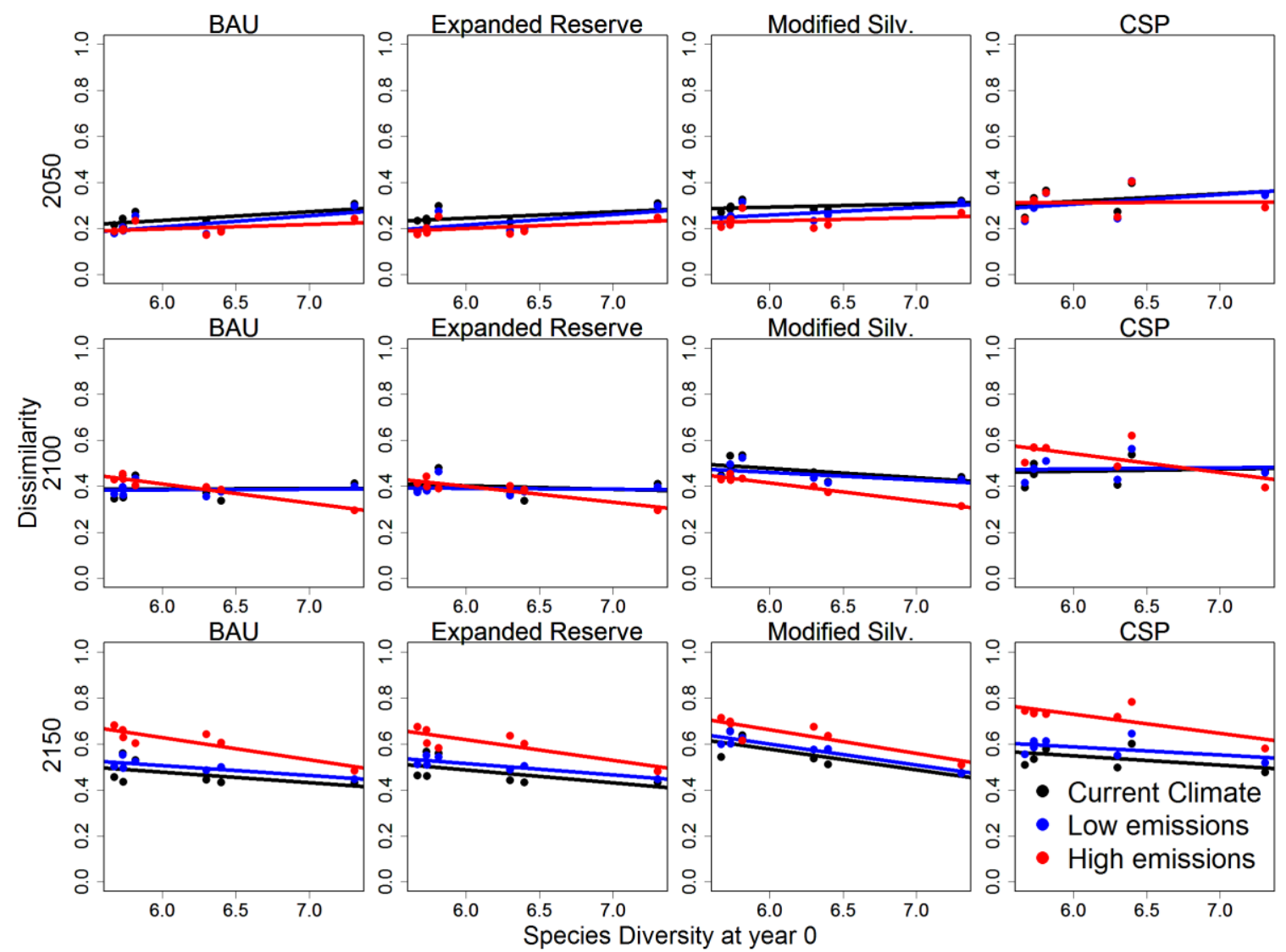
Figure 5.5: The interacting effects of management, climate, and duration (simulation years 2050, 2100, and 2150) on dissimilarity and initial diversity across climate regions in the Michigan landscape.
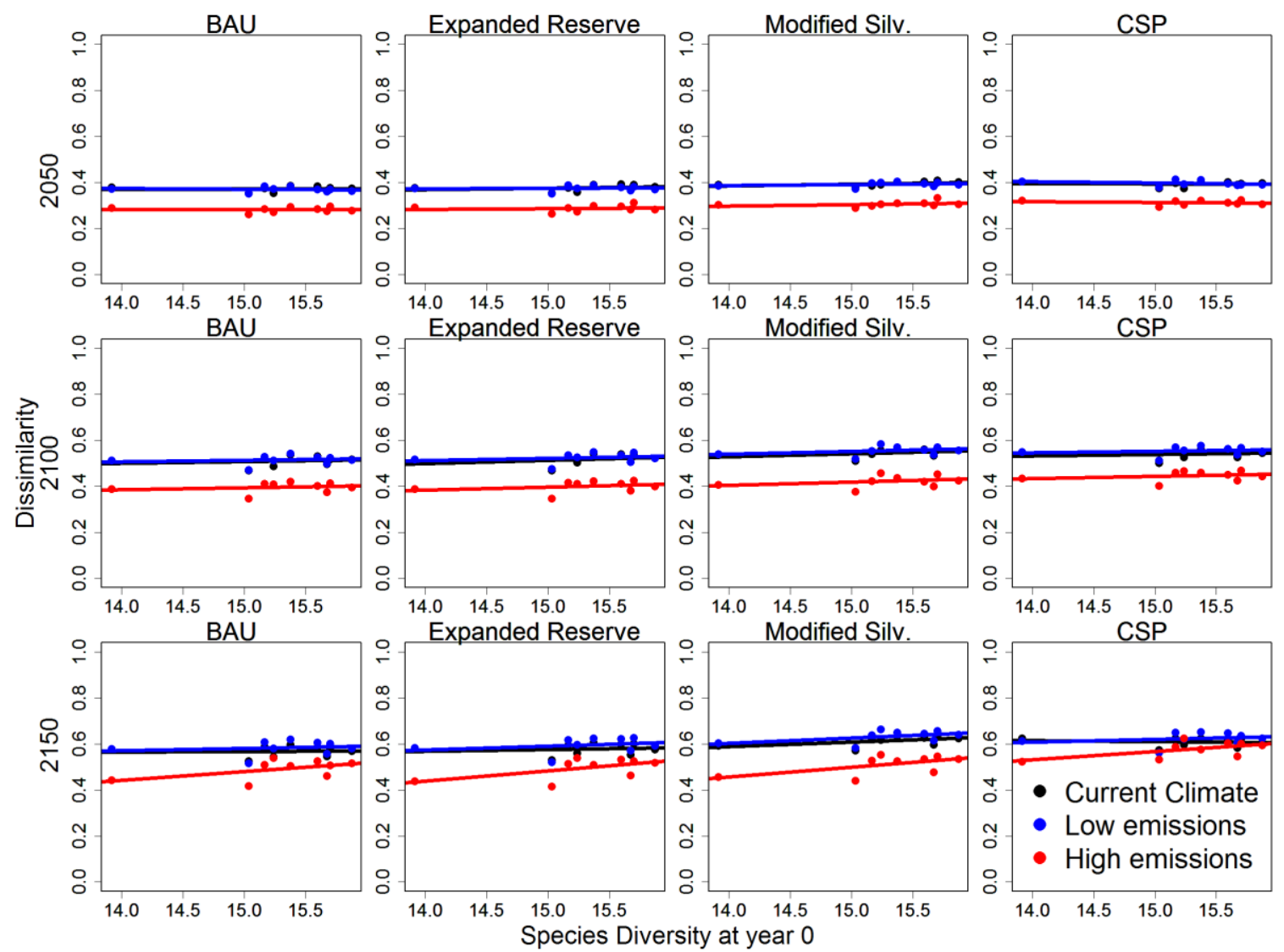
Figure 5.6: Three spatial resolutions of species and functional diversity effect on dissimilarity in the Minnesota landscape under BAU management and high emissions climate. Dissimilarity represents resistance to change between simulation years 2000 and 2100 .
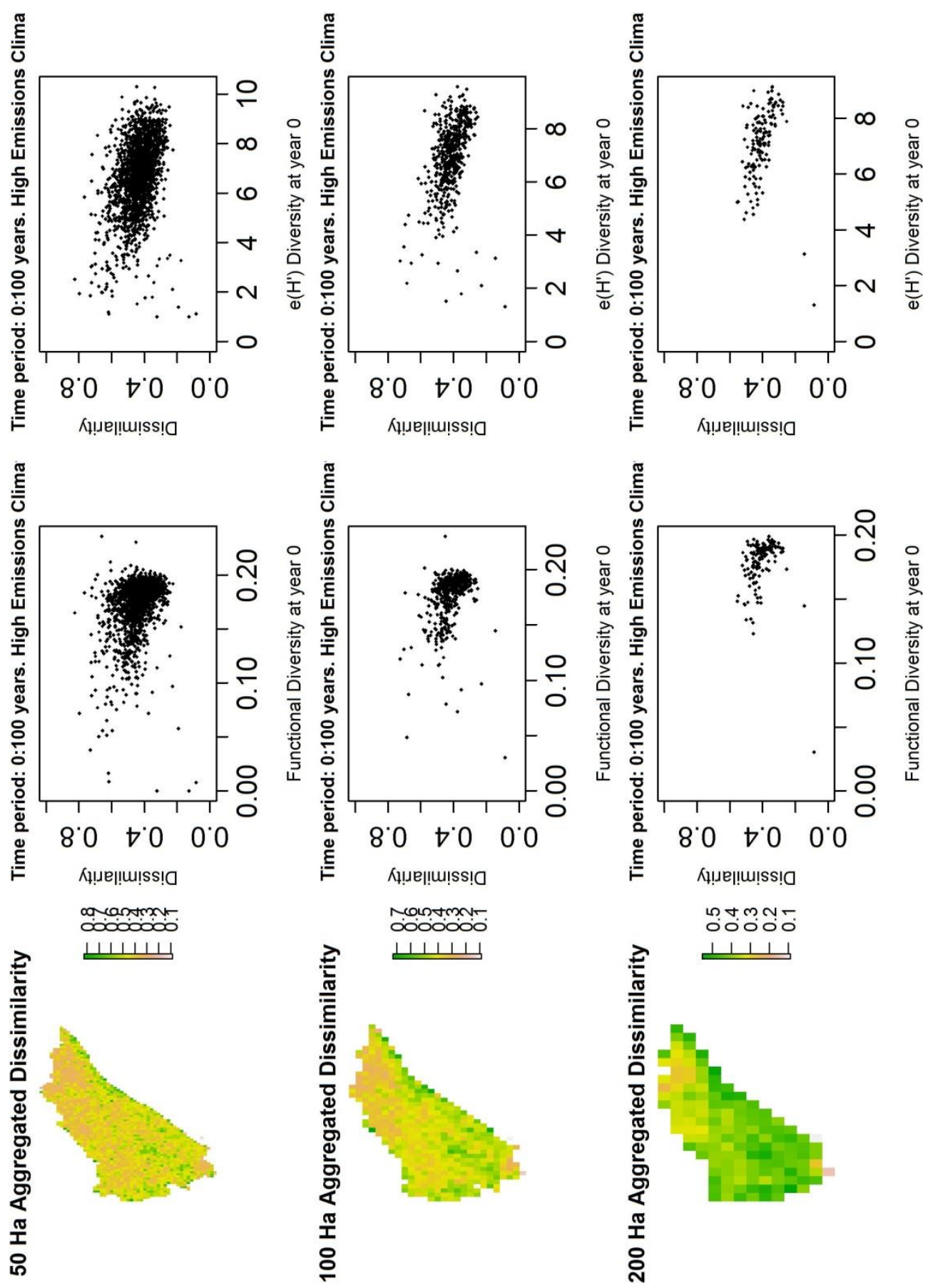
Figure 5.7: Three spatial resolutions of species and functional diversity effect on dissimilarity in the Michigan landscape under BAU management and high emissions climate. Dissimilarity represents resistance to change between simulation years 2000 and 2100 .
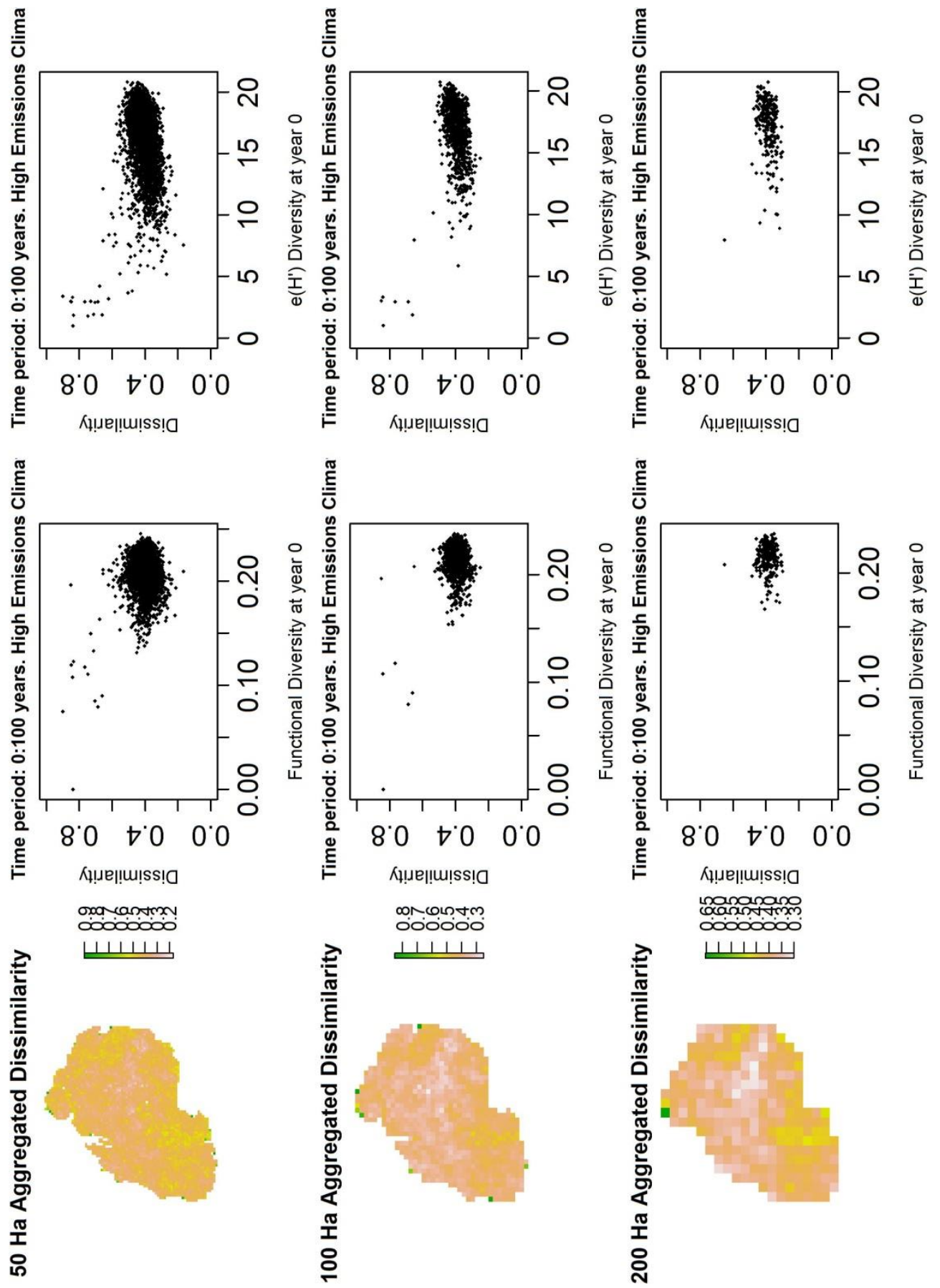
Figure 5.8: Resilience of forest AGB and species dissimilarity to the effect of simulated fires and climate change at year 2005 under alternative management scenarios. Pre-fire conditions are represented by coordinates $(0,0)$ in graph. Successive time steps following fires are represented by line segments between small circles. Variance between fires is represented by dashed lines (+ - standard error). Inflection point of dissimilarity is where species composition and abundance is closest to prefire conditions followed by successional departure. Conditions after 50 years are represented by colored square.
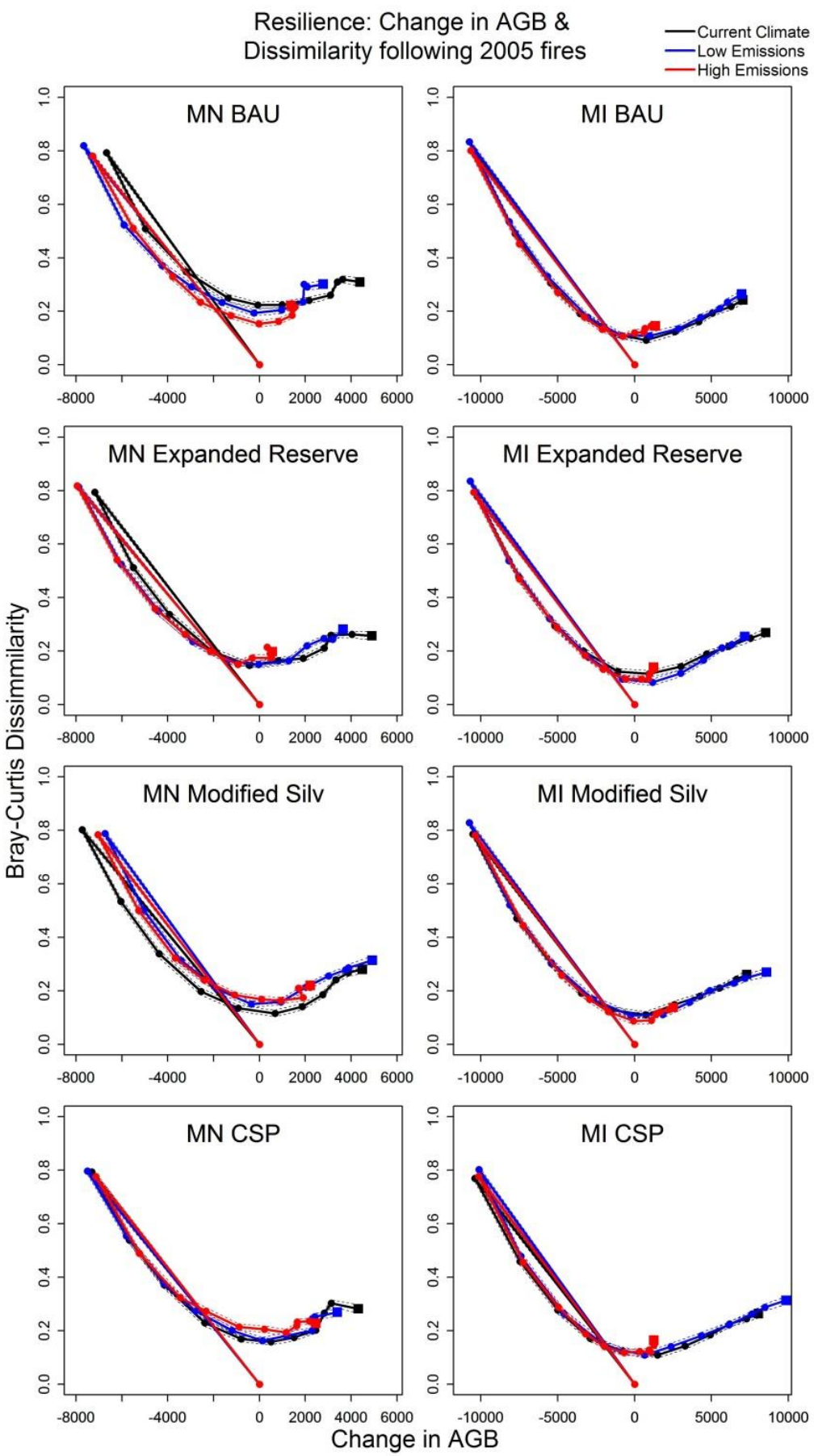
Figure 5.9: Resilience of forest AGB and species dissimilarity to the effect of simulated fires and climate change at year 2100 under alternative management scenarios. Full description of graph is provided in Figure 5.8 caption.
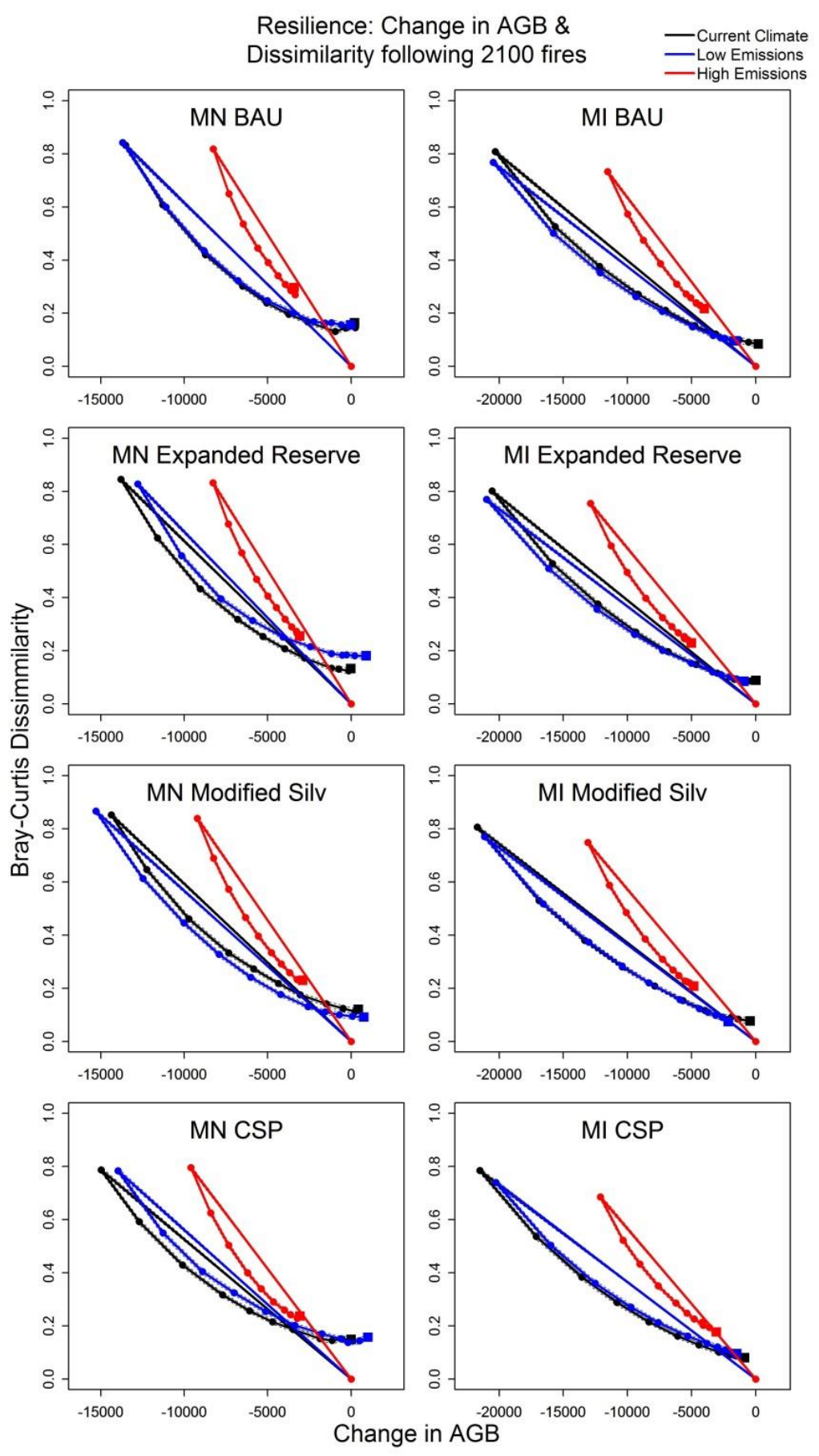


\section{Chapter 6: Summary}

My dissertation research described multiple elements of changing forests to the effects of climate change and management. Although my research was based on northern Great Lake landscapes, results from this work should be applicable to other regions around the globe. For this reason, the landscapes should be considered case studies. By providing detailed descriptions of the study regions, future comparisons of my results from these landscapes can be made. In other landscapes throughout the boreal and temperate region and beyond, productivity and/or resistance to changing species composition may decline. In these systems, the relationship between diversity (species and functional) and stability may become more important. My results describe these relationships under simulations of plausible future emission scenarios and multiple spatial scales. By evaluating possible changes to aboveground biomass (AGB), aboveground annual net primary productivity $\left(\mathrm{ANPP}^{-\mathrm{yr}}\right)$, species diversity, and functional diversity, my results will be valuable to others considering or evaluating management alternatives to preserve these, and other functions in the face of climate change.

In chapter one, I introduced the study areas, forest types, and disturbance regimes. I provided a description of the potential threat of climate change on northern Great Lake systems. In addition, I provided an introduction to how resistance and resilience concepts can be used to understand the vulnerability of forests to climate change and other disturbances. I introduced management strategies specifically designed to increase resilience and maintain ecosystem services in the face of climate change. Finally, I 
introduced the coupled LANDIS-II and PnET-II simulation models describing their functions, and parameters.

In chapter two, I demonstrated how a decline in forest productivity (ANPP) due to climate change generated a stronger positive relationship between productivity and species diversity. The relationship between productivity and diversity has been largely discussed and debated. My research of productivity and tree species diversity contributes to previously understudied relationships under projections of climate change. My results underscore the importance of species diversity preservation in sites where productivity is expected to decline. Species diversity is valued for the moral obligation to preserve species (Wilson 2010). Linking diversity to ecosystem function (i.e., productivity) under climate change adds both a fundamental understanding to the interactions of climate change on these systems and adds value to the preservation of species diversity under climate change.

I described the spatial variation in tree species diversity due to soils, climate, and management differences. These results may indicate where variation in diversity due to soils, climate, and management from other systems may be expected. In addition, I described the general decline in aboveground biomass (AGB) under a high emission climate scenario, and specifically identified boreal species and forest types expected to decline. My results show that by 2150 , under a high emission climate scenario, boreal species as well as many temperate species may decline. Species found in borealtemperate ecotones across the globe may experience similar behavior where boreal species may decline and temperate tree species fail to maintain ecosystem functions previously provided by declining species. 
In chapter three, I simulated the potential effects of two alternative management strategies. I demonstrated that under an expanded reserves scenario, at-risk boreal species such as balsam fir (Abies balsamea) could be maintained longer within reserves. In addition, species diversity and AGB could be increased within reserves. Under a modified silviculture scenario, my simulations demonstrated that more onsite AGB could be maintained at the expense of a reduction in harvested AGB. More interest and value is placed on carbon sequestration around the globe. My results provide a framework that can be applied to other forested landscapes to explore strategies to increase carbon growth and storage while continuing to harvest AGB.

Unfortunately, my scenarios suggested that the effect of alternative management was largely outweighed by the effect of climate change. This implies that management for climate change around the globe may require changing expectations. For example, future management may require accepting the loss of an extant tree species in exchange for facilitating a climate suitable tree species capable of maintaining an ecosystem function (e.g. carbon sequestration). Furthermore, future forest management may require considering tradeoffs between facilitating adaptation (e.g., increasing diversity) in exchange for climate change mitigation (e.g., promoting low diversity high yield species) (e.g., D’ Amato et al. 2011, Burton et al. 2013). Finally, my results demonstrate the challenge to climate change management. This supports global interests to reduce carbon emissions.

In chapter four, I demonstrated the potential effect of broad scale planting of species from outside their range (climate suitable planting (CSP)). I described the effect of CSP on ANPP, species, and functional diversity. These results suggest that CSP 
increases ANPP and AGB marginally under a high emissions climate scenario. My results suggest that CSP has the potential to maintain or increase otherwise declining ecosystem function; however the CSP species that I simulated were not optimized for future high emissions climate. As expected, CSP increased species diversity; however CSP resulted in an asymptote of increased functional diversity. This implies that sites with initial high functional diversity may not benefit from additional species, especially additional species that are similar in function to current species.

My results imply species selection tradeoffs that will challenge successful CSP management outcomes: 1) Species selection should be acceptable to policy makers (I choose species close to or in low abundance within current landscape extents). 2) Tree species selection should be suitable for a future climate given long longevity expected of tree species. 3) For CSP tree species to establish, CSP seedlings and saplings must survive current climate. 4) If management objectives are specifically focused at increasing or maintaining functional diversity under climate change, CSP species should be selected based on traits expected to be lost rather than species with traits expected to be maintained.

In chapter five, I measured the resistance and resilience of forests to the effect of simulated climate change and interactions with additional disturbances. I assessed the relationship between tree species and functional diversity and resistance as measured by dissimilarity. I found that under low diversity, diversity did affect resistance at multiple spatial scales. The relationship between diversity and resistance provides additional support for the preservation of diversity (as discussed in chapter 2) and contributes to a broader understanding of the mechanisms of stability under climate change. In addition, 
these results contribute to a broader understanding of the interaction between spatial scale, diversity, and resistance.

As resilience can be defined in multiple ways I introduced novel methodology to consider resilience using multiple dimensions of identity. Representing two measures of resilience as separate axes provides a valuable framework to help managers and ecologists measure and communicate principles of resilience. Future research may replace the axes I used (AGB and species composition flux) to meet specific objectives. Additionally, future developments may find ways to add additional axes (more than two) to my methodology.

My results however, indicate that resilience of initial species composition and AGB declined with climate change and is affected little by management alternatives at the landscape scale. These results should underscore the importance of finding more innovative strategies to address climate change management while considering the positive effects of management strategies explored.

The Great Lakes region provided excellent case study landscapes where management effects are interacting with natural disturbance regimes and climate change effects are expected to be large. The boreal-temperate transition zone encompasses a unique ecotone that provides many ecosystem services and functions. Climate change projections are expected to change these ecological systems drastically.

Although my results suggest the ability of alternative management to shape landscape trajectories is limited under the high emissions climate scenario, simulations of the low emission climate scenario suggest many similar outcomes as simulated under current climate. Reducing global climate emissions to more closely match my low 
emissions climate future has broad implications for more successful climate change forest management. 


\section{Citations:}

Aber, J. D., and C. A. Federer. 1992. A generalized, lumped-parameter model of photosynthesis, evapotranspiration and net primary production in temperate and boreal forest ecosystems. Oecologia 92:463-474.

Aber, J. D., J. M. Melillo, and C. A. Federer. 1982. Predicting the effects of rotation length, harvest intensity, and fertilization on fiber yield from northern hardwood forests in New England. Forest Science 28:31-45.

Aber, J. D., S. V. Ollinger, C. A. Federer, P. B. Reich, M. L. Goulden, D. W. Kicklighter, J. M. Melillo, and R. G. Lathrop. 1995. Predicting the effects of climate change on water yield and forest production in the northeastern United States. Climate Research 5:207-222.

Ackerly, D. D. 2003. Community assembly, niche conservatism, and adaptive evolution in changing environments. International Journal of Plant Sciences 164:S165S184.

Adger, W., S. Dessai, M. Goulden, M. Hulme, I. Lorenzoni, D. Nelson, L. Naess, J. Wolf, and A. Wreford. 2009. Are there social limits to adaptation to climate change? Climatic Change 93:335-354.

Ainsworth, E. A., C. R. Yendrek, S. Sitch, W. J. Collins, and L. D. Emberson. 2012. The effects of tropospheric ozone on net primary productivity and implications for climate change. Annual review of plant biology 63:637-661.

Albert, D. A. 1995. Regional landscape ecosystems of Michigan, Minnesota, and Wisconsin : a working map and classification. 4th rev., July 1994. edition. North Central Forest Experiment Station, Forest Service, U.S. Dept. of Agriculture, St. Paul, Minn.

Allen, C. D., and D. D. Breshears. 1998. Drought-induced shift of a forest-woodland ecotone: Rapid landscape response to climate variation. Proceedings of the National Academy of Sciences 95:14839-14842.

Anderson, C. E., K. Chapman, M. White, and M. Cornett. 2002. Effects of browsing control on establishment and recruitment of Eastern white pine (Pinus strobus L.) at Cathedral Grove, Lake Superior Highlands, Minnesota, USA. Natural Areas Journal 22:202-210.

Anderson, M. G., and C. E. Ferree. 2010. Conserving the stage: Climate change and the geophysical underpinnings of species diversity. Plos One 5:1-10.

Anderson, M. J., K. E. Ellingsen, and B. H. McArdle. 2006. Multivariate dispersion as a measure of beta diversity. Ecology Letters 9:683-693.

Andresen, J., S. Hilberg, K. Kunkel, and M. R. C. Center. 2012. Historical climate and climate trends in the Midwestern USA.J. Winkler, J. Andresen, J. Hatfield, D. Bidwell, and D. Brown, coordinators. Available from the Great Lakes Integrated Sciences and Assessments (GLISA) Center, http://glisa.msu.edu/docs/NCA/MTIT_Historical.pdf. Pages 1-18.

Barlow, C., and P. Martin. 2004. Bring Torreya taxifolia north now. Wild Earth Winter/Spring:52-56. 
Bennett, E. M., G. Cumming, and G. D. Peterson. 2005. A systems model approach to determining resilience surrogates for case studies. Ecosystems 1:945:957.

Bentz, B. J., J. A. Logan, and G. D. Amman. 1991. Temperature-Dependent Development of the Mountain Pine-Beetle (Coleoptera: Scolytidae) and Simulation of Its Phenology. Canadian Entomologist 123:1083-1094.

Bentz, B. J., J. Régnière, C. J. Fettig, E. M. Hansen, J. L. Hayes, J. A. Hicke, R. G. Kelsey, J. F. Negrón, and S. J. Seybold. 2010. Climate change and bark beetles of the Western United States and Canada: Direct and indirect effects. Bioscience 60:602-613.

Berg, B. 1988. Dynamics of nitrogen $(15 \mathrm{~N})$ in decomposing Scots pine (Pinus sylvestris) needle litter. Long-term decomposition in a Scots pine forest. VI. Canadian Journal of Botany 66:1539-1546.

Berger, A. L., B. Palik, A. W. D'Amato, S. Fraver, J. B. Bradford, K. Nislow, D. King, and R. T. Brooks. 2013. Ecological Impacts of Energy-Wood Harvests: Lessons from Whole-Tree Harvesting and Natural Disturbance. Journal of Forestry 111:139-153.

Birks, H., and H. H. Birks. 2008. Biological responses to rapid climate change at the Younger Dryas-Holocene transition at Kråkenes, western Norway. The Holocene 18:19-30.

Blinn, C. R., and E. R. Buckner. 1989. Normal foliar nutrient levels in North American forest trees: a summary. Station Bulletin 590-1989. Minnesota Agriculture Experiment Station, University of Minnesota, St. Paul, Minnesota, USA. Pages 128.

Blois, J. L., P. L. Zarnetske, M. C. Fitzpatrick, and S. Finnegan. 2013. Climate Change and the Past, Present, and Future of Biotic Interactions. Science 341:499-504.

Bøhn, T., and P.-A. Amundsen. 2004. Ecological Interactions and Evolution: Forgotten Parts of Biodiversity? Bioscience 54:804-805.

Bolstad, P. V., K. J. Davis, J. Martin, B. D. Cook, and W. Wang. 2004. Component and whole-system respiration fluxes in northern deciduous forests. Tree Physiology 24:493-504.

Bolster, K. L., M. E. Martin, and J. D. Aber. 1996. Determination of carbon fraction and nitrogen concentration in tree foliage by near infrared reflectances: a comparison of statistical methods. Canadian Journal of Forest Research 26:590-600.

Böttcher, H., P. J. Verkerk, M. Gusti, P. Havlík, and G. Grassi. 2012. Projection of the future $\mathrm{EU}$ forest $\mathrm{CO} 2$ sink as affected by recent bioenergy policies using two advanced forest management models. GCB Bioenergy 4:773-783.

Bowler, R., A. L. Fredeen, M. Brown, and T. Andrew Black. 2012. Residual vegetation importance to net $\mathrm{CO} 2$ uptake in pine-dominated stands following mountain pine beetle attack in British Columbia, Canada. Forest Ecology and Management 269:82-91.

Bradford, J. B., and D. N. Kastendick. 2010. Age-related patterns of forest complexity and carbon storage in pine and aspen-birch ecosystems of northern Minnesota, USA. Canadian Journal of Forest Research 40:401-409.

Bradshaw, C. J., I. G. Warkentin, and N. S. Sodhi. 2009. Urgent preservation of boreal carbon stocks and biodiversity. Trends in Ecology \& Evolution 24:541-548. 
Bradshaw, R., and M. Lindbladh. 2005. Regional spread and stand-scale establishment of Fagus sylvatica and Picea abies in Scandinavia. Ecology 86:1679-1686.

Bradshaw, R. H. W., N. Kito, and T. Giesecke. 2010. Factors influencing the Holocene history of Fagus. Forest Ecology and Management 259:2204-2212.

Bradt, P., M. Urban, N. Goodman, S. Bissell, and I. Spiegel. 1999. Stability and resilience in benthic macroinvertebrate assemblages. Hydrobiologia 403:123-133.

Breed, M. F., M. G. Stead, K. M. Ottewell, M. G. Gardner, and A. J. Lowe. 2013. Which provenance and where? Seed sourcing strategies for revegetation in a changing environment. Conservation Genetics 14:1-10.

Breshears, D. D., N. S. Cobb, P. M. Rich, K. P. Price, C. D. Allen, R. G. Balice, W. H. Romme, J. H. Kastens, M. L. Floyd, J. Belnap, J. J. Anderson, O. B. Myers, and C. W. Meyer. 2005. Regional vegetation die-off in response to global-change-type drought. Proceedings of the National Academy of Sciences of the United States of America 102:15144-15148.

Buma, B., and C. A. Wessman. 2013. Forest resilience, climate change, and opportunities for adaptation: a specific case of a general problem. Forest Ecology and Management 306:216-225.

Burns, R. M., and B. H. Honkala. 1990. Silvics of North America. Agricultural handbook 654, Washington, DC: US Department of Agriculture, Forest Service.

Burton, J. I., A. Ares, D. H. Olson, and K. J. Puettmann. 2013. Management trade-off between aboveground carbon storage and understory plant species richness in temperate forests. Ecological Applications 23:1297-1310.

Busby, P. E., and C. D. Canham. 2011. An exotic insect and pathogen disease complex reduces aboveground tree biomass in temperate forests of eastern North America. Canadian Journal of Forest Research 41:401-411.

Butler, B. J. 2008. Family Forest Owners of the United States, 2006. Gen. Tech. Rep. NRS-27. Newtown Square, PA: Department of Agriculture, Forest Service, Northern Research Station. 72 p.

Campbell, E. M., S. C. Saunders, D. Coates, D. Meidinger, A. MacKinnon, G. O'Neill, D. MacKillop, C. DeLong, and D. Morgan. 2009. Ecological resilience and complextity: a theoretical framework for understanding and managing British Columbia's forest ecosystems in a changing climate. British Columbia Ministry Forest Range Forest Science Program, Victoria, BC.

Cardille, J. A., and S. J. Ventura. 2001. Occurrence of wildfire in the northern Great Lakes Region: Effects of land cover and land ownership assessed at multiple scales. International Journal of Wildland Fire 10:145-154.

Cardille, J. A., S. J. Ventura, and M. G. Turner. 2001. Enviornmental and social factors influencing wildfires in the Upper Midwest, United States. Ecological Applications 11:111-127.

Carmean, W. H., J. T. Hahn, and R. D. Jacobs. 1989. Site index curves for forest tree species in the Eastern United States 153. US Department of Agriculture, Forest Service.

Carpenter, S., F. Westley, and M. Turner. 2005. Surrogates for Resilience of SocialEcological Systems. Ecosystems 8:941-944. 
Carpenter, S. R., and J. F. Kitchell. 1993. The Trophic cascade in lakes. Cambridge University Press, Cambridge ; New York.

Carpenter, S. R., M. Walker, J. Anderies, and B. Abel. 2001. From metaphor to measurement: resilience of what to what? Ecosystems 4:765:781.

Caspersen, J. P., S. W. Pacala, J. C. Jenkins, G. C. Hurtt, P. R. Moorcroft, and R. A. Birdsey. 2000. Contributions of land-use history to carbon accumulation in U.S. forests. Science 290:1148-1151.

Chapin, F. S., K. Danell, T. Elmqvist, C. Folke, and N. Fresco. 2007. Managing Climate Change Impacts to Enhance the Resilience and Sustainability of Fennoscandian Forests. AMBIO: A Journal of the Human Environment 36:528-533.

Chapin, F. S., O. E. Sala, I. C. Burke, J. P. Grime, D. U. Hooper, W. K. Lauenroth, A. Lombard, H. A. Mooney, A. R. Mosier, and S. Naeem. 1998. Ecosystem consequences of changing biodiversity. Bioscience 48:45-52.

Chapuis, J.-L., Y. Frenot, and M. Lebouvier. 2004. Recovery of native plant communities after eradication of rabbits from the subantarctic Kerguelen Islands, and influence of climate change. Biological Conservation 117:167-179.

Clark, G. F. 2013. Biodiversity-invasibility mechanisms are mediated by niche dimensionality. Functional Ecology 27:5-6.

Clark, K. L., N. Skowronski, J. Hom, M. J. Duveneck, Y. Pan, S. Van Tuyl, J. Cole, M. Patterson, and S. Maurer. 2009. Decision support tools to improve the effectiveness of hazardous fuel reduction treatments in the New Jersey Pine Barrens. International Journal of Wildland Fire 18:268-277.

Cleland, D. T., T. R. Crow, S. C. Saunders, D. I. Dickmann, A. L. Maclean, J. K. Jordan, R. L. Watson, A. M. Sloan, and K. D. Brosofske. 2004. Characterizing historical and modern fire regimes in Michigan (USA): A landscape ecosystem approach. Landscape Ecology 19:311-325.

Clements, F. E. 1916. Plant succession; an analysis of the development of vegetation. Carnegie institution of Washington, Washington,.

Clemmensen, K. E., A. Bahr, O. Ovaskainen, A. Dahlberg, A. Ekblad, H. Wallander, J. Stenlid, R. D. Finlay, D. A. Wardle, and B. D. Lindahl. 2013. Roots and associated fungi drive long-term carbon sequestration in boreal forest. Science 339:1615-1618.

Collingham, Y. C., and B. Huntley. 2000. Impacts of habitat fragmentation and patch size upon migration rates. Ecological Applications 10:131-144.

Cornelissen, J., S. Lavorel, E. Garnier, S. Diaz, N. Buchmann, D. Gurvich, P. Reich, H. Ter Steege, H. Morgan, and M. Van Der Heijden. 2003. A handbook of protocols for standardised and easy measurement of plant functional traits worldwide. Australian Journal of Botany 51:335-380.

Costanza, R. 2012. Ecosystem health and ecological engineering. Ecological Engineering 45:24-29.

Costanza, R., and M. Mageau. 1999. What is a healthy ecosystem? Aquatic Ecology 33:105-115.

Côté, I. M., and E. S. Darling. 2010. Rethinking ecosystem resilience in the face of climate change. PLoS biology 8:e1000438. 
Cumming, G., G. Barnes, S. Perz, M. Schmink, K. Sieving, J. Southworth, M. Binford, R. Holt, C. Stickler, and T. Van Holt. 2005. An Exploratory Framework for the Empirical Measurement of Resilience. Ecosystems 8:975-987.

Cumming, G., and J. Collier. 2005. Change and Identy in Complex Systems. Ecology and Society 1:10:29.

Cumming, G. S., D. H. M. Cumming, and C. L. Redman. 2006. Scale mismatches in social-ecological systems: Causes, consequences, and solutions. Ecology and Society 11.

Curtis, J. T. 1959. The vegetation of Wisconsin; an ordination of plant communities. University of Wisconsin Press, Madison, Wisconsin.

D' Amato, A. W., N. W. Bolton, C. R. Blinn, and A. R. Ek. 2009. Current status and long-term trends of silvicultural practices in Minnesota: A 2008 assessment. Department of Forest Resources University of Minnesota. St. Paul, Minnesota.

D' Amato, A. W., J. B. Bradford, S. Fraver, and B. J. Palik. 2011. Forest management for mitigation and adaptation to climate change: Insights from long-term silviculture experiments. Forest Ecology and Management 262:803-816.

Dale, V. H., L. A. Joyce, S. McNulty, R. P. Neilson, M. P. Ayres, M. D. Flannigan, P. J. Hanson, L. C. Irland, A. E. Lugo, C. J. Peterson, D. Simberloff, F. J. Swanson, B. J. Stocks, and B. Michael Wotton. 2001. Climate Change and Forest Disturbances. Bioscience 51:723-734.

Daly, C., and W. Gibson. 2002. 103-Year high-resolution temperature climate data set for the conterminous United States, The PRISM Climate Group, Oregon State University, Oregon

Daly, C., M. P. Widrlechner, M. D. Halbleib, J. I. Smith, and W. P. Gibson. 2012. Development of a New USDA Plant Hardiness Zone Map for the United States. Journal of Applied Meteorology and Climatology 51:242-264.

Danell, K., R. Bergström, L. Edenius, and G. Ericsson. 2003. Ungulates as drivers of tree population dynamics at module and genet levels. Forest Ecology and Management 181:67-76.

Davidson, E. A., and I. A. Janssens. 2006. Temperature sensitivity of soil carbon decomposition and feedbacks to climate change. Nature 440:165-173.

Davidson, I., and C. Simkanin. 2008. Skeptical of Assisted Colonization. Science 322:1048-1049.

Davis, M., C. Douglas, R. Calcote, K. L. Cole, M. G. Winkler, and R. Flakne. 2000. Holocene climate in the Western Great Lakes national parks and lakeshores: implications for future climate change. Conservation Biology 14:968-983.

De Frenne, P., F. Rodríguez-Sánchez, D. A. Coomes, L. Baeten, G. Verstraeten, M. Vellend, M. Bernhardt-Römermann, C. D. Brown, J. Brunet, J. Cornelis, G. M. Decocq, H. Dierschke, O. Eriksson, F. S. Gilliam, R. Hédl, T. Heinken, M. Hermy, P. Hommel, M. A. Jenkins, D. L. Kelly, K. J. Kirby, F. J. G. Mitchell, T. Naaf, M. Newman, G. Peterken, P. Petř́k, J. Schultz, G. Sonnier, H. Van Calster, D. M. Waller, G.-R. Walther, P. S. White, K. D. Woods, M. Wulf, B. J. Graae, and K. Verheyen. 2013. Microclimate moderates plant responses to macroclimate warming. Proceedings of the National Academy of Sciences. 
Deckard, D., and J. Skurla. 2011. Economic Contribution of Minnesota's Forest Products Industry-2011 Edition. Division of Forestry. Minnesota Department of Natural Resources.

Delworth, T. L., A. J. Broccoli, A. Rosati, R. J. Stouffer, V. Balaji, J. A. Beesley, W. F. Cooke, K. W. Dixon, J. Dunne, and K. Dunne. 2006. GFDL's CM2 global coupled climate models. Part I: Formulation and simulation characteristics. Journal of Climate 19:643-674.

Díaz, S., S. Lavorel, F. de Bello, F. Quétier, K. Grigulis, and T. M. Robson. 2007. Incorporating plant functional diversity effects in ecosystem service assessments. Proceedings of the National Academy of Sciences 104:20684-20689.

Diffenbaugh, N. S., and C. B. Field. 2013. Changes in Ecologically Critical Terrestrial Climate Conditions. Science 341:486-492.

Dixon, G. E., and C. E. Keyser. 2008. Lake States (LS) Variant Overview-Forest Vegetation Simulator. Internal Report. Fort Collins, CO: US Department of Agriculture, Forest Service, Forest Managment Service Center. 44.p.

Duveneck, M. J., and R. M. Scheller. in prep. Climate change effects to productivity and functional diversity in northern Great Lake forests with climate suitable planting Ecological Applications.

Duveneck, M. J., R. M. Scheller, and M. White, A. in review. Effects of alternative forest management strategies in the face of climate change in the northern Great Lake region. Canadian Journal of Forest Research.

Duveneck, M. J., R. M. Scheller, M. White, A, S. Handler, and C. Ravenscroft. accepted. Climate change effects to northern Great Lake forests: A case for preserving diversity. Ecosphere.

Edburg, S. L., J. A. Hicke, P. D. Brooks, E. G. Pendall, B. E. Ewers, U. Norton, D. Gochis, E. D. Gutmann, and A. J. H. Meddens. 2012. Cascading impacts of bark beetle-caused tree mortality on coupled biogeophysical and biogeochemical processes. Frontiers in Ecology and the Environment 10:416-424.

Eisenhauer, N., W. Schulz, S. Scheu, and A. Jousset. 2013. Niche dimensionality links biodiversity and invasibility of microbial communities. Functional Ecology 27:282-288.

Ellison, A. M., M. S. Bank, B. D. Clinton, E. A. Colburn, K. Elliott, C. R. Ford, D. R. Foster, B. D. Kloeppel, J. D. Knoepp, G. M. Lovett, J. Mohan, D. A. Orwig, N. L. Rodenhouse, W. V. Sobczak, K. A. Stinson, J. K. Stone, C. M. Swan, J. Thompson, B. Von Holle, and J. R. Webster. 2005. Loss of foundation species: consequences for the structure and dynamics of forested ecosystems. Frontiers in Ecology and the Environment 3:479-486.

Elton, C. S. 1958. The ecology of invasions by animals and plants. Methuen, London,.

ESRI. 2011. ArcGIS Desktop: Release 10. Redlands, CA. Enviornmental Systems Research Institute.

Eyre, F. H., and Society of American Foresters. 1980. Forest cover types of the United States and Canada. Society of American Foresters, Washington, D.C.

Fahey, T. J., P. B. Woodbury, J. J. Battles, C. L. Goodale, S. P. Hamburg, S. V. Ollinger, and C. W. Woodall. 2010. Forest carbon storage: ecology, management, and policy. Frontiers in Ecology and the Environment 8:245-252. 
Falkowski, M. J. IN PREP. Forest biomass information system.

Falkowski, M. J., A. T. Hudak, N. L. Crookston, P. E. Gessler, E. H. Uebler, and A. M. S. Smith. 2010. Landscape-scale parameterization of a tree-level forest growth model: a k-nearest neighbor imputation approach incorporating LiDAR data. Canadian Journal of Forest Research 40:184-199.

Fisichelli, N., L. Frelich, and P. Reich. 2013. Climate and interrelated tree regeneration drivers in mixed temperate-boreal forests. Landscape Ecology 28:149-159.

Fisichelli, N., L. E. Frelich, and P. B. Reich. 2012. Sapling growth responses to warmer temperatures 'cooled' by browse pressure. Global Change Biology 18:3455-3463.

Flader, S. 1983. The Great Lakes forest : an environmental and social history. Published by the University of Minnesota Press in association with Forest History Society, Inc., Santa Cruz, Minneapolis.

Folke, C., S. Carpenter, B. Walker, M. Scheffer, T. Elmqvist, L. Gunderson, and C. Holling. 2004a. Regime shifts, resilience, and biodiversity in ecosystem management. Annual Review of Ecology, Evolution, and Systematics:557-581.

Folke, C., S. Carpenter, B. Walker, M. Scheffer, T. Elmqvist, L. Gunderson, and C. S. Holling. 2004b. Regime Shifts, Resilience, and Biodiversity in Ecosystem Management. Annual Review of Ecology, Evolution, and Systematics 35:557581.

Folke, C., C. S. Holling, and C. Perrings. 1996. Biological diversity, ecosystems, and the human scale. Ecological Applications 6:1018-1024.

Foster, D. R., D. H. Knight, and J. F. Franklin. 1998. Landscape patterns and legacies resulting from large, infrequent forest disturbances. Ecosystems 1:497-510.

Fownes, J. H. 1985. Water use and primary production of Wisconsin hardwood forests. Dissertation, University of Wisconsin-Madison, Madison, WI, USA.

Frelich, L. E. 2002. Forest dynamics and disturbance regimes : studies from temperate evergreen-deciduous forests. Cambridge University Press, New York.

Frelich, L. E., and P. B. Reich. 2010. Will environmental changes reinforce the impact of global warming on the prairie-forest border of central North America? Frontiers in Ecology and the Environment 8:371-378.

Gauthier, M.-M., K. E. Zellers, M. Löf, and D. F. Jacobs. 2013. Inter-and intra-specific competitiveness of plantation-grown American chestnut (Castanea dentata). Forest Ecology and Management 291:289-299.

Geiszler, D. R., R. I. Gara, C. H. Driver, V. F. Gallucci, and R. E. Martin. 1980. Fire, Fungi, and Beetle Influences on a Lodgepole Pine Ecosystem of South-Central Oregon. Oecologia 46:239-243.

Gheorghe, I. F., I. A. Biriş, and C. M. Valcu. 2010. Efficiency of different forest types in carbon storage depends on their internal structure. Acta Societatis Botanicorum Poloniae 79:325-332.

Glasby, T. M., and A. J. Underwood. 1996. Sampling to differentiate between pulse and press perturbations. Environmental Monitoring and Assessment 42:241-252.

Gleason, H. A. 1926. The individualistic concept of the plant association. 21, 92-110. The American Midland Naturalist 21:92-110.

Goldblum, D., and L. S. Rigg. 2010. The deciduous forest-boreal forest ecotone. Geography Compass 4:701-717. 
Gotelli, N. J., and A. M. Ellison. 2004. A primer of ecological statistics. Sinauer Associates Publishers, Sunderland, Mass.

Gough, C. M., C. S. Vogel, B. Hardiman, and P. S. Curtis. 2010. Wood net primary production resilience in an unmanaged forest transitioning from early to middle succession. Forest Ecology and Management 260:36-41.

Gough, C. M., C. S. Vogel, H. P. Schmid, and P. S. Curtis. 2008. Controls on annual forest carbon storage: Lessons from the past and predictions for the future. Bioscience 58:609-622.

Gray, L. K., T. Gylander, M. S. Mbogga, P.-y. Chen, and A. Hamann. 2010. Assisted migration to address climate change: recommendations for aspen reforestation in western Canada. Ecological Applications 21:1591-1603.

Green, S. D., J. E. Erickson, and E. L. Kruger. 2003. Foliar morphology and canopy nitrogen as predictors of light-use efficiency in terrestrial vegetation. Agricultural and Forest Meteorology 115:163-171.

Grimm, V., E. Schmidt, and C. Wissel. 1992. On the Application of Stability Concepts in Ecology. Ecological Modelling 63:143-161.

Groffman, P., J. Baron, T. Blett, A. Gold, I. Goodman, L. Gunderson, B. Levinson, M. Palmer, H. Paerl, G. Peterson, L. Poff, D. Rejeski, J. Reynolds, M. Turner, K. Weathers, and J. Wiens. 2006. Ecological Thresholds: The Key to Successful Environmental Management or an Important Concept with No Practical Application? Ecosystems 9:1-13.

Gunderson, L. H. 2000. Ecological Resilience--In Theory and Application. Annual Review of Ecology and Systematics 31:425-439.

Gunderson, L. H., C. R. Allen, and C. S. Holling. 2010. Foundations of ecological resilience. Island Press, Washington.

Gunderson, L. H., and C. S. Holling. 2002. Panarchy : understanding transformations in human and natural systems. Island Press, Washington, DC.

Gustafson, E. J., and C. Loehle. 2006. Effects of parcelization and land divestiture on forest sustainability in simulated forest landscapes. Forest Ecology and Management 236:305-314.

Gustafson, E. J., S. R. Shifley, D. J. Mladenoff, K. K. Nimerfro, and H. S. He. 2000. Spatial simulation of forest succession and timber harvesting using LANDIS. Canadian Journal of Forest Research-Revue Canadienne De Recherche Forestiere 30:32-43.

Gustafson, E. J., A. Z. Shvidenko, B. R. Sturtevant, and R. M. Scheller. 2010. Predicting global change effects on forest biomass and composition in south-central Siberia. Ecological Applications 20:700-715.

Hale, C. M., L. E. Frelich, P. B. Reich, and J. Pastor. 2008. Exotic earthworm effects on hardwood forest floor, nutrient availability and native plants: a mesocosm study. Oecologia 155:509-518.

Hampe, A., and R. J. Petit. 2005. Conserving biodiversity under climate change: the rear edge matters. Ecology Letters 8:461-467.

Hanberry, B., B. Palik, and H. He. 2012. Comparison of historical and current forest surveys for detection of homogenization and mesophication of Minnesota forests. Landscape Ecology:1-18. 
Handler, S., M. J. Duveneck, L. Iverson, E. Peters, R. M. Scheller, K. R. Wythers, L. Brandt, P. Butler, M. Janowiak, C. Swanston, K. Barrett, R. Kolka, C.

McQuinston, B. Palik, P. B. Reich, C. Turner, M. A. White, C. Adams, A. W. D' Amato, S. Hagell, R. Johnson, P. Larson, M. Larson, S. Matthews, R. Montgomery, S. Olson, M. Peters, A. Prasad, J. Rajala, P. D. Shannon, J. Daley, M. Davenport, M. R. Emery, D. Fehringer, C. L. Hoving, G. Johnson, L. B. Johnson, D. Neitzel, A. Rissman, C. Rittenhouse, and R. Ziel. in press-a. Minnesota Forest Ecosystem Vulnerability Assessment and Synthesis: A report from the Northwoods Climate Change Response Framework. Gen. Tech. Rep. NRS-XX. Newtown Square, PA; U.S. Department of Agriculture, Forest Service, Northern Research Station. XXX p.

Handler, S., M. J. Duveneck, L. Iverson, E. Peters, R. M. Scheller, K. R. Wythers, L. Brandt, P. Butler, M. Janowiak, C. Swanston, A. C. Eagle, J. G. Cohen, R. Corner, P. B. Reich, T. Baker, S. Chhin, E. Clark, D. Fehringer, J. Fosgitt, J. Gries, K. R. Hall, C. Hall, R. Heyd, C. L. Hoving, I. Ibanez, D. Kuhr, S. Matthews, H. Muladore, K. Nadelhoffer, D. Neumann, M. Peters, A. Prasad, M. Sands, R. Swaty, L. Wonch, J. Daley, M. Davenport, M. R. Emery, G. Johnson, L. B. Johnson, D. Neitzel, A. Rissman, C. Rittenhouse, and R. Zeil. in press-b. Michigan Forest Ecosystem Vulnerability Assessment and Synthesis: A report from the Northwoods Climate Change Response Framework.Gen. Tech. Rep. NRS-XX. Newtown Square, PA; U.S. Department of Agriculture, Forest Service, Northern Research Station. XXX p.

Hansen, L. J., and J. Hoffman. 2011. Climate savvy : adapting conservation and resource management to a changing world. Island Press, Washington, DC.

Hanski, I. 1994. Patch-Occupancy Dynamics in Fragmented Landscapes. Trends in Ecology \& Evolution 9:131-135.

Hanson, J. J., and C. G. Lorimer. 2007. Forest structure and light regimes following moderate wind storms: Implications for multi-cohort management. Ecological Applications 17:1325-1340.

Hardiman, B. S., G. Bohrer, C. M. Gough, C. S. Vogel, and P. S. Curtis. 2011. The role of canopy structural complexity in wood net primary production of a maturing northern deciduous forest. Ecology 92:1818-1827.

Harmon, M. E., W. K. Ferrell, and J. F. Franklin. 1990. Effects on Carbon Storage of Conversion of Old-Growth Forests to Young Forests. Science 247:699-702.

Harris, J. A., R. J. Hobbs, E. Higgs, and J. Aronson. 2006. Ecological Restoration and Global Climate Change. Restoration Ecology 14:170-176.

He, H. S., and D. J. Mladenoff. 1999. Spatially explicit and stochastic simulation of forest-landscape fire disturbance and succession. Ecology 80:81-99.

Heinselman, M. L. 1973. Fire in the virgin forests of the Boundary Waters Canoe Area, Minnesota. Quaternary Research 3:329-382.

Heinselman, M. L. 1996. The Boundary Waters Wilderness ecosystem. University of Minnesota Press, Minneapolis, Minn.

Hewitt, N., and M. Kellman. 2002. Tree seed dispersal among forest fragments: II. Dispersal abilities and biogeographical controls. Journal of Biogeography 29:351363. 
Hobbs, R. J., L. M. Hallett, P. R. Ehrlich, and H. A. Mooney. 2011. Intervention ecology: applying ecological science in the twenty-first century. Bioscience 61:442-450.

Hobbs, R. J., E. Higgs, and J. A. Harris. 2009. Novel ecosystems: implications for conservation and restoration. Trends in Ecology \& Evolution 24:599-605.

Hoegh-Guldberg, O., L. Hughes, S. McIntyre, D. B. Lindenmayer, C. Parmesan, H. P. Possingham, and C. D. Thomas. 2008. Assisted colonization and rapid climate change. Science 321:345-346.

Holdsworth, A. R., L. E. Frelich, and P. B. Reich. 2007. Effects of earthworm invasion on plant species richness in northern hardwood forests. Conservation Biology 21:997-1008.

Holling, C. S. 1973. Resilience and stability of ecological systems. Annual Review of Ecology and Systematics 4:1-23.

Holling, C. S. 1978. Adaptive environmental assessment and management. International Institute for Applied Systems Analysis, Laxenburg, Austria. Chichester, New York.

Holling, C. S. 1996. Engineering resilience vs. ecological resilience. Pages 31-43 in P. C. Schulze, editor. Engineering within ecological constraints. National Academy Press, Washington, D.C.

Holling, C. S., and G. K. Meffe. 1996. Command and control and the pathology of natural resource management. Conservation Biology 10:328-337.

Hooper, D. U., and P. M. Vitousek. 1997. The effects of plant composition and diversity on ecosystem processes. Science 277:1302-1305.

Huston, M. A. 1997. Hidden treatments in ecological experiments: re-evaluating the ecosystem function of biodiversity. Oecologia 110:449-460.

Hyvönen, R., G. I. Ågren, S. Linder, T. Persson, M. F. Cotrufo, A. Ekblad, M. Freeman, A. Grelle, I. A. Janssens, P. G. Jarvis, S. Kellomäki, A. Lindroth, D. Loustau, T. Lundmark, R. J. Norby, R. Oren, K. Pilegaard, M. G. Ryan, B. D. Sigurdsson, M. Strömgren, M. Van Oijen, and G. Wallin. 2007. The likely impact of elevated [CO2], nitrogen deposition, increased temperature and management on carbon sequestration in temperate and boreal forest ecosystems: a literature review. New Phytologist 173:463-480.

IPCC. 2007. Climate change 2007 : The physical science basis : contribution of working group I to the fourth assessment report of the Intergovernmental Panel on Climate Change. Cambridge University Press, Cambridge ; New York.

IPCC. 2013. Climate Change 2013: The Physical Science Basis.

Iverson, L. R., and A. M. Prasad. 2001. Potential changes in tree species richness and forest community types following climate change. Ecosystems 4:186-199.

Iverson, L. R., A. M. Prasad, S. N. Matthews, and M. Peters. 2008. Estimating potential habitat for 134 eastern US tree species under six climate scenarios. Forest Ecology and Management 254:390-406.

Iverson, L. R., M. W. Schwartz, and A. M. Prasad. 2004. Potential colonization of newly available tree-species habitat under climate change: An analysis for five eastern US species. Landscape Ecology 19:787-799. 
Jacobs, D. F., H. J. Dalgleish, and C. D. Nelson. 2013. A conceptual framework for restoration of threatened plants: the effective model of American chestnut (Castanea dentata) reintroduction. New Phytologist 197:378-393.

Jacobs, D. F., and L. R. Severeid. 2004. Dominance of interplanted American chestnut (Castanea dentata) in southwestern Wisconsin, USA. Forest Ecology and Management 191:111-120.

Jandl, R., M. Lindner, L. Vesterdal, B. Bauwens, R. Baritz, F. Hagedorn, D. W. Johnson, K. Minkkinen, and K. A. Byrne. 2007. How strongly can forest management influence soil carbon sequestration? Geoderma 137:253-268.

Jennings, M. 2012. Climate disruption: are we beyond the worst case scenario? Global Policy.

Jost, L. 2006. Entropy and diversity. Oikos 113:363-375.

Jurik, T. W. 1986. Temporal and spatial patterns of specific leaf weight in successional northern hardwood tree species. American Journal of Botany 73:1083-1092.

Karamanski, T. J. 1989. Deep woods frontier a history of logging in northern Michigan. Wayne State University Press, Detroit.

Kashian, D. M., and J. A. Witter. 2011. Assessing the potential for ash canopy tree replacement via current regeneration following emerald ash borer-caused mortality on southeastern Michigan landscapes. Forest Ecology and Management 261:480-488.

Keane, R. E., P. F. Hessburg, P. B. Landres, and F. J. Swanson. 2009. The use of historical range and variability (HRV) in landscape management. Forest Ecology and Management 258:1025-1037.

Keever, C. 1953. Present Composition of Some Stands of the Former Oak-Chestnut Forest in the Southern Blue Ridge Mountains. Ecology 34:44-54.

Kling, G. W., K. Hayhoe, L. B. Johnson, J. J. Magnuson, S. Polasky, S. K. Robinson, B. J. Shuter, M. M. Wander, D. J. Wuebbles, and D. R. Zak. 2003. Confronting climate change in the Great Lakes Region : impacts on our communities and ecosystems. Union of Concerned Scientists; Ecological Society of America, Cambridge, MA, Washington, D.C.

Knapp, A. K., P. A. Fay, J. M. Blair, S. L. Collins, M. D. Smith, J. D. Carlisle, C. W. Harper, B. T. Danner, M. S. Lett, and J. K. McCarron. 2002. Rainfall variability, carbon cycling, and plant species diversity in a mesic grassland. Science 298:2202-2205.

Koo, B., J. Jung, A. K. Pollack, C. Lindhjem, M. Jimenez, and G. Yarwood. 2012. Impact of meteorology and anthropogenic emissions on the local and regional ozone weekend effect in Midwestern US. Atmospheric Environment.

Körner, C. 2006. Plant CO2 responses: an issue of definition, time and resource supply. New Phytologist 172:393-411.

Kremen, C. 2005. Managing ecosystem services: what do we need to know about their ecology? Ecology Letters 8:468-479.

Kuehne, C., and K. J. Puettmann. 2008. Natural Regeneration in Thinned Douglas-fir Stands in Western Oregon. Journal of Sustainable Forestry 27:246-274. 
Kuparinen, A., O. Savolainen, and F. M. Schurr. 2010. Increased mortality can promote evolutionary adaptation of forest trees to climate change. Forest Ecology and Management 259:1003-1008.

Kurz, W. A., C. C. Dymond, G. Stinson, G. J. Rampley, E. T. Neilson, A. L. Carroll, T. Ebata, and L. Safranyik. 2008. Mountain pine beetle and forest carbon feedback to climate change. Nature 452:987-990.

Lal, R. 2005. Forest soils and carbon sequestration. Forest Ecology and Management 220:242-258.

Laliberté, E., and P. Legendre. 2010. A distance-based framework for measuring functional diversity from multiple traits. Ecology 91:299-305.

Landhausser, S. M., and V. J. Lieffers. 2001. Photosynthesis and carbon allocation of six boreal tree species grown in understory and open conditions. Tree Physiology 21:243-250.

Landres, P. B., P. Morgan, and F. J. Swanson. 1999. Overview of the Use of Natural Variability Concepts in Managing Ecological Systems. Ecological Applications 9:1179-1188.

Larson, E. R., K. F. Kipfmueller, C. M. Hale, L. E. Frelich, and P. B. Reich. 2010. Tree rings detect earthworm invasions and their effects in northern Hardwood forests. Biological Invasions 12:1053-1066.

Lawler, J. J., and J. D. Olden. 2011. Reframing the debate over assisted colonization. Frontiers in Ecology and the Environment 9:569-574.

Ledig, T. F., and J. H. Kitzmiller. 1992. Genetic strategies for reforestation in the face of global climate change. Forest Ecology and Management 50:153-169.

Lee, T. D., P. B. Reich, and P. V. Bolstad. 2005. Acclimation of leaf respiration to temperature is rapid and related to specific leaf area, soluble sugars and leaf nitrogen across three temperate deciduous tree species. Functional Ecology 19:640-647.

Lei, X., W. Wang, and C. Peng. 2009. Relationships between stand growth and structural diversity in spruce-dominated forests in New Brunswick, Canada. Canadian Journal of Forest Research 39:1835-1847.

Levin, S. A. 1992. The Problem of Pattern and Scale in Ecology. Ecology 73:1943-1967.

Liancourt, P., L. A. Spence, D. S. Song, A. Lkhagva, A. Sharkhuu, B. Boldgiv, B. R. Helliker, P. S. Petraitis, and B. B. Casper. 2012. Plant response to climate change varies with topography, interactions with neighbors, and ecotype. Ecology 94:444-453.

Litvaitis, J., A, J. Sherburne, A, and J. Bissonette, A. 1986. Bobcat Habitat Use and Home Range Size in Relation to Prey Density. The Journal of Wildlife Managment 50:110-117.

Loarie, S. R., P. B. Duffy, H. Hamilton, G. P. Asner, C. B. Field, and D. D. Ackerly. 2009. The velocity of climate change. Nature 462:1052-1055.

Loreau, M., S. Naeem, P. Inchausti, J. Bengtsson, J. P. Grime, A. Hector, D. U. Hooper, M. A. Huston, D. Raffaelli, B. Schmid, D. Tilman, and D. A. Wardle. 2001. Biodiversity and ecosystem functioning: current knowledge and future challenges. Science 294:804-808. 
Lorimer, C. G., and A. S. White. 2003. Scale and frequency of natural disturbances in the northeastern US: implications for early successional forest habitats and regional age distributions. Forest Ecology and Management 185:41-64.

Lovett, G. M., C. D. Canham, M. A. Arthur, K. C. Weathers, and R. D. Fitzhugh. 2006. Forest ecosystem responses to exotic pests and pathogens in eastern North America. Bioscience 56:395-405.

Lugo, A. E. 2004. The outcome of alien tree invasions in Puerto Rico. Frontiers in Ecology and the Environment 2:265-273.

Lunt, I. D., M. Byrne, J. J. Hellmann, N. J. Mitchell, S. T. Garnett, M. W. Hayward, T. G. Martin, E. McDonald-Maddden, S. E. Williams, and K. K. Zander. 2013. Using assisted colonisation to conserve biodiversity and restore ecosystem function under climate change. Biological Conservation 157:172-177.

Luo, Y., B. O. Su, W. S. Currie, J. S. Dukes, A. Finzi, U. Hartwig, B. Hungate, R. E. Mc Murtrie, R. A. M. Oren, and W. J. Parton. 2004. Progressive nitrogen limitation of ecosystem responses to rising atmospheric carbon dioxide. Bioscience 54:731739.

MacLean, D. A., and D. P. Ostaff. 1989. Patterns of balsam fir mortality caused by an uncontrolled spruce budworm outbreak. Canadian Journal of Forest Research 19:1087-1095.

Malmsheimer, R. W., P. Heffernan, S. Brink, D. Crandall, F. Deneke, C. Galik, E. Gee, J. A. Helms, N. McClure, and M. Mortimer. 2008. Forest management solutions for mitigating climate change in the United States. Journal of Forestry 106:115-173.

Marris, E. 2009. Planting the forest of the future. Nature 459:906-908.

Martin, M. E., and J. D. Aber. 1997. High spectral resolution remote sensing of forest canopy, lignin, nitrogen, and ecosystem processes. Ecological Applications 7:431443.

Maschinski, J., D. A. Falk, S. J. Wright, J. Possley, J. Roncal, and K. S. Wendelberger. 2012. Optimal locations for plant reintroductions in a changing world. Pages 109129 Plant Reintroduction in a Changing Climate. Springer.

McCann, K. S. 2000. The diversity-stability debate. Nature 405:228-233.

McLachlan, J., J. Clark, and P. Manos. 2005. Molecular indicators of tree migration capacity under rapid climate change. Ecology 86:2088-2098.

McLachlan, J. S., J. J. Hellmann, and M. W. Schwartz. 2007. A framework for debate of assisted migration in an era of climate change. Conservation Biology 21:297-302.

MDNRS. 2001. Michigan Department of Natural Resources. IFMAP/GAP Upper Peninsula Land Cover. Lansing, MI.

Menz, M. H. M., K. W. Dixon, and R. J. Hobbs. 2013. Hurdles and Opportunities for Landscape-Scale Restoration. Science 339:526-527.

Mickler, R. A., T. S. Earnhardt, and J. A. Moore. 2002. Regional estimation of current and future forest biomass. Environmental Pollution 116, Supplement 1:S7-S16.

Millar, C. I., and L. B. Brubaker. 2006. Climate change and paleoecology: new contexts for restoration ecology. Pages 315-340 in D. A. Falk, M. A. Palmer, and J. B. Zedler, editors. Foundations of restoration ecology. Island Press, Washington, D.C. 
Millar, C. I., N. L. Stephenson, and S. L. Stephens. 2007. Climate change and forests of the future: managing in the face of uncertainty. Ecological Applications 17:2145:2151.

Minckley, T. A., R. K. Shriver, and B. Shuman. 2012. Resilience and regime change in a southern Rocky Mountain ecosystem during the past 17000 years. Ecological Monographs 82:49-68.

Mokany, K., J. Ash, and S. Roxburgh. 2008. Functional identity is more important than diversity in influencing ecosystem processes in a temperate native grassland. Journal of Ecology 96:884-893.

Moore, J. E., S. B. Franklin, and J. W. Grubaugh. 2011. Herbaceous plant community responses to fluctuations in hydrology: Using Mississippi River islands as models for plant community assembly1. The Journal of the Torrey Botanical Society 138:177-191.

Moritz, C., and R. Agudo. 2013. The future of species under climate change: resilience or decline? Science 341:504-508.

Murphy, H. T., and J. Lovett-Doust. 2004. Context and connectivity in plant metapopulations and landscape mosaics: does the matrix matter? Oikos 105:3-14.

Naeem, S., and S. Li. 1997. Biodiversity enhances ecosystem reliability. Nature 390:507:509.

Namkoong, G. 2008. The misunderstood forest. Ministry of Forests and Range, Research Branch, Victoria, B.C.

Nelson, M. D., G. C. Liknes, and B. J. Butler. 2010. Forest ownership in the conterminous United States: ForestOwn_v1 geospatial dataset. Newtown Square, PA: U.S. Department of Agriculture, Forest Service, Northern Research Station. doi:10.2737/RDS-2010-0002.

NERC. 2010. Northeastern Ecosystem Research Cooperative (NERC) chemistry database. USDA Forest Service Northeastern Research Station and University of New Hampshire Complex Systems Research Center. (http://www.folchem.sr.unh.edu).

Norby, R. J., E. H. DeLucia, B. Gielen, C. Calfapietra, C. P. Giardina, J. S. King, J. Ledford, H. R. McCarthy, D. J. Moore, and R. Ceulemans. 2005. Forest response to elevated $\mathrm{CO} 2$ is conserved across a broad range of productivity. Proceedings of the National Academy of Sciences of the United States of America 102:1805218056.

Nuttle, T., A. A. Royo, M. B. Adams, and W. P. Carson. 2013. Historic disturbance regimes promote tree diversity only under low browsing regimes in eastern deciduous forest. Ecological Monographs 83:3-17.

O'Dowd, D. J., P. T. Green, and P. S. Lake. 2003. Invasional 'meltdown' on an oceanic island. Ecology Letters 6:812-817.

O’Neill, G. A., A. Hamann, and T. Wang. 2008. Accounting for population variation improves estimates of the impact of climate change on species' growth and distribution. Journal of Applied Ecology 45:1040-1049.

Palmer, M. W., and P. S. White. 1994. Scale Dependence and the Species-Area Relationship. The American Naturalist 144:717-740. 
Pan, Y., J. Hom, J. Jenkins, and R. Birdsey. 2004. Importance of foliar nitrogen concentration to predict forest productivity in the Mid-Atlantic region. Forest Science 50:279-289.

Paquette, A., and C. Messier. 2011. The effect of biodiversity on tree productivity: from temperate to boreal forests. Global Ecology and Biogeography 20:170-180.

Pérez, I., J. D. Anadón, M. Díaz, G. G. Nicola, J. L. Tella, and A. Giménez. 2012. What is wrong with current translocations? A review and a decision-making proposal. Frontiers in Ecology and the Environment 10:494-501.

Peters, E. B., K. R. Wythers, S. Zhang, J. B. Bradford, and P. B. Reich. 2013. Potential climate change impacts on temperate forest ecosystem processes. Canadian Journal of Forest Research 43:939-950.

Peters, G. P., R. M. Andrew, T. Boden, J. G. Canadell, P. Ciais, C. Le Quéré, G. Marland, M. R. Raupach, and C. Wilson. 2012. The challenge to keep global warming below 2 [deg] C. Nature Climate Change.

Peterson, G., C. R. Allen, and C. S. Holling. 1998. Ecological resilience, biodiversity, and scale. Ecosystems 1:6:18.

Pickett, S. T. A., and M. L. Cadenasso. 2002. The Ecosystem as a Multidimensional Concept: Meaning, Model, and Metaphor. Ecosystems 5:1-10.

Pimm, S. L. 1984. The Complexity and Stability of Ecosystems. Nature 307:321-326.

Potter-Witter, K. 2005. A cross-sectional analysis of Michigan nonindustrial private forest landowners. Northern Journal of Applied Forestry 22:132-138.

Powers, M. D., R. K. Kolka, J. B. Bradford, B. J. Palik, S. Fraver, and M. F. Jurgensen. 2012. Carbon stocks across a chronosequence of thinned and unmanaged red pine (Pinus resinosa) stands. Ecological Applications 22:1297-1307.

Puettmann, K. J. 2011. Silvicultural challenges and options in the context of global change: Simple fixes and opportunities for new management approaches. Journal of Forestry 109:321-331.

Puettmann, K. J., K. D. Coates, and C. C. Messier. 2009. A critique of silviculture : managing for complexity. Island Press, Washington, DC.

Pyne, S. J. 1982. Fire in America : a cultural history of wildland and rural fire. Princeton University Press, Princeton, N.J.

Pyne, S. J. 1997. Fire in America : a cultural history of wildland and rural fire. Pbk. edition. University of Washington Press, Seattle.

Quinn, G. P., and M. J. Keough. 2002. Experimental design and data analysis for biologists. Cambridge University Press, Cambridge, UK ; New York.

R Development Core Team. 2011. R: A language and environment for statistical computing. R Foundation for Statistical Computing, Vienna, Austria. ISBN 3900051-07-0, URL. http://www.R-project.org/.

Radeloff, V. C., D. J. Mladenoff, E. J. Gustafson, R. M. Scheller, P. A. Zollner, H. S. He, and H. R. Akcakaya. 2006. Modeling forest harvesting effects on landscape pattern in the Northwest Wisconsin Pine Barrens. Forest Ecology and Management 236:113-126.

Radtke, P. J., and A. P. Robinson. 2006. A Bayesian strategy for combining predictions from empirical and process-based models. Ecological Modelling 190:287-298. 
Raupach, M. R., G. Marland, P. Ciais, C. Le Quéré, J. G. Canadell, G. Klepper, and C. B. Field. 2007. Global and regional drivers of accelerating CO2 emissions. Proceedings of the National Academy of Sciences 104:10288-10293.

Ravenscroft, C., R. M. Scheller, D. J. Mladenoff, and M. A. White. 2010. Forest restoration in a mixed-ownership landscape under climate change. Ecological Applications 20:327-346.

Rehfeldt, G. E., N. L. Crookston, M. V. Warwell, and J. S. Evans. 2006. Empirical analyses of plant-climate relationships for western United States. International Journal for Plant Science 167:1123-1150.

Reich, P. B., and S. E. Hobbie. 2012. Decade-long soil nitrogen constraint on the CO2 fertilization of plant biomass. Nature Climate Change 3:278-282.

Reich, P. B., M. B. Walters, and D. S. Ellsworth. 1991. Leaf age and season influence the relationships between leaf nitrogen, leaf mass per area and photosynthesis in maple and oak trees. Plant, Cell \& Environment 14:251-259.

Reich, P. B., M. B. Walters, B. D. Kloeppel, and D. S. Ellsworth. 1995. Different photosynthesis-nitrogen relations in deciduous hardwood and evergreen coniferous tree species. Oecologia 104:24-30.

Reiners, W. A., and K. L. Driese. 2001. The propagation of ecological influences through heterogeneous environmental space. Bioscience 51:939-950.

Ricciardi, A., and D. Simberloff. 2009. Assisted colonization is not a viable conservation strategy. Trends in Ecology \&amp; Evolution 24:248-253.

Richardson, D. M., J. J. Hellmann, J. S. McLachlan, D. F. Sax, M. W. Schwartz, P. Gonzalez, E. J. Brennan, A. Camacho, T. L. Root, O. E. Sala, S. H. Schneider, D. M. Ashe, J. R. Clark, R. Early, J. R. Etterson, E. D. Fielder, J. L. Gill, B. A. Minteer, S. Polasky, H. D. Safford, A. R. Thompson, and M. Vellend. 2009. Multidimensional evaluation of managed relocation. Proceedings of the National Academy of Sciences of the United States of America 106:9721-9724.

Rizzo, D. M., and M. Garbelotto. 2003. Sudden oak death: endangering California and Oregon forest ecosystems. Frontiers in Ecology and the Environment 1:197-204.

Royer, D. L., P. Wilf, D. A. Janesko, E. A. Kowalski, and D. L. Dilcher. 2005. Correlations of climate and plant ecology to leaf size and shape: potential proxies for the fossil record. American Journal of Botany 92:1141-1151.

Rudnick, D. A., P. Beier, S. Cushman, F. Dieffenbach, and C. Epps. 2012. The role of landscape connectivity in planning and implementing conservation and restoration priorities. Issues in Ecology 16:1-20.

Running, S. W. 2012. A measurable planetary boundary for the biosphere. Science 337:1458-1459.

Russell, E. W. 1987. Pre-blight distribution of Castanea dentata (Marsh.) Borkh. Bulletin of the Torrey Botanical Club:183-190.

Rydgren, K., R. H. Okland, and G. Hestmark. 2004. Disturbance severity and community resilience in a boreal forest. Ecology 85:1906-1915.

Sankaran, M., and S. J. McNaughton. 1999. Determinants of biodiversity regulate compositional stability of communities. Nature 401:691-693.

Scheller, R. M., J. B. Domingo, B. R. Sturtevant, J. S. Williams, A. Rudy, E. J. Gustafson, and D. J. Mladenoff. 2007a. Design, development, and application of 
LANDIS-II, a spatial landscape simulation model with flexible temporal and spatial resolution. Ecological Modelling 201:409-419.

Scheller, R. M., J. B. Domingo, B. R. Sturtevant, J. S. Williams, A. Rudy, E. J. Gustafson, and D. J. Mladenoff. 2007b. Design, development, and application of LANDIS-II, a spatial landscape simulation model with flexible temporal and spatial resolution. Ecological Modelling 201:409-419.

Scheller, R. M., A. M. Kretchun, S. Van Tuyl, K. L. Clark, M. S. Lucash, and J. Hom. 2012. Divergent carbon dynamics under climate change in forests with diverse soils, tree species, and land use histories. Ecosphere 3:art110.

Scheller, R. M., and D. J. Mladenoff. 2002. Understory species patterns and diversity in old-growth and managed northern hardwood forests. Ecological Applications 12:1329-1343.

Scheller, R. M., and D. J. Mladenoff. 2004. A forest growth and biomass module for a landscape simulation model, LANDIS: design, validation, and application. Ecological Modelling 180:211-229.

Scheller, R. M., and D. J. Mladenoff. 2005. A spatially interactive simulation of climate change, harvesting, wind, and tree species migration and projected changes to forest composition and biomass in northern Wisconsin, USA. Global Change Biology 11:307-321.

Scheller, R. M., and D. J. Mladenoff. 2008. Simulated effects of climate change, fragmentation, and inter-specific competition on tree species migration in northern Wisconsin, USA. Climate Research 36:191-202.

Scheller, R. M., S. Van Tuyl, K. Clark, N. G. Hayden, J. Hom, and D. J. Mladenoff. 2008. Simulation of forest change in the New Jersey Pine Barrens under current and pre-colonial conditions. Forest Ecology and Management 255:1489-1500.

Schlaepfer, M. A., D. F. Sax, and J. D. Olden. 2011. The Potential Conservation Value of Non-Native Species. Conservation Biology 25:428-437.

Schulte, L. A., and D. J. Mladenoff. 2005. Severe wind and fire regimes in northern forests: Historical variability at the regional scale. Ecology 86:431-445.

Seidl, R., W. Rammer, D. Jäger, and M. J. Lexer. 2008. Impact of bark beetle (Ips typographus $L$.) disturbance on timber production and carbon sequestration in different management strategies under climate change. Forest Ecology and Management 256:209-220.

Seidl, R., W. Rammer, and M. J. Lexer. 2011. Adaptation options to reduce climate change vulnerability of sustainable forest management in the Austrian Alps. Canadian Journal of Forest Research 41:694-706.

Sherry, J. 2012. Informing Fire and Fuels Management Decisions in the Mixed-Pine Ecosystems of the Northern Lake States. Master of Science. Ohio State University, Columbus, $\mathrm{OH}$.

Silver, E. J., A. W. D’Amato, S. Fraver, B. J. Palik, and J. B. Bradford. 2013. Structure and development of old-growth, unmanaged second-growth, and extended rotation Pinus resinosa forests in Minnesota, USA. Forest Ecology and Management 291:110-118. 
Skog, K. E., and G. A. Nicholson. 1998. Carbon cycling through wood products: The role of wood and paper products in carbon sequestration. Forest Products Journal 48:75-83.

Smith, D. M. 2000. American chestnut: Ill-fated monarch of the eastern hardwood forest. Journal of Forestry 98:12-15.

Smith, M.-L., and M. E. Martin. 2001. A plot-based method for rapid estimation of forest canopy chemistry. Canadian Journal of Forest Research 31:549-555.

Smith, T. B., R. K. Wayne, D. J. Girman, and M. W. Bruford. 1997. A role for ecotones in generating rainforest biodiversity. Science 276:1855-1857.

Soja, A. J., N. M. Tchebakova, N. H. F. French, M. D. Flannigan, H. H. Shugart, B. J. Stocks, A. I. Sukhinin, E. I. Parfenova, F. S. Chapin, and P. W. Stackhouse. 2007. Climate-induced boreal forest change: predictions versus current observations. Global and Planetary Change 56:274-296.

Speed, J. D. M., E. J. Cooper, I. S. Jónsdóttir, R. Van Der Wal, and S. J. Woodin. 2010. Plant community properties predict vegetation resilience to herbivore disturbance in the Arctic. Journal of Ecology 98:1002-1013.

Spies, T., T. Giesen, F. Swanson, J. Franklin, D. Lach, and K. Johnson. 2010. Climate change adaptation strategies for federal forests of the Pacific Northwest, USA: ecological, policy, and socio-economic perspectives. Landscape Ecology 25:1185-1199.

Spittlehouse, D. L., and R. B. Stewart. 2003. Adaptation to climate change in forest managment. BC Journal of Ecoystems and Management 4:11.

SSURGO Soil Survey Staff. 2011. Natural Resources Conservation Service, United States Department of Agriculture. Soil Survey Geographic (SSURGO) Database for Michigan. Available online at http://soildatamart.nrcs.usda.gov. Accessed [12/20/2011].

St Clair, J. B., and G. T. Howe. 2007. Genetic maladaptation of coastal Douglas-fir seedlings to future climates. Global Change Biology 13:1441-1454.

STATSGO. 1994. State soil geographic database. Data use information. U.S. Department of Agriculture National Cartography and GIS Center. Fort Worth, Texas, USA.

Steenberg, J. W., P. N. Duinker, and P. G. Bush. 2011. Exploring adaptation to climate change in the forests of central Nova Scotia, Canada. Forest Ecology and Management 262:2316-2327.

Stoner, A. M. K., K. Hayhoe, X. Yang, and D. J. Wuebbles. 2012. An asynchronous regional regression model for statistical downscaling of daily climate variables. International Journal of Climatology:n/a-n/a.

Svenning, J.-C., and B. Sandel. 2013. Disequilibrium vegetation dynamics under future climate change. American Journal of Botany.

Swanston, C., and M. Janowiak. 2012. Forest Adaptation Resouces: Climate change tools and approaches for land managers. Gen. Tech. Rep. NRS-87. Page 121 in F. S. U.S. Department of Agriculture, Northern Research Station, editor., Newtown Square, PA. 
Syphard, A. D., R. M. Scheller, B. C. Ward, W. D. Spencer, and J. R. Strittholt. 2011. Simulating landscape-scale effects of fuels treatments in the Sierra Nevada, California, USA. International Journal of Wildland Fire 20:364-383.

Tansley, A. G. 1935. The Use and Abuse of Vegetational Concepts and Terms. Ecology 16:284-307.

Taylor, S. W., and A. L. Carroll. 2004. Disturbance, Forest Age, and Mountain Pine Beetle Outbreak Dynamics in BC: A Historical Perspective. Page 298 p. in Mountain Pine Beetle Symposium: Challenges and Solutions. Natural Resources Canada, Canadian Forest Service, Pacific Forestry Centre, Elowna, British Columbia.

The American Chestnut Foundation. 2013.

The Conservation Biology Institute. 2010. Protected Areas - Michigan, USA. Corvallis, Oregon.

Thompson, J. R., D. N. Carpenter, C. V. Cogbill, and D. R. Foster. 2013. Four Centuries of Change in Northeastern United States Forests. Plos One 8:e72540.

Thompson, J. R., D. R. Foster, R. Scheller, and D. Kittredge. 2011. The influence of land use and climate change on forest biomass and composition in Massachusetts, USA. Ecological Applications 21:2425-2444.

Thrush, S. F., J. Halliday, J. E. Hewitt, and A. M. Lohrer. 2008. The effects of habitat loss, fragmentation, and community homogenization on resilience in estuaries. Ecological Applications 18:12-21.

Tilman, D., and J. A. Downing. 1994. Biodiversity and stability in grasslands. Nature 367:363-365.

Tilman, D., P. B. Reich, and F. Isbell. 2012. Biodiversity impacts ecosystem productivity as much as resources, disturbance, or herbivory. Proceedings of the National Academy of Sciences 109:10394-10397.

Tilman, D., P. B. Reich, and J. M. H. Knops. 2006. Biodiversity and ecosystem stability in a decade-long grassland experiment. Nature 441:629-632.

Urban, D. L. 2005. Modeling ecological processes across scales. Ecology 86:1996-2006.

USFWS. 2010. Upper Midwest/Great Lakes LCC Draft Development \& Operations Plan, http://www.fws.gov/midwest/climate/LCC/UpperMidwest/.

Vanderwel, M. C., and D. W. Purves. 2013. How do disturbances and environmental heterogeneity affect the pace of forest distribution shifts under climate change? Ecography.

Villéger, S., N. W. Mason, and D. Mouillot. 2008. New multidimensional functional diversity indices for a multifaceted framework in functional ecology. Ecology 89:2290-2301.

Walker, B. 1992. Biodiversity and Ecological Redundancy. Conservation Biology 6:1823.

Walker, B., A. Kinzig, and J. Langridge. 1999. Plant attribute diversity, resilience, and ecosystem function: the nature and significance of minor species. Ecosystems 2:95-113.

Walkinshaw, L. H. 1983. Kirtland's Warbler: the natural history of an endangered species. Cranbrook Institute of Science Bloomfield Hills, Michigan, USA. 
Wangen, S. R., and C. R. Webster. 2006. Potential for multiple lag phases during biotic invasions: reconstructing an invasion of the exotic tree Acer platanoides. Journal of Applied Ecology 43:258-268.

Washington, W. M., J. W. Weatherly, G. A. Meehl, A. J. Semtner Jr, T. W. Bettge, A. P. Craig, W. G. Strand Jr, J. Arblaster, V. B. Wayland, and R. James. 2000. Parallel climate model (PCM) control and transient simulations. Climate Dynamics 16:755-774.

Webb, T. 1986. Is vegetation in equilibrium with climate? How to interpret lateQuaternary pollen data. Vegetatio 67:75-91.

Wheeler, T., and J. von Braun. 2013. Climate Change Impacts on Global Food Security. Science 341:508-513.

Whelan, R. J. 1995. The ecology of fire. Cambridge University Press, Cambridge ; New York.

White, M., A, and G. E. Host. 2000. Mapping range of natural variation in ecosystems classes for the Northern Superior Uplands. NRRI Technical Report. Natural Resources Research Institute. NRRI/TR-2000/39.

White, M. A. 2011. Modeling carbon storage and forest management in mixed hardwood and conifer forests in northeastern Minnesota. Report submitted to the Minnesota Department of Natural Resources, Office of Science and Policy. 500 Lafayette Rd, St Paul, MN 55155-4010.

White, M. A., and G. E. Host. 2008. Forest disturbance frequency and patch structure from pre-European settlement to present in the mixed forest province of Minnesota, USA. Canadian Journal of Forest Research 38:2212-2226.

White, M. A., and D. J. Mladenoff. 1994. Old-Growth Forest Landscape Transitions from Pre-European Settlement to Present. Landscape Ecology 9:191-205.

Whitney, G. G. 1986. Relation of Michigan's presettlement pine forests to substrate and disturbance history. Ecology 67:1548-1559.

Whittaker, R. J., K. J. Willis, and R. Field. 2001. Scale and species richness: towards a general, hierarchical theory of species diversity. Journal of Biogeography 28:453470.

Wiens, J. A. 1989. Spatial Scaling in Ecology. Functional Ecology 3:385-397.

Wild, M., H. Gilgen, A. Roesch, A. Ohmura, C. N. Long, E. G. Dutton, B. Forgan, A. Kallis, V. Russak, and A. Tsvetkov. 2005. From Dimming to Brightening: Decadal Changes in Solar Radiation at Earth's Surface. Science 308:847-850.

Williams, J. W., S. T. Jackson, and J. E. Kutzbach. 2007. Projected distributions of novel and disappearing climates by 2100 AD. Proceedings of the National Academy of Sciences 104:5738-5742.

Willis, K., R. Bailey, S. Bhagwat, and H. Birks. 2010. Biodiversity baselines, thresholds and resilience: testing predictions and assumptions using palaeoecological data. Trends in Ecology \& Evolution 25:583-591.

Wilson, E. O. 2010. The diversity of life. 1st Harvard University Press pbk. edition. Belknap Press of Harvard University Press, Cambridge, Mass.

Winchester, N. N. 1998. Severing the Web: Changing biodiversity in converted northern temperate ancient coastal. Northwest Science 72:124-126. 
Wittig, V. E., E. A. Ainsworth, S. L. Naidu, D. F. Karnosky, and S. P. Long. 2008. Quantifying the impact of current and future tropospheric ozone on tree biomass, growth, physiology and biochemistry: a quantitative meta-analysis. Global Change Biology 15:396-424.

Woodall, C., P. Ince, K. Skog, F. Aguilar, C. Keegan, C. Sorenson, D. Hodges, and W. Smith. 2011. An overview of the forest products sector downturn in the United States. Forest Products Journal 61:595-603.

Worrall, J. J., G. E. Rehfeldt, A. Hamann, E. H. Hogg, S. B. Marchetti, M. Michaelian, and L. K. Gray. 2013. Recent declines of Populus tremuloides in North America linked to climate. Forest Ecology and Management 299:35-51.

Xu, C., G. Z. Gertner, and R. M. Scheller. 2009. Uncertainties in the response of a forest landscape to global climatic change. Global Change Biology 15:116-131.

Xu, C. G., G. Z. Gertner, and R. M. Scheller. 2007. Potential effects of interaction between $\mathrm{CO} 2$ and temperature on forest landscape response to global warming. Global Change Biology 13:1469-1483.

Youngs, R. L. 2000. " A Right Smart Little Jolt": Loss of the Chestnut and a Way of Life. Journal of Forestry 98:17-21.

Zhang, Q.-B., and R. J. Hebda. 2005. Abrupt climate change and variability in the past four millennia of the southern Vancouver Island, Canada. Geophys. Res. Lett. 32:L16708.

Zhang, Q., K. S. Pregitzer, and D. D. Reed. 1999. Catastrophic disturbance in the presettlement forests of the Upper Peninsula of Michigan. Canadian Journal of Forest Research 29:106-114.

Zhu, K., C. W. Woodall, and J. S. Clark. 2012. Failure to migrate: lack of tree range expansion in response to climate change. Global Change Biology 18:1042-1052. 


\section{Appendix: Supplementary Material}

Table A1: Tree species life history characteristics used in the LANDIS-II simulations. Table description found on next page.

\begin{tabular}{|c|c|c|c|c|c|}
\hline SPECIES & M.A. ${ }^{(19)}$ & M.R.A. ${ }^{(19)}$ & S.T. ${ }^{(20)}$ & M.LMA & F.N. \\
\hline Abies balsamea & 200 & 25 & 5 & $204^{(8)}$ & $1.56^{(14,16)}$ \\
\hline Acer rubrum & 150 & 10 & 4 & $64^{(14,16)}$ & $1.74^{(1,4-6,8,10,12-13)}$ \\
\hline Acer saccharum & 400 & 40 & 5 & $60^{(2,4,10,13,16)}$ & $1.86^{(1,4,6-8,10,13,16)}$ \\
\hline Betula alleghaniensis & 300 & 40 & 4 & $66^{(8)}$ & $2.37^{(14,16)}$ \\
\hline Betula papyrifera & 200 & 20 & 2 & $74.4^{(8)}$ & $2.26^{(14,16)}$ \\
\hline Fagus grandifolia** & 350 & 60 & 4 & $70^{(2)}$ & $2.3^{(15)}$ \\
\hline Fraxinus americana & 300 & 30 & 4 & $76^{(14,16)}$ & $2.13^{(14,16)}$ \\
\hline Fraxinus nigra & 150 & 30 & 4 & $76^{(16)}$ & $2.11^{(3,16)}$ \\
\hline Fraxinus pennsylvanica & 150 & 30 & 2 & $76^{(16)}$ & $2.13^{(3,16)}$ \\
\hline Picea glauca & 300 & 25 & 3 & $286^{(11,16)}$ & $1.34^{(11,16)}$ \\
\hline Picea mariana & 215 & 30 & 3 & $286^{(16)}$ & $1.21^{(4,16)}$ \\
\hline Pinus banksiana & 200 & 10 & 1 & $244^{(4,7,16)}$ & $1.24^{(4,16)}$ \\
\hline Pinus resinosa & 250 & 15 & 2 & $250^{(4,16)}$ & $1.35^{(4-7,16)}$ \\
\hline Pinus strobus & 450 & 15 & 3 & $175^{(8)}$ & $1.7^{(11,16)}$ \\
\hline Pinus sylvestris** & 250 & 15 & 1 & $244 \dagger^{(4,7,16)}$ & $1.24^{(17)}$ \\
\hline Populus balsamifera** & 150 & 10 & 1 & $90.8^{(7)}$ & $2.47 \dagger^{(14,16)}$ \\
\hline Populus grandidentata & 125 & 20 & 1 & $85.8^{(2,13,16)}$ & $2.29^{(5,13,16)}$ \\
\hline Populus tremuloides & 100 & 15 & 1 & $90.8^{(4,10,13,16)}$ & $2.47^{(14,16)}$ \\
\hline Prunus serotina & 200 & 20 & 3 & $101^{(14,16)}$ & $2.7^{(14,16)}$ \\
\hline Quercus alba & 400 & 40 & 3 & $88^{(14,16)}$ & $2.29^{(15)}$ \\
\hline Quercus ellipsoidalis & 200 & 35 & 2 & $88^{(18)}$ & $2.29^{(18)}$ \\
\hline Quercus macrocarpa* & 400 & 30 & 2 & $88^{(14,16)}$ & $2.35^{(14,16)}$ \\
\hline Quercus rubra & 250 & 25 & 2 & $93^{(1-2,4,8,12-13)}$ & $2.22^{(1,4-5,6,8,10,12)}$ \\
\hline Quercus velutina** & 200 & 40 & 2 & $98^{(1)}$ & $2.4^{(15)}$ \\
\hline Thuja occidentalis & 800 & 30 & 2 & $222^{(14,16)}$ & $1.28^{(14,16)}$ \\
\hline Tilia americana & 250 & 15 & 4 & $48^{(8)}$ & $2.4^{(1,5-6,8,13,16)}$ \\
\hline Tsuga canadensis & 800 & 250 & 5 & $170^{(8)}$ & $1.19^{(15)}$ \\
\hline Ulmus americana & 85 & 20 & 4 & $62^{(13,16)}$ & $2^{(11,13,16)}$ \\
\hline
\end{tabular}


Table A1 Notes: M.A. is maximum longevity (yrs). M.R.A is the minimum age of reproduction (yrs). S.T. is shade tolerance with 1 being the least tolerant and 5 the most tolerant. M. LMA is the maximum leaf mass area $\left(\mathrm{g} \mathrm{m}^{-2}\right)$. F.N. is the foliar nitrogen concentration (\%). Sources are indicated by superscripts: (1) (Fownes 1985), (2) (Jurik 1986), (3) (Blinn and Buckner 1989), (4) (Reich et al. 1995), (5) (Bolster et al. 1996), (6) (Martin and Aber 1997), (7) (Landhausser and Lieffers 2001), (8) (Smith and Martin 2001), (9) (Green et al. 2003), (10) (Bolstad et al. 2004), (11) (Scheller and Mladenoff 2004), (12) (Lee et al. 2005), (13) (Royer et al. 2005), (14) (Scheller and Mladenoff 2005), (15) (NERC 2010), (16) (Ravenscroft et al. 2010), (17) (Berg 1988), (18) (Reich et al. 1991). * = species simulated in the Minnesota landscape only. $* *=$ species simulated in the Michigan landscape only. $\dagger=$ estimated from Populus tremuloides. $\dagger \dagger$ estimated from Pinus banksiana. 
Table A2. Common harvest prescriptions in northeastern Minnesota as used in BAU scenarios by landowner groups : Private Non-Industrial Forests (PNIF), United States Forest Service (USFS), Minnesota Department of Natural Resources \& county lands (MN DNR \& CO), and Private Industrial Forests (PIF).

Reserve areas are not harvested. For each harvest prescription, values represent percent of each management area in Figure 2.1 treated per five-year time step.

\begin{tabular}{lccccc} 
MINNESOTA PRESCRIPTIONS & PNIF & USFS & MN DNR \& CO & PIF & RESERVE \\
\hline Aspen Clearcut & 2.81 & 4.41 & 6.80 & 6.10 & 0.00 \\
Upland Spruce Clearcut & 1.61 & 1.99 & 1.66 & 1.90 & 0.00 \\
Jack Pine Clearcut & 0.18 & 0.29 & 0.18 & 0.19 & 0.00 \\
Northern Hardwood Shelterwood & 0.00 & 0.00 & 0.60 & 0.00 & 0.00 \\
Northern Hardwood Clearcut & 0.00 & 0.00 & 0.57 & 0.00 & 0.00 \\
Northern Hardwood Patchcut & 0.68 & 3.03 & 3.01 & 2.65 & 0.00 \\
Oak Shelterwood & 0.09 & 0.08 & 0.10 & 0.10 & 0.00 \\
Red Pine Clearcut & 0.12 & 0.23 & 0.13 & 0.08 & 0.00 \\
White Pine Clearcut & 0.09 & 0.09 & 0.08 & 0.07 & 0.00 \\
\hline
\end{tabular}


Table A3. Common harvest prescriptions in northern lower Michigan as used in BAU scenarios by landowner groups: Private Non-Industrial Forests (PNIF), United States Forest Service (USFS), Michigan Department of Natural Resources (MI DNR), and Private Industrial Forests (PIF). Reserve areas are not harvested. For each harvest prescription, values represent percent of each management area (Figure 2.1) treated per five-year time step.

\begin{tabular}{lccccc} 
MICHIGAN PRESCRIPTIONS & PNIF & USFS & MI DNR & PIF & RESERVE \\
\hline Aspen/Birch Clearcut & 0.06 & 1.72 & 2.39 & 3.49 & 0.00 \\
Jack Pine Clearcut & 0.12 & 0.82 & 0.53 & 0.05 & 0.00 \\
Northern Hardwood Shelterwood & 0.11 & 0.08 & 0.09 & 0.06 & 0.00 \\
Northern Hardwood Patchcut & 4.62 & 3.39 & 3.67 & 2.67 & 0.00 \\
Oak Clearcut & 0.16 & 0.79 & 0.59 & 0.29 & 0.00 \\
Oak Patchcut & 1.04 & 1.27 & 0.95 & 0.47 & 0.00 \\
Oak Shelterwood & 0.42 & 0.51 & 0.38 & 0.19 & 0.00 \\
Oak Thinning & 1.43 & 1.75 & 1.31 & 0.64 & 0.00 \\
Birch Shelterwood & 0.01 & 0.01 & 0.01 & 0.02 & 0.00 \\
Red Pine Clearcut & 0.05 & 0.23 & 0.15 & 0.02 & 0.00 \\
Red Pine Patchcut & 0.16 & 0.36 & 0.23 & 0.03 & 0.00 \\
Red Pine Shelterwood & 0.04 & 0.09 & 0.06 & 0.01 & 0.00 \\
Red Pine Thinning & 0.52 & 1.16 & 0.73 & 0.10 & 0.00 \\
Upland Spruce-Fir Clearcut & 0.10 & 0.54 & 0.95 & 1.62 & 0.00 \\
Swamp Hardwoods Clearcut & 0.02 & 0.11 & 0.16 & 0.50 & 0.00 \\
Swamp Hardwoods Patchcut & 0.10 & 0.06 & 0.08 & 0.25 & 0.00 \\
Swamp Hardwoods Shelterwood & 0.05 & 0.03 & 0.04 & 0.11 & 0.00 \\
Swamp Hardwoods Thinning & 0.02 & 0.01 & 0.02 & 0.05 & 0.00 \\
White Pine Clearcut & 0.07 & 0.15 & 0.11 & 0.06 & 0.00 \\
White Pine Patchcut & 0.30 & 0.47 & 0.35 & 0.20 & 0.00 \\
White Pine Shelterwood & 0.12 & 0.19 & 0.14 & 0.08 & 0.00 \\
White Pine Thinning & 0.31 & 0.48 & 0.36 & 0.20 & 0.00 \\
\hline
\end{tabular}


Table A4. Dominant species within northern Great Lake forest types and associated soils.

\begin{tabular}{|c|c|c|}
\hline FOREST TYPE & DOMINANT SPECIES & SOILS \\
\hline Northern Hardwoods & $\begin{array}{l}\text { Acer saccharum, Acer rubrum, Tilia } \\
\text { americana, Quercus rubrum, Fagus } \\
\text { grandifolia }\end{array}$ & Deep and moist. \\
\hline White Pine & $\begin{array}{l}\text { Pinus strobus, Pinus resinosa, Pinus } \\
\text { banksiana }\end{array}$ & $\begin{array}{l}\text { Coarse textured shallow to well- } \\
\text { drained. }\end{array}$ \\
\hline Aspen-Birch & $\begin{array}{l}\text { Populus tremuloides, Populus grandidentata, } \\
\text { Betula papyrifera, Acer rubrum, Populus } \\
\text { balsamifera }\end{array}$ & $\begin{array}{l}\text { Wide range of type and moisture } \\
\text { gradients. }\end{array}$ \\
\hline Red/Jack Pine & $\begin{array}{l}\text { Pinus banksiana, Pinus resinosa, Quercus } \\
\text { rubra, Quercus ellipsoidalis, Quercus } \\
\text { velutina }\end{array}$ & $\begin{array}{l}\text { Coarse-textured to exces sively } \\
\text { drained-drought-prone soils. } \\
\text { Low soil nutrients common. }\end{array}$ \\
\hline Oak Associations & $\begin{array}{l}\text { Quercus rubra, Acer rubrum, Quercus alba, } \\
\text { Qurecus velutina, Quercus ellipsoidalis }\end{array}$ & Sandy or loamy sand to mesic. \\
\hline Spruce-Fir & $\begin{array}{l}\text { Picea mariana, Abies balsamea, Picea } \\
\text { glauca, Tsuga candadensis, Thuja } \\
\text { occidentalis }\end{array}$ & $\begin{array}{l}\text { Sandy soils, dunes, glacial lake } \\
\text { plains, thin soils over bedrock, and } \\
\text { lowland poorly drained peat or } \\
\text { outwash soils. }\end{array}$ \\
\hline
\end{tabular}


Table A5. Indicator species used in forest type classification. Classification dominance is based on AGB density within a cell. Indicator species selection is based on a balance of high abundance unique species within groups. To balance the number of species that contribute to each forest type, select non-indicator species are subtracted from each forest type classification.

FOREST TYPE

Northern Hardwoods
Acer saccahrum, Prunus serptina, Quercus rubra, Tilia americana, Tsuga canadiensis*

Pinus strobus

Populus tremuloides, Populus grandidentata, Populus balsamifera **, Betula papyrifera

Pinus banksiana, Pinus resinosa

Quercus rubra, Quercus alba, Quercus ellipsoidalis, Quercus macrocarpa*, and Quercus velutina**

Picea mariana, Picea glauca, Abies balsamea, Thuja occidentalis**

\section{SUBSTRACT}

Populus tremuloides, Populus grandidentata

Acer saccarum, Abies

balsamea
Red/jack pine

Oak

Spruce-fir

\section{only}

*Minnesota landscape only

**Michigan landscape only 
Table A6: Common silviculture prescriptions used in Northeastern Minnesota BAU scenarios and the associated adjustments used in the modified silviculture scenario. Common landowner groups include: Private Non-Industrial Forests (PNIF), United States Forest Service (USFS), Minnesota Department of Natural Resources \& county lands (MN DNR \& CO), and Private Industrial Forests (PIF). Planted northern hardwoods include: black cherry, yellow birch, American elm, and American basswood. Planted oak species include: white oak, northern red oak, and bur oak. Within individual prescriptions, patch sizes were also reduced in modified silviculture prescriptions.

\begin{tabular}{|c|c|c|c|c|c|c|c|}
\hline & \multicolumn{4}{|c|}{$\frac{\text { BAU \% LANDSCAPE TREATED PER }}{\text { TIMESTEP }}$} & \multirow{2}{*}{$\begin{array}{c}\text { BAU PLANTED } \\
\text { SPECIES } \\
\text { FOLLOWING } \\
\text { HARVEST }\end{array}$} & \multicolumn{2}{|c|}{$\frac{\text { MODIFIED SILVICULTURE }}{\underline{\text { ADJUSTMENT }}}$} \\
\hline & PNIF & USFS & $\begin{array}{l}\text { MN DNR } \\
\quad \& \mathrm{CO}\end{array}$ & PIF & & $\begin{array}{c}\% \text { CHANGE IN } \\
\text { TREATED AREA } \\
\text { PER TIMESTEP }\end{array}$ & $\begin{array}{l}\text { SPECIES } \\
\text { PLANTED }\end{array}$ \\
\hline Aspen Clearcut & 2.81 & 4.41 & 6.80 & 6.10 & $\begin{array}{l}\text { white spruce, } \\
\text { white pine \& red } \\
\text { pine }\end{array}$ & $-40 \%$ & $\begin{array}{l}\text { Removed } \\
\text { white spruce }\end{array}$ \\
\hline $\begin{array}{l}\text { Upland Spruce } \\
\text { Clearcut }\end{array}$ & 1.61 & 1.99 & 1.66 & 1.90 & NA & $-10 \%$ & NA \\
\hline Jack Pine Clearcut & 0.18 & 0.29 & 0.18 & 0.19 & $\begin{array}{l}\text { jack pine } \& \text { red } \\
\text { pine }\end{array}$ & $-10 \%$ & $\begin{array}{l}\text { Removed jack } \\
\text { pine }\end{array}$ \\
\hline $\begin{array}{l}\text { Northern Hardwood } \\
\text { Shelterwood }\end{array}$ & 0.00 & 0.00 & 0.60 & 0.00 & NA & $-10 \%$ & NA \\
\hline $\begin{array}{l}\text { Northern Hardwood } \\
\text { Clearcut }\end{array}$ & 0.00 & 0.00 & 0.57 & 0.00 & NA & $-100 \%$ & NA \\
\hline $\begin{array}{l}\text { Northern Hardwood } \\
\text { Patchcut }\end{array}$ & 0.68 & 3.03 & 3.01 & 2.65 & NA & $25 \%$ & $\begin{array}{l}\text { Added } \\
\text { northern } \\
\text { hardwoods \& }\end{array}$ \\
\hline Oak Shelterwood & 0.09 & 0.08 & 0.10 & 0.10 & NA & $0 \%$ (no change) & $\begin{array}{l}\text { Added oak } \\
\text { species }\end{array}$ \\
\hline Red Pine Clearcut & 0.12 & 0.23 & 0.13 & 0.08 & $\begin{array}{l}\text { red pine \& white } \\
\text { spruce }\end{array}$ & $-10 \%$ & $\begin{array}{l}\text { Removed } \\
\text { white spruce }\end{array}$ \\
\hline White Pine Clearcut & 0.09 & 0.09 & 0.08 & 0.07 & white pine & $-10 \%$ & NA \\
\hline
\end{tabular}


Table A7: Common silviculture prescriptions used in Northern lower Michigan BAU scenarios and the associated adjustments used in the modified silviculture scenario.

\begin{tabular}{|c|c|c|c|c|c|c|c|}
\hline & \multicolumn{4}{|c|}{ BAU \% LANDSCAPE TREATED } & \multirow[b]{2}{*}{$\begin{array}{l}\text { BAU PLANTED SPECIES } \\
\text { FOLLOWING HARVEST }\end{array}$} & \multicolumn{2}{|c|}{ MODIFIED SILVICULTURE ADJUSTMENT } \\
\hline & PNIF & USFS & MI DNR & PIF & & $\begin{array}{c}\% \text { CHANGE IN } \\
\text { TREATED AREA } \\
\text { PER TIMESTEP }\end{array}$ & SPECIES PLANTED \\
\hline Aspen/Birch Clearcut & 0.06 & 1.72 & 2.39 & 3.49 & red pine $\&$ jack pine & $-50 \%$ & northern hardwoods \\
\hline Jack Pine Clearcut & 0.12 & 0.82 & 0.53 & 0.05 & red pine $\&$ jack pine & $0 \%$ (no change) & NA \\
\hline $\begin{array}{l}\text { Northern Hardwood } \\
\text { Shelterwood }\end{array}$ & 0.11 & 0.08 & 0.09 & 0.06 & NA & $-15 \%$ & NA \\
\hline $\begin{array}{l}\text { Northern Hardwood } \\
\text { Patchcut }\end{array}$ & 4.62 & 3.39 & 3.67 & 2.67 & NA & $25 \%$ & NA \\
\hline Oak Clearcut & 0.16 & 0.79 & 0.59 & 0.29 & red pine $\&$ jack pine & $-15 \%$ & oak species \\
\hline Oak Patchcut & 1.04 & 1.27 & 0.95 & 0.47 & NA & $25 \%$ & NA \\
\hline Oak Shelterwood & 0.42 & 0.51 & 0.38 & 0.19 & NA & $-15 \%$ & NA \\
\hline Oak Thinning & 1.43 & 1.75 & 1.31 & 0.64 & NA & $0 \%$ & NA \\
\hline Birch Shelterwood & 0.01 & 0.01 & 0.01 & 0.02 & NA & $-100 \%$ & NA \\
\hline Red Pine Clearcut & 0.05 & 0.23 & 0.15 & 0.02 & red pine $\&$ jack pine & $-15 \%$ & NA \\
\hline Red Pine Patchcut & 0.16 & 0.36 & 0.23 & 0.03 & NA & $0 \%$ & NA \\
\hline Red Pine Shelterwood & 0.04 & 0.09 & 0.06 & 0.01 & NA & $-15 \%$ & NA \\
\hline Red Pine Thinning & 0.52 & 1.16 & 0.73 & 0.10 & NA & $0 \%$ & NA \\
\hline $\begin{array}{l}\text { Upland Spruce-Fir } \\
\text { Clearcut }\end{array}$ & 0.10 & 0.54 & 0.95 & 1.62 & NA & $-15 \%$ & oak species \\
\hline $\begin{array}{l}\text { Swamp Hardwoods } \\
\text { Clearcut }\end{array}$ & 0.02 & 0.11 & 0.16 & 0.50 & NA & $-15 \%$ & northern hardwoods \\
\hline $\begin{array}{l}\text { Swamp Hardwoods } \\
\text { Patchcut }\end{array}$ & 0.10 & 0.06 & 0.08 & 0.25 & NA & $0 \%$ & NA \\
\hline $\begin{array}{l}\text { Swamp Hardwoods } \\
\text { Shelterwood }\end{array}$ & 0.05 & 0.03 & 0.04 & 0.11 & NA & $-15 \%$ & NA \\
\hline $\begin{array}{l}\text { Swamp Hardwoods } \\
\text { Thinning }\end{array}$ & 0.02 & 0.01 & 0.02 & 0.05 & NA & $0 \%$ & NA \\
\hline White Pine Clearcut & 0.07 & 0.15 & 0.11 & 0.06 & NA & $-15 \%$ & NA \\
\hline White Pine Patchcut & 0.30 & 0.47 & 0.35 & 0.20 & NA & $0 \%$ & NA \\
\hline $\begin{array}{l}\text { White Pine } \\
\text { Shelterwood }\end{array}$ & 0.12 & 0.19 & 0.14 & 0.08 & NA & $-15 \%$ & NA \\
\hline White Pine Thinning & 0.31 & 0.48 & 0.36 & 0.20 & NA & $0 \%$ & NA \\
\hline
\end{tabular}


Notes for Table A7: Common landowner groups include: Private Non-Industrial Forests (PNIF), United States Forest Service (USFS), Michigan Department of Natural Resources (MI DNR), and Private Industrial Forests (PIF). Planted northern hardwoods include: black cherry, yellow birch, American basswood, American elm, and sugar maple. Planted oak species include: black oak, white oak, northern pin oak, and northern red oak. Within individual prescriptions, patch sizes were also reduced in modified silviculture prescriptions. 
Table A8: Species traits used to calculate FDis (Paquette and Messier 2011). H=average maximum height (m); GR=growth rate (1: slow, 2: moderate,3:rapid) ; LS=leaf size (1: needle/scale, 2 : small $<10 \mathrm{~cm}, 3$ : large, 4: compound; $\mathrm{WD}=$ wood density (specific gravity $\left(\mathrm{g} \mathrm{m}^{-3}\right)$ ); WDR=wood decay resistance(1: not, 2:moderate, 3:resistant, 4: very resistant); Veg=vegetative reproduction (0: never,1: possible, 2: common); $\mathrm{SeM}=$ seed mass (mg); $\mathrm{Pa}=$ abiotic pollination ( 0 : not possible, 1 : possible); $\mathrm{Pb}=$ biotic pollination ( 0 : not possible, 1: possible); TolS=shade tolerance (1: intolerant, 5: tolerant); TolD=drought tolerance (1: intolerant, 5: tolerant); TolW=waterlogging tolerance (1: intolerant,5: tolerant); $\mathrm{AM}=$ arbuscular mycorrhiza (0: not possible, 1: possible); $\mathrm{EM}=$ ectomycorrhiza (0: not possible, 1: possible); LL=leaf longevity (months); LMA=leaf mass per area $\left(\mathrm{g} \mathrm{m}^{-2}\right) ; \mathrm{N}=$ nitrogen content per leaf mass unit $(\%)$.

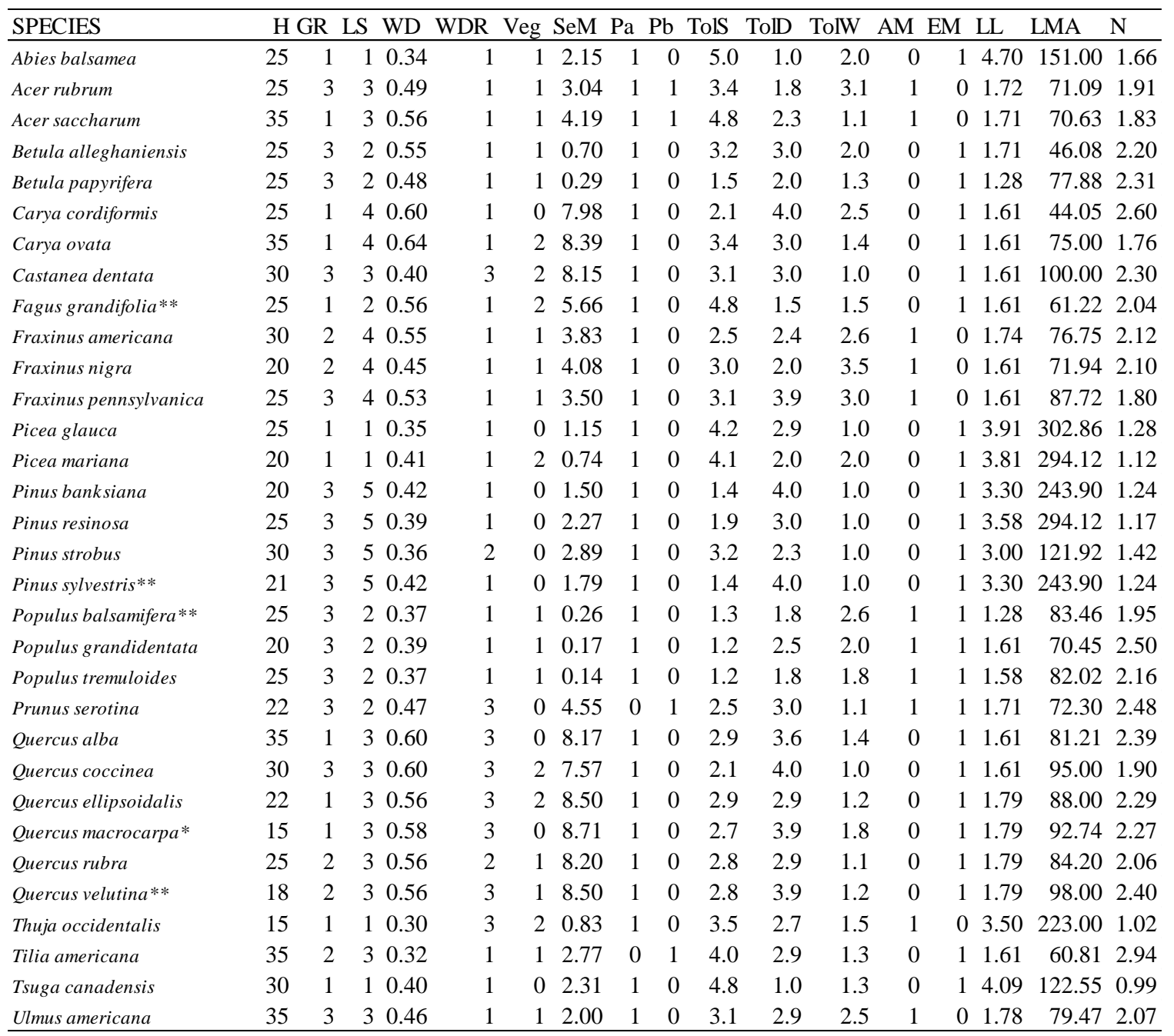

*Minnesota landscape only

**Michigan landscape only 
Table A9: Management effect on average change in AGB and dissimilarity after 50 years following simulated fires at year 2100 under the high emissions climate. $\mathrm{N}=$ number of fires within each scenario. $\mathrm{AGB}=$ change in aboveground biomass. $\mathrm{DIS}=$ dissimilarity. $\mathrm{DIFF}=$ denote significant differences between management scenarios ( $\mathrm{p}<0.05$, Tukey-Kramer).

\begin{tabular}{|c|c|c|c|c|c|c|}
\hline \multirow[b]{2}{*}{ MANAGEMENT } & \multicolumn{3}{|c|}{ MINNESOTA } & \multicolumn{3}{|c|}{ MICHIGAN } \\
\hline & $\mathrm{N}$ & AGB & DIS & $\mathrm{N}$ & AGB & DIS \\
\hline BAU & 148 & -3415 & 0.7 & 187 & -4005 & 0.78 \\
\hline XR & 141 & -3080 & 0.74 & 191 & -5011 & 0.77 \\
\hline AS & 156 & -2899 & 0.77 & 171 & -4826 & 0.79 \\
\hline CSP & 142 & -3070 & 0.76 & 223 & -3066 & 0.82 \\
\hline & & DIFF & \multicolumn{2}{|c|}{ DIFF } & DIFF & DIFF \\
\hline & & None & \multirow{2}{*}{\multicolumn{2}{|c|}{$\begin{array}{l}\text { BAU \& CSP } \\
\text { BAU \& AS }\end{array}$}} & AS \& CSP & XR \& CSP \\
\hline & & & & & XR \& CSP & BAU \& CSP \\
\hline
\end{tabular}

